IIASA COLLABORATIVE PROCEEDINGS SERIES

$$
\text { CP-82-S1 }
$$

\title{
HUMAN SETTLEMENT SYSTEMS: SPATIAL PATTERNS AND TRENDS
}




\title{
IIASA COLLABORATIVE PROCEEDINGS SERIES
}

\author{
CP-81-S1 LARGE-SCALE LINEAR PROGRAMMING \\ Proceedings of an IIASA Workshop, 2-6 June 1980 \\ G.B. Dantzig, M.A.H. Dempster, and M.J. Kallio, Editors \\ CP-81--S2 THE SHINKANSEN PROGRAM: Transportation, Railway, \\ Environmental, Regional, and National Development Issues \\ A. Straszak, Editor \\ CP-82-S1 HUMAN SETTLEMENT SYSTEMS: SPATIALPATTERNS \\ AND TRENDS \\ Selected Papers from an IIASA Conference \\ T. Kawashima and P. Korcelli, Editors
}




$$
\text { CP-82-S1 }
$$

\section{HUMAN SETTLEMENT SYSTEMS: SPATIAL PATTERNS AND TRENDS}

T. Kawashima and P. Korcelli, Editors

INTERNATIONAL INSTITUTE FOR APPLIED SYSTEMS ANALYSIS Laxenburg, Austria 1982 


\section{International Standard Book Number 3-7045-0029-1}

This volume in the Collaborative Proceedings Series contains selected, revised papers first presented at an IIASA conference. However, the views or opinions expressed do not necessarily represent those of the Institute, its National Member Organizations, or other organizations supporting the work.

Copyright (C) 1982

International Institute for Applied Systems Analysis

All rights reserved. No part of this publication may be reproduced or transmitted in any form or by any means, electronic or mechanical, including photocopy, recording, or any information storage or retrieval system, without permission in writing from the publisher. 


\section{FOREWORD}

The papers in this volume were originally presented at a conference on the analysis of human settlement systems held at the International Institute for Applied Systems Analysis (IlASA) from October 18 to 20,1978. This meeting closed an IIASA research activity, started in 1975, that had the goals of identifying functional urban regions in several industrialized countries and making comparative analyses of their population and employment trends to enhance our understanding of the spatial and temporal evolution of human settlement systems.

Supported in part by the Ford Foundation, and led during consecutive periods by Harry Swain (Canada), Niles Hansen (USA), and Tatsuhiko Kawashima (Japan), this research on human settlement systems and strategies established a wide intemational collaborative network and created a sizeable data base for examining demographic and economic changes. This book presents the findings of some of this work.

Subsequently, the Human Settlements and Services Area at IIASA used both the network and the data base in research focusing on the recent dramatic shifts in spatial development trends observed in several of the countries with IIASA National Member Organizations.

Andrei Rogers

Chairman, Human Settlements and Services Area 


\section{ACKNOWLEDGMENTS}

Part of the research on which this volume is based was supported by a grant from the Ford Foundation. The encouragement and criticism received from Dr. William Pendleton, who acted on behalf of the Foundation, was very much appreciated. Special thanks are also due to Professor Andrei Rogers, Chairman of the Human Settlements and Services Area at IIASA, for his substantive support, and to all the staff members who participated in the various stages of the study. Anna-Maria Buitikofer, Gabrielle Adam, and James Thompson efficiently provided the technical services for the Conference, while Susanne Stock and Lucy Tomsits carefully typed and retyped the successive versions of the manuscript.

The Editors 
1 


\section{CONTENTS}

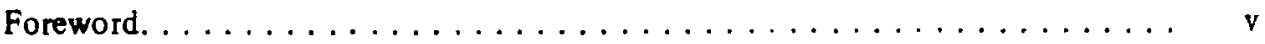

Acknowledgments . . . . . . . . . . . . . . . .

The human settlement systems study: an overview. . . . . . . . . . . 1 Piotr Korcelli

Functional urban regions in the United States: nature and significance . . . . . . 7 Niles Hansen

Recent urban trends in Japan: analysis of functional urban regions . . . . . . . . 21 Tatsuhiko Kawashima

Urban regions in the settlement system of Poland $\ldots \ldots \ldots \ldots \ldots \ldots$. $\ldots \ldots$ Piotr Korcelli

The settlement system and functional urban regions in the German Democratic Republic. Part I: structure and dynamics of the settlement system . . . . . 61 Joachim Heinzmann

The settlement system and functional urban regions in the German Democratic

Republic. Part II: the hierarchy of functional urban regions. . . . . . . . 73 Rudolf Krönert

On urban change in Finland. . . . . . . . . . . . . . . . . 89 Marti Hirvonen

Exploratory and nomnative assumptions in the identification of functional urban regions in Romania . . . . . . . . . . . . . . . . . . . . . . . 107 Mircea Enache and Senino Holtier

Functional regions and regional development in Hungary . . . . . . . . . . . 123 László Lackó

Recent trends in urban growth and population redistribution in Canada. . . . . . . 139 Larry S. Bourne

Settlement systems: development and management strategies . . . . . . . . . . 159 A. V. Kochetkov and O.S. Pchelintsev 
Population dispersal from core regions: a description and tentative explanation of the patterns in 20 countries. . . . . . . . . . . . . . 171 Daniel R. Vining, Jr., Robert Pallone, and Chung Hsin Yang

Deconcentration without a "clean break" . . . . . . . . . . . . . 193 Peter Gordon

Appendixes

A. List of ILASA publications on human settlement systems . . . . . . 203

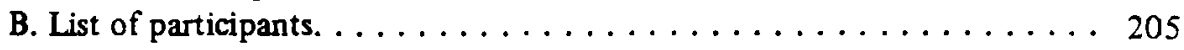

Author index ............................ 210 


\title{
THE HUMAN SETTLEMENT SYSTEMS STUDY: AN OVERVIEW
}

\author{
Piotr Korcelli \\ Human Settlements and Services Area, International Institute for Applied \\ Systems Analysis, Laxenburg (Austria)
}

\section{THE BACKGROUND}

Human settlement systems throughout the globe have been undergoing important transformations during the past decades, yet these trends have had a limited impact on the theory of urban growth and settlement structure. Traditional approaches, including the central-place, rank-size, and optimal city-size concepts, have emphasized the stability of settlement patterns over time, thus largely disregarding the observed changes. More recent developments such as the growth-pole approach have focused on the explanation of a major, albeit not universal, pattern of settlement change that is characterized by the increasing dominance of large cities within national and regional settlement systems. The growing role of these cities, as Lasuén (1973) or Pred (1975) suggest, stems from the repetitive hierarchical diffusion of innovations, the inertia of established organizational linkages, the continuous augmentation of multiplier effects, and the persisting role of agglomeration economies. (For a discussion of these concepts see Hansen and Korcelli (1978). An alternative notion - one of polarization reversal (Richardson, 1979) - has yet to be developed.)

Available empirical data for recent periods, in particular the 1970s, show a picture of settlement changes that is more complicated than that postulated by conventional theory. While urban population has become increasingly concentrated in the primate cities of the less developed countries, the large urban agglomerations in the highly urbanized industrialized countries have experienced growth rates that are generally lower than those typical of other settlements, and even in some cases absolute popuiation losses. The latter phenomenon is attributed to secular demographic processes, shifts in the locational requirements of industrial plants, and the evolving perception of environmental quality is a factor in residential location. Hence recent urbanization pat terns have been characterized by a polarization of trends which is likely to continue during the next decades.

The lag of the response to these changes in terms of the emergence of viable concepts of settlement dynamics has had adverse effects in the domain of urban and settlement policy. Existing measures, such as the large-city growth-limitation policies which are 
followed in a number of European countries, have supported trends that are no longer regarded as favorable to national socioeconomic development. In the case of the less developed countries urban and regional policies have not helped to produce spatially and vertically more balanced settlement structures, and a part of this failure has rightly or wrongly been attributed to the inadequacy of urban growth concepts.

These were some of the considerations that prompted a number of authors to propose international comparative studies of human settlement trends and patterns. These studies were conceived as an aid to, and even a prerequisite for, the pending reformulation of both settlement theory and settlement policy. Consequently, research efforts have focused on the question of standardized spatial units of reference, the identification of which has been treated by some as a means of achieving data comparability for cross-sectional analyses of urbanization, and by others as a justifiable self-contained research task.

\section{FUNCTIONAL URBAN REGIONS}

Differences of perspective on the nature of spatial units have been a recurrent issue in urban and regional analysis since its early days. Few will recall that metropolitan districts were used for the first time in the United States Population Census of 1910 and that data on conurbations were first collected by the General Register Office in Great Britain during the 1930s. Also, attempts, started by the sociologist Kingsley Davis, to define metropolitan areas on the universal scale are now based on a 20-year tradition (Davis, 1959). These efforts reflect early observations that the political boundaries of urban areas rarely coincide with their physical extent; the latter is normally considered more relevant as a statistical and/or planning unit.

However, studies of human settlement patterns have for a long time revealed the regularity of their configurations and their transitions from one spatial structure to another following social and economic development. This was the essence of the concept of the metropolitan community developed by McKenzie (1933) and based on earlier work by R. Blanchard, P. Geddes, and N.S.B. Gras. The same is true of alternative definitions of urban regions such as the city-hinterland region or regional settlement system; each was formulated within a framework of a broader settlement theory which predicted the emergence of relevant spatial units as basic morphological components in human settlement systems.

The appeal of the notion of a Functional Urban Region (FUR) has consisted in its ability to combine the statistical with the theoretical perspective. As proposed by Berry (1973) and Hall (1973), the FUR definitions were couched in the terminology of spatial interaction yet were meant to retain fully operational characteristics. This compromise was achieved on the basis of a latent assumption according to which a single measure of connectivity, namely, the intensity of commuter flows, represents a proxy variable for a broad range of interactions related to labor, services, education, and leisure. Hence the functional urbc 1 region has emerged as a generic term for a family of urban/regional units including the metropolitan labor markets, daily urban systems, and urban fields.

As analy tical data-aggregation units, FURs offer a bridge between studies of intraand inter-metropolitan systems. For example, their use has been postulated in studies of 
labor-oriented migration as well as in land-use-transportation studies. However, national statistical agencies have so far been rather reluctant to adopt FURs and sirnilar units as standardized spatial aggregations. This has been true of the Bureau of Economic Analysis (BEA) regions in the United States as well as of the Metropolitan Economic Labor Area (MELA) or functional regions in the United Kingdom. The units adopted earlier such as standard metropolitan statistical areas and conurbations still prove to be viable in terms of data-processing costs and public acceptance of the boundaries. Changes of statistical definitions usually take time, and the newly proposed units have to withstand a number of tests. In fact the functional regions, identified by Coombes et al. (1980) and recommended for use in the 1981 UK Census, introduce a hierarchical regional pattem, which thus overcomes one of the most frequently pointed out limitations of all previous operational FUR definitions.

\section{EVOLUTION OF THE STUDY PERSPECTIVE}

The life span of the Human Settlement Systems Task at the International lnstitute for Applied Systems Analysis (IIASA) corresponded to the period between two major conferences, both of which were devoted to surveying research and policy efforts in the lield of settlement ${ }^{*}$. During the four-year period (1975-1979) the research scope underwent an evolution that should be taken into account in evaluating the results of the Task.

The initial concept, presented by Hall (1973), consisted of an ex tended comparative study of several densely populated and highly urbanized world regions, sometimes referred to as megalopolises. The study was expected to focus on the changing distribution of people and jobs (especially in terms of their concentration and deconcentration), occupational structure, and journey-to-work and land-occupancy patterns, and to lead to generalized social indexes for urban areas as well as indicators measuring the efficiency of the use of resources, particularly land. To identify comparable spatial units of reference was postulated as an essential first stage in the analysis.

Subsequently, a working definition of functional urban regions was formulated and the range of the study extended to cover all the countries with IIASA national member organizations, and also the remaining European countries. The regions were seen as consisting of urban cores, basically corresponding to cities of 50,000 inhabitants and over. and their spatially continuous hinterlands, delineated so as to ensure a high degree of closure of employment and residence within the regions (Hall et al., 1975). (The criteria adopted allowed the substitution of alternative measures of spatial integration, such as central-place linkages, for the missing commuting data. At a later stage of the study the FUR definition was modified (Gordon and Kawashima, 1978). In this later version core cities were combined with their commuting fields to form functional urban cores while

\footnotetext{
* The earlier conrerence, held in Laxenburg, Austria, in December 1974, was devoted to National Settlement Systems and Strategies, while the later one, held in October 1978, dealt with the Analy sis of Human Settlement Systems. An intermediatc event was the Conference on the Dynamics of Human Settlement Systems, organized at ${ }^{-}$'SA in October 1976. Papers from the 1974 conference were published in three volumes edited by Swain (1975), Swain and MacKinnon (1975), and Swain et al. (1975). The 1976 conference yielded the volume edited by Hansen (1978). The present volume is based on the 1978 conference.
} 
hinterlands were delineated on the basis of commodity, migration, and information flows and/or administrative criteria. When such definition did not yield an exhaustive division of the national territory, the balance was considered to be a rural area.) It was maintained that the establishment and use of the comparative spatial framework should provide a better understanding of the impacts of public policies in the fields of population distribution and economic development.

As time passed, the focus shifted from the study of changing physical urban patterns to the study of economic development processes over space, as reflected in the transformations of settlement systems (Hansen, 1976a). This trend yielded a series of contributions on such topics as interurban economic growth (Pred, 1976) and the economic development of border regions (Hansen, 1976b).

Before its conclusion the study was to undergo yet another turn. Reports on population trends for the early 1970s have revealed the phenomenon of large-city decline in a number of highly urbanized countries and have precipitated heated disputes on spatial population concentration and deconcentration processes (Vining and Kontuly, 1978; Klaassen and Paelinck, 1979). The material accumulated in the Human Settlement Systems study provided a convenient reference point in this debate (Gordon and Kawashima, 1978; Gordon, 1978). However, the restriction of the scope of comparative analysis to the study of aggregate spatial population shifts reflected the paucity of regionally disaggregated data on employment, income, and production; this limitation prevented economic modeling efforts from being carried out.

Despite the cutbacks in the original research agenda, the study succeeded in developing an interacting international network of scholars concerned with the spatial analysis of human settlement systems and in assembling an information file for 19 countries, containing population data for the period 1950-1970 (for some countries 1950-1975) at the level of FURs and their major constituent parts. This task was accomplished in collaboration with a parallel research project led by Hall at the University of Reading, UK (Hall and Hay, 1980). More extensive analyses of settlement trends have been conducted for several countries out of the 19, including Finland, Hungary, Poland, and the German Democratic Republic.

The work has delineated a set of research issues pertaining to the evolution of human settlement systems which require intensive study. These issues include (a) the impacts of technological change and the evolving sectoral composition of national economies on settlement systems, (b) the interrelations between intraurban patterns and the performance of urban areas in terms of population and employment change, (c) the consequences of spatial and sectoral policies carried out at the national, regional, and urban levels, and (d) the interaction between demographic change and the urban economy. These topics have formed the background for the subsequent research on urban change that started in 1979 (see Rogers, 1979).

\section{THE SCOPE OF THIS VOLUME}

This book contains revised and updated versions of selected papers presented at the conference that brought the Human Settlement Systems Task to an end. The conference reviewed the work directly related to the Task and discussed future research directions on 
the basis of a survey of recent developments in the field of settlement studies. The contributions included here reflect the first aspect of the conference. Appendix $A$ lists all the publications of the Human Settlement Systems Task, and Appendix B is a list of the conference participants.

Most of the volume is devoted to eight papers dealing with recent settlement patterns and trends in individual countries: the USA, Japan, Poland, the GDR, Finland, Hungary, Romania, and Canada. All these studies introduce disaggregation into functional urban regions, or corresponding units and, to varying degrees, contribu te to developing the concept of urban regions as basic morphological units within national settlement systems. For example, Hansen evaluates recent interurban and regional shifts in the USA, as portrayed by a number of authors who have adopted in their analyses the regional division proposed by the Bureau of Economic Analysis (the BEA regions), while Heinzmann and Kroenert explore the implications of alternative definitions of urban regions and the ways in which urban hierarchy is reflected in the regional structure of the GDR.

The national papers are followed by a theoretical statement by Kochetkov and Pchelintsev that develops a concept of settlement systems from the planning perspective. The final two papers by Vining et al. and by Gordon summarize the results of crosssectional analyses of recent population shifts in a number of countries. The authors use different spatial aggregation units and data (on interregional migration in one case and on population growth rates in the other) and arrive at opposite conclusions. While Vining et al. present evidence for a recent reversal of secular trends toward population concentration, as observed in a number of countries, Gordon shows a continuarion of earlierestablished deconcentration trends. This juxtaposition of two al ternative interpretations of the same process gives another proof of the importance of regional divisions in the study of population and settlement change. However, as suggested earlier in this overview, the validity of individual spatial aggregation systems can only be assessed within a framework of a given concept of settlement development, and so the uses of the systems should be determined accordingly.

\section{REFERENCES}

Berry, B.J.L. (1973). Growth Centers in the American Urban System, Vols. 1 and 2. Ballinger, Cambridge, Massachusetts.

Coombes, M.G., Dixon, J.S., Goddard, J.B., Taylor, P.J., and Openshaw, S. (1980). Frunctional regions for the 1981 census of Britain: is user's guide to the CURDS definitions. Discussion Paper 30 . Centre for Urban and Regional Development Studies, University of Newcastle upon I:ne, Newcastle upon Tyne.

Davis, K. (1959). The World's Metropolitan Areas. University of California Press, Berkeley and Los Angeles, California.

Gordon, P. (1978). Deconcentration without a clean break. RM-78-39. International Institu te for Applied Systems Analysis, Laxenburg, Austria.

Gurdon, P. and Kawashima, T. (1978). Human settlement systems: development processes and strategies. Background paper for the Cont. on the Analysis of Human Settiement Systems, October 1978. WP-78-23. International Institute for Applied Systems Analysis, Laxenburg, Austria.

Hall, P. (1973). The Containment of Urban England, Vols. 1 and 2. George Allen and Unwin. London. 
Hall, P., Hansen, N., and Swain, H. (1975). Status and future directions of the comparative urban region study : a summary of workshop conclusions. RM-75-59. International Institute for Applied Systems Analy sis, Laxenburg, Austria.

Hall, P. and Hay, D. (1980). Growth Centres in the European Urban System. Heinemann Educational Books, London.

Hansen, N.M. (1976a). Systems approaches to human settlements. RM-76-36. International Institute for Applied Systems Analysis, Laxenburg, Austria.

Hansen, N.M. (1976b). The economic development of border regions. RM-76-37. International Institute for Applied Systems Analysis, Laxenburg, Austria.

Hansen, N.M. (1978). Human Settlement Systems. International Perspectives on Structure, Change, and Public Policy. Ballinger, Cambridge, Massachusetts.

Hansen, N.M. and Korcelli, P. (1978). The development of urban agglomerations within the national settlement systems. Geographia Polonica, 39:211-222.

Klaassen, L.H. and Paelinck, J.H.P. (1979). The future of large towns. Environment and Planning A, $11: 1095-1104$.

Lasuén, J. (1973). Urbanization and development. The temporal interaction between geographical and sectoral clusters. Urban Studies, 10:78-101.

McKenzie, R.D. (1933). The Metropolitan Community. McGraw-Hill, New York.

Pred, A. (1975). Diffusion, organization, spatial structure, and city-system development. Economic Geography, $51: 321-337$.

Pred, A. (1976). The interurban transmission of growth in advanced economies: empirical findings versus regional planning assumptions. RR-76-4. International Institute for Applied Systems Analysis, Laxenburg, Austria.

Richardson, H. (1979). Defining population distribution goals in development planning. Paper presented at the United Nations/UN Fund for Population Activities Workshop on Population Distribution Policies in Development Planning, Bangkok, September 4-13, 1979.

Rogers, A. (1979). The human settlements and services area: the first five years. SR-79-1. International Institute for Applied Systems Analysis, Laxenburg, Austria.

Swain, H. (Editor) (1975). National Settlement Strategies, East and West. CP-75-3. International Institute for Applied Systems Analy sis, Laxenburg, Austria.

Swain, H. and MacKinnon, R.D. (Editors) (1975). Issues in the Management of Urban Systems. CP-75-4. International Institute for Applied Systems Analysis, Laxenburg, Austria.

Swain, H., Cordey-Hayes, M., and MacKinnon, R.D. (Editors) (1975). Selected papers from IIASA Conf. on National Settlement Systems and Strategies. Environment and Planning A, 7(7).

Vining, D. and Kontuly, T. (1978). Population dispersal from major metropolitan regions: an international comparison. International Regional Science Review, 3:49-73. 


\section{FUNCTIONAL URBAN REGIONS IN THE UNITED STATES: NATURE AND SIGNIFICANCE}

Niles Hansen

Department of Economics, University of Texas (USA)

\section{INTRODUCTION}

During the 1960s regional analysts became increasingly concerned about the lack of appropriate geographic units of observation for the study of spatial systems. In the United States, a nationally exhaustive set of State Economic Areas (SEAs) had been delineated for the 1950 census and data from the 1950 and 1960 censuses were organized in terms of these regions (as was the case again in 1970). The SEAs consist of counties or groups of counties that have similar economic and social characteristics. However, all state boundaries are regarded as SEA boundaries, a condition imposed in order to permit the publication of SEA data for each state. While the SEAs may reflect relatively homogeneous regions they have not readily lent themselves to development planning. They are essentially descriptive and provide little insight into the functional relations involved in such processes as services delivery and joumey-to-work patterns.

Fox and Kumar (1965) in particular argued that heterogeneous nodal regions should be used in regional economic analysis. These "functional economic areas" should he delineated in recognition of the fact that a large number of services and a large share of regional employment opportunities are found in the central (or nodal) city of a region but that the outer perimeter of the region should be defined in terms of journey-to-work patterns from outlying areas to the central city. Thus functional economic areas are extended urban fields. with peripheral towns acting as service centers for nearby residents in much the same way as do suburban shopping centers in a large metropolitan area.

Berry et al. (1968) applied this concept at the national level and identified a national system of regions including over $80 \%$ of the land area and $96 \%$ of the population. Meanwhile, Henry DeGraff of the Bureau of Economic Analysis (BEA), US Departinent of Commerce, was delineating a similar but nationally exhaustive set of functional economic areas. These BEA regions have been used increasingly for a wide range of regional research. 


\section{THE DELINEATION OF BEA-REGION BOUNDARIES}

The boundaries of the BEA regions were delineated by identifying the urban centers of the regions and then determining the counties that were most closely linked to the centers. Standard Metropolitan Statistical Areas (SMSAs) - which have a minimum popu. lation of 50,000 - were usually chosen as centers. Where an SMSA was an integral part of a larger metropolitan complex a multi-SMSA center was used; the New York City BEA region is a case in point. However, in parts of the country where there are no SMSAs, cities with populations of between 25,000 and 50,000 were chosen as regional centers if they functioned as labor-market and trade nodes.

After the urban centers were selected, each of the approximately 2600 counties that did not fall within a center was studied to determine the center with which it was most closely tied. In most instances the primary data source used in this task was journeyto-work information from the 1960 population census; counties were assigned to centers in accordance with commuting patterns. In places where the commuting sheds of adjacent centers overlapped, counties were included in the area containing the center to which most workers commuted. Where ties with two centers were exceptionally strong the two were combined into one BEA region. In many cases the association between counties and a particular region was not based on direct commuting ties but rather on commuting ties to noncentral counties, which in tum were tied to the urban centers. In relatively remote rural areas where commuting data were not adequate, other allocation criteria were used, in particular metropolitan-newspaper circulation and the advice of authorities, such as state planning agents, who were familiar with the geography and economy of the areas.

The 1969 delineation process resulted in the identification of 173 BEA regions, ranging in population size from 18.2 million (New York) to 104,000 (Scottsbluff, Nebraska). Because there was a minimum of commuting across BEA-region boundaries each region included the place of work and place of residence of its labor force. Each area was also relatively self-sufficient in the output of its local service industries. The types of export activity within a particular region depend on its relative endowment of the inputs required in the production process. Regions export commodities for which they have a comparative advantage and import other commodities. By this participation in interregional trade the various BEA regions resemble nations engaging in international trade, except that the regions are less affected by barriers to trade and to the movement of labor and capital.

Changes in the regional distribution of economic activity during the past decade have made it necessary to revise the 1969 BEA-region delineations. In addition, expansion of the interstate highway system has affected commuting patterns and thereby altered area boundaries. Thus new delineations were made in 1977, resulting in a total of 183 BEA regions. The revisions were primarily based on three sets of data: (1) commuting data from the 1970 population census; (2) newspaper circulation data for 1972 ; (3) 1975 intercounty commuting data developed from Social Security Administration and Internal Revenue Service records. 


\section{STRUCTURAL CHANGES AND GROWTH IN BEA REGIONS FROM 1950 TO 1973}

Using cluster analysis of personal-income sources in 1973, the Regional Economic Analysis Division of the BEA (Bureau of Economic Analysis, 1975) assigned each BEA region to one of five industrial (economic-activity) groups. In general the groupings corresponded closely to those that would have resulted if each region had been assigned to a group according to its most important basic industry as measured by share of regional income.

Forty-two regions, most of them in the Great Plains and adjacent areas (see Figure 1), fell in to the agricultural group; they accounted for only $8 \%$ of total personal income in the nation in 1973. The 76 regions constituting the manufacturing group accounted for $45 \%$ of national personal income. The corresponding figure for the 34 government-group regions was $11 \%$. There were no regions in the mining category in 1973 but 21 regions were designated "other"; these latter were dominated by service activities that were oriented more toward distant markets than toward local consumers. The "other" group included Las Vegas, Miami, and such national and regional trade and finance centers as New York, Atlanta, Denver, and San Francisco. This group accounted for $36 \%$ of total personal income in 1973.

The data in Table 1 show that the distribution of BEA regions among the five industrial groups was significantly different in 1973 compared to what it had been in 1950. During this period the number of regions in the agriculture group fell from 67 to 42 while the number in the mining category dropped from six to zero. Each of the other three groups increased in size, reflecting a shift in specialization from primary activities toward the manufacturing, government, and service sectors. Manufacturing did not grow as fast nationally as government and services but the number of manufacturing regions rose from 63 to 76 because of geographic dispersion.

TABLE 1 The number of BEA regions by industrial group in 1950 and $1973^{\circ}$.

\begin{tabular}{llcccc}
\hline Industrial group & \multicolumn{2}{l}{ Industrial group in 1973} & & \\
\cline { 2 - 6 } in 1950 & Agriculture & Manufacturing & Government & Other & Total \\
\hline Agriculture & 41 & 12 & 10 & 4 & 67 \\
Mining & 1 & 4 & 1 & 0 & 6 \\
Manufacturing & 0 & 58 & 3 & 2 & 63 \\
Government & 0 & 2 & 18 & 1 & 21 \\
Other & 0 & 0 & 2 & 14 & 16 \\
Total & 42 & 76 & 34 & 21 & 173 \\
\hline
\end{tabular}

a Source: Bureau of Economic Analysis (1975), p. 19.

In 1973 the regions with the highest per capita incomes tended io be in the East, on the Lower Great Lakes, and in the Far West (see Figure 2). Regions with the lowest per capita incomes were concentrated in the Plains, the Rocky Mountains, the Southeast, and the Southwest. The high-income regions tended to have relatively large populations while 


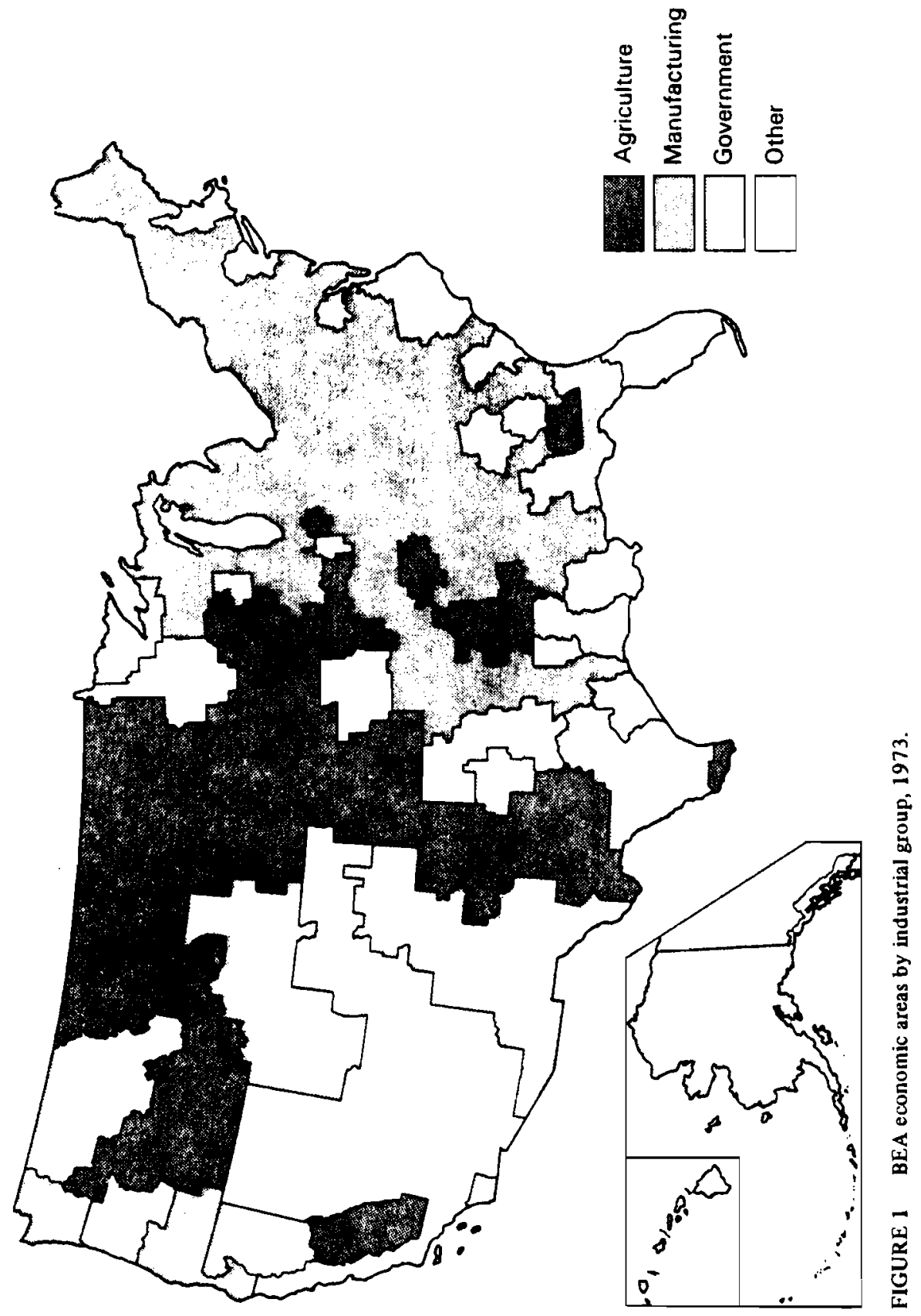




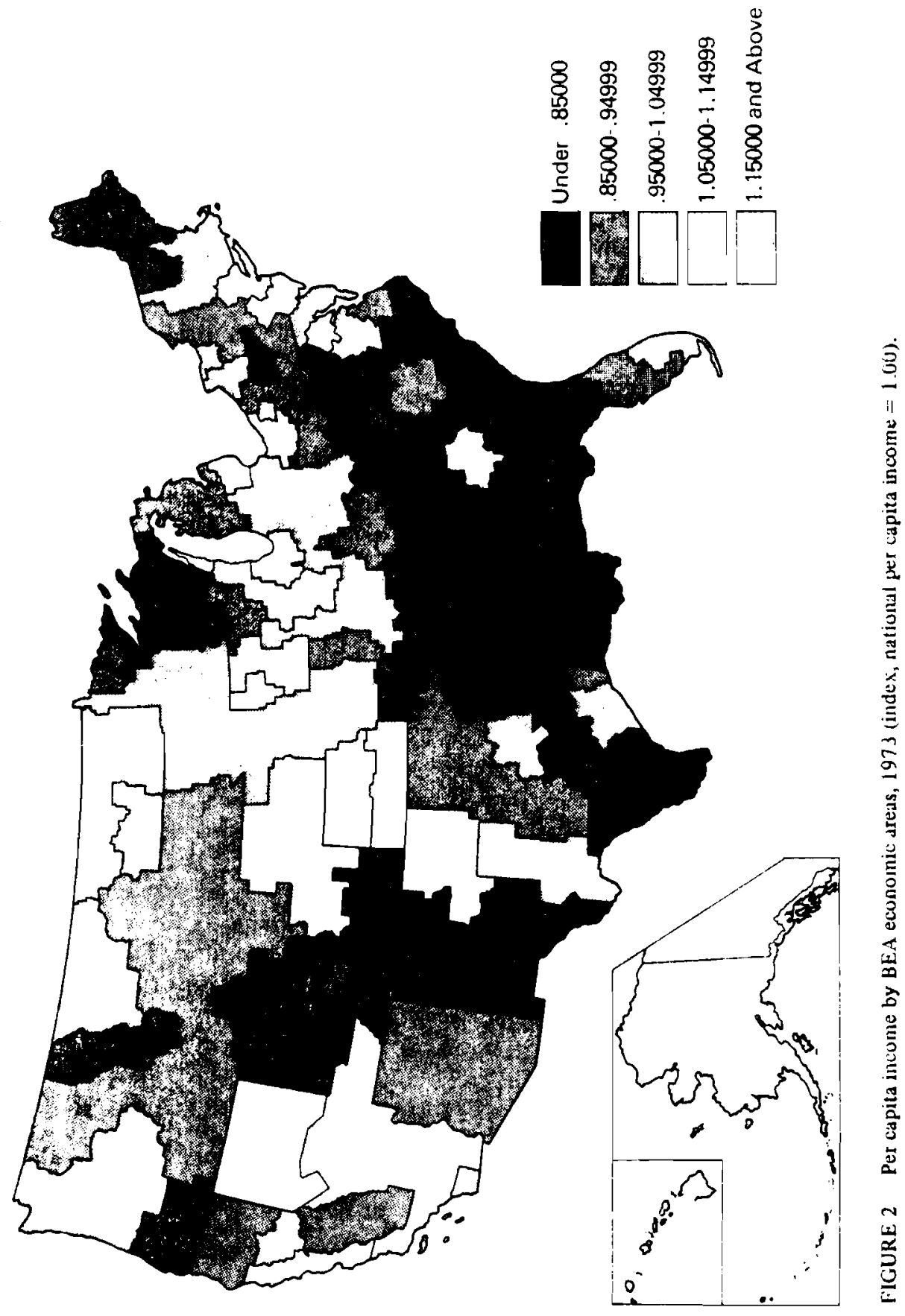


the low-income regions tended to have relatively small populations. The high-income regions were specialized in sectors with high earnings per worker; these activities, e.g., manufacturing and finance, often derive advantages from scale and agglomeration economies. In contrast, the low-income small-population regions tended to specialize in agriculture.

Regional income disparities were reduced during the 1950-1973 period as per capita income levels in the relatively poor areas rose more rapidly than those in the relatively rich areas (see Figure 3 ). This narrowing of differences was associated with the fact that BEA regions specializing in industries with relatively high earnings per worker (e.g. manufacturing and government) grew relative to those specializing in mining and agriculture. Meanwhile technological improvements were increasing earnings per worker in the latter two sectors. The number of BEA regions where per capita income was more than $15 \%$ above the national average was reduced from 19 to ten between 1950 and 1973. During the same period the number of regions where per capita income was more than $15 \%$ below the national average declined from 78 to 63 . The greatest income gains were made in the South and the West whereas slower growth characterized the agricultural Plains, the Northeastern and Great Lakes manufacturing belts, northern California, central Texas, the Ozarks region, and northern and central Appalachia. It is noteworthy that during the 1969-1973 period favorable agricultural and mining conditions were generating rapid income growth in the Plains, the Ozarks, central Texas, and parts of Appalachia. However, relatively slow income growth continued in the Northeastern and Great Lakes manufacturing areas.

Olsen and Westley (1974) used a market potential (gravity) model to analyze changes in the degree of accessibility that each of the 171 contiguous BEA regions had to the system of BEA regions. Changes in income accessibility and in population accessibility between 1950 and 1960 and between 1960 and 1970 were measured. Truck operating times served as the basis for determining market potentials. In general it was found that the market potentials of BEA regions in the Northeast grew most rapidly during the 1950s whereas those of the South (especially with respect to income) and West (especially with respect to population) grew most rapidly during the 1960s. In order to gain a better understanding of how much market accessibility contributes to regional economic development the Olsen-Westley market-potential model was incorporated into MULTIREGION, Olsen's computer model of regional and interregional socioeconomic development (Olsen et al., 1977; Olsen, 1978). The model interprets the economy of each $\mathrm{BEA}$ region as a labor market, measures all activity in terms of people as members of the population or as employees, and simultaneously forecasts the demands and supplies of labor in each BEA region at five-year intervals.

\section{THE HEARTLAND-HINTERLAND AND HIERARCHICAL DIFFUSION MODELS OF REGIONAL DYNAMICS IN THE UNITED STATES}

In the early 1960s it was common to view the spatial organization of the American economy in terms of a heartland-hinterland relationship. The industrial heartland (New England, the Middle Atlantic States, and the Great Lakes area) was regarded as the propulsive section of the nation: 


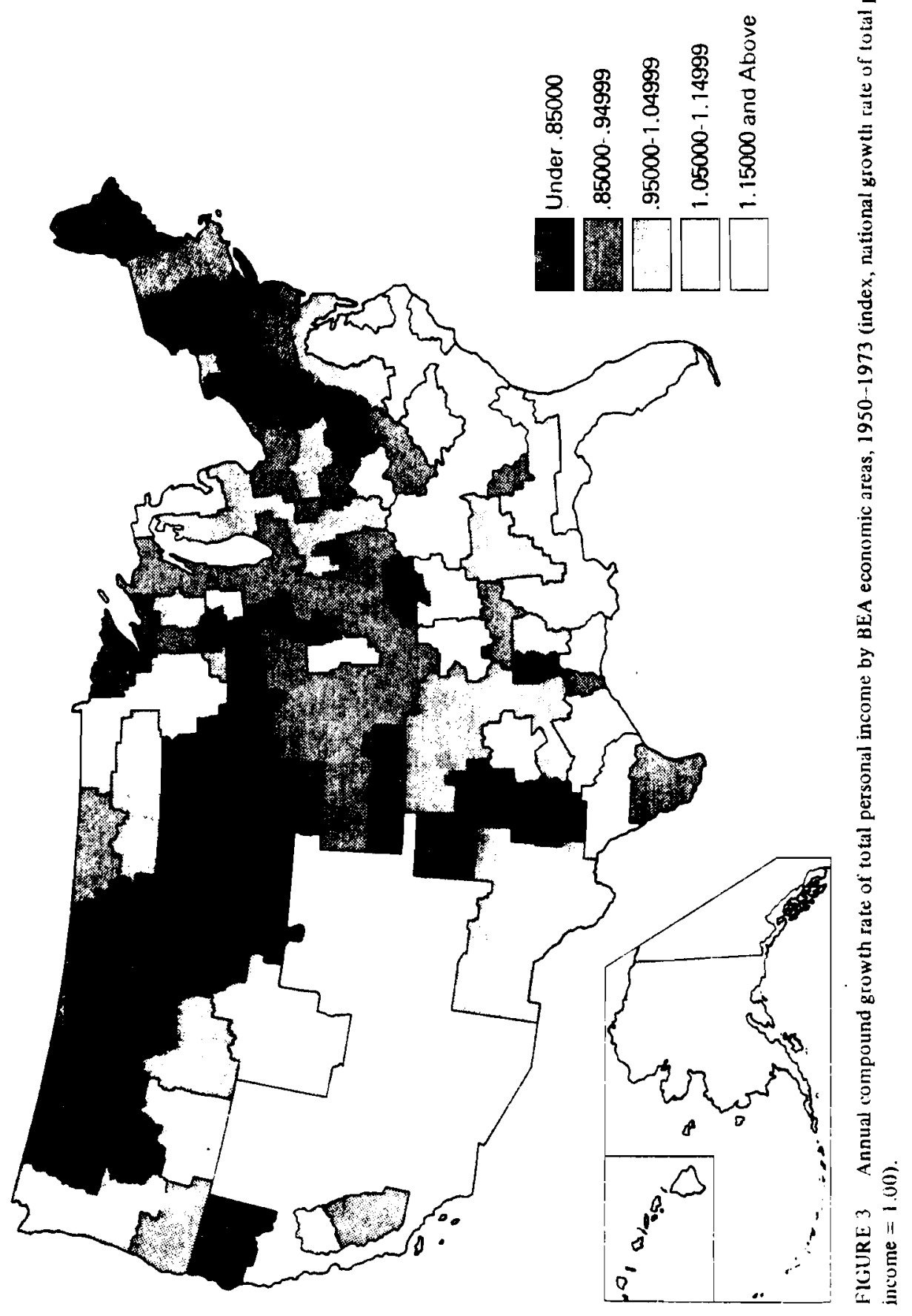


"Central to [this scheme] is the great heartland nucleation of industry and the national market, the focus of the large-scale, nation-serving industry, the seedbed of new industries responding to the dynamic structure of national final demand, and the center of high levels of per capita income. Radiating out across the national landscape are the resource-dominant, regional hinterlands specializing in the production of resource and intermediate inputs for which the heartland reaches out to satisfy the input requirements of its great manufacturing plant." (Perloff and Wingo, 1961, pp. 210-212)

A decade later another spatial paradigm had come to the fore: the hierarchical diffusion model. This synthesis of several geographic and economic analytic strands of thought focused on the national system of functional economic areas (BEA regions) and was only indirectly concerned with the Northeast and North Central regions vis-d-vis the rest of the nation.

The hierarchical diffusion paradigm maintained that spatial-temporal development processes are driven by innovations that either originate or are first adopted in the largest cities. These innovations are transmitted from higher-order to lower-order centers in the urban hierarchy; meanwhile there is a concurrent spread of development-inducing innovations from urban core areas to their respective hinterlands. Growth-center notions could readily be incorporated into this approach in that public policy measures could be called on to induce growth in strategic places, which would be selected with the objective of accelerating innovation diffusion to economically lagging regions.

The hierarchical diffusion model offered a more general explanation of regional development processes than did the heartland-hinterland scheme and it seemed to be supported by empirical evidence from the 1960s (Berry, 1973; Richardson, 1973). However, it was implictly consistent with the heartland-hinterland paradigm in one important respect: since most of the nation's largest cities are in the heartland, this broad area could still be viewed as the major source of development-inducing innovations for the entire national economy.

In recent years the once-vaunted heartland has experienced a reversal of fortune; it is now discussed and analyzed primarily in terms of its problems rather than its successes. The data presented in Table 2 illustrate this phenomenon from a demographic perspective. Between 1970 and 1975 the population of the USA grew by nearly 2 million persons annually. However, the Northeast and North Central regions (roughly, the "heartland") grew by only 296,000 persons per year whereas the corresponding growth in the "hinterland" South and West regions was 1.66 million, or $85 \%$ of the total national increase. The Northeast and North Central regions both had heavy net out-migration while the South and West both experienced substantial net in-migration.

The data in Table 3 indicate that between 1970 and 1975 the population living in metropolitan areas with over 3 million inhabitants declined absolutely; the population in the 2-3 million size-class grew slightly but this group as a whole experienced net outmigration. All other metropolitan population size-classes had growth rates exceeding the national average; this was also the case for nonmetropolitan areas even though they experienced net out-migration during the 1960s (see Table 2). The data in Table 2 indicate that out-migration from large metropolitan areas is particularly pronounced in the Northeast and North Central regions. In the South large metropolitan areas actually had net in-migration of 525,000 persons annually between 1970 and 1975 . Southern 


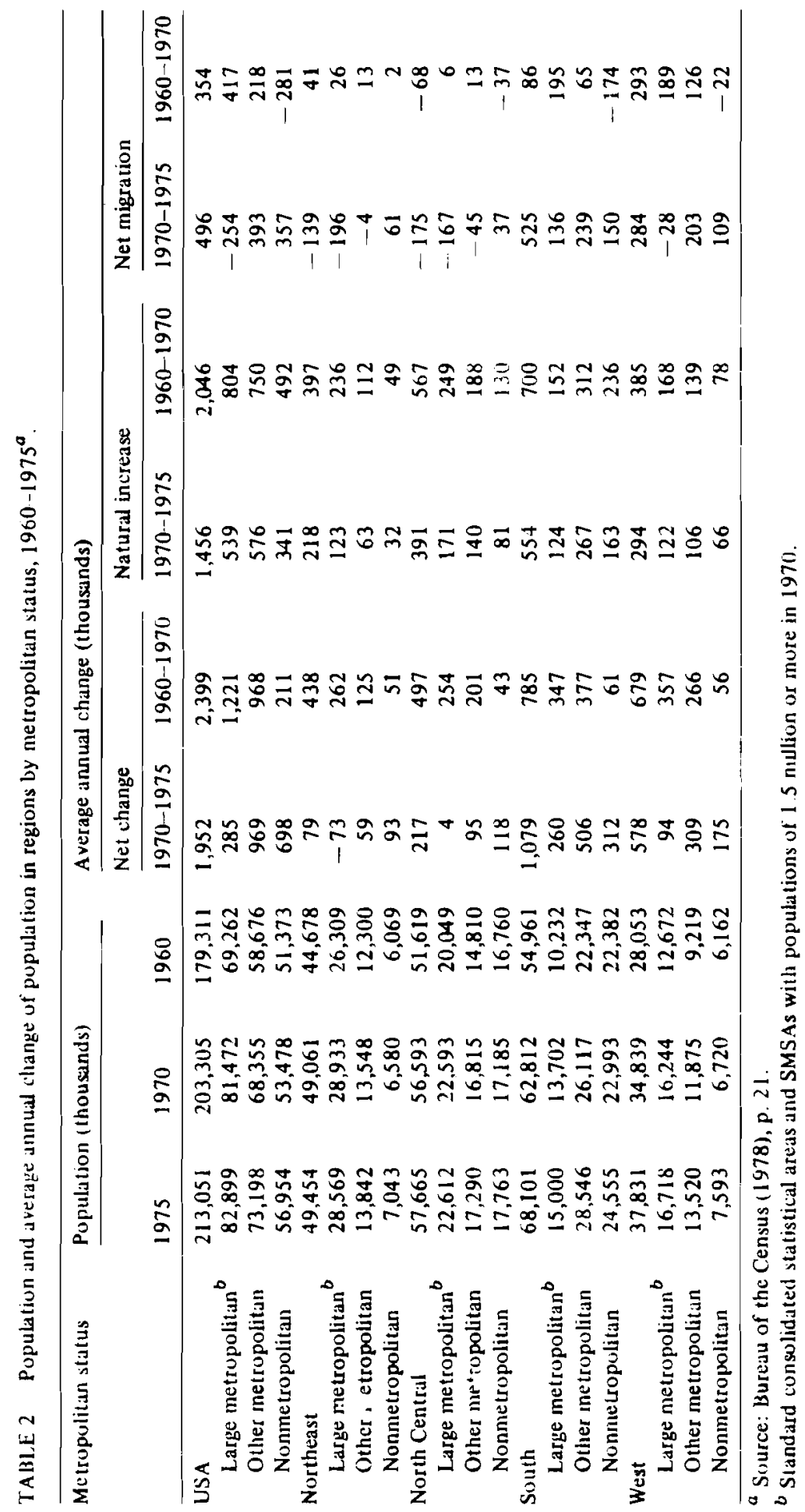




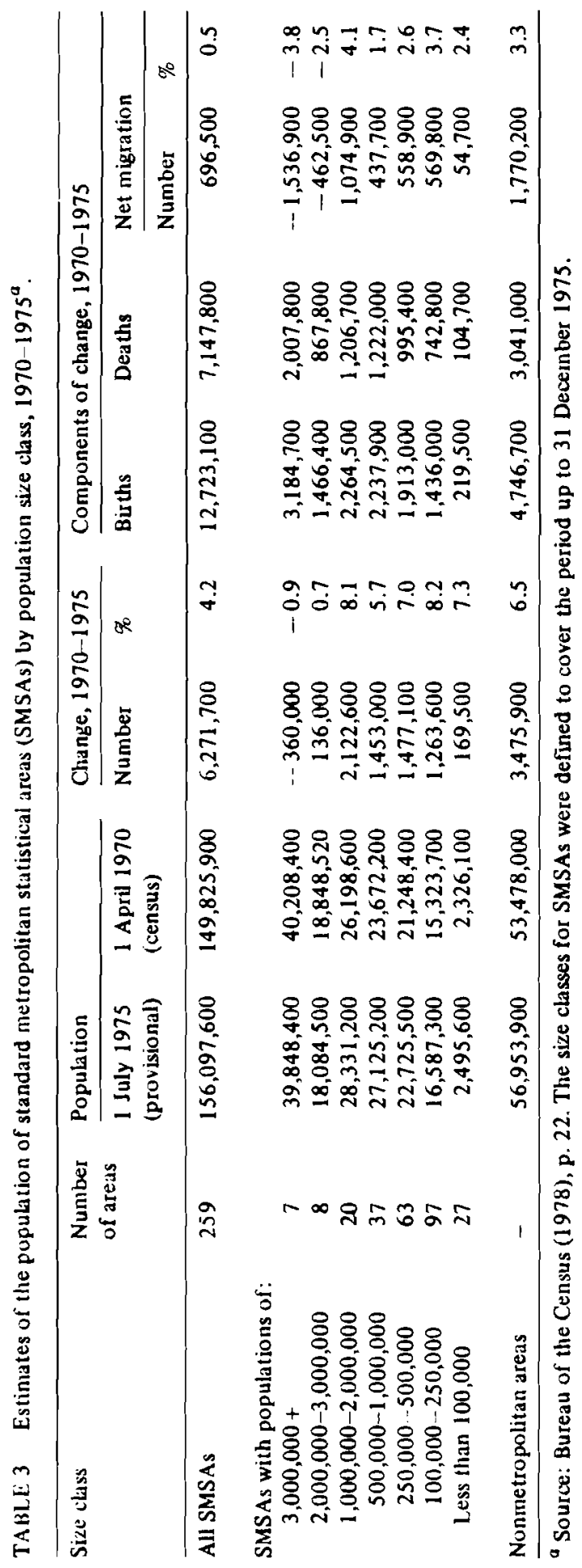


nonmetropolitan areas aiso had net in-migration of 150,000 persons anually from 1970 to 1975 after annual net out-migration of 174,000 persons during the 1960 s.

These recent changes clearly are not consistent with the spatial-temporal innovation processes suggested by the heartland-hinterland and hierarchical diffusion models. Thus it is not surprising that regional scientists and policy makers alike largely failed to anticipate them.

\section{RECENT PATTERNS OF REGIONAL CHANGE AS REFLECTED IN STUDIES OF BEA REGIONS}

Into the 1960s the nature of southem manufacturing growth was consistent with Thompson's version (Thompson, 1968) of the hierarchical diffusion theory. Thompson argued that innovations take place primarily in the larger metropolitan areas of industrially mature regions but, as industries age and their technology matures, skill requirements fall and competition forces them to relocate to lower-wage areas. The lower an area is in the skill and wage hierarchy, the older an industry tends to be when it arrives, and the slower its national growth rate. In fact the industrialization of the South was based initially on the attraction of low-wage slow-growth industries. However, a study using BEA regions indicates that this pattern has changed signiticantly in recent years; there has been an upgrading of types of industry, worker qualifications, and incomes (Hansen, 1973). Although manufacturing employment in the South is still dominated by low-wage industries, the high-wage industries are those with the highest growth rates whereas employment in the low-wage sectors has been declining.

Beyers' analysis (Beyers, 1978) of differential rates of growth among the BEA regions for the 1965-1975 period indicates that the growth of the South and West has not been dependent on technological linkages with the North. The sectors that have expanded most rapidly in the South appear to be more tied to final demand (capital goods, military equipment, foreign exports, durable consumer goods) than to intermediate producers located in the North. The fact that the manufacturing sectors that grew rapidly at the national level also tended to locate in the South and West suggests that their technologies are "new" and not represented strongly in components of these same sectors in the North. It is also noteworthy that wages and salaries plus proprietors' income now account for a smaller proportion of total personal income than formerly. Between 1950 and 1975 dividends, interest. transfer payments, and other nonearnings income sources increased from $18 \%$ to $29 \%$ of total personal income in the USA. Beyers points out that this has enhanced freedom of residential mobility and that entrepreneurs among migrants may be "leading" development in high-amenity areas of the South and West.

Allaman and Birch (1975) examined employment changes between the beginning of 1970 and the end of 1972 in the SMSA and non-SMSA portions of BEA regions. Their itudy found that firms rarely move from one region to another; this runs contrary to the prevalent notion that firms move from one area to another to lower costs. Firms themselves stay where they are presently located or else go out of business. It is entrepreneurs who move and start up new firms in more favorable locations, though more favorable locations may also receive new branch plants of large companies. Moreover, entrepreneurs appear to have been rethinking their historical location patterns at least as much 
as other people have, and maybe more so. Non-SMSA areas were growing much more rapidly than metropolitan areas in the early 1970 s.

"An important consideration in this employment shift is its character. Is it simply a few large manufacturers locating remotely to find cheaper land for single-storey plants, or is it complete societies moving out, with stores and offices and automobile dealers and bowling alleys and all the other forms of enterprise that make up an integrated economy? In partial resolution of this question, we broke the components of change into metropolitan and rural parts for each of our five industry types. The result is quite clear. All forms of activity are moving out - particularly trade and service. It would appear that, as a nation, we are finding ways to live and work in the countryside, and have been capitalizing on that possibility far more in the past few years than in the previous few decades." (Allaman and Birch, 1975, p. 14)

Thus it is clear that changes in the metropolitan-nonmetropolitan settlement pattern of the United States have spontaneously taken the direction advocated by most proponents of a national policy to promote more "balanced growth" in favor of nonmetropolitan areas.

\section{SUMMARY AND CONCLUSIONS}

Because the BEA regions are relatively self-contained labor sheds and trading areas they are uniquely valuable as units of observation for analyses of a wide range of regional issues in the United States. These regions also have a significant advantage with respect to the manner in which various data sets are reported. In particular, data from the population census are reported by place of residence whereas many other data are reported on the basis of place of work. Such diverse data sets can be brought together within the BEA-region framework because there is a minimum of commuting across regional boundaries. In addition, this property makes the BEA regions highly useful for analyzing service-delivery issues and, more generally, functional relations between urban centers and their respective hinterland areas. Finally, the BEA regions lend themselves to international comparative studies to the extent that other countries delineate similar areas and organize regional data accordingly.

There are, however, some offsetting limitations to the use of BEA regions. For example, they are not in themselves satisfactory for the analysis of rural labor markets in more remote parts of the country. Also, their boundaries do not correspond to those of any political unit that could design or implement policies and programs on a regionwide basis.

Despite such problems it is likely that the BEA regions will increasingly be used for future regional research. They have already been used as the basis for an elaborate set of projections of regional population, employment, personal income and earnings by economic sector to the year 2020 (Bureau of Economic Analysis, 1974). These projections are being revised by the BEA. The BEA regions are also the framework within which energy availabilities for regional development are being projected for 1980 and 1985 (Vogt et al., 1978). This continuing program at the Oak Ridge National Laboratory 
provides a consistent base of historic and projected energy information in a standard format. Finally, in other research currently under way the BEA regions are being used to analyze economic development prospects and strategies in the areas bordering Mexico. and to study migration patterns as reflected in the $10 \%$ Continuous Work History Samples of the Social Security Administration.

In the past the lack of explicit regional policies in the United States was of ten blamed at least in part on the absence of an adequate framework for spatial analysis and then on the paucity of appropriately organized data once the BEA regions were delineated. These objections no longer carry much weight and they are even less likely to do so in the future.

\section{REFERENCES}

Allaman, P.M. and Birch, D.L. (1975). Components of employment changes for metropolitan and rural areas in the United States by industry group, 1970-1972. Inter-Area Migration Project Working Paper No. 8. Joint Center for Urban Studies of Massachusetts Institute of [echnology and Harvard University, Cambridge, Massachusetts.

Berry, B.J L. (1973). Growth Centers in the American Urban System, Vol. L. Ballinger, Cambridge, Massachusetts.

Berry, B.J.L., Goheen, P.G. and Goldstein, H. (1968). Metropolitan area definition: a reevaluation of concept and practice. Working Paper No. 28. US Department of Commerce, Washington, D.C.

Beyers, W.B. (1978). Contemporary trends in the regional economic development of the United States. Unpublished paper. Department of Geography, University of Washington, Seattle.

Bureau of the Census (1978). Data Book for the White House Conference on Balanced National Growth and Economic Development. US Department of Commerce, Washington, D.C.

Burcau of Economic Analy sis (1974). OBERS Projections of Regional Economic Activity in the US, Vol. 2. US Department of Commerce and Economic Research Service, US Department of Agriculture, Washington, D.C.

Bureau of Economic Analysis (1975). The BEA economic areas: structural changes and growth, 1950-73. US Department of Commerce. Survey of Current Business, 55(11):14-25.

Fox, K.A. and Kumar, T.K. (1965). The functional economic area: delineation and implications for economic analysis and public policy. Papers and Proceedings of the Regional Science Association 15:57-85.

Itansen, N.M. (1973). The Future of Nonmetropolitan America. D.C. Heath, Lexington, Massachusetts.

Olsen, R.J. (1978). MULTIREGION: a socioeconomic computer model for labor market forecasting. In N. Hansen (Editor), Human Settlement Systems. Ballinger, Cambridge, Massachusetts, pp. $213-230$.

Olsen, R.J. and Westley, G.W. (1974). Regional differences in the growth of market potentials, 19501970. Regional Science Perspectives, 4(1):99-111.

Oisen, R.J.. Westley, G.W., Vogt, D.P., Kerley, C.R., Bjornstad, D.J., Herzog, H.W., Bray, L.G., Grady, S.T. and Nakosteen, R.H. (1977). MULTIREGION: A Simulation-1 orecasting Hodel of BEA Economic Area Population and Employment. Oak Ridge National Laboratory, Oak Ridge, Tennessee.

Periuff, H. and Wingo, L. (1961). Natural resources endowment and regional economic growth. In J.J. Spengler (Editor), Natural Resources and Economic Growth. Resources for the Furure. Washington, D.C., pp. 191-212.

Richardson. H. (1973). The Economics of Urban Size. Saxon House, Famborough, Hampshire, UK. Thompson, W. (1968). Internal and external factors in the development of urban econumies. In H.S. Perloff and L. Wingo, Jr. (Editors), Issues in Urban Economics, Johns Hopkins University Press, Baltimore, Maryland, pp. 43-62.

Vogt, D.P., Rice, P.L. and Pai, V. . (1978). Energy Avuilabilities for State and Local Development Projected Energy Patterns for 1980 and 1985 . Oak Ridge National Laboratory, Oak Ridge, Tenressee. 


\title{
RECENT URBAN TRENDS IN JAPAN : ANALYSIS OF FUNCTIONAL URBAN REGIONS
}

\author{
Tatsuhiko Kawashima \\ Human Settlements and Services Area, International Institute for Applied \\ Systems Analysis, Laxenburg (Austria)
}

\section{INTRODUCTION}

Distinctive shifts in the spatial patterns of urban systems have recently been observed in many of the industrialized countries. While the concentration of the urban population is continuing in a macroscopic sense (although at a decreased rate), some of the older urban centers have started to lose their population. There is also an indication of the deconcentration of population to nonmetropolitan areas, which raises the possibility of a newly emerging empirical regularity, namely urban decline.

Al though the phenomenon of urban decline could be regarded as a transitory trend there is a widespread feeling that it might also reflect a long-term tendency toward the spatial deconcentration of population and economic activities.

Some of the research scholars who interpret the implications of these spatial developments have advanced the hypothesis of reversal of the trend while others emphasize its continuation. The former group argues that "the current deconcentration of population . . is a clean break with the past" (Vining and Strauss, 1977). (For further ideas along the line of a "clean break" see also Beale (1975), Berry (1978), and Berry and Dahmann (1977).) The latter group suggests that "urbanization which has spilled over metropolitan boundaries may simply be more of the same outward growth but shows up as a metropolitan-to-nonmetropolitan growth shift" (Gordon, 1978; see also Wardwell, 1977); they thus advocate the hypothesis of continuous urban deconcentration (Gordon, 1978).

At the same time, policy makers in a number of industrialized countries have begun to view urban change as one of their major concerns and are eager to find more adequate urban strategies for stopping population outflows from cities and attracting jobs back to city centers.

Huwever, the widespread debate on urban decline and corresponding policy strategies has been severely constrained by the mere fact that both the scholars and the policy makers are often talking about different urban units without having a clear idea as to what part of urban decline is due to the particular delineation of the boundaries for the 
urban units involved. In fact, depending on the criteria applied in delineating urban areas, it is often possible to draw two different sketches of the profile of recent urban change patterns for the same country - one a picture of urban decline and the other a picture of continuously growing large urban areas (see Appendix 1 of this paper for examples of urban decline juxtaposed with continuous urban growth). The spatial delineation of urban units is therefore important.

\section{FUNCTIONAL URBAN REGIONS IN JAPAN}

There is a growing realization that urbanization has recently proceeded significantly beyond the administratively defined city boundaries in many countries; Japan is no exception to this rule. Under these circumstances it is necessary for studies of urbanization to delineate the following:

(i) An urban unit that covers the entire urban area in and around an administratively defined city where various types of activities form a functionally integrated economic and social subsystem. This urban unit may be called a functional urban core which is composed of a core city and its commuting field and which should reasonably correspond to the concept of a metropolitan area (or of the Standard Metropolitan Statistical Area (SMSA) adopted by the US Bureau of the Census; for the underlying philosophy and definition of the SMSA, see US Executive Office of the President (1964)).

(ii) An economically linked hinterland surrounding a functional urban core.

The whole region, composed of a functional urban core and its hinterland, may be termed a Functional Urban Region (FUR). All the FURs are contiguous spatial units and are designed in such a way that they are mutually exclusive and collectively exhaustive, covering a whole national territory. In these respects FURs are similar to the Bureau of Economic Analysis (BEA) regions delineated by De Graff of the US Department of Commerce*, to the Daily Urban Systems (DUSs) defined by Berry (1973) although DUSs are not completely nationally exhaustive, and to the Metropolitan Economic Labor Areas (MELAs) introduced in Hall's study (Hall et al., 1973).

As to the procedure followed to delineate the FURs in Japan, we first introduced the following criteria for the selection of core cities.

(a) Prefectural capitals have to be core cities whether or not they meet the conditions (b)-(d) listed below. Other core cities should satisfy conditions (b)-(d).

(b) The minimum population size should be equal to or greater than 100,000 in 1970 .

(c) The daytime-nighttime ratio of population should be greater than 1.0 .

(d) $75 \%$ of the ordinary households must be either "nonagricultural workers' households" or "agricultural and nonagricultural workers' mixed households". (This criterion was adhered to less rigorously than conditions (b) and (c).)

(e) If the distance between core cities is no more than $20 \mathrm{~km}$, then those core cities compose multiple-center core cities.

\footnotetext{
* For a discussion on urbanization in the United States and critical arguments on economic regionalizations in conjunction with the concept of FURs, see Hansen (1975), Morrison (1975), and Beyers (1978).
} 
After the core cities had been determined each of the approximately 3300 administrative units at the level of shi (city), machi (town), and mura (village) that had not been selected initially as core cities were examined to check whether they met the following criteria for identifying functional urban cores (for more discussion on the functional urban cores in Japan, see Glickman (1976) and Kawashima (1977).)

(a) The number of commuters from the localities to the core city must be greater than 500 .

(b) The number of commuters from each locality to the core city must be greater than $5 \%$ of the total employment in that locality.

(c) If a locality is eligible to be combined with more than one core city it is combined with the core city to which the largest number of commuters go.

(d) 75\% of the ordinary households must be either "nonagricultural workers' households" or "agricultural and nonagricultural workers' mixed households." (This criterion was adhered to less rigorously than the others.)

Finally, for the identification of the hinterland for each functional urban core, the magnitude of the economic linkage of each locality to the functional urban cores through flows of people, goods and services, and information was considered in detail.

Other political and geographical factors were also taken into consideration on a secondary basis, if necessary, to complement the foregoing criteria for the final delineation of core cities and their commuting fields and hinterlands.

The work of delineating functional urban cores was originally started in 1973 by Glickman in collaboration with the present author, who has since revised the boundaries of functional urban cores and delineated their corresponding FURs.

As indicated in Table 1,86 FURs were obtained for Japan. The geographical boundaries of the functional urban cores and FURs are shown in Figures 1 and 2,

TABLE 1 FURs in Japan.

\begin{tabular}{|c|c|c|c|c|c|c|c|}
\hline 1 & Sapporo & 23 & Kiryu & 45 & Tsu & 67 & Takamatsu \\
\hline 2 & Hakodate & 24 & Chiba & 46 & Ise & 68 & Matsuyama \\
\hline 3 & Asahikawa & 25 & Tokyo & 47 & Otsu & 69 & Imabari \\
\hline 4 & Muroran & 26 & Yokohama $^{a}$ & 48 & Kyoto & 70 & Niihama \\
\hline 5. & Kushiro & 27 & Odawara & 49 & Osaka & 71 & Kochi \\
\hline 6 & Obihiro & 28 & Niigata & 50 & Kobe & 72 & Kitakyushu \\
\hline 7 & Aomori & 29 & Nagaoka & 51 & Himeji & 73 & Fukuoka \\
\hline 8 & Hirosaki & 30 & Toyama & 52 & Nara & 74 & Omuta ${ }^{a}$ \\
\hline 9 & Hachinohe & 31 & Takaoka & 53 & Wakayama & 75 & Kurume \\
\hline 10 & Morioka & 32 & Kanazawa & 54 & Tottori & 76 & Saga \\
\hline 11 & Sendai & 33 & Fukui & 55 & Yonago & 77 & Nagasaki \\
\hline 12 & Ishinomaki & 34 & Kofu & 56 & Matsue & 78 & Sasebo \\
\hline 13 & Akita & 35 & Nagano & 57 & Okayama & 79 & Kumamoto \\
\hline 14 & Yamagata & 36 & Matsumoto & 58 & Kurashiki & 80 & Yatsushiro \\
\hline 15 & Fukushima & 37 & Gifu & 59 & Hiroshima & 81 & Oita \\
\hline 16 & Aizuwakamatsu & 38 & Shizuoka & 60 & Kure & 82 & Miyasaki \\
\hline 17 & Koriyama & 39 & Hamamatsu & 61 & Fukuyama & 83 & Miyakonojo \\
\hline 18 & Mito & 40 & Numazu & 62 & Shin onoseki & 84 & Nobeoka \\
\hline 19 & Hitachi & 41 & Fuji & 63 & $\mathrm{Ube}^{a}$ & 85 & Kagoshina \\
\hline 20 & Utsunomiya & 42 & Nagoya & 64 & Yamaguchi & 86 & Naha \\
\hline 21 & Maebashi & 43 & Toyohashi & 65 & Iwakuni & & \\
\hline 22 & Takasaki & 44 & Toyota & 66 & Tokushima & & \\
\hline
\end{tabular}

${ }^{a}$ FUR without a hinterland. 


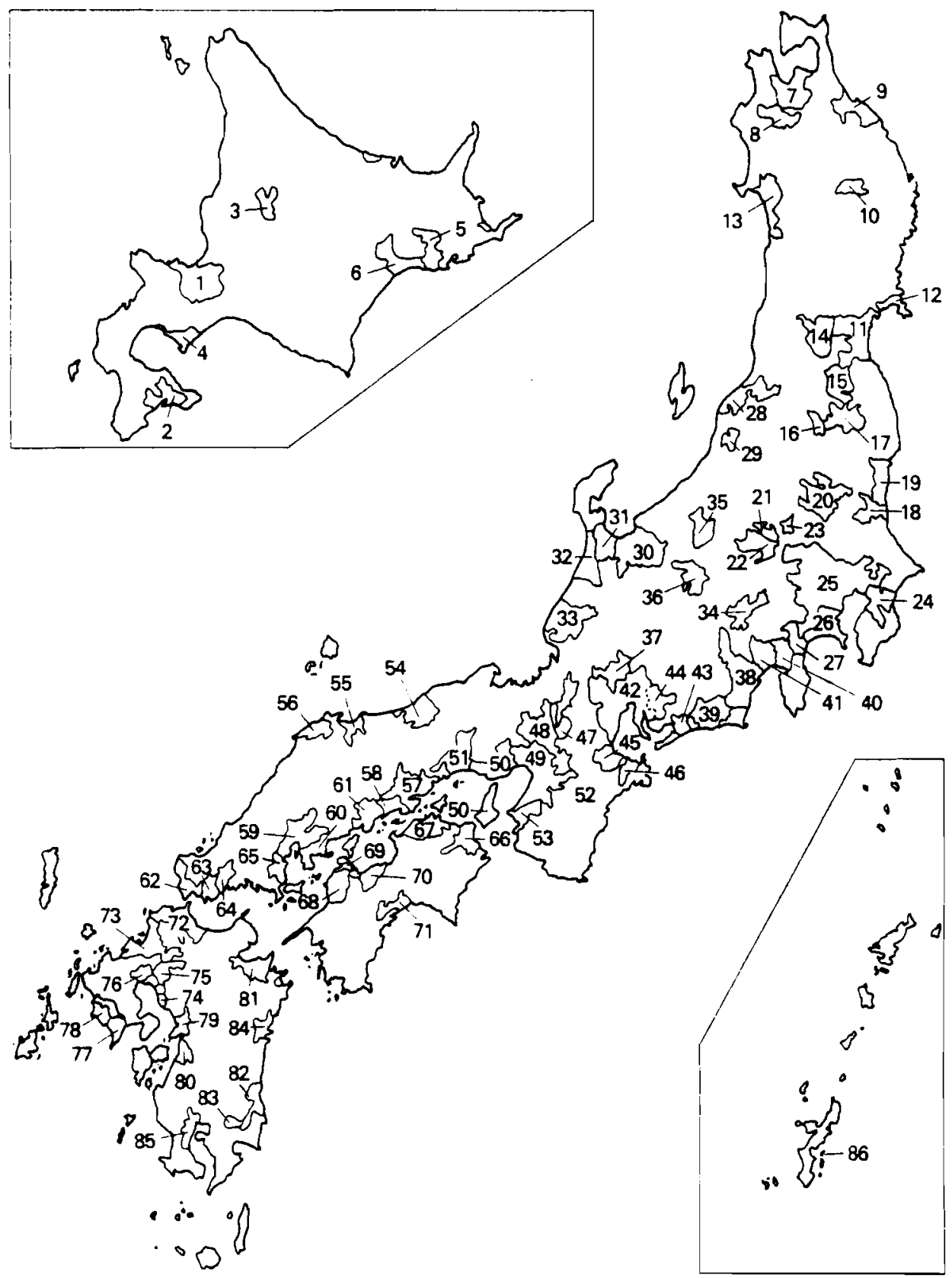

FIGURE 1 Functional urban cores in the system of Japanese FURs. 


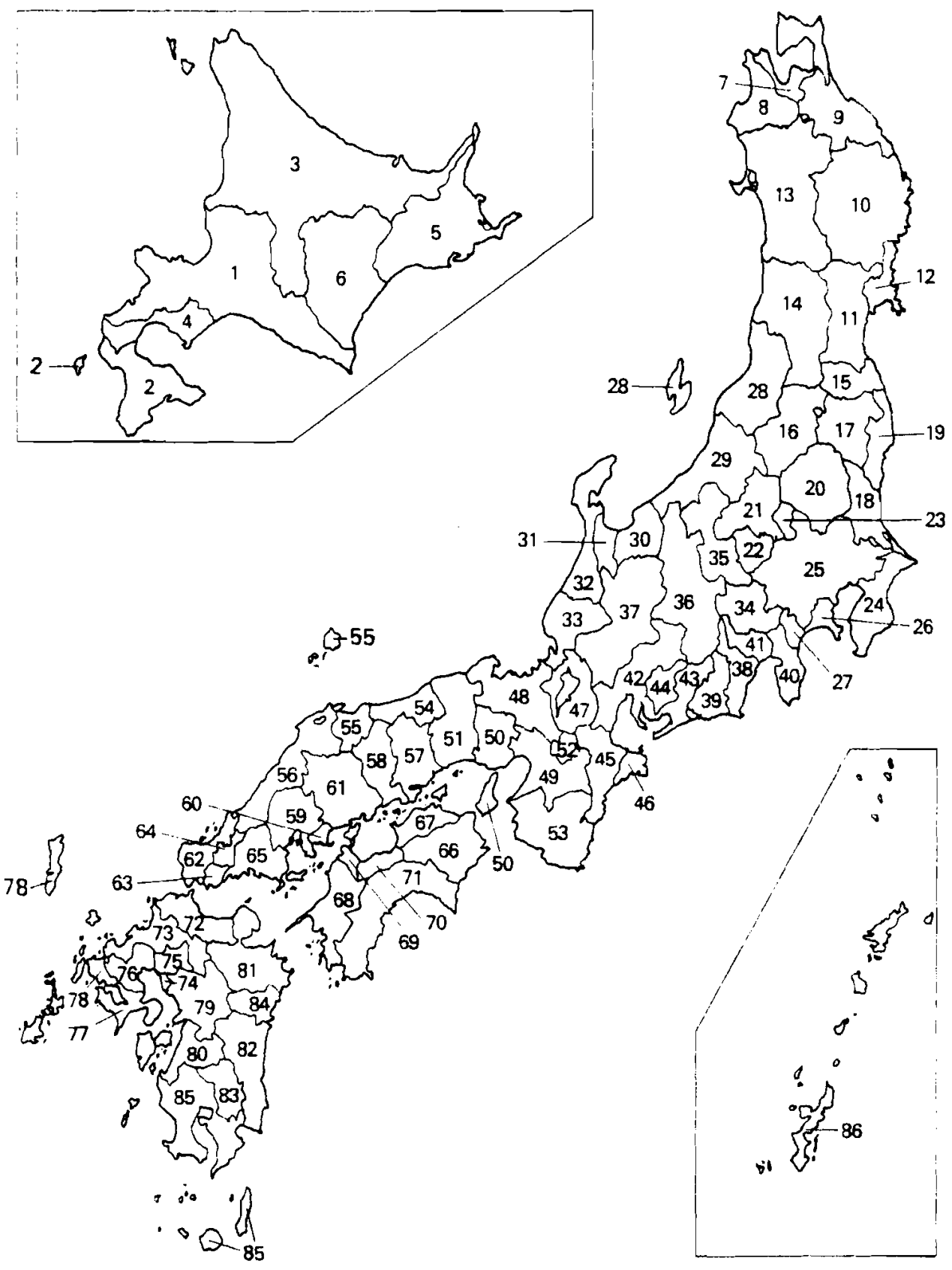

FIGURE 2 FURs in Japan. 
respectively (note that no hinterlands exist for the Yokohama, Ube, and Omuta FURs). For each of the three types of spatial unit (i.e. functional urban cores, hinterlands, and FURs) a data file was organized including information on area (hectares), and population and employment (for the years 1960, 1965, 1970, and 1975).

These data show the following basic characteristics of the system of FURs in Japan as of 1970.

(1) For functional urban cores (86 units): (i) they cover $23.35 \%(8,546,511$ ha) of the land area and $71.40 \%(74,731,359)^{*}$ of the population; (ii) they range in population size from 0.13 million (Yamaguchi) to 18.01 million (Tokyo); (iii) the average area is 99,378 ha and the average population size is 868,969 .

(2) For hinterlands ( 83 units): (i) they range in population size from 0.01 million (Odawara) to 1.76 million (Tokyo); (ii) the average area is 338,013 ha while the average population size is 360,648 .

(3) For FURs (86 units): (i) they range in population size from 0.15 million (Yamaguchi) to 19.76 million (Tokyo); (ii) the average area is 425,600 ha while the average population size is 1.22 million.

\section{RECENT TRENDS IN JAPANESE URBANIZATION}

Although a variety of analyses could be carried out by using our data file, in this paper we report only on population changes, particularly those in urban cores (unless otherwise stated, an urban core hereafter denotes a functional urban core).

By employing the "log-equal scale mode" (see Davis, 1972, pp. 17-20) to classify spatial units by population size we constructed Tables 2-4. (Below the population size class S4 there are theoretically three more classes: S1, 0-31,249; S2, 31,250-62,499; $S 3,62,500-124,999$.) From the tables the following basic information and interpretations can be derived with regard to the spatial evolution of FURs in Japan.

(1) The urban-core area as a whole has grown much faster than the national average since 1960 , al though its growth rate has been gradually reduced.

(2) The hinterland area as a whole has been continuously losing population since 1960. Nevertheless, the speed of net outflow of the population from the hinterland area has been drastically reduced (the weighted average growth rate is $-0.9214 \%$ and the simple average growth rate is $-1.5202 \%$ for the period $1970-1975$ ).

(3) According to Table 5, which is based on Tables 2-4, the ratio of the weighted average growth ratio and the simple average growth ratio (which we may refer to as the ROXY (ratio of $x$ to $y$ ) index) has been decreasing since 1960 for the total urban cores. Even though the ROXY index is a very crude measure for explaining the interclass evolution patterns we can reasonably speculate that the continuous decrease of the value of the ROXY index reflects the process of population deconcentration over urbanized areas.

\footnotetext{
* The urban population (i.e. the population residing in functional urban cores) as a fraction of the total population for the other three years for which data were collected was $64.34 \%(60,670,350)$ in $1960,68.18 \%(67,639,658)$ in 1965 , and $73.50 \%(82,275,810)$ in 1975 .
} 


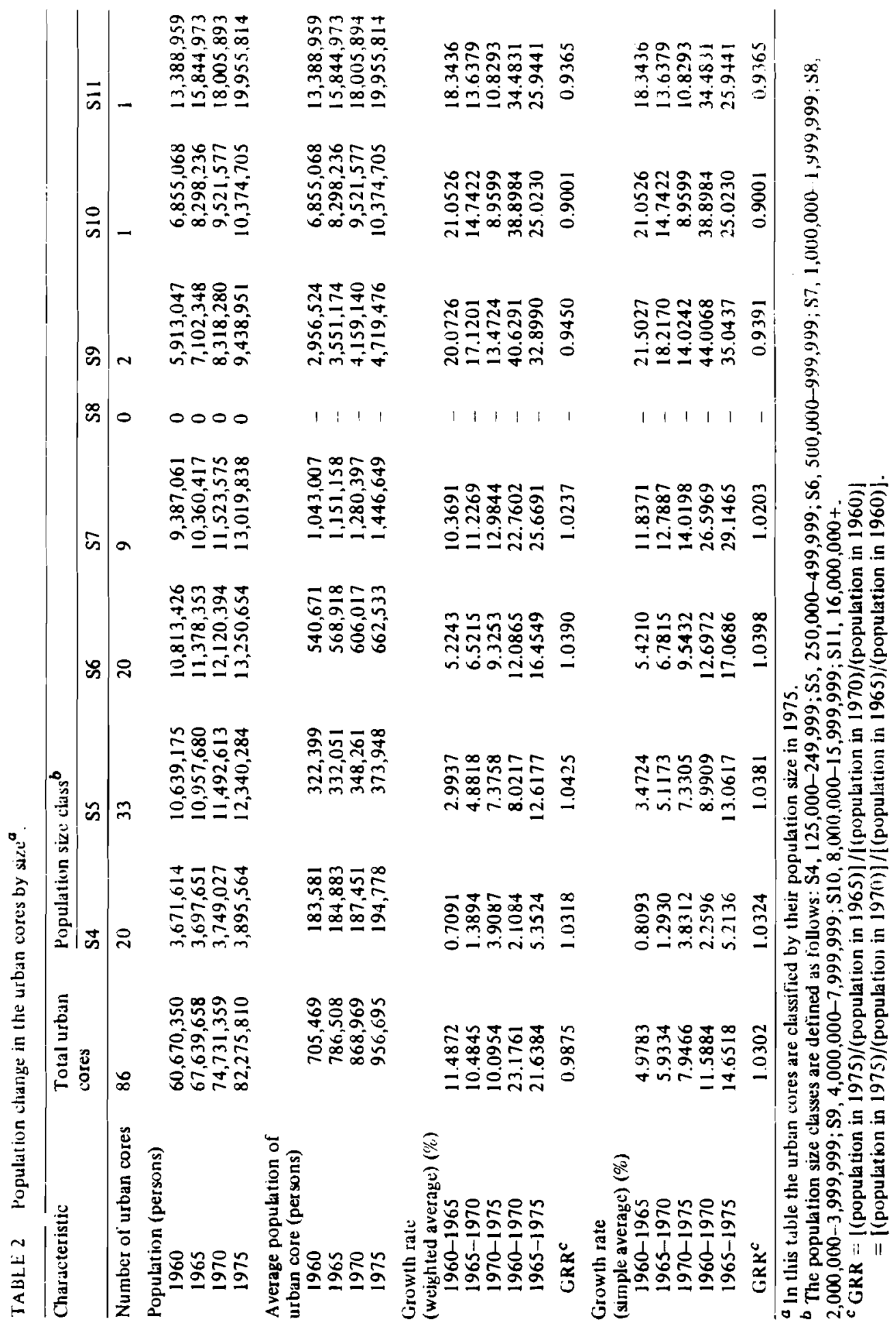




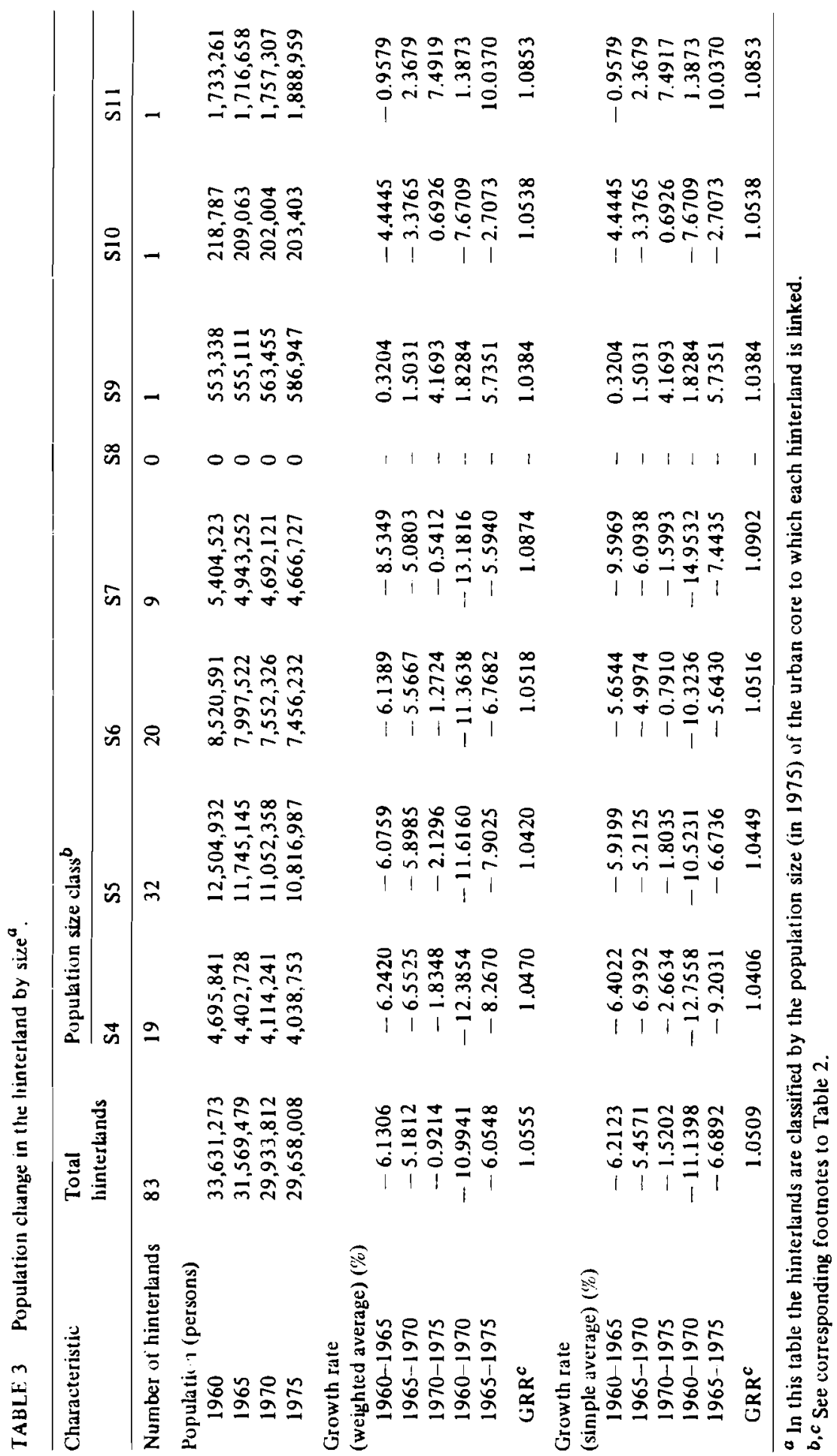




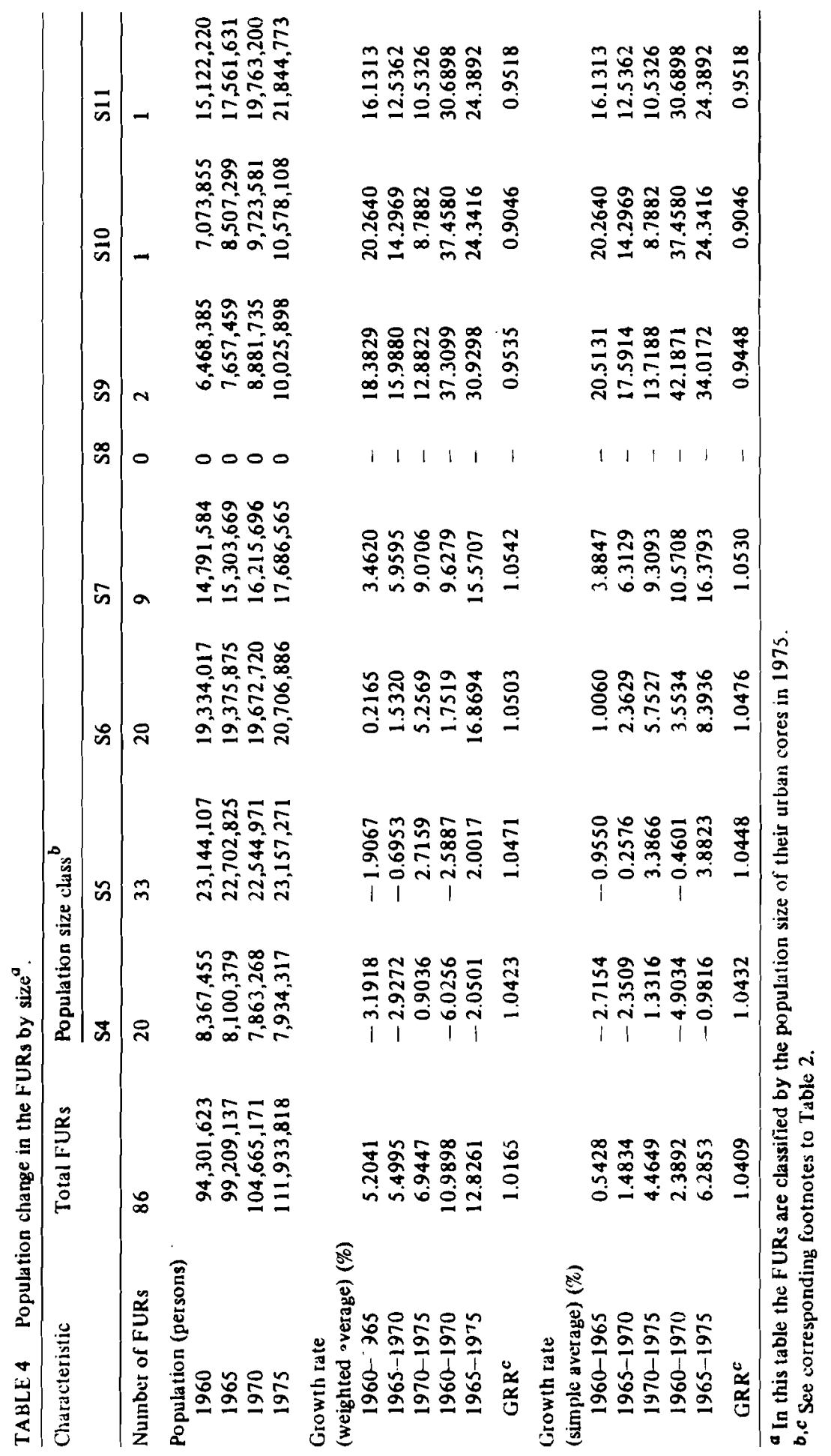


TABLE 5 The ROXY index: the ratio of the weighted average growth ratio and the simple average growth ratio ${ }^{b}$.

\begin{tabular}{llll}
\hline Spatial unit & Time period & \\
\cline { 2 - 4 } & $1960-1965$ & $1965-1970$ & $1970-1975$ \\
\hline Total urban cores & $1.0620^{c}$ & 1.0430 & 1.0199 \\
Total hinterlands & 1.0008 & 1.0029 & 1.0061 \\
Total FURs & 1.0464 & 1.0396 & 1.0237 \\
\hline
\end{tabular}

a Weighted average growth ratio $=1.0+[$ weighted average growth rate $(\%)] / 100$.

b Simple average growth ratio $=1.0+[$ simple average growth rate $(\%)] / 100$.

c We can obtain 1.0620 from $1.114872 / 1.049783$. The other results are obtained similarly.

(4) The ROXY index for the total hinterlands has been increasing since 1960. This suggests that hinterlands with larger populations have either grown relatively faster or declined relatively slower than hinterlands with smaller populations. This interpretation becomes more justifiable in general if we look at changes in the growth rates of hinterlands for each population size class.

(5) For the total FURs the ROXY index has decreased since 1960, although more slowly than for the total urban cores. However, we should be careful not to confuse the view that the phenomenon could be primarily associated with the deconcentration of population over the urban cores with an alternative interpretation according to which it could imply the leveling-off of the hinterlands with respect to population size. Closer investigation of the growth rates by population size class (see Tables 2-4) is more likely to support the former view.

Having obtained these basic facts (see Appendix 2 of this paper for some observations on the assumptions underlying Tables $2-4$ ) on the general urbanization trends in Japan, we shall now concentrate our attention on the growth rate of the urban cores by population size class shown in Table 2. If we plot, using the semilogarithmic scale, the five-year population growth rate (in terms of the weighted average) along the vertical axis and the average population level along the horizontal axis, we obtain the kinds of kinked lines shown in Figure 3.

Our rather casual empirical approach now allows us to adopt the view that the growth-rate line has a tendency to turn in a dextrorotary sense with the fixed pivot point in the vicinity of a population size of 1.5 million (in this context we may call the population size class S7 the pivot class) and a growth rate of $12 \%$. Consequently, the growthrate line first becomes flatter and then gradually its negative slope increases.

Two questions emerge from this, namely (1) how to formulate this phenomenon quantitatively on the basis of our limited data sources without conflicting with earlier knowledge of the urbanization process in Japan and (2) how to use this formulation for short-term projections of urbanization trends.

These issues will be discussed in the next section. 


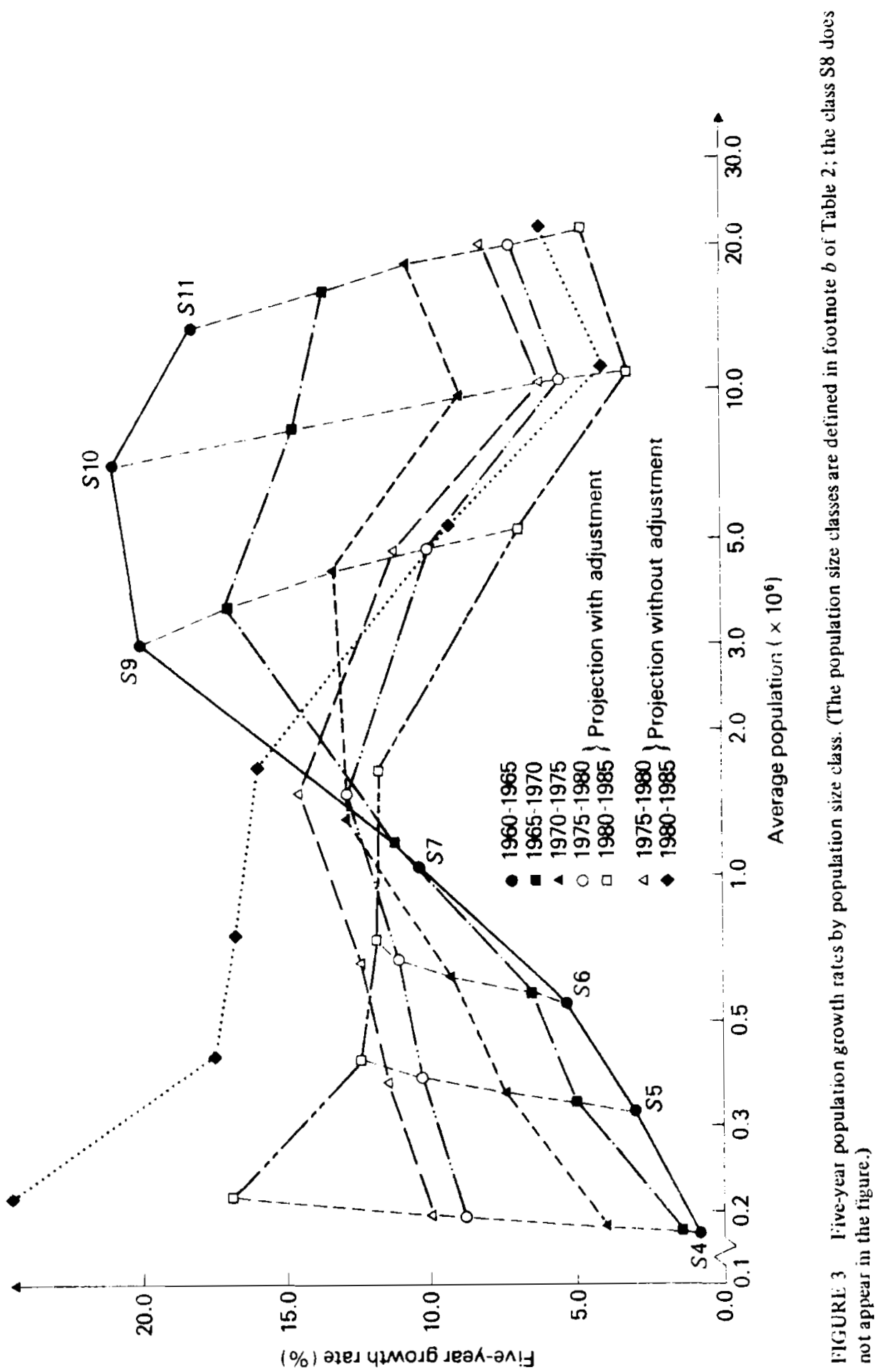




\section{SHORT-TERM PROJECTION OF THE URBANIZATION PROCESS}

It was noted in the last section that the population growth rate will probably continue to increase in smaller urban cores but will decrease in larger cores. It is widely felt that this tendency will continue in Japan for at least a decade or so from now. It is also generally admitted that (1) a significant negative growth rate of population in the larger urban cores in Japan will not be experienced within the next 10-15 years and (2) the share of urban population in the national population will not increase dramatically in the near future but will instead tend to follow past trends.

These preconditions have led us to formulate a framework which, in order to account for the phenomenon of urban rotation (this notion is used in view of the dextrorotary characteristics of the growth-rate line discussed in Section 3), consists of the following steps.

\section{First round}

(1) For each population size class, as well as for the total urban cores, the path of the growth rate (three data points for each class) is approximated by a simple linear regression line. The related parameters and statistics are shown in the upper part of Table $6^{*}$

(2) For each population size class the regression equation is used to estimate the growth rate of population for the period 1975-1980 which appears in the first row of Table 7. We shall call this "the growth rate without adjustment". As an example, for the population size class S1 1 the growth rate without adjustment for the period 1975-1980 can be obtained through the computation

$$
436.6080-58.7068 \log _{10}(19,955,814)=8.0443(\%)
$$

(3) For each population size class the total population in 1980 is estimated on the basis of the growth rate without adjustments.

(4) Aggregation of the population for each class results in a growth rate of $10.4737 \%$ for the total urban cores.

(5) For the total urban cores the regression equation expressed in Table 6 is used to estimate the growth rate of population for the period 1975-1980. The estimated growth rate is $9.3534 \%$.

(6) For each population size class the ratio between $9.3534 \%$ and $10.4737 \%$, equalling 0.8930 , is multiplied by the growth rate without adjustment to obtain the growth rate with adjustment appearing in the second row of Table 7.

(7) For each population size class the total population and the average population are estimated for 1980 on the basis of the growth rate with adjustment. They are shown in the third and fourth rows of Table 7.

\footnotetext{
* I am indebted to H. Tsipouris for valuable assistance in the computer work necessary to complete this table.
} 


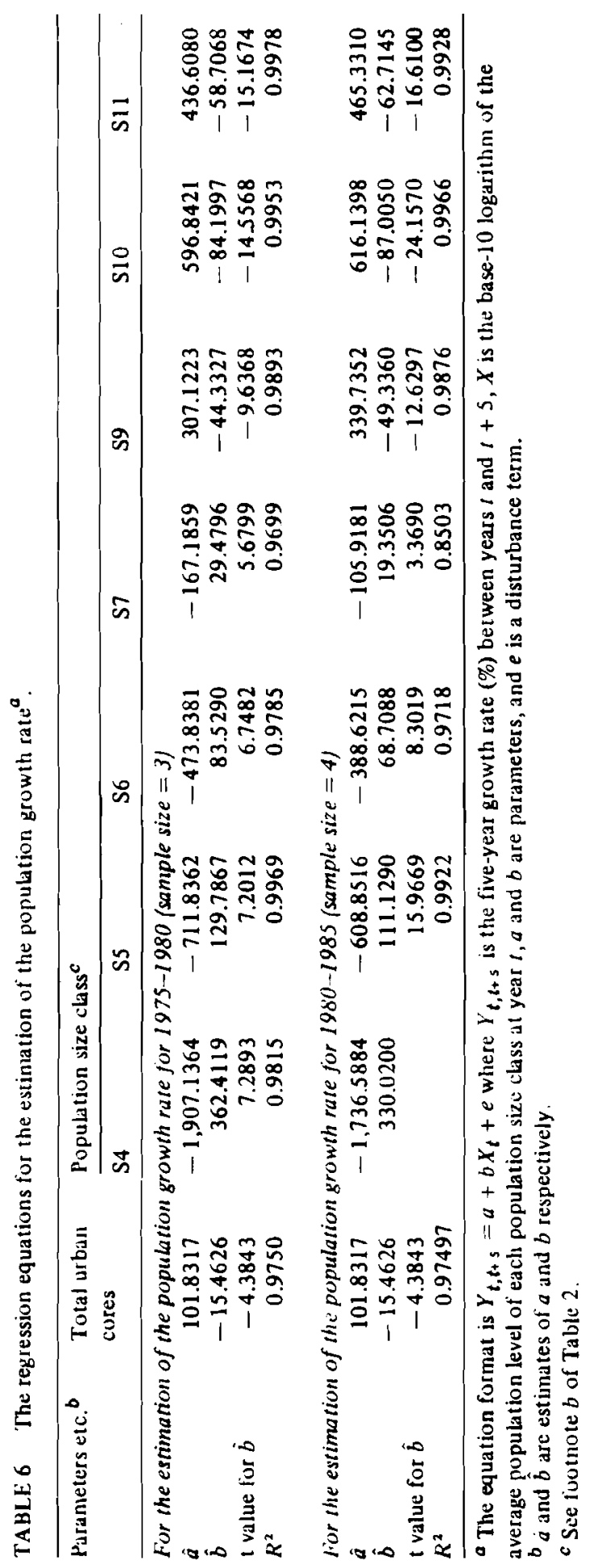




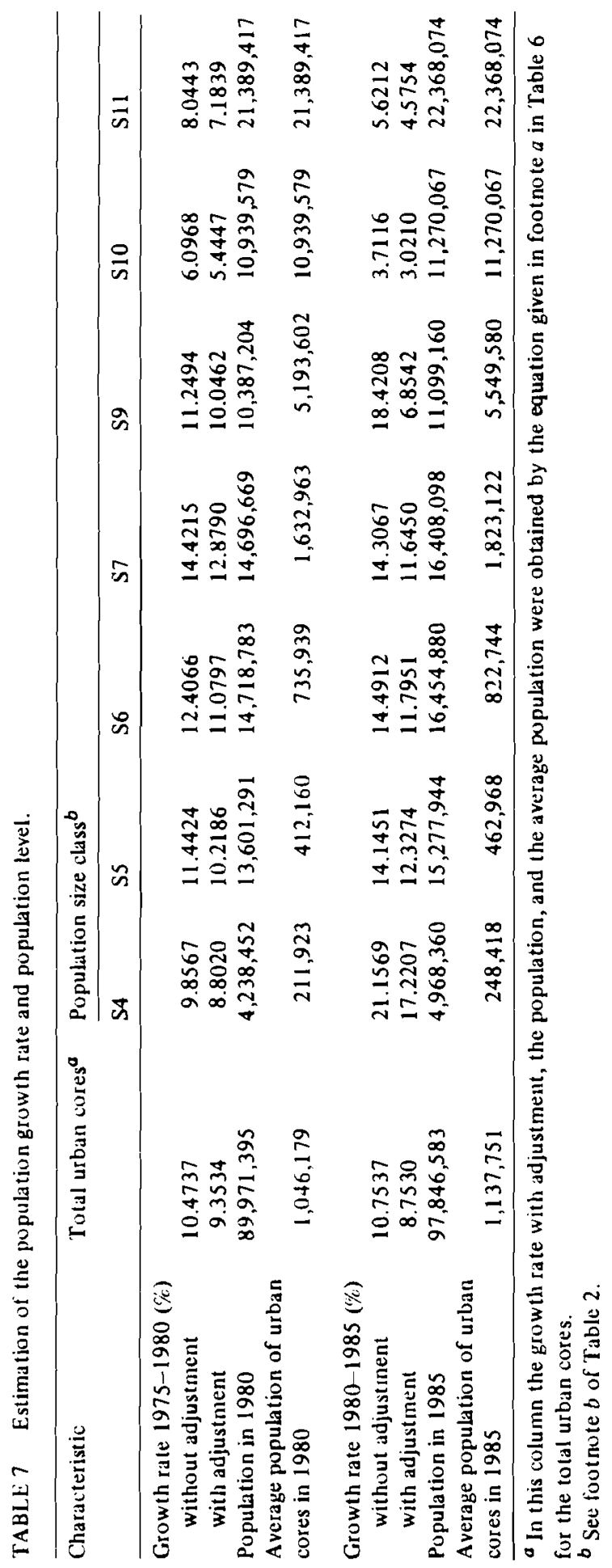




\section{Second round}

(1) For each population size class the future path of the growth rate, including the new point indicating the 1975 average population and the growth rate with adjustment for the period 1975-1980, is approximated using a simple regression line whose parameters and related statistics are shown in the lower part of Table 6 .

(2) Procedures similar to steps (2)-(7) in the first round are used in order to obtain both the total and the average population in 1985 for each population size class. The results are shown in the seventh and eighth rows respectively in Table 7. (With the help of L. Castro, the author estimated the total population of Japan in 1980 as $116,423,976$ and in 1985 as $120,639,624$ by means of the Rogers-Willekens method (Willekens and Rogers, 1978). A comparison of the total population in urban cores (shown in Table 7) with the estimated national population enables us to obtain $77.2767 \%$ and $81.1067 \%$ as the share of urban population in 1980 and 1985 , respectively.)

As clearly shown, this framework has the two following built-in pawls, one to restrict the height of the ceiling and the other to guarantee the level of the floor. (1) The regression equation for the total urban cores serves as a tool to provide a sort of constraint value to limit the ceiling of the growth of each population size class. (2) The format of our regression equation and the method used to obtain the growth rate with adjustnent ensure that larger urban cores have positive growth rates.

Attempts to draw the two net growth-rate lines for the periods 1975-1980 and 1980-1985 by using the results in Table 7 have resulted in the one-circle broken line $(\ldots-)$ ) and the two-circle broken line (-..-) in Figure 3 (just for reference the growthrate lines without adjustment are also shown by dotted lines for the periods 1975-1980 and 1980-1985). There are two noteworthy aspects of this figure. First, the urban-rotation phenomena are explicitly represented. (This might be natural because our original intention was to formulate a framework in which urban-rotation processes could be reasonably simulated.) Second, the growth-rate line for the pivot class (population size class S7) originally went up and then started to come down.

Summing up the preceding discussion, it should be noted that; (1) we have applied simple regression analysis to examine the relationship between the mean value of population and the mean value of growth rate for each population class size, (2) the use of mean values has generated rather high coefficients of determination in our regression analysis, and (3) the limits and merits of carrying out the regression analysis by use of such mean values, for our study on the urbanization process, should be more carefully probed.

\section{CONCLUDING REMARKS}

In this paper we first delineated the FURs in Japan. Then recent urban evolution prucesses in that country were examined by means of empirical and descriptive analysis, based on the data arranged for each FUR. No attempts were made to offer a framework cxplaining the observed trends. However it is the intention of the author to undertake such an effort. A promising theoretical approach to follow relates to the concept of urban agglomeration economies. 


\section{REFERENCES}

Beale, C. (1975). The revival of population growth in nonmetropolitan America. ERS-605. Economic Research Service, US Department of Agriculture, Washington, D.C.

Berry, B.J.L. (1973). Growth Centers in the American Urban System, Vols. 1 and 2. Ballinger, Cambridge, Massachusetts.

Berry, B.J.L. (1978). The counterurbanization process: how general? In N. Hansen (Editor), Human Settlement Systems. Ballinger, Cambridge, Massachussets.

Berry, B.J.L. and Dahmann, D.C. (1977). Population redistribution in the United States in the 1970s. Population Development Review, 3:443-471.

Beyers, W.B. (1978). Contemporary trends in the regional economic development of the United States. Unpublished paper. Department of Geography, University of Washington, Seattle, Washington.

Davis, K. (1972). World Urbanization 1950-1970, Vol. II: Analysis of Trends, Relationships and Development. Population Monograph Series, 9. Greenwood Press, Westport, Connecticut.

Glickman, N.J. (1976). On the Japanese urban systems. Journal of Regional Science, 16:317-336.

Gordon, P. (1978). Deconcentration without a “clean break". RM-78-39. International Institute for Applied Systems Analysis, Laxenburg, Austria.

Hall, P., Gracey, H., Drewett, R., and Thomas, R. (1973). The Containment of Urban England, Vols. 1 and 2. George Allen and Unwin, London.

Hansen, N.M. (1975). A critique of economic regionalizations of the United States. RR-75-32. International Institute for Applied Systems Analysis, Laxenburg, Austria.

Kawashima, T. (1977). Changes in the spatial population structure of Japan. RM-77-25. International Institute for Applied Systems Analysis, Laxenburg, Austria.

Morrison, P. (1975). The current demographic context of national growth and development. P-5514. The Rand Corporation, Santa Monica, California.

US lixecutive Office of the President, Burcau of the Budget (1964). Standard Metropolitan Statistical Areas. US Government Printing Office, Washington, D.C.

Vining, D.R. and Strauss, A. (1977). A demonstration that the current deconcentration of population in the United States is a clean break with the past. Environment and Planning A, 9:751-758.

Wardwell, J.M. (1977). Equilibrium and change in nonmetropolitan growth. Rural Sociology, 42:156178.

Willekens, F. and Rogers, A. (1978). Spatial population analysis: methods and computer programs. WP-78-30. International Institute for Applied Systems Analysis, Laxenburg, Austria.

\section{APPENDIX 1: PICTURES OF URBAN DECLINE AS OPPOSED TO CONTINUOUS URBAN GROWTH}

Table A1.1 shows examples which allow us to draw pictures of both urban decline and continuous urban growth, depending on the criteria used for delineating urban areas.

On the basis of this table one could talk about the absolute urban decline in the cities of Tokyo and Osaka since 1965. In contrast continuous urban growth is suggested for both Tokyo and Osaka if we use the functional urban core as the spatial unit. It should be noted that although the population growth rates of the functional urban cores in both Tokyo and Osaka have been declining they are still cigher than the national average. The growth rates of the hinterland areas for both Tokyo and Osaka have been continuously increasing since 1960. 


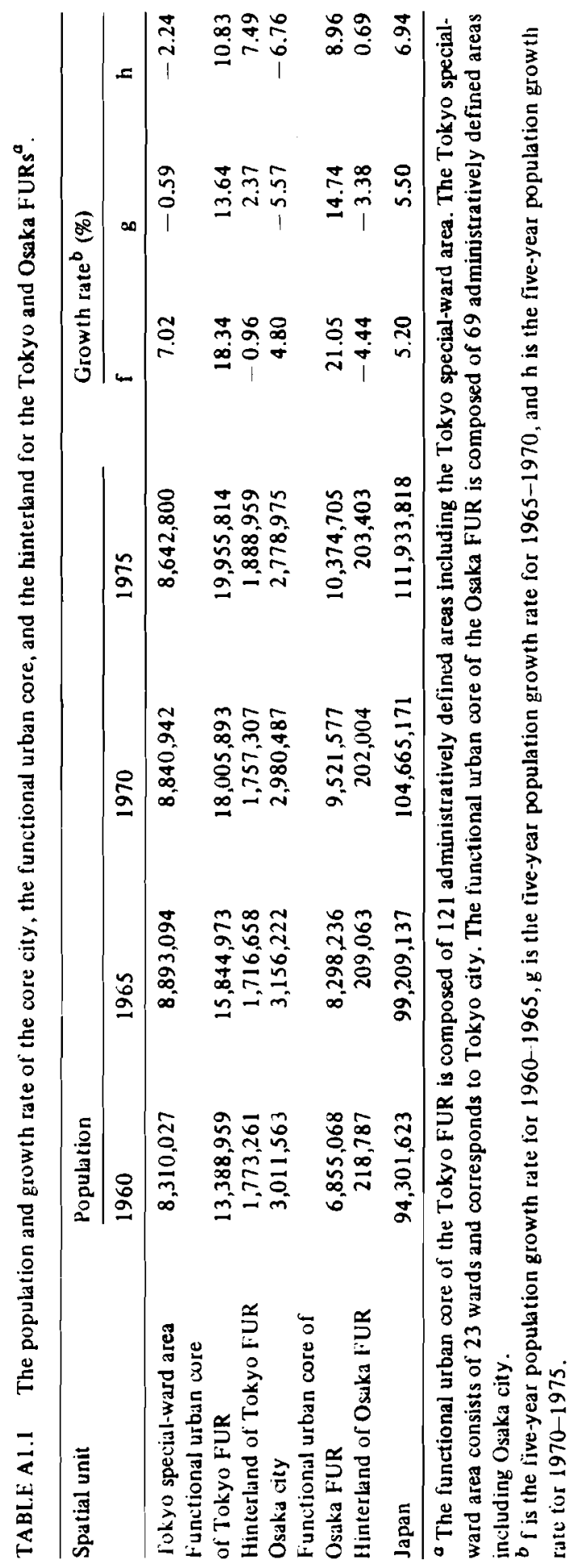


APPENDIX 2: ALTERNATIVES TO TABLES 2 AND 3

The facts derived from Tables 2-4 are based on the classification of spatial units by the populations of the urban cores in 1975 . Here, two questions are raised. (1) Would we do better to classify the urban cores by the population size observed in the base year for each five-year period, for which the corresponding growth rate has been calculated? (2) Would we do better to classify the hinterlands by their population size instead of the population size of the urban cores to which they are linked? Tables A2.1 and A2.2 were constructed to answer these questions partially. Roughly, the general implications derived from these two alternative tables seem not to differ significantly from those of Tables 2 and 3 al though much closer investigation would be required before a definite conclusion could be reached. 


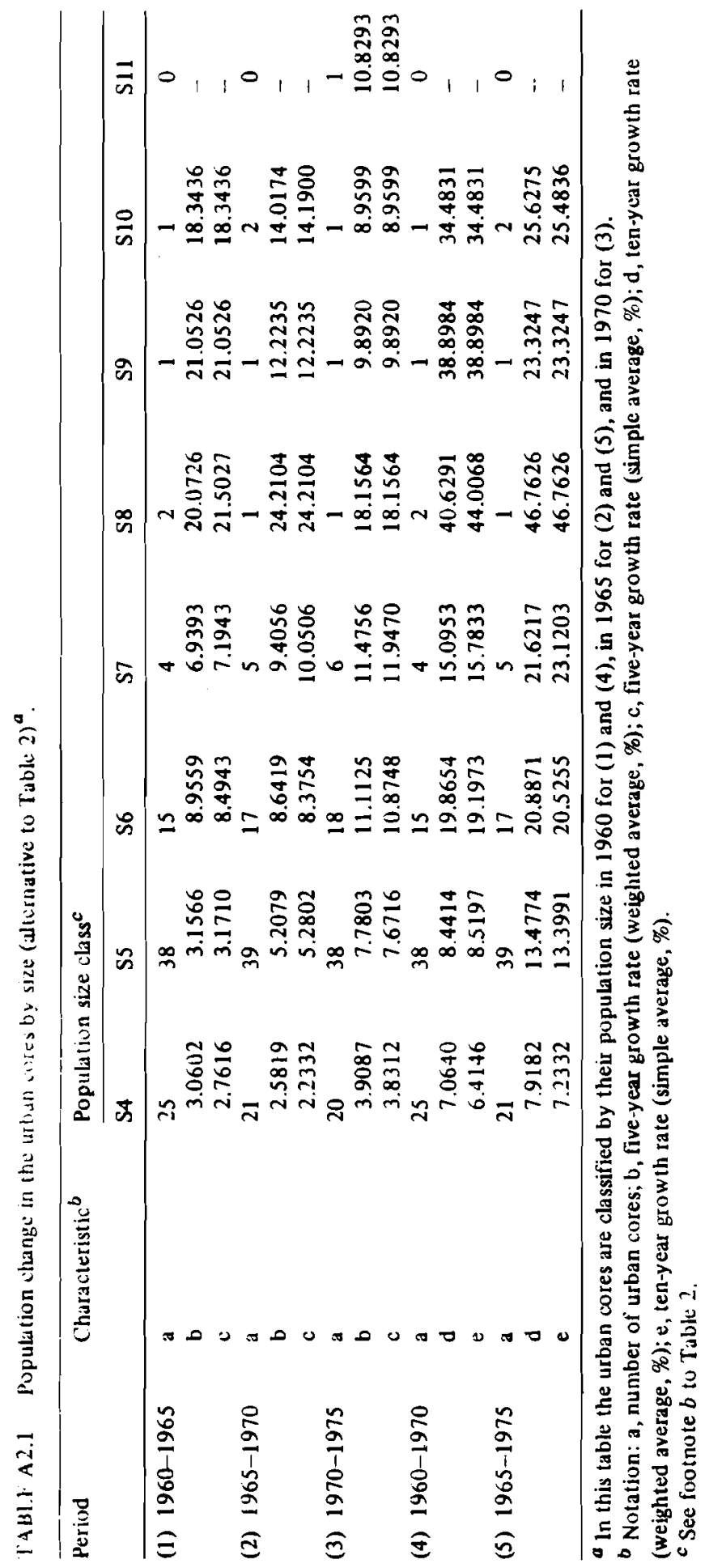




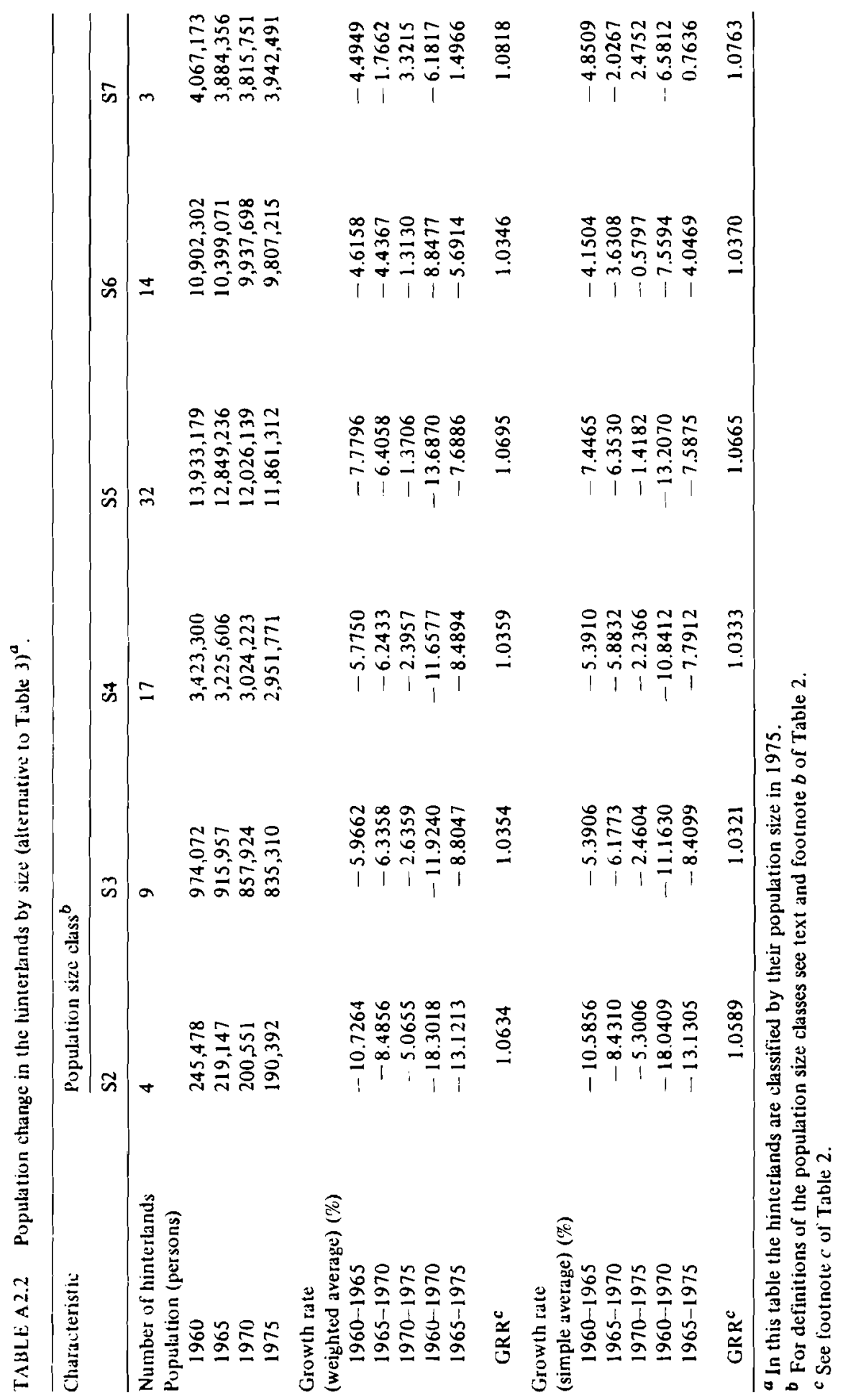




\title{
URBAN REGIONS IN THE SETTLEMENT SYSTEM OF POLAND
}

\author{
Piotr Korcelli \\ Human Settlements and Services Area, Internutional Institute for Applied \\ Systems Analysis, Laxenburg (Austria)
}

\section{CONCEPTUAL BACKGROUND}

Traditionally, urban studies have been subdivided into several research approaches, e.g., settlement-network analysis, urban social ecology, land-use and population-density models, and diffusion-oriented models of urban growth. Linkages between the individual approaches remained very restricted until the late 1960s but since then their development has become increasingly interdependent. The concept of Functional Urban Regions (FURs) is a fairly typical product of this development, as it penetrates through a number of well-established branches of urban and population research. More specifically, the interest that it lias attracted recently is related to three different albeit interconnected functions which it performs, namely those of (a) a spatial frame of reference in urban analysis, (b) a theoretical concept of settlement patterns, and (c) a policy-oriented concept of urban space. (These interrelated aspects were identified by Dziewoński (1967a) in relation to the more general notion of economic regions.)

Scientists and planners had been dissatisfied for a long time with the ways in which urban areas were defined, following administrative criteria, by national as well as international statistical agencies. This gave rise to the adoption of a number of more aggregate statistical units such as the conurbation, the metropolitan area, and the urban agglomeration. More recently it has been postulated that the FURs represent a still more comprehensive spatial framework, not only from the perspective of comparative analyses of urbanization trends but also in the context of the study of population flows. In fact the concept of FURs provides a spatial frame of reference that is well suited for research on spatial interaction and migration. A more comprehensive cognition of the anatomy of FURs should make it possible to restructure the existing models of spatial interaction which, in both their analytical and planning versions, are based on a rather oversimplified view of the interrelating between the spatial patterns of residences, workplaces, and services within an urban region. In contrast to daily human interaction, the main concern in migration studies is with moves occurring between, rather than contained within, urban regions. Migration that is attributable to labor factors takes place typically over 
internediate and long distances, whereas within the short-distance range which corresponds to the spatial dimensions of urban regions such moves tend to be replaced by the daily journey to work. Hence, the adoption of FURs as spatial units in migration analysis allows the separation of the basic types of move while focusing primarily on labororiented migration.

The theoretical aspect of the FUR concept relates to its role of linking interurban with intraurban analysis. Attempts have been made in the past to apply individual conceptual frameworks, notably the central-place theory, at different spatial levels but these efforts have mostly represented a static approach. The concept of urban regions serves to interpret the extension of an urban place to a local settlement system as well as the transition from a local to a regional scale in the analysis of settlement patterns.

The development of settlement systems has been portrayed basically in three ways. The first approach is the one implied in the analysis of urban rank-size patterns. It has been generally found that the regularity in city rank-size distributions tends to increase over time and that it is positively correlated with the intensity and stability of humanoccupancy and economic-activity patterns. With this as a premise, the rank-size regularity has been postulated to represent a measure of the integration of national settlement systems, and the development of such systems has been depicted by the evolution of urban rank-size curves. This concept, unlike the remaining two, has no explicit spatial dimension.

The second interpretation of the evolution of settlement systems is closely related to the notion of urban regions and to the concepts which lie behind it. The starting point in the sequence is a hierarchical pattem of central places which evolves as a result of exogenous economic and technological factors. The spatial change involves, inter alia, the growing territorial division of labor and functional specialization, including the dissociation of places of residence from places of work and recreation, as well as trends towards concentration and, subsequently, deconcentration of population and economic activity. These phenomena bring about a diminution of earlier differences between urban and rural areas in terms of conditions and patterns of life; this trend is particularly emphasized in centrally planned economies. If one assumes that a concentration-deconcentration syndrome operates on a regional scale in the form of a cycle, then the former trend may give rise to a pattern of metropolitan regions (as described in the metropolitan-dominance theory) while the latter may in the long run result in a pattern of urban fields, as defined in the theory of spatial interaction. However, if variations in overall population densities are introduced as an exogenous variable, the urban pattern may become polarized, as sug. gested by Boudeville (1978), into (a) central-place-derivative forms with a discernible and ordered structure of flows and (b) metropolitan-area-related forms that are characterized by a high level of internal functional specialization accompanied by the disappearance of hierarchical distance. In any case, according to this interpretation the development of settlement systems is to be seen as an evolution of linkages between cities and regions and in terms of the emergence of FURs.

The third interpretation starts basically from the same point as the second, i.e. from a hierarchical central-place model, but the change of this pattern over time is attributed not so much to intraregional linkages as to growing specialization and functional interdependence on a multiregional or national scale. The evolution of a settlement system is therefore depicted in terms of a growing range and spatial scale of interactions. At an 
advanced stage in the development of a system, it may be claimed, interrelations between large cities (metropolitan areas, urban agglomerations) on a national scale become more important and intensive than relations between an individual city and its hinterland. Such assumptions prevail, for example, in the "large-city-focused model of city system development" proposed by Pred (1973). This approach to the structure of settlement systems is based on the analysis of spatially discontinuous linkages, in the case of which the friction of distance, usually represented by a distance-decay function, is of less importance.

A review of theoretical assumptions and empirical evidence shows that the last two interpretations of the evolution of settlement systems are complementary rather than contradictory (Korcelli, 1978). Each deals with a different set of functions, which are characterized by a specific scale of interaction. This may be easily assumed in the case of every single function under static conditions. However, one can also postulate that when individual functions are plotted against a measure of distance (i.e. the spatial range of interactions which they generate) the resulting frequency distribution will reveal the clustering of functions within a few distance intervals. These intervals and the relevant sets of functions (interactions) represent major dimensions in the organization of human settlement systems. Two such intervals, which seem to account for a disproportionately large share of interactions, relate to the spatial scale of urban regions on the one hand and to the distance range separating major metropolitan areas (urban agglomerations) on the other.

Admittedly, other intensive interactions within settlement systems can be identified (e.g., linkages between specialized manufacturing centers on a national level) which are not accounted for by either of the two dimensions identified. Nevertheless, the existing typologies of settlement systems (Bourne, 1975; Dziewonski, 1971; Alayev and Khorev, 1976 ) suggest that these two dimensions tend to dominate the overall pattern. The place of urban regions within the morphology of a settlement system depends, however, on factors such as the spatial scale of a given country, the density of its urban network, the type and level of socioeconomic development, the natural environment, and the degree of internal homogeneity. Depending on these factors and configurations, the fraction of the total national territory that falls within the realm of urban regions varies substantially between individual countries. However, the expansion of this proportion over time represents a universal trend.

The foregoing hypotheses should of course be subjected to tests. In particular, investigations should be made of the spatial range of individual interactions within settlement systems and of their shifts over time. Such temporal trends, if identified, might support hypotheses according to which certain dimensions are replaced by others in the course of settlement system development (e.g., interactions which were on an intraurban scale in the past may now be typical of the scale of urban regions). In addition, studies can be made of individual spatial dimensions within human settlement systems. This last approach is followed in the present paper which deals with the internal structure of, and interrelations between, urban regions.

The planning and policy-oriented aspects of the FUR concept may be illustrated in the context of one of the basic regional planning issues, namely that of the functional versus territorial organization of human activity. There is a great deal of evidence of the increasing ascendancy of functional over territorial components in human-activity patterns. Professional affiliations become of greater importance than neighborhood ties (the trend persuasively depicted by Webber (1964) in his discussion of nonplace urban realms); 
growing population mobility makes regional communities less stable in terms of their composition and internal links; consumption patterns become more uniform on an interregional scale; finally, territorial divides have of ten been regarded as obstacles to economic and social integration on a national scale and have thus been fought against. Nevertheless, in the literature on interregional disparities it is frequently pointed out that resources that are allocated to less developed regions tend to create welfare effects in the more developed regions, an observation that has prompted authors such as Friedmann (1977) and Stöhr and Tödling (1976) to argue in favor of selective regional closure as a development-planning principle.

The concept of FURs can give rise to the following interpretation of the evolution of interregional disparities: the emergence of urban regions represents a spatial polarization of socioeconomic activity into production-and consumption-oriented patterns, i.e. the increase of the interregional division of labor and the expansion of daily humanactivity patterns from a local to a regional scale. The spatial extension of interindustry linkages contributes to the lessening of interregional disparities as measured by aggregate social and economic indicators. Such disproportions are more likely to persist on an intraregional scale, despite the intensity of human interaction within urban regions. This trend has been identified for a number of highly urbanized countries (see for example Drewe, 1980).

It has been suggested that the notion of FURs builds on a number of concepts of settlement structure and evolution. However, in order to describe its scope more precisely it is necessary to go back to the alternative definitions of urban regions, as used within the framework of individual theoretical approaches to the study of urban and regional systems. The following versions of the notion of urban region can be identified.

(1) "The nodal region" in regional analysis and regionalization theory (see Wróbel, 1965). According to Whittlesey (1954) the specific characteristics of such regions include (a) uniform internal organization, (b) the existence of a focus, usually represented by a city, (c) the existence of an internal circulation system, (i.e. flows of people, goods, and information), and (d) a "readable" morphology (i.e. division into a core, which contains the focus, and marginal zone).

(2) "City hinterland" or "the tributary area" in central-place theory, This is also some times referred to as "the functional region" (Ray, 1968) and is defined as an area within which the flows of people and goods interconnect the given set of urban and rural communities into a functional whole. According to this concept, the regional boundary corresponds to zero demand for goods and services that are available in the center and is determined by the structure of transportation costs and the distribution of alternative (competitive) centers. The flatter the gradient of transportation costs with distance from the center, the less pronounced is the spatial concentration of economic activity within the region and the larger is the tributary, or service, area of a particular urban center.

(3) "City-region" in the theory of the urban economic base and functional structure of cities (Dziewoniski, 1967). This notion refers to an analogy between the city and the economic region, defined as a subspace in the general socieconomic space. To delineate an economic region within the space in question it is necessary to determine its identity in relation to other (peripheral) areas as well as to reveal its connections with those areas. The procedure that is followed in urban economic-base studies is largely similar to the one described earlier; the identification of city exogenous functions allows 
one to determine relations between the city and the socioeconomic space (the rest of the economy) while the endogenous functions and their range can be interpreted as delimitation of the city (i.e. a subspace) within the general space. The relative openness or closure of the urban economy is treated as a function of the spatial mobility of the population. Increasing mobility leads to the identification of the city with what was originally its service area. As a consequence of this the lower-order centers that are located within such an area become transformed into elements of the internal structure of the city-region.

(4) "Metropolitan region" in the theory of metropolitan dominance (Duncan et al.. 1960). According to this concept, the emergence of a metropolis is considered as an effect of advanced economic specialization and territorial division of labor. This development leads towards a transformation of the settlement structure described by centralplace theory, i.e. towards the concentration of the productive, commercial, and managerial functions of a large region within a single metropolitan area. The concentration proceeds at the expense of smaller urban places situated in the zone of metropolitan dominance (the metropolitan shadow). These towns gradually lose their former functions or specialize in a few functions, thus becoming subdominant centres. In the concept under discussion the stage of metropolitan economy is associated with technological improvements in transportation and the replacement of local linkages in production and commercial activity by regional linkages.

(5) "Urban region" in the growth-pole theory (Boudeville, 1978). According to this concept the transformation of a traditional settlement network under the impact of economic and social change results in the emergence of two distinct types of urban pattern, namely the polarized region and the urban region ("la région urbaine"). The latter is formed in densely populated areas and is characterized by (a) the replacement of internal migrations (still a dominant type of population movement in the case of the polarized region) by the daily journey to work, (b) the high internal specialization of economic functions and, in particular, the development of quaternary activities as a major sector of the regional economy, (c) nonhierarchical spatial diffusion patterns, and (d) a tendency to retain and reinvest locally created wealth (this feature results in the ability of the region to transform and modemize periodically its basic activities as well as the infrast ructure).

(6) "Regional settlement system" in the concept of national settlement systems in both its positive (Dziewonski, 1971) and its normative (Khorev, 1971) versions. The former claims that at an advanced stage of settlement integration the major structural dimension of settlement is represented by interrelations between urban agglonierations while the relations of each agglomeration with its surrounding region pertain mostly to consumption, public services, and administration rather than to specialized manufacturing functions. In the planning concept of unified settlement systems (which in fact refers to a higher level of spatial aggregation) local systems correspond to regional settlement systems, which are identified with territorial-production complexes.

(7) "Urban field" or "daily urban systems" in spatial-interaction theory (Friedmann and Miller, 1965; Berry, 1973). The spatial extent of such units (containing a core and periphery) is determined by the range of daily contacts (basically trips) by the resident population. Following this definition, settlement systems are built of mutually overlapping networks of places performing residential, employment, service, educational, social, 
and recreational functions that are interconnected by a pattern of everyday flows. Together with declining transportation costs (relative to other costs) and/or declining demand elasticity for transportation, the boundaries of urban fields or daily urban systems are pushed away from their centers while the peripheral zones gain functions which were originally concentrated in the core. This process may ultimately lead to a reversal of the traditional core-periphery proportions. The limits of the spatial expansion of urban fields are usually identified with economic factors and restrictions on individual time budgets rather than with technological barriers to movement.

The foregoing versions of the notion of urban regions do overlap considerably but since each has been generated within a different theoretical framework it points to different aspects of spatiai patterns and relationships. The versions can be ranked according to the spatial scale to which they pertain as well as according to the temporal sequence of the phenomena and processes described. The former approach was adopted by Dickinson (1964) who identified four distinct aspects of the regional ties of the city, namely the spheres of (a) urban land use, (b) urban settlement (i.e. daily commuting), (c) social and cultural relations, and (d) economic relations. However, most of the versions of the notion listed are multidimensional in the sense that they refer to both the economic and the sociocultural linkages as well as to daily person-trips. Nevertheless, it is possible to divide them in to two broad groups, one following the functional and the other the morphological tradition in urban studies. The former category includes the notion of city hinterlands, as postulated in the central-place theory, the city-region in urban economic-base theory, the metropolitan region, as well as the concepts of regional settiement systems. The remaining concepts fall basically into the morphological category although all of them share some functional characteristics as well.

The concept of FURs is perhaps most closely associated with the notion of daily urban systems but it is broader and less operational than the definition of daily urban systems. The FUR has been claimed to represent a generalized concept of urban regions although it fails to account for all the major characteristics of the specific concepts. For example, both Boudeville's urban regions and Duncan's metropolitan regions refer to relationships and magnitudes which extend well beyond the scope of a standard FUR definition. This is particularly true when the FURs are tailored in such a way as to allow (for comparative purposes) the exhaustive division of a territory in question into urban regions.

The boundaries of FURs have been commonly associated with the range of the journey to work for at least two reasons. First, it was the labor-market structure which constituted the focus of interest to the authors of the classical studies in the field (Berry, 1973; Hall et al., 1973). Second it has been stipulated that commuting may serve as a diagnostic variable for a much broader range of phenomena since its patterns tend to correspond to the spatial structure of other social and economic variables such as tertiary. sector linkages, the organization of the technical infrastructure, as well as social and economic characteristics of the population including the occupational structure, the demographic structure, and the educational level. Although such assumptions have never been tested o1. extensive sets of empirical data the available evidence (see for example Potrykowska, 1979) does not disprove them. Therefore commuting is meant to serve in the FUR concept as a proxy for a more complete description of the spatial configurations and flow patterns with respect to socioeconomic phenomena. As a consequence of this 
FURs defined according to the range of commuting to and between urban centers ian also be treated as multidimensional socioeconomic regions (see also Alayev and Khorev, 1976).

\section{IDENTIFICATION OF FUNCTIONAL URBAN REGIONS}

There have been a large number of studies published on economic regionalization. the delineation of urban agglomerations, and commuting patterns in Poland. It is beyond the scope of this paper to review that voluminous work but its contribution should be acknowledged. The present study was aimed at the identification of basic trends in population employment and housing distribution by types of urban regions and their morphological zones. Such trends were studied over the period 1950-1973 for which comparable data exist. It was stipulated that spatial units should be defined for a midpoint (rather than an endpoint) of the period under analysis. In practice FURs were identified on the basis of the commuting survey carried out in 1968 by the Central Statistical Office (Główny Urząd Statystyczny, 1973). The survey covered all cities with a population of 50,000 and over as well as a few urban places just below this threshold. Territorially contiguous cities were considered as one core area even if some of them had less than 50,000 inhabitants; similarly two or more noncontiguous urban places were also considered as one core area if their commuting sheds overlapped substantially. As a consequence of applying these rules the 1968 survey covered the commuting zones of 73 urban places. They include all major regional and subregional centers performing labor-market functions, except for several specialized industrial centers which attract a considerable number of commuters but which have been omitted on the grounds of the population threshold criterion. By application of the aforementioned rules of aggregation, the 73 urban places were collapsed into 41 core areas. The boundaries of the commuting sheds were defined according to the ratio of commuters among the economically active nonagricultural population. The threshold value representing the extent of the commuting regions was arbitrarily chosen to be $20 \%$.

For the purposes of the present study the Central Statistical Office definitions were modified to allow for an analysis of urban trends over time. In particular (a) more aggregate spatial units were used as basic building blocks in the regionalization procedure, (b) areas characterized by substantial overlaps of commuting flows were merged to form larger regions, and (c) several additional core areas were defined on the basis of labormarket, central-place, and planning-related criteria.

A more detailed description of the procedures followed is contained in an earlier paper (Korcelli, 1977). The peripheral zones, i.e. areas situated beyond the commuting sheds of individual centers, were defined on the basis of central-place and administrative criteria. In most areas the peripheral zones send some commuters to the cores but their share with respect to the total nonagricultural labor force is less than $20 \%$. In the southern and central parts of Poland, where commuting to work is more widespread, the peripheral zones account for a smaller proportion of the total area than in the remaining regions.

The resulting spatial nattern of FURs is shown in Figure 1 and Table 1. Like any regionalization scheme it can be criticised because of the arbitrariness of the criteria used and/or for its lack of correspondence with the observed variations of the phenomena under study. Both types of reservation are valid in the present case. The population- 


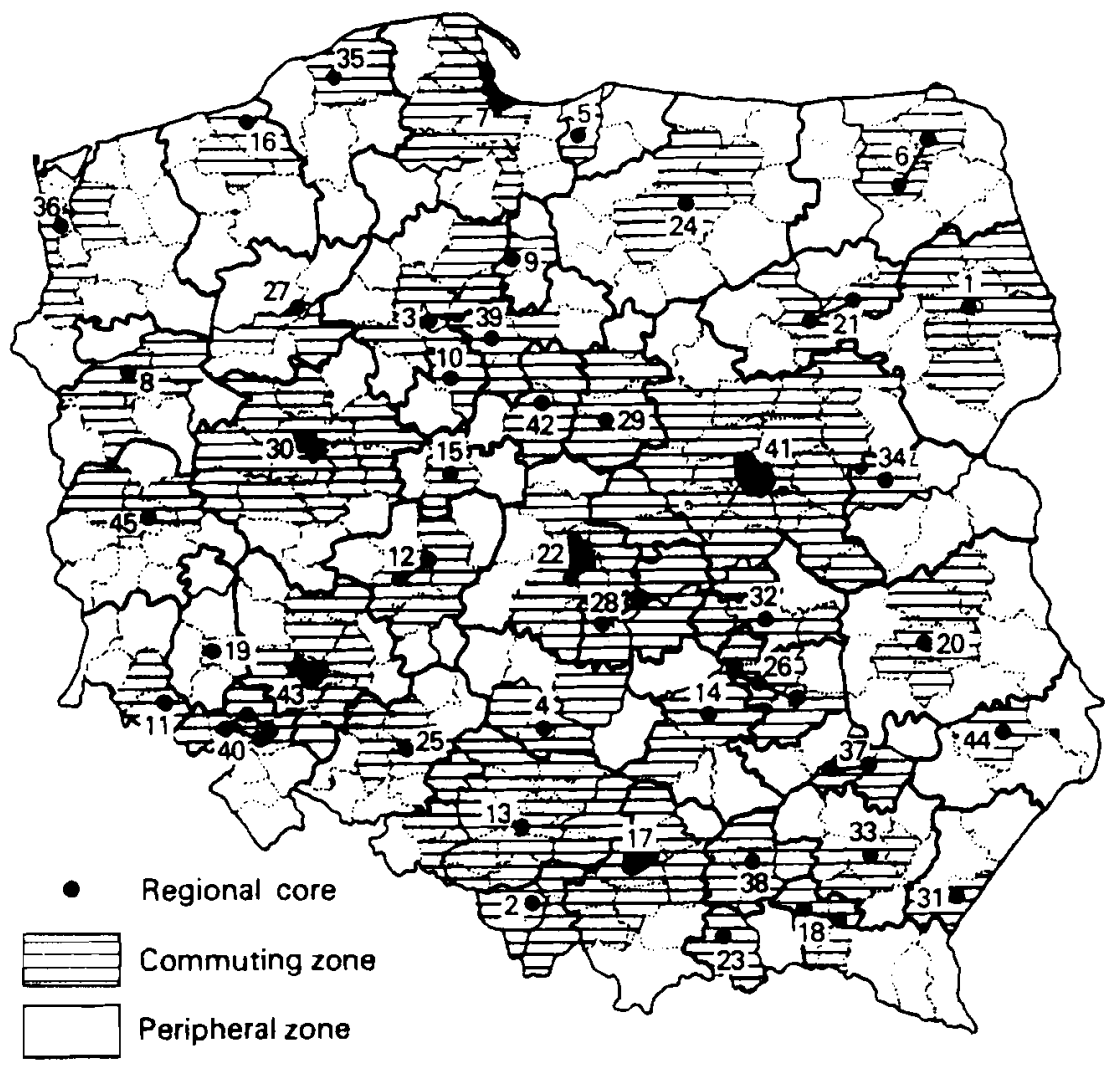

FIGURE 1 Functional urban regions in Poland. The names of the regions are given in Table 1.

threshold criterion for the core areas, despite its nonrigorous use, still eliminates a number of smaller labor-markets which, if included, would have substantially modified the regional pattern. Furthermore, the urban regions identified vary considerably in terms of their economic and population potential as well as their spatial-occupancy patterns. No account is taken of the regional hierarchy which had been reflected in, and to a degree shaped by, the previous administrative divisions. In fact the regional pattern is dominated by a subset of some eight core areas of national importance to which the remaining cores are subordinated in terms of transportation networks and specialized tertiary and, in particular, quaternary functions. The leading cores attract commuters from all parts of their hinterland; in contrast, regions with smaller core areas, unless they are located close to metropolitan centers, have a larger fraction of their area covered by locally oriented settlement systems.

Variations that exist between the FURs are illustrated by the distribution of the selectivity of the joumey-to-work parameter derived from Schneider's interveningopportunity formula. The selectivity is defined as

$$
L=\ln \left[\left(1 / \sum_{j} R_{i j}\right) y_{i}^{-1}\right] \quad(j=1,2, \ldots, n)
$$




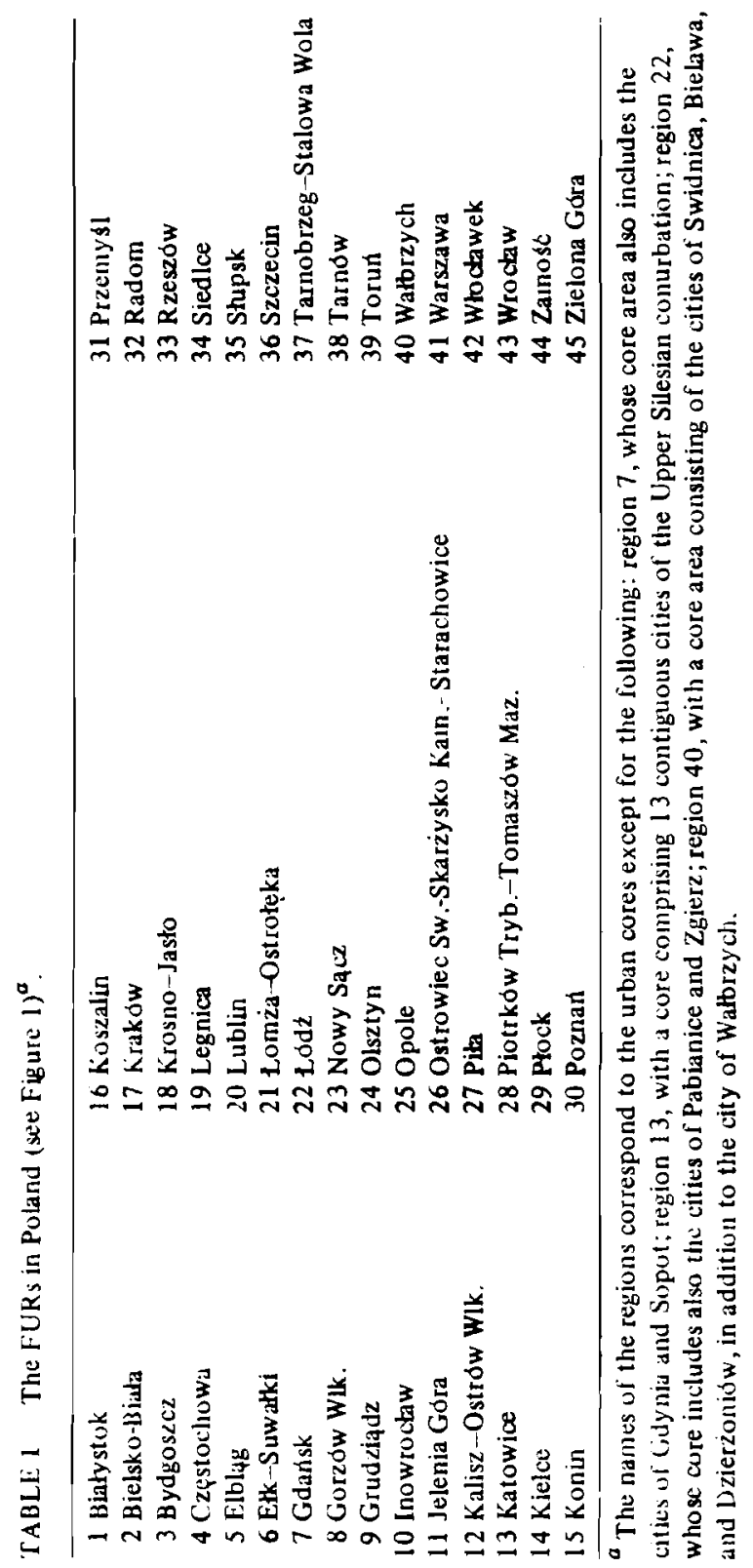


where $y_{i}$ is the number of nonagricultural jobs in region $i$ and $R_{i j}$ is the percentage of the labor force in region $i$ which, owing to "insufficient opportunities" there, travels to work to other regions (see Głogowski, 1978). A frequency distribution of values of the selectivity parameter, when calculated for the same set of basic spatial units which were used in delineating the FURs, reveals the existence of several hierarchical levels, corresponding to the patterns outlined earlier (see Figure 2). The lowest $L$ values are characteristic of the largest metropolitan centers; the next-lowest indexes correspond to second-ranking regional centers and to the hinterlands of the largest cities, in which case the $R$ term becomes dominant. The subsequent categories of progressively higher selectivity values are attributable to smaller areas and to the outlying zones of the large FURs.

A comparison of commuting and migration patterns throws more light on the question of hierarchy and nesting within the system of FURs. For Poland these patterns are highly intercorrelated in space, which suggests that the daily journey to work tends

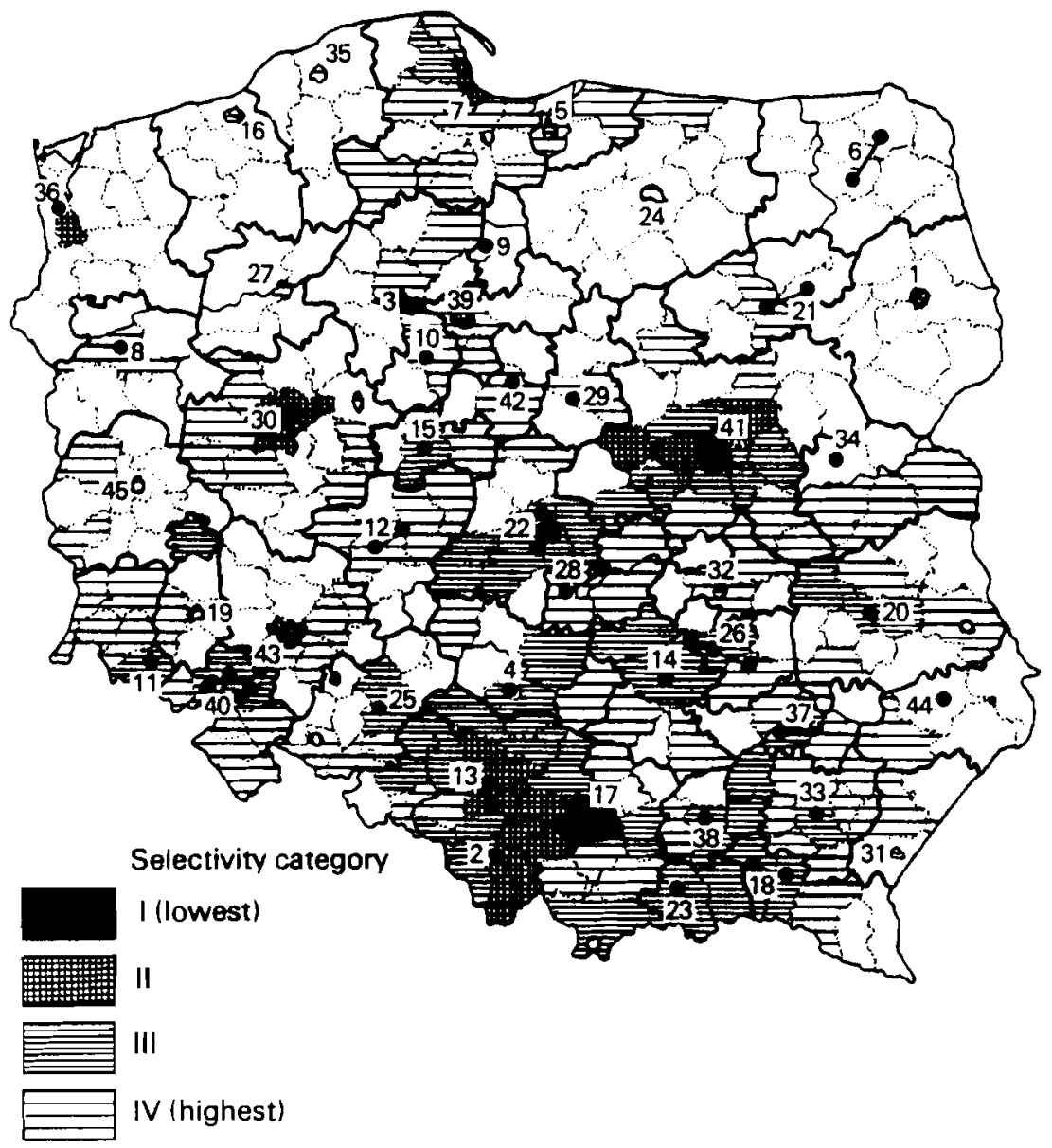

FIGURE 2 The distribution of values of the journey-to-work selectivity in 1973 (after Gtogowski, 1978). 
to serve as a substitute for migration over a considerable distance range. The majority of moves are regional in terms of range; this is true even in the case of the city-voivodship of Warsaw, the area with the highest net migration gain. The exception to this rule is the Upper-Silesian conurbation which attracts migrants from all regions of Poland. Typically, rural-to-urban moves are focused on a local town or city and moves between urban places follow the urban size hierarchy while also obeying the spatial-proximity rule. However, moves originating from middle-size cities (as well as large cities) break the prevailing regionally centered pattern of internal migration. These cities represent the main linkage in the national system of human interaction, especially since the volume of intermetropolitan moves is relatively small (the patterns of business, tourist and vacation, and fanily-related travel are nationwide and are dominated by metropolitan centers). It should be emphasized that particular reference is made here to urban places in the $40,000-100,000$ population bracket, i.e. to a group of smaller core cities as identified in the FUR study.

The pattern of FURs is relatively close to the new administrative division into voivodships (first-order units). (The reform was conducted during 1973-1975 and involved a shift from a three-level division with 22 voivodships, 391 poviats, and some 4300 communities, to a two-level structure with 49 voivodships and some 2200 townships.) This finding is hardly surprising since it was an objective of the administrative reform to create regions with a high degree of closure with respect to the settlement network. Major differences between the two patterns can be found in the vicinities of the largest cities, i.e. Warsaw, Łodz, and Cracow. In the administrative division these regions were delined so as to encompass the respective urbanized areas rather than their much Iarger labor-supply and service-supply sheds. This is illustrated in Figure 3 which gives the distribution of the values of an index of regional closure

$$
S=\left(T_{i}-T_{i}\right) P_{i}^{-1}
$$

where $T_{i}$ is the number of persons commuting to voivodship $i$ from all other volvodships, $\Gamma_{i}$. is the number of persons living in voivodship $i$ but working in other voivodships, and $P_{i}$ is the population of voivodship $i$. It follows from Figure 3 that those administrative regions which are situated in the proximity of Warsaw, Łodz, and Cracow are characterized by a lower level of closure than the remaining units. Furthermore, the pattern supports the notion of a hierarchy of urban regions discussed earlier.

One can expect that the new administrative structure will have an impact on the formation and evolution of FURs and that the two patterns will tend towards convergence. This is largely due to the role of spatial administrative units, under plannedeconomy conditions, as planning and economic regions (see Leszczycki, 1971). In fact a feedback relation exists between the pattern of administrative regions and the pattern of spatial economic structure. For example, a policy in establishing townships since 1973 has been that these units should have sufficient size, population, and economic potential to stimulate the transmission of agricultural innovations and the efficient organization of community services (particularly educational systems which, like other quarternary activities, are spatially organized on the basis of administrative divisions). On a conceptual note, it is also possible to talk about complementary characteristics of the two spatial divisions, one of which emphasizes the journey to work while the other emphasizes the central place and administrative linkages. The spatial ranges of these two types of 


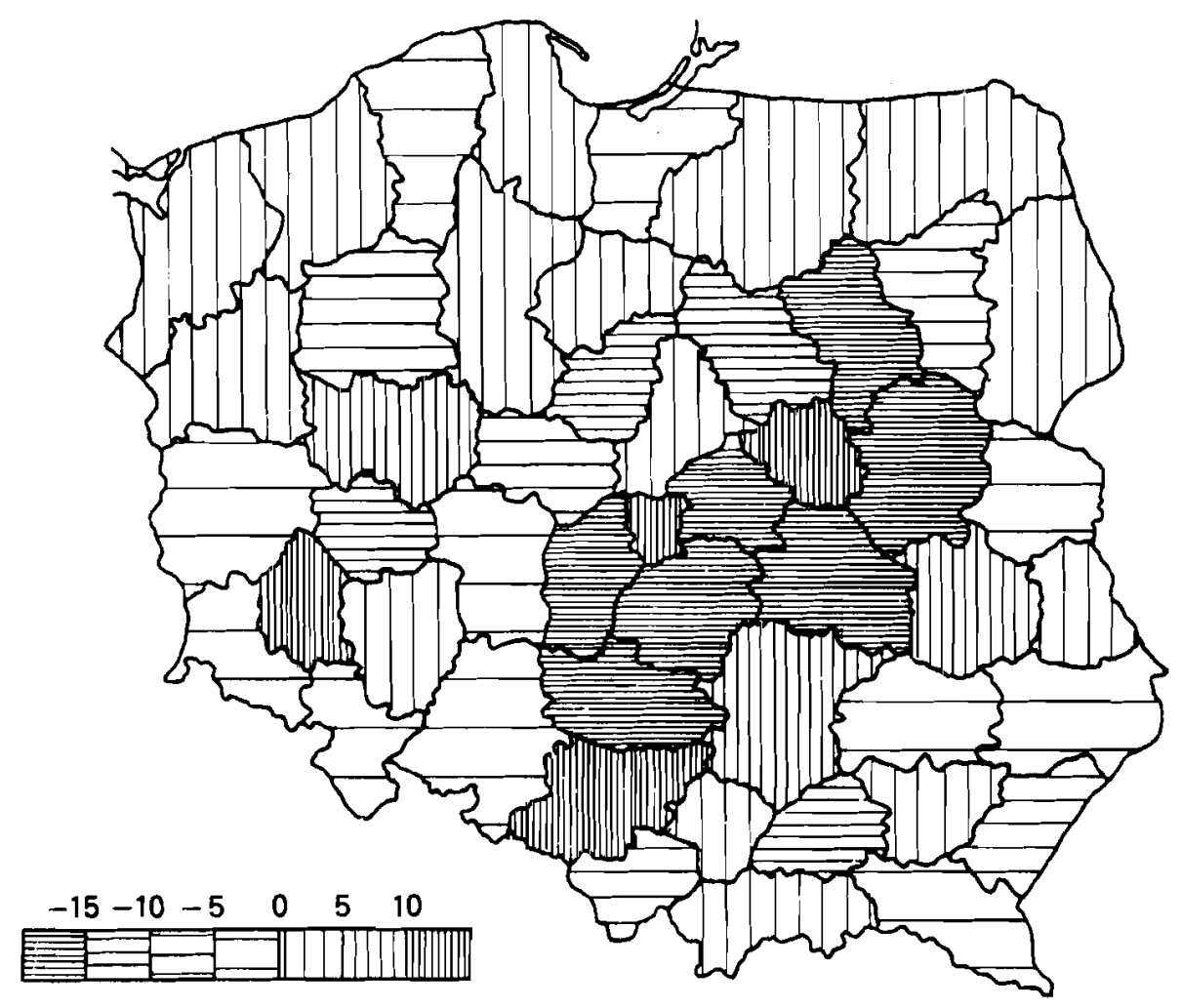

FIGURE 3 The joumey to work between voivodships in 1973: the distribution of regional-closure index values.

interaction are superimposed one on the other but they do not overlap completely. It should be noted that about one-half ( $48 \%$ in 1968) of all commuter trips are accounted for by the industrial sector, the internal organization of which is primarily vertical in character. One can therefore treat the commuting regions and the administrative regions as two specific, although partly overlapping, spatial-interaction frameworks.

\section{THE EVOLVING STRUCTURE OF FUNCTIONAL URBAN REGIONS}

Variations between the FURs are reflected in (a) the degree of "maturity" and (b) the degree of internal closure. These factors help to explain the observed relations between the core areas, the commuting zones, and the peripheral areas with respect to the distribution of population, workplaces, service facilities, and housing stock. The graphs in Figures 4-6 show notable regularities in the way population growth rates evolved during the 1950-1973 period (the FURs are arranged by size of core which serves as a proxy for maturity). There is a negative correlation between the population size of a core and its share in the total regional population on the one hand and the mag. nitude of the change over time on the other. In fact this negative relation is true of the 


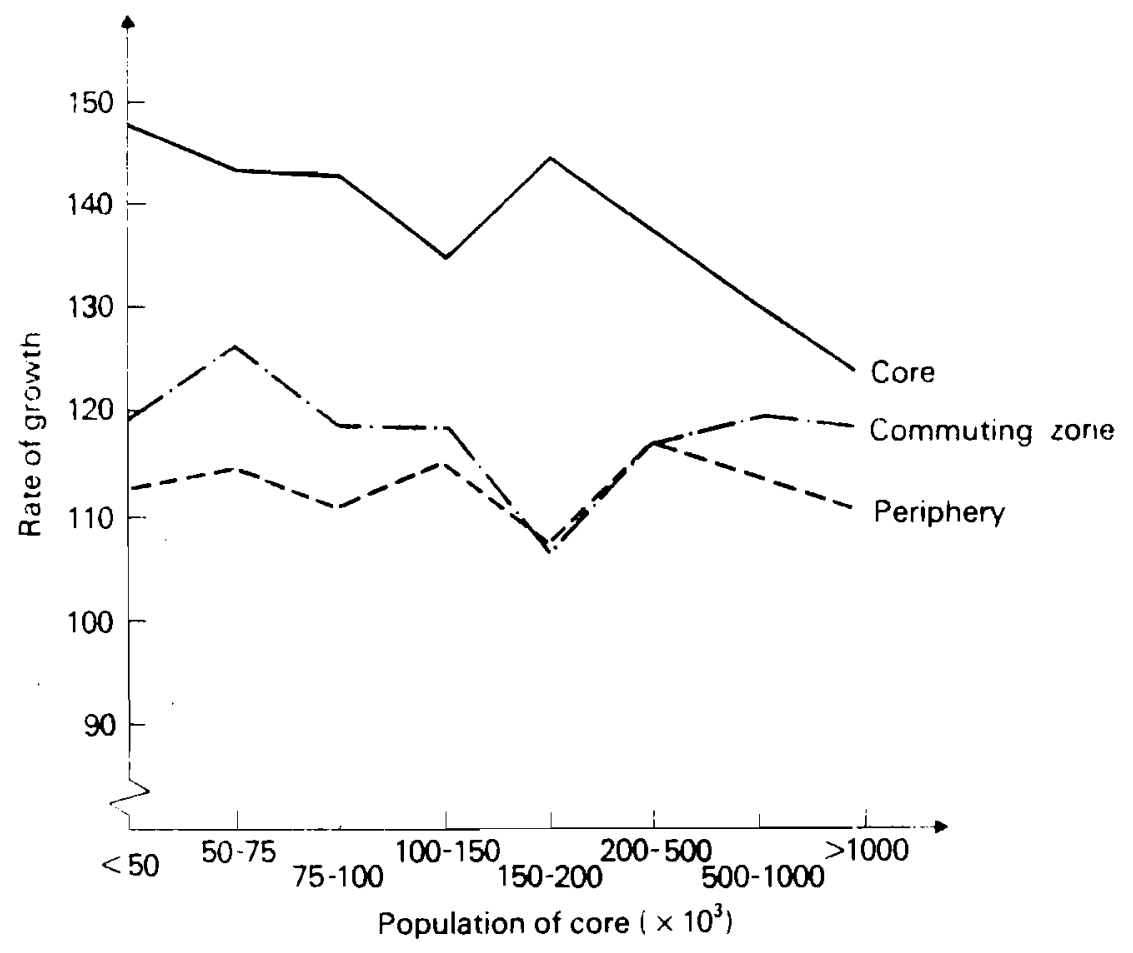

FIGURE 4 Population change by zones of FURs for 1950-1960.

lour categories of urban regions at the top of the scale (i.e. those with core areas of over i.50.000 inhabitants); in these cases the share of the core expressed in percentage points grew by $1.6,6.4,8.1$, and 10.1 , respectively. For the smaller size categories of urban regions the relevant values were nearly uniform, i.e. $4.8,4.9,4.7$, and 4.5 , respectively. Individual periods were characterized by substantial variations in the rate of population change although it can be seen that the highest rates were moving somewhat up the size scale of urban regions.

During the decade of the 1950s the negative relation between size of core and population growth rates was quite regular, with the only deviation occurring in the $100,000-150,000$ core-population category. The rapid expansion at the core was due to the rebuilding of cities after wartime destruction and to the extensive industrialization underway. Commuting zones and the peripheral zones (as in 1968) in that period grew only about half as fast as the core areas, and there were no pronounced regularities in the distribution of these rates of growth according to size of core except for the clear case of substitution in the population dynamics between the cores and hinterlands of medium-to-large cities with 150,000-200,000 inhabitants.

The next derade witnessed a decline in the rates of growth of core areas accompanied uy a parallel but less pronounced decrease of the corresponding rates within the commuting zones. For large cores the growth rates were matched or even surpassed by the respective rates encountered in the surrounding zone. Finally, after 1970 large core 


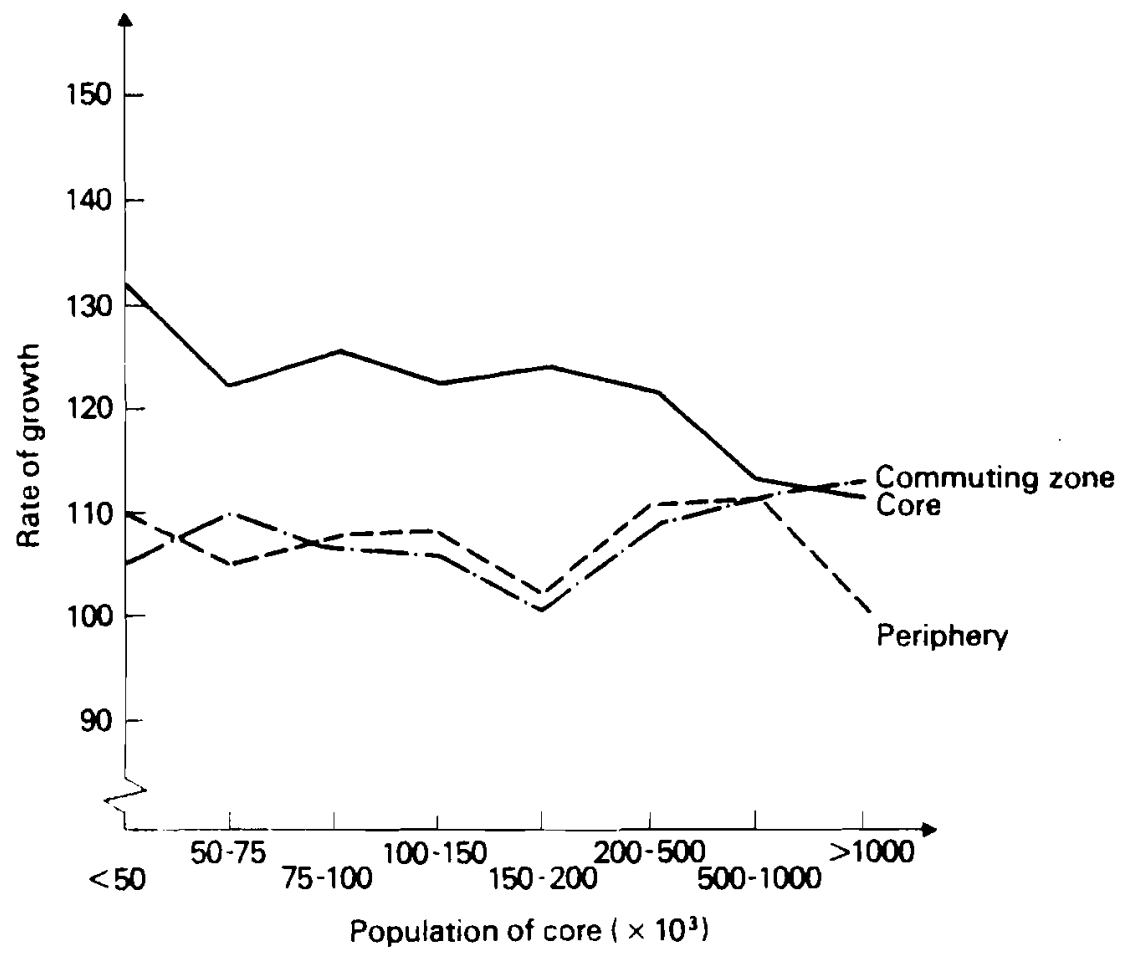

FIGURE 5 Population change by zones of FURs for 1960-1970.

areas registered an acceleration of growth both in absolute terms and relative to their hinterlands.

Thus over the whole 1950-1973 period the population concentration was becoming greater in all groups of regions, but particularly in those units whose core areas are cities of 200,000-600,000 inhabitants. The population share of the largest cores remained stable, and even declined somewhat during the 1960s, a trend which can be largely attrib. uted to urban growth-limitation policies followed during that period. The reversal of this trend since 1970 reflects the new spatial policies spelled out in the National Plan of Physical Development (1970-1990) which aims at "a moderate polycentric concentration". Another generalization that can be drawn from the population distribution patterns relates to peripheral areas. Their rates of growth were typically lowest in the case of regions with large city cores but higher than the growth rates of the commuting zones in the regions dominated by middle-size cities. Thus, while the commuting zones in the former category of regions experienced fast growth as a consequence of spillover from the center, in the case of the latter group the cores were growing to a certain degree at the expense of their immediate hinterlands.

The changes in core/rest-of-region pi oportions in terms of housing stock (Figure 7) are, as expected, quite close to the trends in population dist ribution. The share of core areas grew even faster with respect to the number of dwelling units than with respect to population size. This is partly explained by variations in family size and composition but 


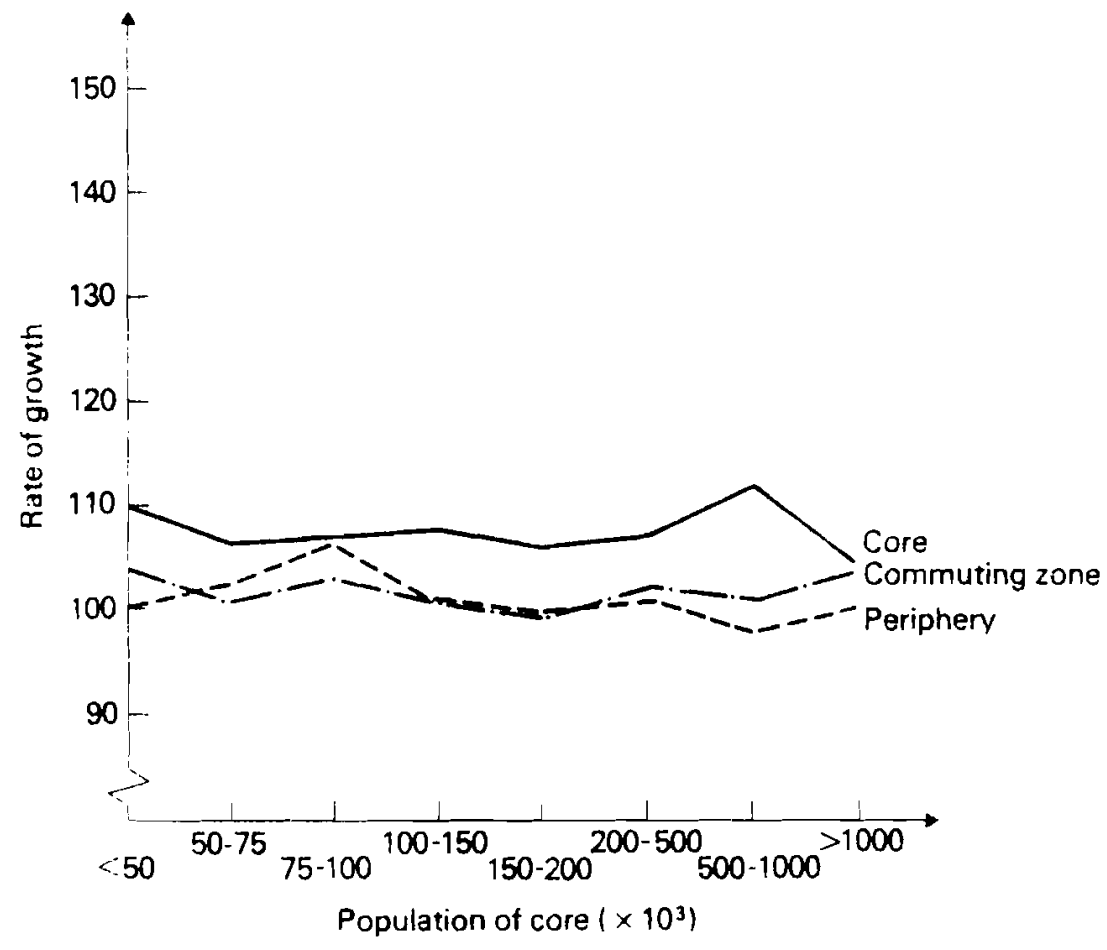

FIGURE 6 Population change by zones of FURs for 1970-1973.

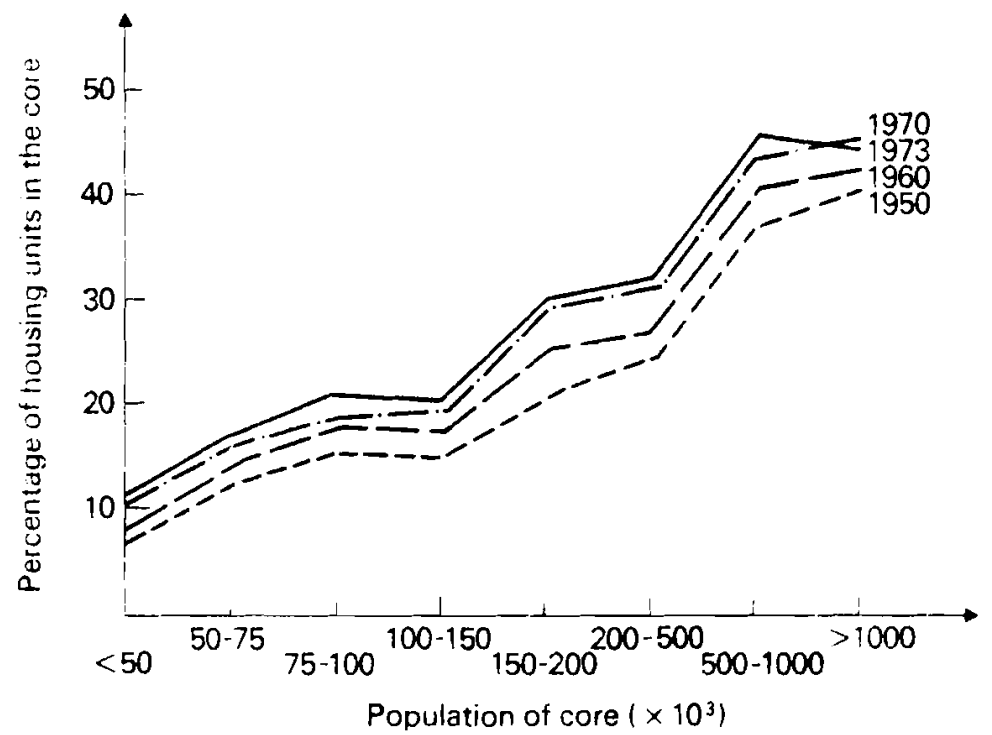

FIGURE 7 Trends in the spatial distribution of housing for 1950-1973. 
it also indicates that core areas were generally favored over the remaining areas by housing-construction and housing-allocation policies.

The distribution of industrial employment (Figure 8) followed a somewhat different pattern. The 1960-1970 decade showed a trend towards concentration of industrial jobs in the core areas but the early 1970s saw a decline in the share of central zones, particularly in the three largest size categories of urban regions. This is a characteristic phenomenon in the evolution of the internal structure of urban regions; according to the existing evidence it is not completely clear whether it precedes or follows the population deconcentration. The question requires further study since it pertains to an important aspect of the interrelations between the internal change of urban regions as places of residence on the one hand and as labor markets on the other.

Yet another aspect of the evolving structure of urban regions refers to the distribution of tertiary functions and the specialization of individual urban places in servicesector functions. The existing theory contends that the per capita intensity of tertiary activities tends to be related to city size, the size being strongly correlated with both the hierarchical orders and the proportions of the urban economy accounted for by the endogenous sector. Another segment of the theory (i.e. the metropolitan-region concept) puts forward the notion of the metropolitan shadow but this concept has been implicitly revoked by the proponents of the urban-deconcentration (or even counter-urbanization)

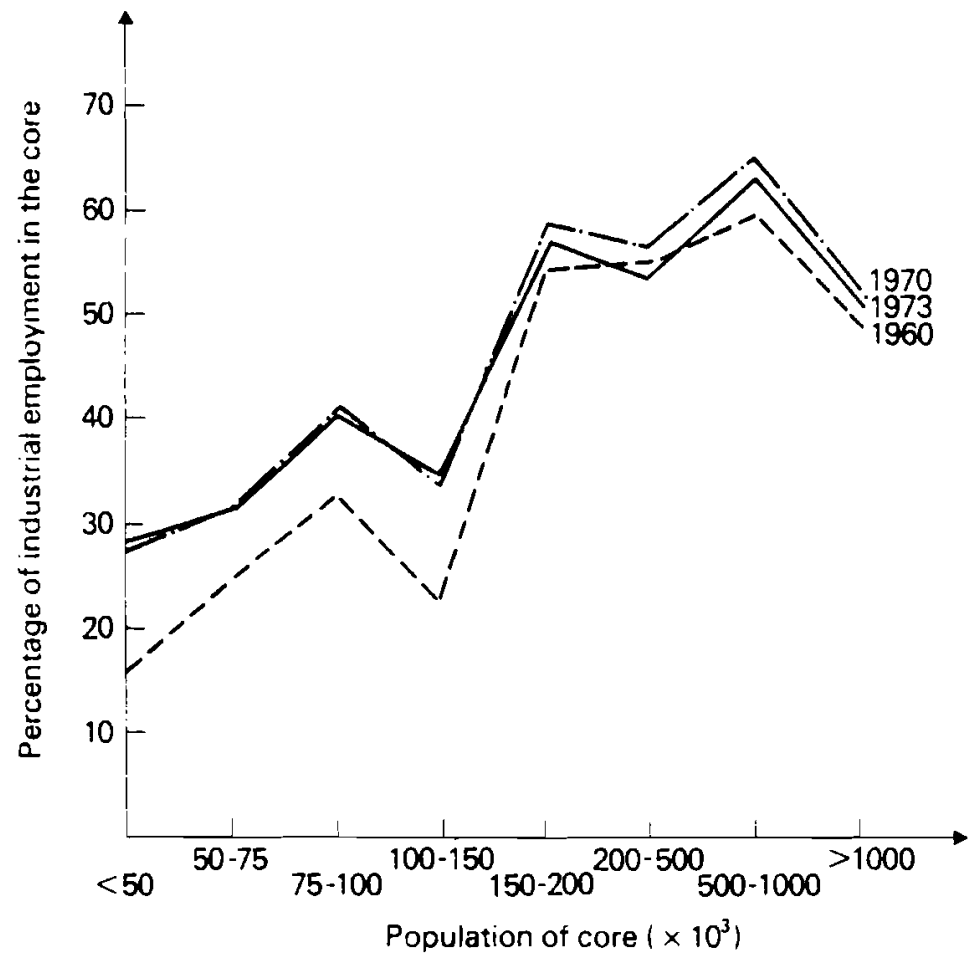

FIGURE 8 Trends in the spatial distribution of industrial employment for 1960-1973. 
TABLE 2 Median sums of ranks for selected tertiary-sector indexes ${ }^{\alpha}$.

\begin{tabular}{|c|c|c|c|c|}
\hline No. & Urban places by categories & 1960 & 1965 & 1973 \\
\hline \multicolumn{5}{|c|}{ FUR criterion } \\
\hline 1 & Core cities & 3470 & 3626 & 3969 \\
\hline 2 & Urban places in the commuting zone & 3748 & 3788 & 3373 \\
\hline 3 & Urban places in the peripheral areas & 3224 & 3137 & 2940 \\
\hline \multicolumn{5}{|c|}{ Administrative criterion } \\
\hline 4 & Former voivodship capitals ( 17 units) & 3599 & 3570 & 3036 \\
\hline 5 & New voivodship capitals (49 units) & 3385 & 3528 & 3806 \\
\hline 6 & Former povist centers ( 326 units) & 2938 & 3060 & 2962 \\
\hline 7 & All urban places $b$ & 3493 & 3436 & 3177 \\
\hline
\end{tabular}

${ }^{a}$ Source: Korcelli and Potrykowska (1979). The indexes refer to per capita numbers of retail outlets, eating and drinking establishments, dry cleaners, theater seats, hotel beds, high school students, secondary vocational school students, and volumes in public libraries borrowed during a year.

${ }^{b} 891$ units in 1960 and $1965 ; 814$ units in 1973 .

approach, as expressed in the concept of urban fields. What do the data for Polish cities suggest, against this background? It follows from Table 2 that the per capita concentration of tertiary-sector activity is highest in those urban places which are situated in the penipheral areas of FURs. Typically, these are small and medium-size market centers serving the surrounding rural territory. About $50 \%$ of these towns were seats of administrative units of the second level (a subcategory in group 6); the second-level administrative units have the highest aggregate ranks (lowest sums of ranks) of all the categories of urban place, as shown in Table 2. Urban places located in the commuting zones represent an opposite case, i.e., the lowest level of tertiary-sector development, in accordance with the concept of metropolitan shadow. A large part of these units, particularly those in the bottom quintile of the rank-ordered structure, are specialized manufacturing towns situated within urban agglomerations. During the $1950-1973$ period the pattern underwent substantial transformations. The tertiary-sector indicators increased in the case of the commuting-zone towns while they declined, relative to mean values, for the core cities.

In order to interpret the observed pattern it is necessary to refer to (a) the proportions accounted for by other components of the urban economy, especially the industrial sector, (b) the changing character of service functions depending on city size (i.e., the same function may fall into an exogenous or an endogenous category), and (c) the absence of high-order functions among those under study. The decline in the median service-sector ranks in the case of core cities can be explained by referring back to differences in population dynamics between the individual zones of FURs (if the rural population is excluded the aggregate growth rates for the commuting and peripheral zones are still lower than those for the cores). Against the trend for all urban places during the early 1970s, the core cities were attracting industry and population faster than they were attracting service activities. Two possible complementary interpretations can be suggested. According to one, the trend reflects a short-term disequilibrium. Alternatively, the development of tertiary activity in these cities was mostly contained within the endogenous sector of their economy. 


\section{CONCLUSIONS}

A number of research hypotheses pertaining to the structure and evolution of urban regions have been put forward in the relevant literature. The following objectives seem to be among the most justifiable: (a) to determine the degree to which the pattern of urban regions is reflected in the spatial structure of population, economic activity, and infrastructure, and to find out whether this pattern is becoming more, or less, pronounced over time; (b) to identify interactions (linkages) which are typical of the scale of an urban region and to unfold the interdependence between the range of individual interactions and the intemal structure of urban regions; (c) to study the nature and intensity of the linkages between the cores of FURs; (d) to interpret intraregional changes in population, economic activity, and infrastructure from the perspective of general economic and demographic trends as well as spatial policies and planning goals.

The empirical part of the present paper pertains mostly to the last of the objectives listed but some of the other items are incorporated in ongoing research on the settlement system, migrations, and daily human-interaction pattems in Poland.

\section{REFERENCES}

Alayev, E. and Khorev, B. (1976). Formation of a unified settlement system in the USSR. In Soviet Geographical Studies, Social Sciences Today. Moscow, pp. 169-180.

Berry, B.J.L. (1973). Growth Centers in the American Urban System, Vols. 1 and 2. Ballinger, Cambridge, Massachusetts.

Boudeville, J. (1978). Les régions de villes en l'Europe. In J.H. Paelinck (Editor), La Structure Urbaine en Europe Occidentale: Faits, Theories, Modeles. Saxon House, Farnborough, Hampshire, UK.

Bourne, L.S. (1975). Urban Systems: Strategies for Regulation. Oxford University Press: Clarendon Press, Oxford.

Dickinson, R. (1964). City and Region: A Geographical Interpretation. Routledge and Kegan Paul, London.

Drewe, P. (1980). Structure and Composition of the Population of Urban Areas with Special Reference to Inner City Areas. Council of Europe, Strasbourg.

Duncan, O.D., Scott, W.R., Lieberson, S., Duncan, B. and Winsborough, M.H. (1960). Metropolis and Region. Resources for the Future. Johns Hopkins University Press, Baltimore, Maryland.

Dziewonski, K. (1967a). Teoria regionu ekonomicznego (Theory of the economic region). Przeglad Geograficzny, 45:220-242.

Dziewonski, K. (1967b). Baza ekonomiczna i struktura funkcjonalna miast (Economic base and the functional structure of cities). Prace Geograficzne, 63. Institute of Geography, Polish Academy of Sciences, Warsaw.

Dziewonski, K. (1971). Program Badan Systemu Osadniczego Polski (A Program of Research on the Settlement System of Poland). Institu te of Geography, Polish Academy of Sciences, Warsaw.

Friedmann, J. (1977). Territory and Function. Paper presented at European Congress of the Regional Science Association, 17 th, Cracow.

Friedmann, J. and Miller, J. (1965). The Urban Field. Journal of the American Institute of Planners, $31: 312-319$.

Grogowski, K. (1978). Badania nad struktura parametru selektywnosci dojazdow do pracy (Studies on the structure of the selectivity of commuting to work). Doctoral dissertation. Technological Academy, Wroctaw.

Glowny Urzad Statystyczny (1973). Strefy wplywow duzych miast w swietle dojazdow do pracy (Zones of influence of large cities in the light of commuting to work). Statystyka Regionalna, 35. Glowny Urzad Statystyczny, Warsaw. 
Hall, P., Gracey, H., Drewett, R. and Thomas, R. (1973). The Containment of Urban England, Vols. 1 and 2. George Allen and Unwin, London.

Khorev, B. (1971). Problemi Gorodov (Problems of Urban Development). Mysl, Moscow.

Korcelli, P. (1977). An approach to the analysis of functional urban regions: a case study of Poland. RM-77-52. International Institute for Applied Systems Analysis, Laxenburg, Austria.

Korcelli, P. (1978). On interrelations between human settlement systems and regional socioeconomic systems. In N.N. Hansen (Editor), Human Settlement Systems; International Perspective on Structure, Change and Public Policy. Ballinger, Cambridge, Massachusetts.

Korcelli, P. and Potrykowska, A. (1979). Rozwoj funkcji uslugowych a hierarchia administracyjna miast $w$ Polsce (Development of tertiary functions and administrative hierarchy of urban places in Poland). Przeglad Geograficzny, 51:209-233.

Leszczycki, S. (1971). Long-term Planning and Spatial Structure of Poland's National Economy. Ossolineum, Wroctaw.

Potrykowska, A. (1979). Zaleznosci miedzy dojazdami do pracy a struktura spoleczno-zawodowa i demograficzna w regionie miejskim Warszawy (lnterdependence between commuting to work and socio-uccupational and demographic structure in the urban regions of Warsaw). Doctoral dissertation. Institute of Geography and Spatial Organization, Polish Acaderny of Sciences, Warsaw.

Pred, A. (1973). The growth and development of systems of cities in advanced economies. In. Systems of Cities and Information Flows: Two Essays. Lund Studies in Geography, Series B, 38.

Ray, M. (1968). Urban growth and the concept of functional regions. Geographia Polonica, 15: 199240.

Stöhr, W. and Tödling, F. (1976). Spatial equity - some antitheses to current regional planning doctrine. Paper presented at European Congress of the Regional Science Association, 16th, Copenhagen.

Webber, M.M. (1964). The urban place and the non-place urban realm. In M.M. Webber (Editor), Explorations into Urban Structure. University of Pennsylvania Press, Philadelphia, Pennsyivania.

Whittlesey, D. (1954). The Regional Concept and the Regional Method, American Geography: Inventory and Prospect. University of Syracuse Press, Syracuse, New York.

Wróbel, A. (1965). Pojecie regionu ekonomicznego a teoria geografii (The notion of economic region and geographic theory). Prace Geograticzne, 45. Institute of Geography, Polish Academy of Sciences, Warsaw. 



\title{
THE SETTLEMENT SYSTEM AND FUNCTIONAL URBAN REGIONS IN THE GERMAN DEMOCRATIC REPUBLIC
}

\author{
Part I: Structure and Dynamics of the Settlement System
}

Joachim Heinzmann

Institute of Geography and Geoecology, Leipzig (GDR)

\section{INTRODUCTION}

During the 1970s extensive research work was carried out in the German Democratic Republic pertaining to the role of the settlement system within the overall territorial structure and to settlement dynamics. It was generally recognized that the optimal development of settlements represents an important precondition for the harmonious development of the territorial structure of the country as a whole. The Institute of Geography and Geoecology of the Academy of Sciences of the GDR is actively partici. paring in these research efforts. This paper, which is based on reports and findings by a number of scientists of the Institute, summarizes major results of these investigations.

\section{MAIN FEATURES OF THE SETTLEMENT STRUCTURE}

International comparative studies (see for example Dziewonski, 1979) show that in inany countries the settlement system is subdivided in to three main levels. However, the nature of these spatial dimensions varies between individual countries since it is determined by the respective socioeconomic and spatial conditions.

The hierarchical structure of the settlement system in the GDR can be described in the following way: (1) a national level representing the integrated settlement system of the country; (2) a regional level comprising settlement systems larger than a subdistrict (Kreis); (3) a local level comprising settlements and settlement systems below the subdistrict scale.

The most stable complex economic regions and settlement systems are fairly well approximated by the existing spa:is' political-administrative units. On the local level these units are towns and communes while at the regional level they are subdistricts and districts. Because of the development of functional interrelations, however, the administrauve boundaries are increasingly crossed and new complex spatial units are formed: 
e.g., associations of communities (Gemeindeverbaende) on the local level and cityhinterland regions (Stadt-Umland-Regionen) on the regional level (see Krönert, 1977).

Between the settlement systems on the local and the regional level on the one hand and on the national level on the other there are not only differences in scale but also differences in quality. Obviously there is a difference in the priority of the elements and relations constituting these systems. The local and regional systems, especially the cityhinterland regions, are delineated mainly by spatial social relations. On the national level the most important system-forming functional relations are of an economic character, e.g., supply distribution and organizational linkages.

\subsection{The Role of the Political-Administrative Division in the Development of the Settlement Systems}

The most important spatial political-administrative units in the GDR are the districts (Bezirks) and subdistricts (Kreises); major social and economic processes are contained within these units. The present division of the GDR into districts and subdistricts was established in 1952. This included the designation of both district and subdistrict centers. Thus a spatial framework was set up for the further development of the regional economy and the settlement system. As far as their social effectiveness and the principle of spatial order are concerned, the delineation of district and subdistrict boundaries went far beyond political importance.

The capital of the GDR (Berlin), the 14 district towns, and some 200 subdistrict towns represent chief nodes within the settlement system, and centers of social development and planning. Twenty-five years of experience have shown that the establishment of districts and subdistricts and their respective centers has created a stable and welloperating spatial framework for the development of social and economic activities.

The functions of the capital, Berlin, include the provision of impulses for the development of the system of regional distribution of social and economic activities and thus for the development of the settlement system. The district towns are political, administrative, economic, social, and cultural centers for the corresponding spatial units. The subdistrict towns fulfill analogous functions on the lower hierarchical level. They provide focal points higher than the community scale which impinge directly on the living and working sphere of all individuals. Therefore the daily accessibility of these centers to the inhabitants of the communities is an important criterion of the efficiency of the local settlement systems (Grimm, 1974; Luedemann and Heinzmann, 1978).

\subsection{The National Settlement System}

The large and medium-sized towns in the GDR constitute the framework for national socioeconomic development over space. They are the largest concentrations of production and the most important centers of the working class, of political and economic management and planning, of science and education, and of communication and transport. Finally, they form core areas for city-hinterland regions. 
The identification of the intensity and quality of the functions and functional relations between large and medium-sized towns has led to a hypothesis according to which a relatively autonomous town system exists in the GDR. This system is interpreted as a subsystem of the national settlement system and is characterized by specific interurban linkages in terms of production, management, and information flows.

\subsection{The Regional Settlement Systems}

Apart from the political-administrative entities, the most fully developed complex spatial units are the city-hinterland regions. This type of regional settlement system has been extensively studied in the GDR. The city-hinterland regions are characterized by a number of internal functional relations and common structural features. Their boundaries and interior subdivisions are basically determined by social factors. These social components are of course interrelated with economic conditions and activities.

The city-hinterland region is defined as a complex economic and residential region influenced by a town, and at present it extends in many respects beyond the boundaries of a subdistrict.

The territorial division of functions connected with working, housing, education, service activities, and recreation takes place particularly on the regional level. The part of the requirements which cannot be satisfied at a given place of residence can be realized within the scope of city-hinterland relations. Thus the urban centers offer working places as well as material and cultural services to the rural population in their hinterland. Conversely, the urban population uses the hinterland for recreation and leisure. Hence the concept of the city-hinterland region allows the rationalization, management, and planning of a territorial division of functions. The planned development of such regions can contribute to the diminution of existing differences in the living standards between urban and rural areas.

\subsection{The Local Settlement Systems}

On the local level the administrative towns and communities are the most stable elements. However, since about 1968 , the formation of local settlement systems has been promoted owing to the development of associations of communities (Gemeindeverbände). These associations are cooperative ventures aimed at jointly carrying out communal policy and adapting government management and planning to the development of the productive forces, mainly in agriculture. A starting point of this process was the transfer of industrial production methods to agriculture, which led to the formation of large production units extending far beyond the boundaries of one municipality. Although cooperation in agriculture greatly stimulated the formation of the community associations it was not the only determinant of the extent of such groupings. With respect to the development of settlement systems, their emergence promotes the concentration process.

The Local Representatives Act of 12 July 1973, expressly stresses that the formation ot associations of communities has to be " . . . in correspondence with the long-term government settlement policy and with the developments of industry and agricuiture". 
The aim of such cooperation is the coordinated and concentrated utilization of material and financial resources for a more rapid improvement in the working and living conditions of the local population. Small towns are also included in the associations and act as their centers. Where such small towns do not exist a larger rural settlement is designated as the center. One generally observes that these centers gradually take over more and more central functions for the whole association. Central institutions for agriculture (e.g. agricultural-chemical stations, processing plants, infrastructural units) and also housing construction tend to be concentrated in them. Functional relations between municipalities increase in both quality and quantity, which gives rise to the stepwise formation of a new type of settlement system on a local level.

\section{THE MAIN RECENT TRENDS IN THE SETTLEMENT SYSTEM}

Changes in the structure and function of settlement systems are long-term processes. Such changes are expressions of the continual adaptation of the settlement to more dynamic social and economic development. The network of rural and urban places is regarded as the most stable element within the settlement system. In contrast, their functions show a greater variability.

The degree of urbanization in the GDR has increased constantly over the last few decades, although a high initial level had already been reached before World War II. The percentage of the population living in towns of over 20,000 inhabitants increased from 39.2 in 1950 to 40.5 in $1960,44.1$ in 1970 , and 48.1 in 1979 (see Statistisches Jahrbuch der DDR, 1980). The urbanization process continued to advance in spite of a decreasing population total for the country as a whole.

The rank order of the large and medium-sized towns basically remained constant over the same period. This is an expression of the relatively high stability of the settlement network of the GDR. The largest increases in population occurred in those towns that were characterized by extensive new industrial development (e.g., Hoyerswerda, Schwedt, Eisenhuettenstadt, Cottbus) or in those which had been designated as new administrative centers of districts (Neubrandenburg, Suhl).

\subsection{Development of the Employment Structure}

The employment structure can be used as a measure of the development of town functions. For 320 major towns a distinct increase was noted between 1950 and 1970 in employment related to infrastructure (i.e. tertiary activities) as opposed to industrial employment. The proportion of people working in industry decreased from 1950 to 1964 but it remained about the same from 1964 to 1971.

It follows from Table 1 that the changes in the share of industrial employment in the 320 towns were opposite to trends for the remaining settlements. However, in the towns the absolute number of people who were employed in industry also increased. These tendencies reflect the decrease in the differences between rural and urban areas as a result of industrialization and the productivity growth in agriculture as well as of the transformation of villages and small towns into workers' residences. In the towns of the 
ГABLE 1 Percentage of total employment in industry and in infrastructure, $1950-1971^{a}$.

\begin{tabular}{lllll}
\hline Sector & Region & 1950 & 1964 & 1971 \\
\hline Industry & 320 towns & 54.8 & 50.8 & 50.8 \\
& GDR & 44.0 & 49.3 & 51.5 \\
Infrastructure & 320 towns & 40.0 & 45.7 & 47.0 \\
(tertiary activities) & GDR & 28.2 & 35.0 & 36.1 \\
\hline
\end{tabular}

a Source: Institute of Geography and Geoecology (1978).

agriculturally oriented northern and central districts of the GDR the share of industrial employment also increased between 1964 and 1971 (e.g., in the district of Schwerin from $34 \%$ to $36 \%$, in the district of Neubrandenburg from $31 \%$ to $34 \%$, and in the district of Frankfurt/Oder from $41 \%$ to $44 \%$ ).

\subsection{Development of Migration}

A summary presentation of migration processes in the GDR was given by Luedemann uni Ifeinzmann (1978). Their account can be supplemented with some more recent results.

Since the early 1960s long-distance (interregional) migration has favored the eastern districts of Cottbus and Frankfurt/Oder and the capital Berlin. That means that a continuous migration loss has occurred in the districts of Schwerin and Neubrandenburg and in the industrialized districts of Halle, Karl-Marx-Stadt, and Leipzig (see Table 2).

The population gain of Berlin results from the extensive reconstruction of the capital in the last decade and the development of its metropolitan functions. The main cause of the gains in the districts of Frankfurt/Oder and Cottbus is the establishment of a number of new industrial plants there, particularly in the lignite, power, chemical, and electronic industries.

Since the beginning of the 1970 s a decline in the distance of migration has been observed. While migration between districts dominated in the sixties, migrations within districts have increased considerably during the last decade (see Table 3).

At present two-thirds of all population flows take place within districts. Migration patterns are therefore dominated by moves over relatively short distances. The majority

TABLE 2 Net migration by districts (five-year rates per 1,000 inhabitants), $1970-1975^{\circ}$.

\begin{tabular}{lclr}
\hline Berlin & +51.8 & Suhl & -0.5 \\
Frankfurt/Oder & +28.9 & Dresden & -3.4 \\
Cottbus & +12.0 & Erfurt & -4.0 \\
Gerd & +11.1 & Magdeburg & 7.6 \\
Potsdam & +5.9 & Leipzig & -7.7 \\
Rostock & +5.2 & Karl-Marx-Stadt & -8.4 \\
& & Schwerin & -9.5 \\
& & Halle & -15.1 \\
& & Neubrandenburg & -23.6 \\
\hline
\end{tabular}

Source: Veumann (1978). 
TABLE 3 Percentage of migrations across the boundaries of municipalities, subdistricts, and districts, $1963-1972^{a}$.

\begin{tabular}{llll}
\hline Year & $\begin{array}{l}\text { Across } \\
\text { district } \\
\text { boundaries }\end{array}$ & $\begin{array}{l}\text { Across subdistrict } \\
\text { boundaries within } \\
\text { districts }\end{array}$ & $\begin{array}{l}\text { Across municipality } \\
\text { boundaries within } \\
\text { subdistricts }\end{array}$ \\
\hline 1963 & 41.0 & 30.0 & 29.0 \\
1964 & 40.4 & 30.0 & 29.5 \\
1965 & 40.6 & 30.6 & 28.8 \\
1966 & 38.1 & 30.4 & 31.5 \\
1967 & 36.0 & 30.7 & 33.3 \\
1968 & 34.0 & 30.3 & 35.7 \\
1969 & 34.9 & 32.6 & 32.5 \\
1970 & 34.6 & 32.9 & 32.5 \\
1971 & 34.6 & 33.6 & 31.8 \\
1972 & 34.4 & 34.6 & 31.0 \\
1973 & 33.7 & 34.4 & 32.0 \\
\hline
\end{tabular}

a Source: Mohs (1980).

of the intradistrict migrations take place within the zones of influence of the major urban centers while only a small fraction take place in the subdistricts located at the borders of individual districts.

Within the districts the migration gains of large towns and district centers in particular are especially high. In some subdistricts near the capital, Berlin, the gains indicate suburbanization trends in this area.

The analysis of migration at a subdistrict scale shows that (1) as a rule migration gains are connected with centers of investment and are therefore of a temporary nature and (2) the number of subdistricts characterized by migration gains is decreasing, i.e., migrations are becoming mainly directed to more important centers and the spatial concentration of population is progressing.

However, an evaluation of migration patterns from the point of view of long-term settlement system planning cannot be carried out on the basis of individual settlements or administrative subdistricts. Regional settlement systems, especially city-hinterland regions, are more suitable for this purpose. An analysis based on such regions allows the identification of areas where negative demographic effects would occur if the present trend continued, thus leading to the endangering of the stability and efficiency of individual city-hinterland regions. The situation is most difficult in areas characterized by high migration losses, a low population potential, and the dominance of small settlements. This is mainly the case for some sparsely populated areas in the nor thern and central districts. Here an acceleration of spatial concentration could lead to an increase in the number of small settlements, which in turn would hinder the improvement of the working and living conditions of the population as well as improvements in the efficiency of pror". rion and the infrastructure. Therefore the settlement policy of the government aims at the intensification of functional relations between centers and hinterland zones in the regions in question and at the development of centers in such a way that the migration balance of the region is approximately equalized. 
For such an analysis the delineation of dominant areas of migration has proved to be an effective method. These areas are identified by assigning individual subdistricts to the destination area (a subdistrict) which attracts the absolute and the relative majority of moves across subdistrict boundaries. On this basis, relatively simple delineation of these areas was possible for the whole territory of the GDR. The different sizes of duminant areas of migration demonstrate the leading role of district centers in the overall migration patterns.

The dominant areas of migration have a high temporal and spatial stability which results from the fact that other functional relations in addition to migration have leveloped within the scope of these areas. Thus the dominant areas tend to be relatively losed complex spatial units. The towns which constitute the focal points of such areas have good preconditions for becoming important elements in the national settlement system.

\subsection{Development of Commuting}

Since the beginning of the 1960s the role of commuting to work in the GDR has expanded substantially. This is clearly proved for the period between the censuses of 1964 and 1971 (Neumann, 1974). The growing population mobility is expressed by increased commuting within districts but across subdistrict boundaries.

A more detailed disaggregation based on communities shows that the number of out-commuters increased in most cases. In the same period the population numbers stagnated or partly decreased in rural regions. Hence the proportion-of out-commuters markedly increased, which is evidence for the growth of residential functions in most of the communities (see Table 4).

In regions with little commuting during the initial period of analysis, a large number of communities have later been included in the commuting fields of larger towns. Thus functional interrelations with the respective towns are intensified. New opportunities are uffered to many people to use facilities of the infrastructure of the towns. The improvement of transportation between towns and their hinterlands leads to the greater attractiveness of the towns. In agriculturally oriented regions smaller centers of in-commuting develop as a result of the concentration of industrial production facilities for agriculture.

The reverse side of the phenomenon of increasing out-cornmuting from many communities is the spatial expansion of commuting fields and the increasing numbers of commuters travelling into the larger centers of the settlement system. In this respect, the listrict and subdistrict towns also hold leading positions. At the same time, however, the number of commuters from larger urban centers to workplaces located in the hinterlands aiso tends to increase. Commuting in opposite directions is promoted by the increasing functional relations between town and hinterland.

A number of detailed studies show the further expansion of the role played by cornmuting to work during the 1970s. This refers in particular to agricultural sommunities. A strong trend towards the formation of local commuting areas is noticeable. Mus trend is likely to continue in the near future.

The commuting fields of the district and subdistrict towns have developed into regions with relatively stable commuting intensity. Whereas in the rural regions an 
TABLE 4 Increase in the number of commuters (commuting to their place of work across district and subdistrict boundaries) $1964-1972$ (rates per 1,000 inhabitants) $^{a}$.

\begin{tabular}{lcccc}
\hline District & $\begin{array}{l}\text { Total number } \\
\text { of commuters }\end{array}$ & $\begin{array}{l}\text { Across subdistrict } \\
\text { borders within } \\
\text { districts }\end{array}$ & $\begin{array}{l}\text { Out-commuters } \\
\text { (to other } \\
\text { districts) }\end{array}$ & $\begin{array}{l}\text { In-commuters } \\
\text { (from other } \\
\text { districts) }\end{array}$ \\
\hline Rostock & 12.4 & 9.3 & 3.1 & 10.7 \\
Schwerin & 11.2 & 6.8 & 4.4 & 0.8 \\
Neubrandenburg & 15.4 & 9.4 & 6.0 & 1.2 \\
Potsdam & 13.8 & 9.7 & 4.1 & 5.1 \\
Frankfurt/Oder & 7.9 & 4.0 & 3.9 & 3.3 \\
Cottbus & 17.2 & 10.8 & 6.4 & 3.1 \\
Magdeburg & 12.2 & 7.8 & 4.4 & 3.5 \\
Haile & 36.2 & 25.7 & 10.5 & 3.2 \\
Erfurt & 13.4 & 8.9 & 4.5 & 5.2 \\
Gera & 11.2 & 7.4 & 3.8 & 4.5 \\
Suhl & 12.2 & 9.4 & 2.8 & 1.6 \\
Leipzig & 9.6 & 4.6 & 5.0 & 8.8 \\
Diesden & 17.3 & 9.7 & 7.6 & 8.0 \\
Karl-Marx-Stadt & 25.9 & 17.9 & 8.0 & 4.0 \\
\hline
\end{tabular}

a Source: Grundmann (1978).

expansion of commuting fields is expected, in agglomerations the commuting fields will probably remain relatively constant.

\section{DIFFERENCES IN THE DEVELOPMENT OF THE SETTLEMENT SYSTEM ON THE NATIONAL, REGIONAL, AND LOCAL LEVELS}

The development of the settlement structure is determined above all by the current social conditions and processes. The forms of organization and development of the settlement structure represent a specific image of fundamental social development processes and relationships.

Very often, concentration trends in the national distribution of production and population are interpreted as part of urbanization and industrialization. However, experience shows that concentration and deconcentration are linked phenomena in the process of national distribution of production and population and in the development of the settlement systems.

In the following section these partly opposing trends of concentration and deconcentration in the settlement system of the GDR are presented. The discussion is based on an unpublished research report of the Institute of Geography and Geoecology of the Academy of Sciences of the GDR (Schmidt and Usbeck, 1978).

\subsection{Urbanization and population distribution}

Urbanization is known to result in a territorial concentration of population. There are, however, clear differences in this respect between the large regions of the GDR (see Table 5). 
TABLE 5 Level of urbanization (the percentage of the population living in municipalitics with more than 2,000 inhabitants), $1965-1979^{a}$.

\begin{tabular}{|c|c|c|c|c|c|c|c|}
\hline \multirow[t]{2}{*}{ Regions } & \multicolumn{4}{|c|}{ Urbanization level } & \multicolumn{3}{|c|}{ Rate of change } \\
\hline & 1965 & 1970 & 1975 & 1979 & $1965 / 70$ & $1970 / 75$ & $1965 / 79$ \\
\hline Northern districts & 61.0 & 63.1 & 66.3 & 68.4 & +2.1 & +3.2 & +7.4 \\
\hline Central districts & 67.5 & 68.4 & 71.2 & 74.4 & +0.9 & +2.8 & +6.9 \\
\hline Southwestern districts & 65.7 & 66.6 & 67.5 & 68.1 & +0.9 & +0.9 & +2.4 \\
\hline Southern districts ${ }^{b}$ & 78.4 & 78.4 & 79.5 & 79.4 & \pm 0.0 & +1.1 & +1.0 \\
\hline GDR & 73.0 & 73.8 & 75.3 & 76.1 & +0.8 & +1.5 & $\div 3.1$ \\
\hline
\end{tabular}

Source: Statistisches Jahrbuch der DDR (1980).

${ }^{b}$ Excluding Berlin.

TABLE 6 Net migration across municipality boundaries (by size categories of municipalities). $1968-1974^{\circ}$.

\begin{tabular}{|c|c|c|c|c|}
\hline \multirow{2}{*}{$\begin{array}{l}\text { Size group } \\
\text { (number of } \\
\text { inhabitants) }\end{array}$} & \multicolumn{4}{|c|}{ Net migration rate (per 1,000 inhabitants) } \\
\hline & 1968 & 1970 & 1972 & 1974 \\
\hline Below 2,000 & -5.1 & -8.1 & -9.8 & -10.6 \\
\hline $2.000-5,000$ & -1.7 & -2.7 & -4.6 & -5.9 \\
\hline $5,000-10,000$ & +5.3 & +1.2 & -2.3 & -2.0 \\
\hline $10.000-20,000$ & -0.6 & +1.7 & +1.7 & +3.6 \\
\hline $20,000-50,000$ & +3.3 & +5.8 & +4.8 & +3.1 \\
\hline $50,000-100,000$ & +2.2 & +7.8 & +17.2 & +17.7 \\
\hline 100,000 and over & +2.4 & +3.7 & +5.7 & +78 \\
\hline
\end{tabular}

a Source: Statistisches Jahrbuch der DDR (1980).

For the period 1965-1975 the towns of the northern and central districts show above-average growth rates whereas the towns in the industrialized southern districts have grown at well below the GDR average rate.

On the regional level urbanization is unambiguously expressed as a process of concentration. District and subdistrict towns have the greatest rates of population growth. This growth is based mostly on migration gains (see Table 6).

On the local level urbanization includes features of both concentration and deconcentration. Trends of deconcentration include, for instance, the spatial expansion of the towns, the decreasing populations in the city centers, and the location of new housing estates at the periphery of towns. Also on this level, the population concentration in urban places, especially in large and medium-size towns, is mainly due to migration.

On the national level long-distance migration brings about an overall deconcentration as a result of migration losses from the agglomeration districts and migration gains in the eastern districts of Cottbus and Frankfurt/Oder.

\subsection{Industrial Development}

Concentration and deconcentration can also be shown to be interrelated with respect to industrial development over space. Thus industrial employment and industrial 
TABLE 7 Development of industrial gross production and of industrial employment (by groups of districts), $1955-1972$ (in percent) ${ }^{a}$.

\begin{tabular}{lll}
\hline Region & Increase between 1955 and 1972 in & \\
\cline { 2 - 3 } & $\begin{array}{l}\text { Gross production } \\
\text { (GDR increase = 365\%) }\end{array}$ & $\begin{array}{l}\text { Employment } \\
\text { (GDR increase = 109\%) }\end{array}$ \\
\hline Agglomerarions & & \\
Berlin & 306 & 95 \\
Dresden & 394 & 106 \\
Halle & 326 & 109 \\
Karl-Marx-Stadt & 346 & 88 \\
Leipzig & 317 & 94 \\
& & \\
Industrial districts & & 126 \\
Erfurt & 441 & 99 \\
Gera & 319 & 109 \\
Magdeburg & 344 & 122 \\
Suhl & 367 & \\
Industrially less developed districts & 450 & 119 \\
Cottbus & 725 & 154 \\
Frankfurt/Oder & 585 & 168 \\
Neubrandenburg & 458 & 136 \\
Potsdam & 410 & 145 \\
Rostock & 456 & 136 \\
Schwerin & &
\end{tabular}

a Source: Heinrichs and Maier (1976), p. 786.

gross production increase more quickly in the industrially less developed regions than in the traditional industrial districts (see Table 7).

The policy of equalization of the level of industrialization, effected by governmental planning of the spatial distribution of the productive forces, presents itself as a deconcentration process on the national level. On the regional level industrial development is above all a concentration process. Large and medium-sized towns are the main investment centers, but there are also tendencies to move plants out from these centers, especially for production processes that have an adverse effect on the environment or which demand a lot of space. These are examples of deconcentration on the regional and local levels. On the local level, however, the trend of concentration in the form of industrial complexes is dominant and is caused by the efficiency factor in the utilization of infrastructure and natural resources.

\subsection{Housing Construction}

In the development of housing construction over the last 20 years deconcentration trends have dominated on the national level (with the exception of Berlin). Higher rates of dwelling units completed per 1000 inhabitants have characterized the more thinly populated areas (see Table 8 ). 
TABLE 8 Housing construction by groups of districts (new dwelling units per 1,000 inhabitants). $1955-1975^{a}$.

\begin{tabular}{lllr}
\hline District group & 1955 & 1965 & 1975 \\
\hline Berlin & 4.3 & 4.6 & 12.9 \\
Northern districts & 1.9 & 5.2 & 10.9 \\
Contral districts & 1.9 & 4.5 & 9.3 \\
Southwestern districts & 1.3 & 3.7 & 8.4 \\
Agglomeration districts (excluding Berlin) & 1.6 & 3.8 & 7.8 \\
GDR & 1.8 & 4.0 & 9.0 \\
\hline
\end{tabular}

a Source: Statistisches Jahrbuch der DDR (1980).

On the regional level, however, concentration of housing construction in district and subdistrict towns is dominant. The construction of rural housing and privately owned houses represents a concentration trend on the local level since new units tend to be located in the centers of associations of communities or in small towns. Large housing estates at the peripheries of large and medium-sized towns are an expression of spatial deconcentration on the local level.

\section{REFERENCES}

Dzieworiski, K. (1979). The National Settlement Systems, Vols. 1 and 2. International Geographic Union, Commission on National Settlement Systems, Warsaw.

Grimm, F. (1974). Die Kreisstadte der DDR und ihre Rolle im Siedlungssystem. Geographische Berichte, 19(4):229-247.

Frundmann, L. (1978). Research Report. Institute of Geography and Geoecology of the Academy of Stiences of the GDR, Leipzig, unpublished.

Ileinrichs, W. and Maier, H. (Editors) (1976). Gesetzmässigkeiten der intensiv erweiterten Reproduktion bei der weiteren Gestaltung der entwickeiten sozialistischen Gesellschaft. AkademıeVerlag, Berlin.

Institute of Geography and Geoecology (1978). Research Report. Institute of Geography and Geoecology of the Academy of Sciences of the GDR, Leipzig, unpublished.

Kronert, R. (1977). Stadt-Umland-Regionen von Gross- und Mittel-städten der DDR. Geographische Berichte, 22(2):81-101.

Lüdemann, H. and Heinzmann. J. (1978). On the settlement system of the German Democratic Republic: development, trends and strategies. In N.M. Hansen (Editor), Human Settlement Systems. International Perspectives on Structure, Change and Public Policy. Ballinger, Cambridge. Massachusetts, pp. 121-143.

Mohs. G. (1980). Migration and Settlement: 4. German Democratic Republic. R R-80-6. International Institute for Applied Systems Analysis, Laxenburg, Austria.

Neumann, H. (1974) Territoriale Wirkungsbedingungen und Entwicklungstendenzen der Pendelwanderung-Moeglichkeiten und Aspekte künftiger Gestaltung. Dissertation (A). Halle.

Neumann, H. (1978). Research Report. Institute of Geography and Geoecology of the Academy ot Sciences of the GDR, Leipzig, unpublished.

Schmidt and Usbeck (1978). Research Report. Institute of Geography and Geoecology of the Icademy of Sciences of the GDR, Leipzig. unoublisheo.

Statistisches Jahrbuch der DDR (1980). staatsverlag der Deutschen Demokratischen Republik, Berlin. 



\title{
THE SETTLEMENT SYSTEM AND FUNCTIONAL URBAN REGIONS IN THE GERMAN DEMOCRATIC REPUBLIC
}

\author{
Part II: The Hierarchy of Functional Urban Regions
}

Rudolf Krönert

Institute of Geography and Geoecology, Leipzig (GDR)

\section{INTRODUCTION}

According to the International Institute for Applied Systems Analysis (IIASA) Task un Human Settlement Systems, the Functional Urban Regions (FURs) are considered to represent economic regions. They consist of a central city or agglomeration and an urban hinterland, with the core area and hinterland being interconnected by flows of people, goods, services, and information. Commuting data are used as the main criterion for the determination of regional boundaries. FURs are delineated so as to represent relatively closed labor markets (labor regions).

A brief survey of methods used in the delineation of FURs in the United States has been presented by Sherill (1977). Korcelli (1981) has discussed the status of FURs in the broader concepts of national settlement systems, identifying such regions for Poland and comparing them with the administrative structure of that country. In fact divisions of a number of national territories into FURs are available and may be compared with the FURs in the German Democratic Republic.

Following on from Heinzmann's examination of the structure and dynamics of the settlement system in the GDR (Heinzmann, 1981: previous paper in this volume), the present paper reports and discusses some results of several years of research on cityhinterland regions in the country (in the initial phase of research, city-hinterland regions were termed Zentrumsregionen (Grimm et al., 1975)). Shown in this context are those types of cities which constitute relatively closed and independent regions. Second, the criteria used by Sherill (1977) are examined for their applicability to conditions in the GDR. Third, some aspects of the development of administrative regions in the GDR are pointed out.

\section{CITY-HINTERLAND REGIONS IN THE GERMAN DEMOCRATIC REPUBLIC}

City-hinterland regions are determined on the basis of functional patterns. Previous studies in this area that have been conducted in the GDR have taken into account 
those flows of people which were related to work, education, the supply of consumer goods and services, medical care, etc. Accordingly, city-hinterland regions have been considered as areas of human activity and communication aimed at the satisfaction of everyday human needs.

However, the city-hinterland regions may also be interpreted as labor regions within the national economic structure. In the case of medium-sized and large cities the city-hinterland and labor regions are identical in many respects since the economic structure forms an essential framework for the development of city-hinterland linkages.

The city-hinterland region is a spatial unit which consists of an urban core and a hinterland and which is integrated by the movement of people. Its structure is based on population and settlement patterns. Since it is the political, economic, and cultural center, the central city is the dominant area within the region.

To identify the city-hinterland regions it is necessary to take into account relations which arise from (1) the need for work (journey-to-work relations between town and hinterland), (2) the need for material supplies, health and social care, and education (service relations between town and hinterland), and (3) the need for recreation, cultural, and sports activities (leisure-time relations between town and hinterland).

The boundaries and internal division of city-hinterland regions are determined on the basis of the intensity, complexity, and range of these relations. Under socialist planned-economy conditions it is justifiable to divide city-hinterland relations into territorially fixed and territorially flexible relations (Grimm et al., 1975).

For the territorially fixed relations the spheres of activity are determined by the government. They include not only political and administrative linkages but also economic organization and management. Territorially fixed relations are effected above all within the administrative limits of communities, subdistricts (Kreises), and districts (Bezirks). For example, the service areas of schools and hospitals are largely coincident with administrative units. In contrast, territorially flexible linkages develop under the influence of the material conditions and behavior of the people concerned. They include above all the journey-to-work, shopping, recreational and leisure-time relations, and partly visits to doctors.

During the past few decades these particular services have become increasingly concentrated in the administrative centers, thus giving these centers priority in the settlement network of the GDR. This trend is encouraged by the organization of public bus networks which focus on these centers.

The intensity, complexity, and range of city-hinterland linkages are dependent on the type of urban center (its importance for the hinterland), the hinterland structure, and the extent to which services are utilized to satisfy the needs of people living in the center and hinterland, respectively.

Because the type of urban core (i.e., its hierarchical level) is an essential factor in the development of city-hinterland regions the hierarchical order of cities and towns in the GDR will be presented here, following the work by Grimm and Hoensch (1974). The significance of the political and administrative functions of cities and towns can be clearly seen in the following di ision scheme.

(1) The capital city, Berlin.

(2) Higher-rank cities. These are subdivided into two categories: 
(2a) Major centers. These include Bezirk towns with a complex of episodically utilized specialized functions for a Bezirk, with some of these functions also serving areas situated outside the Bezirk territory. Leipzig and Dresden belong to this category.

(2b) District centers. These include Bezirk towns having a complex of episodically utilized specialized functions for a Bezirk. This category includes the large Bezirk towns (more than 200,000 inhabitants) of Karl-Marx-Stadt, Magdeburg, Halle, Rostock, and Erfurt, as well as the smaller Bezirk centers of Potsdam, Schwerin, and Cottbus.

The major centers and the Bezirk centers can be reached by inhabitants of the respective regions in less than 120 minutes by public transport.

(3) Medium-rank cities. These are subdivided into two categories:

(3a) Subregional centers. These include Kreis towns and the smaller of the Bezirk towns with a complex of periodically utilized services and workplaces serving approximately the area of a subdistrict (Kreis). Some of the specialized functions of these towns may be of significance for several subdistricts. This category includes the smaller Bezirk towns of Gera, Frankfurt/Oder, Neubrandenburg, and Suhl. While fulfilling political and administrative functions on the district level they extend the range of their specialized functions and may be considered as on the way to becoming full-fledged district centers. This hierarchical type also includes 25 subdistrict towns with populations between 25,000 and 130,000 .

(3b) Subdistrict (Kreis) centers. These include Kreis towns with a complex of periodically utilized services and workplaces for one Kreis. Kreis centers have populations of $10,000-50,000$.

Subregional and Kreis centers can be reached by the inhabitants of the respective subdistricts in less than 40 minutes or, in exceptional cases, 60 minutes by public transport.

(4) Lower-rank towns. These are subdivided into two categories:

(4a) Partial subdistrict centers. These include Kreis towns and small towns with no administrative functions but with daily utilized services and workplaces serving areas smaller than a subdistrict. The populations of these urban places range from 5,000 to 20,000 .

(4b) Local centers. These include small towns with no administrative functions. They offer daily utilized and, occasionally, periodically utilized functions for parts of a subdistrict. Their populations are below 15,000.

The urban hinterland can be divided into zones and subzones according to the intensity of city-hinterland relations. A close relationship can be seen between zoning, location, and the types of subcenters in the city-hinterland region (see Krönert and Schmidt, 1974; Kronert, 1977).

For the communities situated in hinterland zone 1 (i.e. the inner zone) the center is the dominant place of work. People living in zone 1 can satisfy their daily and some of their periodical service requirements for services in the center.

For the communities in hinterland zone 2 (i.e. the intermediate zone) the center of the region can still be reached daily by commuters. Hence zones 1 and 2 together form an area of commuting to work. Inhabitants of zone 2 can satisfy their periodical service requirements in the center. Accordinz to the frequency of city-hinterland relations, people living in zone 2 tend to be more strongly linked with regional subcenters than with the core of the region. 
For hinterland zone 3 (i.e. the outer zone) the center of the region is of importance as a place of work to only a small proportion of employees, mostly those living in the more-central parts of the zone. The more-peripheral parts of zone 3 are connected with the center mainly through weekly commuting by persons who live away from home during the working week. The central city offers to people living in zone 3 above all specialized shopping facilities and medical, educational, and cultural services. The intensity of functional relations between zone 3 and the central city is distance dependent. This suggests further subdivision into subzones.

Interpretation of the city-hinterland region in terms of spatial labor linkages requires that its hierarchical structure be taken into account. If the labor region is defined as the city together with the entire commuting zone then it comprises the city-hinterland region including zone 3 . If the labor region is defined so as to embrace the compact daily commuting area then it corresponds to the city-hinterland region without zone 3 . Finally, an alternative form of the labor region, treated as the dominant field of commuting for a particular urban place, corresponds to the city-hinterland region excluding zones 2 and 3.

Our research on city-hinterland linkages focused on towns of medium hierarchical levels. More recently it was also possible to use the indexes of commuting to work and a few other indexes in an effort to determine, and to differentiate further, the hinterland zones 1 and 2 of subdistrict and higher-rank centers (see Table 1).

So far 55 city-hinterland regions which include a zone 2 have been identified (see Figure 1) and studied on a comparative basis. These include the regions of the capital Berlin, the major urban centers (2), the district centers (8), the subregional centers (29), and 15 subdistrict centers with a population of more than 40,000 .

City-hinterland regions can be grouped not only by the type of center but also according to the type of region to which they belong. Taking into account three basic types of economic region one can distinguish the following areas (according to von Kaenel and Scholz, 1969): (1) urban agglomerations with the metropolitan centers of Berlin, Halle, Leipzig, Dresden, Karl-Marx-Stadt, Zwickau, and Magdeburg; (2) the southern part of the GDR (without urban agglomerations), to the south of the Magdeburg-Cottbus line, which is characterized not only by a fairly uniform high level of industrialization

TABLE 1 The criteria of delineation of zones 1 and 2 and their subzones for city-hinterland regions.

\begin{tabular}{|c|c|c|c|c|c|}
\hline Zone & Subzone & $\begin{array}{l}\text { Employees } \\
\text { commuting to } \\
\text { the center out } \\
\text { of the total } \\
\text { number of } \\
\text { out-commuters } \\
\text { (\%) }\end{array}$ & $\begin{array}{l}\text { Out-commuters as } \\
\text { percentage of all } \\
\text { employed residents }\end{array}$ & $\begin{array}{l}\text { Residents and } \\
\text { employees per } \\
\text { square kilometer }\end{array}$ & $\begin{array}{l}\text { Percentage of } \\
\text { resident employees } \\
\text { among all employed } \\
\text { residents }\end{array}$ \\
\hline 1 & $\begin{array}{l}b \\
c\end{array}$ & $\begin{aligned}> & 60 \\
> & 50 \\
> & 60 \\
& 30-60\end{aligned}$ & $\begin{array}{l}>15 \\
>30 \\
>15 \\
>5\end{array}$ & $\begin{array}{l}>600 \\
>600\end{array}$ & $\begin{array}{l}>0.5 \\
>0.5\end{array}$ \\
\hline 2 & $\begin{array}{l}a \\
b\end{array}$ & $\begin{array}{l}10-60 \\
10-30\end{array}$ & $>5^{5-15}$ & $>200$ & $>0.5$ \\
\hline
\end{tabular}




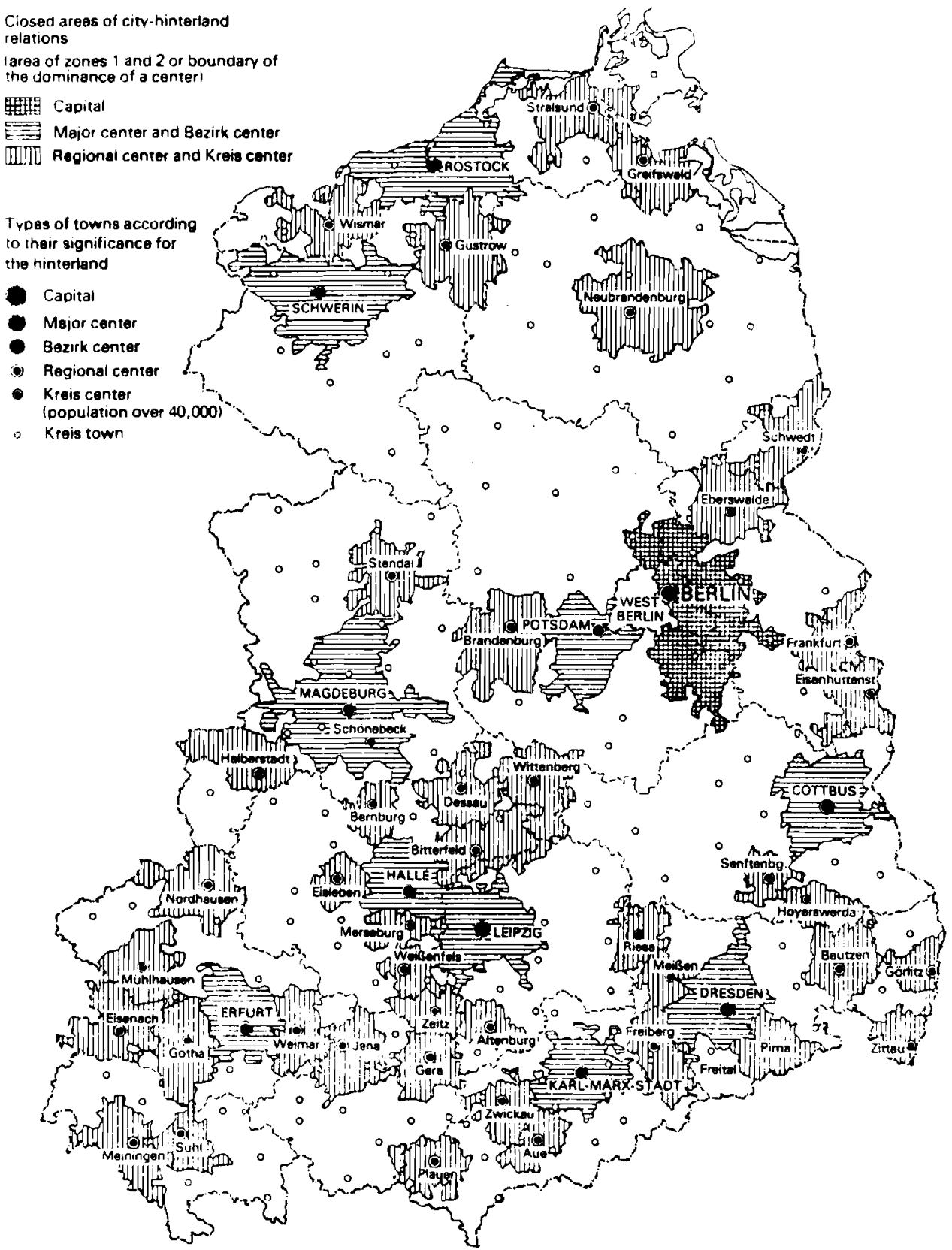

FIGURE 1 Map of the GDR showing the city-hinterland regions of the capital, major centers, Bezirk centers, regional centers, and selected Kreis centers. 
throughout the area but also by intensive agriculture; (3) the northern part of the GDR (exclusive of the Berlin agglomeration), to the north of the Magdeburg-Cottbus line, which is characterized by the dominance of agriculture and the presence of individual industrial centers.

Tables 2 and 3 contain aggregate values for individual categories of the 55 cityhinterland regions identified. The proportion of employees working in a particular territorial unit to those who are both gainfully employed and living there is a measure of the commuter balance of a territorial unit. Averages higher than 1.10 indicate positive commuter balances. It can be seen that the proportion of jobs held by commuters is especially high in subregional and Kreis centers.

A relatively well-balanced pattern is usually found for city-hinterland regions which include zone 2 . In the majority of cases city-hinterland regions including zone 2 represent relatively closed labor regions. However, major variations occur for the subregional and Kreis centers of urban agglomerations. In urban agglomerations the centeroriented city-hinterland regions (with zone 2 included) often do not constitute a closed regional unit in terms of labor balance. The values of about 1.02 indicate the existence of center-oriented commuting even from zone 3 of the respective regions. This shows the importance of this particular group of towns in the settlement structure of the GDR.

As far as the outer range of labor regions (i.e. city-hinterland regions with zone 2 included) is concerned, an obvious difference can be seen between the region of the capital Berlin and the regions of the major and district centers. This is also true when one compares the range of the latter regions with the ranges of subregional and Kreis centers (category (3b)). In general the range is smaller in the southern urban agglomerations and larger in the north of the country with its relatively widely spaced network of urban centers.

In conclusion, it should be emphasized that the data for the larger Kreis centers (with populations of over 40,000 ), which are located mainly in urban agglomerations, are not quite representative of all Kreis centers. Today the smaller Kreis centers (with populations of under 40,000 ) represent the major employment and service centers for areas situated outside the hinterland zones 1 and 2 of the 55 cities as shown in Figure 1. These towns are also major destinations of commuters with the number of in-commuters ranging from 3,000 to 5,000 .

\section{DELINEATION OF FUNCTIONAL URBAN REGIONS}

From the foregoing discussion on city-hinterland regions in the GDR it is apparent that the regions in question belong to different hierarchical levels. The same is true in the case of FURs. A clear distinction should be made between the following hierarchical levels: (a) regions of district (Bezirk) centers and regions of higher-rank centers, with zones 1, 2, and 3 included: (b) regions of subdistrict (Kreis) centers and regions of higherrank centers, with zones 1 and 2 included; (c) regions of local centers and of higher-rank centers with only zone 1 included.

Regions of major centers, of subregional centers, and of partial Kreis centers may be considered as transitional spatial forms. According to observed development tendencies, it is possible to assign them to the three basic forms of regions, (a), (b), and (c), listed above. 


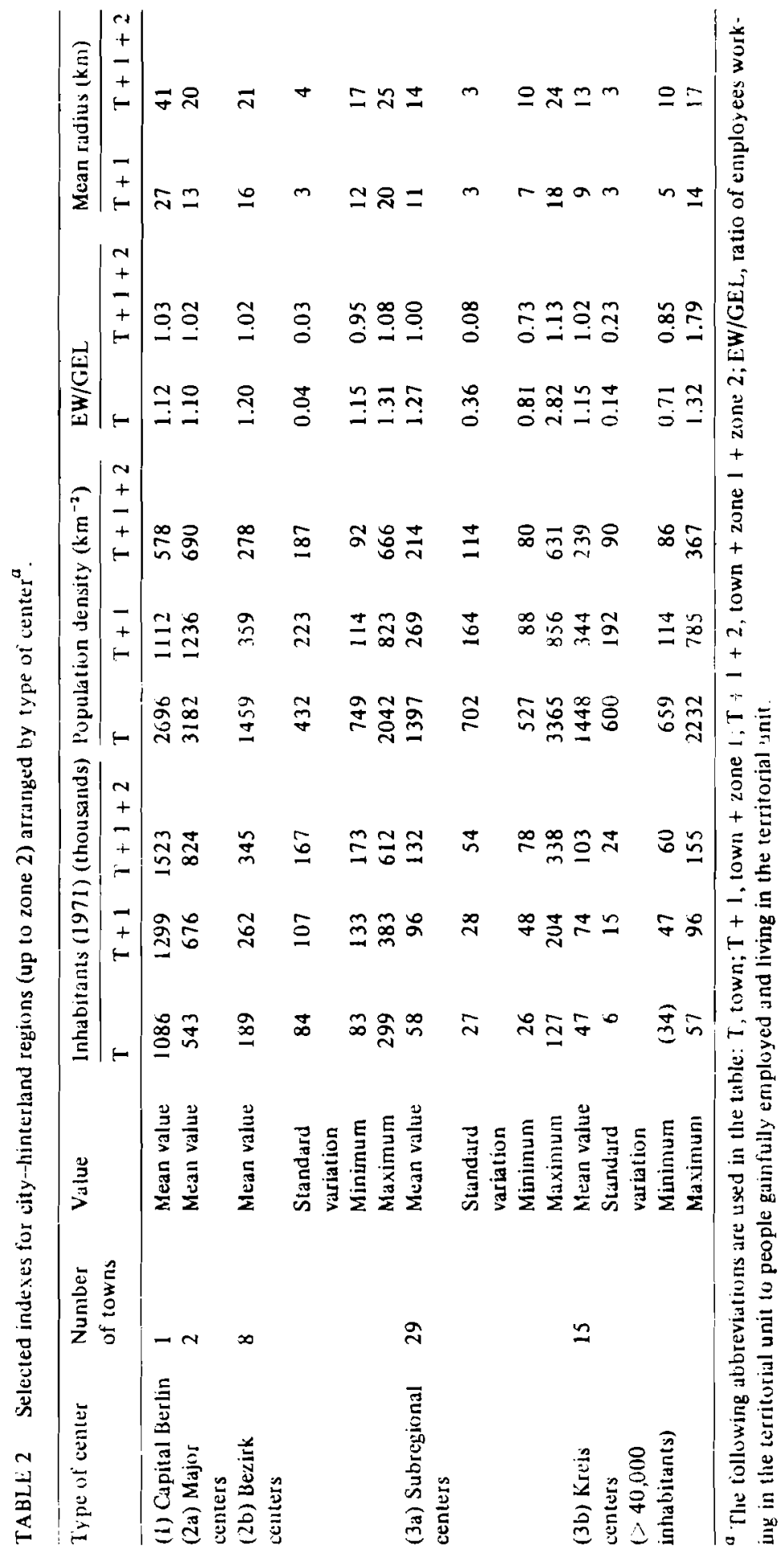




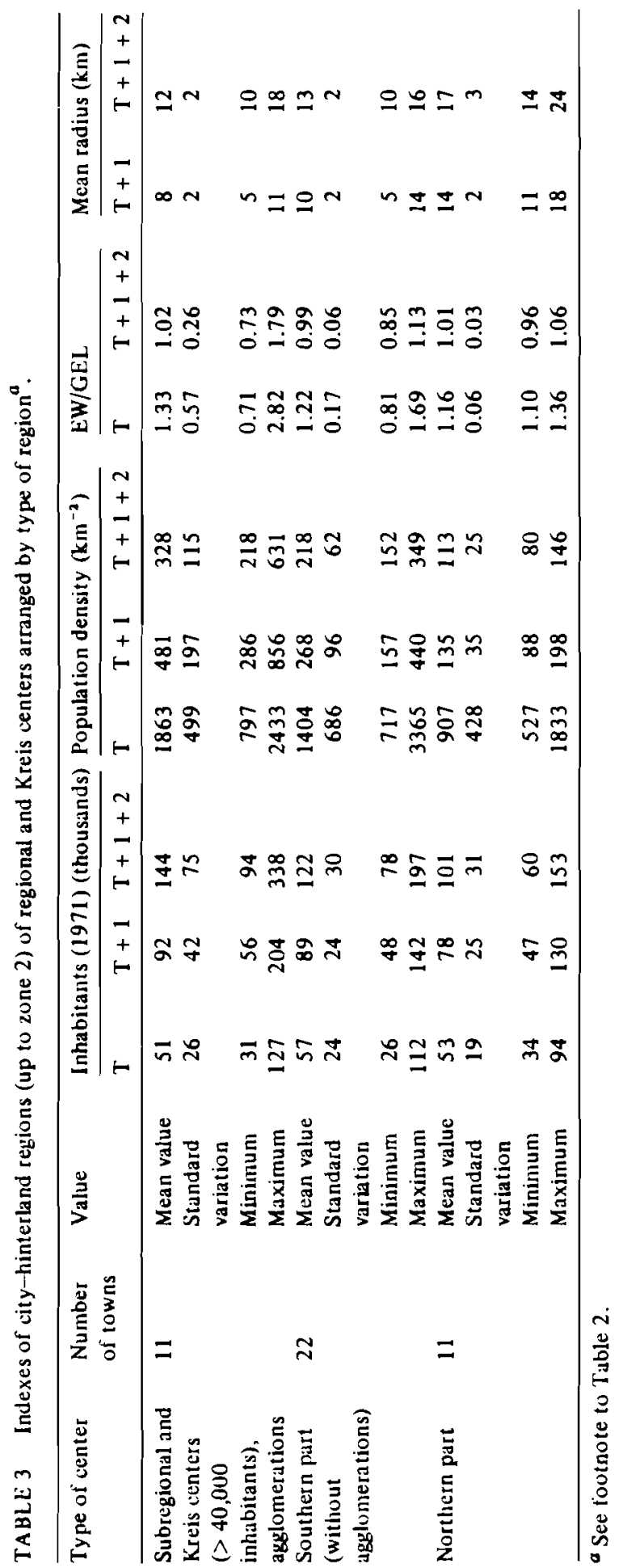




\subsection{Functional Urban Regions of Medium Hierarchical Level}

Figure 1 shows that the regions (with zone 2 included) of subregional and higherrank centers as well as Kreis centers with a population of over 40,000 do not by any means cover the entire national territory. Therefore, as a next step in the regionalization procedure one can consider those Kreis centers which constitute urban places of medium hierarchical level. On this level a total of 125 cities form relatively independent cityhinterland regions, i.e. regions (with zone 2 included) which do not, or only slightly, overlap with each other. These cities are able to supply the whole national territory with goods, services, and workplaces. As a rule, all the centers identified can be reached by people living in their hinterlands (i.e. zones 1 and 2) by public transport in less than 60 minutes (Bezirk towns) or less than 40 minutes (Kreis towns). Daily commuting is possible for certain population groups not only from zone 1 but also from zone 2 . The average Irea of such a region is $865 \mathrm{~km}^{2}$. Thus regions of this level cannot be compared with the FURs determined by Sherill $(1976,1977)$ for Austria $\left(6,500 \mathrm{~km}^{2}\right)$, the Federal Republic of Germany $\left(3,181 \mathrm{~km}^{2}\right)$, and Switzerland $\left(3,176 \mathrm{~km}^{2}\right)$.

\subsection{Functional Urban Regions of Higher Hierarchical Level}

A study was undertaken to check whether the criteria used by Sherill (1977) were applicable to conditions in the GDR. The 55 medium and large cities referred to earlier (sce Table 4) served as a basis for the selection of cores. The results are as follows.

If we take a population of 50,000 , a labor force of 20,000 , and a positive commuter balance as a base we obtain a total of 25 cores. However, if the delineation criteria are defined as a labor force of 20,000 and a positive commuter balance only, then (according to data for 1971) 49 cities can be classified as cores. In both cases allocation of all subdistricts to individual cores is possible by using the data on the direction and extent of commuting beyond Kreis boundaries, and by applying the principle of dominance. However, the results are unsatisfactory in both cases inasmuch as spatial units are obtained which are incongruent with the hierarchical structure of city-hinterland regions (the nonhierarchical characteristics of the settlement structure are not in general considered here). The regions obtained are essentially as follows.

(1) District (Bezirk) and subregional centers fulfilling Bezirk-town functions with zones 1 and 2 and parts of zones 3. The parts of zones 3 identified are those in which medium-level FURs are formed by cores with a population of under 50,000 and a labor force of 20,000 .

(2) Subregional and large Kreis centers with zones 1 and 2 and, in some cases, areas that are not functionally related to the central city. These regions also constitute parts of zones 3 of district centers, a fact which is totally ignored by the set of criteria applied.

As a consequence the regional division consists in this case of units of unequal levels and different natures. It must therefore be regarded as unsatisfactory.

An alternative approacin was to choose Berlin and the district (Bezirk) towns, both large and small (i.e. Gera, Frankfurt/Oder, Neubrandenburg, and Suhl), as cores of FURs. It should be noted that the small Bezirk towns fulfill both the same political and administrative functions and the same leading economic functions as do the large Bezirk towns. 


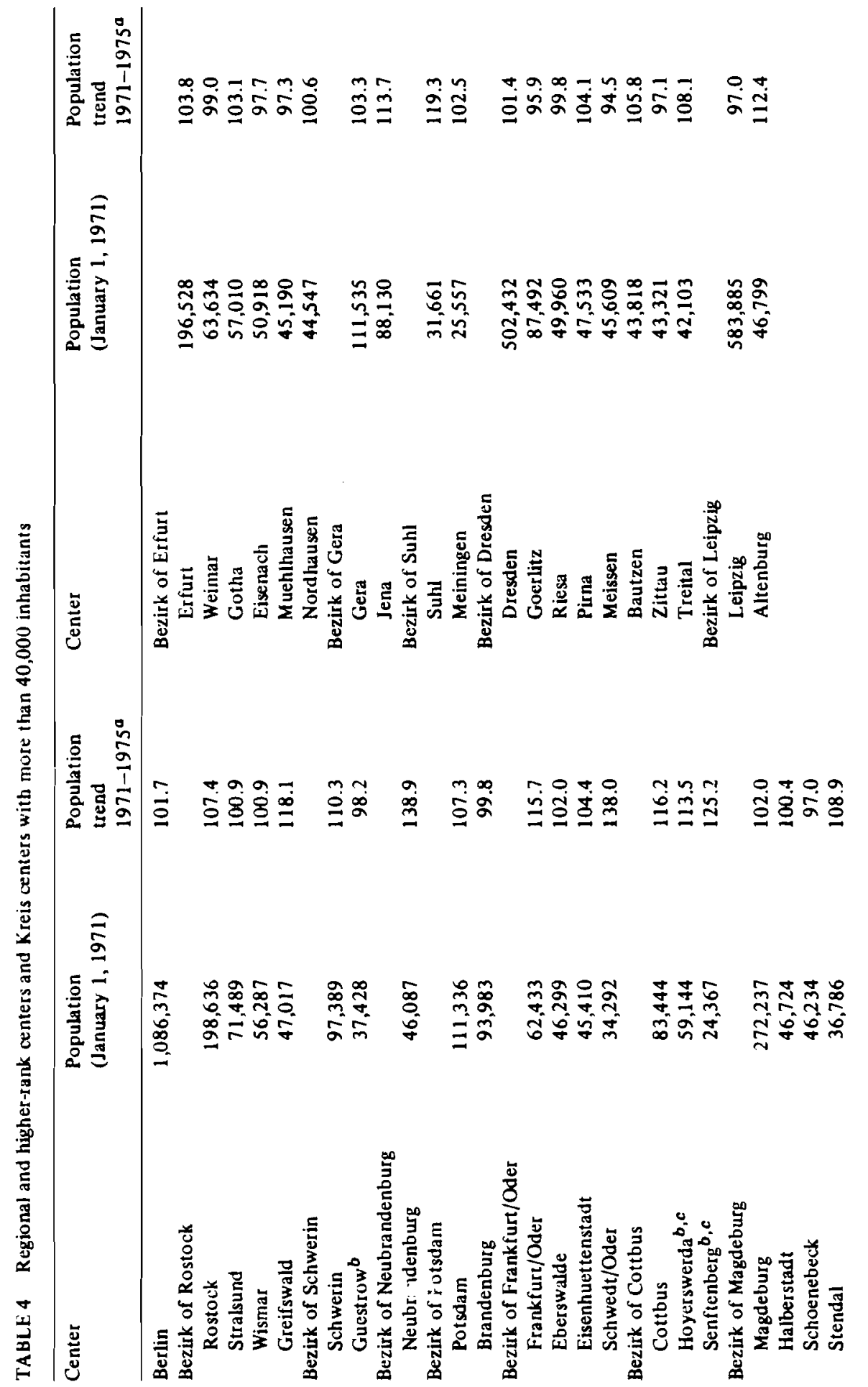


GDR settlement system and FURs: II

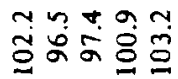

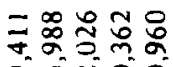

จำ

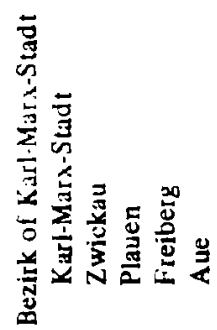

ํํㅇ영

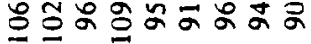

官

III

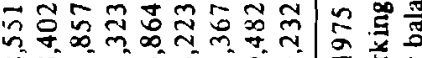

总

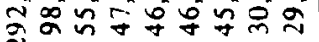

每

$\equiv 3$

昰

곡월

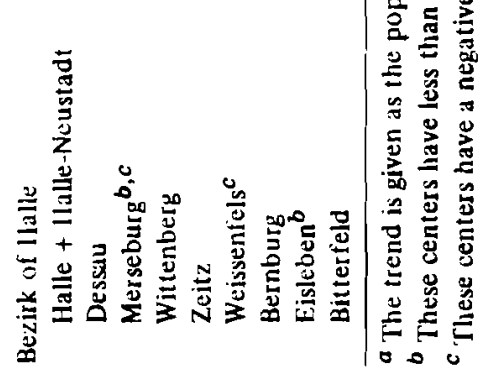


Also, the smaller Bezirk towns had relatively rapid rates of growth during the early 1970s (see Table 5), with industrialization proceeding at a great pace and social infrastructure facilities being completed. There are numerous economic interrelations within the administrative regions, e.g., between agriculture, the food-processing industry, and the food wholesale and retail trades. Also closely interconnected are building enterprises within a region. Hence these regions represent spatial economic units with a considerable degree of closure. This fact is reflected in the structure of commuting to work. The commuter zones of Bezirk towns correspond quite closely to Bezirk boundaries (see Figure 2).

It can be shown that over a period of more than 25 years (the division into districts was implemented in 1952) a balance has been achieved between political and administrative regions and higher-rank economic regions. Notable exceptions are found in the districts of Frankfurt/Oder and Potsdam, and Schwerin and Neubrandenburg, some subdistricts of which are oriented towards either Berlin and Rostock, respectively. Berlin, in spite of its close functional interconnections with the hinterland, has no Bezirk of its own and thus necessarily interacts with adjoining districts. The district of Rostock extends for only a relatively small distance in the north-south direction and its functional relations extend southward beyond the Bezirk border.

Therefore, for the purposes of the IIASA Human Settlement Systems Task, it is justifiable to consider the districts of the GDR as FURs. For the Berlin area two spatial aggregations can be used for further analysis: (a) Berlin, Potsdam Bezirk, and Frankfurt/ Oder Bezirk as independent units; (b) Berlin, Potsdam Bezirk, and Frankfurt/Oder Bezirk as one region.

The use of Bezirks has the advantage that some harmony is achieved between FURs and actual planning regions. One can claim that in the present state of development of productive forces relatively large regional units are required as a spatial framework for the efficient organization of the national economy and the provision of proper working and living conditions for the population in all parts of the country. The new administrative division of Poland, which became effective in 1975, introduced voivodships of a size roughly equal to that of Bezirks in the GDR. Korcelli (1981) pointed out the similarities of FURs with the new voivodships. In the USSR, where there are no administrative units of the dimension discussed here, proposals have been made to establish group settlement systems as planning regions, the centers of which should be accessible from all other settlements in about 2 hours' traveling time (Kochetkov et al., 1977). This corresponds to the accessibility of Bezirk centers in the GDR. Chorev (1975) considers the development of centers for regions of approximately equal size to be of extreme importance to the development of a uniform settlement system in the USSR, and recommends that a correspondence be established between the economic region, the regional settlement system, and the planning region.

\section{DEVELOPMENT OF THE DISTRICTS IN THE GERMAN DEMOCRATIC REPUBLIC: GENERAL TRENDS}

A number of indexes are available at the Bezirk level, based on data collected over a period of many years. They show, among other things, the following trends: (a) a 


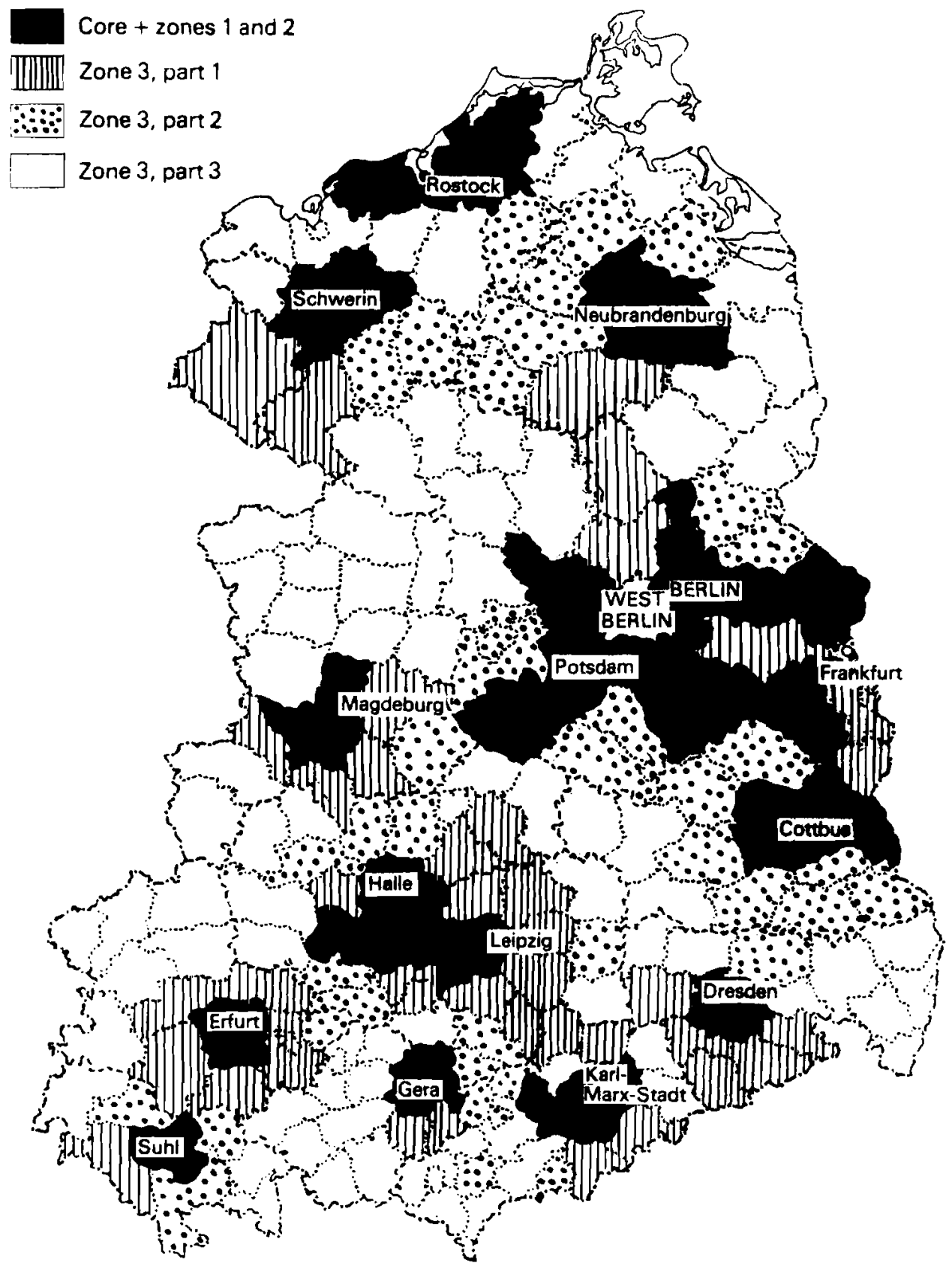

FIGURE 2 The FURs of Berlin and the Bezirk towns of the GDR (according to commuting actoss the boundaries of a Kreis, 1971). 
tendency toward balancing the levels of development among the Bezirks; (b) a tendency toward concentration within the Bezirks.

.The destruction of the big cities during World War II and the inflow of resettlers led to a major increase in the population of villages and small and medium-sized towns; as far as the overall population distribution is concerned, it also resulted in higher population densities in agricultural regions. The result was a more uniform population distribution among the districts. This trend has continued in recent decades (see Table 5). In the Bezirks of Halle, Dresden, Leipzig, and Karl-Marx-Stadt which contain major urban and industrial agglomerations the population density showed a marked decrease in the period 1965-1975. In the industrialized Bezirks of Erfurt, Gera, and Suhl the population densities remained unchanged over the same period. In the sparsely populated districts, however, the densities either showed a certain increase (Rostock, Frankfurt/Oder, Cottbus) or else remained at approximately the same level. There are many reasons for this; the most important of them are the following.

(a) A regional policy was implemented which aimed at balancing the levels of working and living conditions on an interregional scale, with progressive industrialization of former agricultural regions.

(b) A more efficient maritime economy was developed and the port facilities were extended in the Rostock Bezirk; in the Frankfurt/Oder Bezirk industries and the processing of raw materials supplied by the USSR and Poland were expanded; coal mining and power generation were extended in the Cottbus Bezirk.

(c) The demographic structure of the districts is unequal. Those Bezirks with major urban agglomerations show high proportions of old retired people and low proportions of

TABLE 5 Trends in the population density, the proportion of the work force employed in industry, and the gross production of industry, by district, $1965-1975^{\circ}$.

\begin{tabular}{|c|c|c|c|c|c|}
\hline \multirow[t]{2}{*}{ District } & \multicolumn{2}{|c|}{$\begin{array}{l}\text { Population } \\
\text { density }\left(\mathrm{km}^{-2}\right)\end{array}$} & \multicolumn{2}{|c|}{$\begin{array}{l}\text { Proportion of } \\
\text { people employed } \\
\text { in industry (\%) }\end{array}$} & \multirow{2}{*}{$\begin{array}{l}\text { Index of the } \\
\text { gross production } \\
\text { of industry } \\
1975(1965 \equiv 100)\end{array}$} \\
\hline & 1965 & 1975 & 1965 & 1975 & \\
\hline Berlin & 2,673 & 2,725 & 28.6 & 26.4 & 168 \\
\hline Rostock & 119 & 123 & 20.5 & 23.7 & 184 \\
\hline Schwerin & 69 & 68 & 15.4 & 22.1 & 213 \\
\hline Neubrandenburg & 59 & 58 & 10.4 & 18.2 & 232 \\
\hline Potsdam & 90 & 89 & 26.5 & 29.8 & 219 \\
\hline Frankfurt/Oder & 92 & 96 & 21.0 & 27.8 & 257 \\
\hline Cottbus & 102 & 106 & 36.1 & 41.2 & 211 \\
\hline Magdeburg & 115 & 112 & 27.2 & 32.3 & 178 \\
\hline Halle & 220 & 214 & 42.9 & 44.7 & 180 \\
\hline Erfurt & 168 & 162 & 43.0 & 44.8 & 206 \\
\hline Gera & 184 & 184 & 42.0 & 43.5 & 186 \\
\hline Suhl & 142 & 142 & 41.6 & 50.6 & 192 \\
\hline Dresden & 280 & 272 & 43.5 & 43.8 & 176 \\
\hline Leipzig & 304 & 291 & 39.3 & 39.4 & 173 \\
\hline Karl-Marx-Stadt & 346 & 329 & 50.2 & 50.4 & 180 \\
\hline GDR average & 158 & 155 & 35.4 & 38.1 & 187 \\
\hline
\end{tabular}

Source: Statistisches Jahrbuch der DDR (1977). 
children. In contrast, Bezirks with lower population densities show relatively smaller shares of the old-age categories and higher proportions of children.

Berlin, because of the numerous functions this city has to fulfill as the capital of the r.DR, receives numerous growth impulses, which generate increases in both population size and population density.

The tendency toward balancing of interregional differences is very clearly reflected in the data on the numbers employed in industry and on industrial production during the period 1965-1975. In the large agglomerations (Berlin, Halle, Dresden, Leipzig, KarlMarx-Stadt) the percentage of people employed in industry remained roughly the same throughout the period. In the southwestern districts (Erfurt and Suhl) and the central and northern districts (Potsdam, Frankfurt/Oder, Cottbus, Rostock, Schwerin, and Neubrandenburg), the corresponding shares increased considerably. Also, the increase in gross industrial output in the southwestern and the central and northern regions was markedly higher than the GDR average.

\section{SUMMARY OF POPULATION TRENDS WITHIN THE DISTRICTS}

The regions based on the Bezirk structure have been internally subdivided following the criteria for the delineation of city-hinterland regions and FURs identified earlier $m$ the paper. The basic spatial units, the Kreises, have been aggregated in a way which allows us to treat the core and its immediate hinterland (zones 1 and 2 ) as one unit and to disiggregate the peripheral parts of the regions (i.e. zone 3 ) intu subzones $3 / 1,3 / 2$, and $3 / 3$. This is done by assigning the individual Kreises to ranges of distance or to ranges of intensity of functional relations with the center, respectively (see Figure 2).

TABLE 6 Population trends of the FURs of Bezirk towns, 1971-1975 (GDR average $=98.5)^{a}$

\begin{tabular}{lllcc}
\hline Region & $\begin{array}{l}\text { Core } \\
\text { + zone } 1 \\
\text { + zone } 2\end{array}$ & Zone 3 & & $3 / 3$ \\
\cline { 2 - 5 } & 100.7 & $3 / 1$ & $3 / 2$ & Not calculated \\
\hline Berlin & 103.3 & 98.2 & 99.9 & 99.5 \\
Rostock & 109.2 & - & - & 96.2 \\
Schwerin & 107.4 & 96.8 & 97.4 & 96.4 \\
Neubrandenburg & 101.0 & 95.5 & 95.9 & 98.2 \\
Potsdam & 105.8 & - & 98.0 & 101.0 \\
Frankfurt/Oder & 104.4 & 99.7 & 98.3 & 97.1 \\
Cottbus & 101.0 & 98.7 & 101.8 & 97.4 \\
Magdeburg & 103.9 & 94.8 & 96.4 & 97.6 \\
Halle & 102.0 & 94.2 & 95.6 & 98.4 \\
Erfurt & 99.9 & 98.0 & 97.3 & 100.9 \\
Gera & 104.3 & 95.3 & - & 97.8 \\
Suhl & 100.1 & 98.5 & 99.3 & 96.6 \\
Dresden & 96.5 & 96.6 & 97.2 & 96.0 \\
Leipzig & 98.2 & 97.2 & 98.9 & 95.4 \\
Karl-Marx-Stadt & 95.3 & 96.0 & \\
\hline
\end{tabular}

${ }^{a}$ The figures indicate the population in $1975(1971=100)$. 
This division allows us to pay due consideration to the internal structure of FURs and to represent the development tendencies of their individual parts.

Table 6 shows overall population trends for four constituent parts of FURs. The data indicate a remarkable tendency when compared with average population trends in the GDR (a decrease to $98.5 \%$ of the 1971 figure by 1975). The Bezirk centers together with their immediate hinterland (zones 1 and 2 ) have favorable and often positive population trends compared to the peripheral sections of the Bezirk territory. As a rule the central city has experienced an absolute increase in population. Thus the phenomenon of suburbanization has so far been the exception in the GDR. A marked decrease in population is typically found for subzone $3 / 1$. These are areas which still maintain daily (though rather weak) commuting linkages with the center. For subzones $3 / 2$ and $3 / 3$ population changes have been positive or above the GDR average in a few cases only. The current process of concentration of the population within FURs is quite apparent from the data presented in Table 6 . This process results in the upgrading of Bezirk centers and selected secondary centers and in the relative stability of medium-size centers situated in the peripheral parts (i.e. zone 3) of the FURs.

\section{REFERENCES}

Chorev, B.S. (1975). Problemy gorodov. Mysl, Moscow.

Grimm, F. and Hönsch, I. (1974). Zur Typisierung der Zentren der DDR nach ihrer Umlandbedeutung. Petermanns Geographische Mitteilungen, 118(4):282-288.

Grimm, F., Krönert, R., and Lidemann, H. (1975). Aspects of urbanization in the German Democratic Republic. CP-75-3. International Institute for Applied Systems Analysis, Laxenburg, Austria, pp. $74-85$.

Kochetkov, A.V., Listengurt, F.M., Solofnenko, N.A., and Khodzhaev, D.G. (1977). The objectives of an integrated development of a system of human settlements in the USSR. Geographia Polonica, $37: 61-71$.

Korcelli, P. (1981). Die Raumstruktur der funktionalen Stadtregionen in der VR Polen. Vortrag III. Geographisches Seminar Polen-DDR, Leipzig, April 1977. Beiträge zur Geographie (Berlin), 30:85-104.

Krönert, R. (1977). Stadt-Umland-Regionen von Gross- und Mittelstädten der DDR. Geographische Berichte, 22(2):81-101.

Krönert, R. and Schmidt, R. (1974). Das Umland von Mittelstädten - dargestellt am Beispielsgebiet Dessau. Petermanns Geographische Mitteilungen, 118(4): 289-293.

Sherill, K. (1976). Functional urban regions in Austria. RM-76-01. International Institute for Applied Systems Analysis, Laxenburg, Austria.

Sherill, K. (1977). Functional urban regions and central place regions in the Federal Republic of Germany and Switzerland. RM-77-17. International Institute for Applied Systems Analysis, Laxenburg, Austria.

Statistisches Jahrbuch der DDR (1977). Staatsverlag der Deutschen Demokratischen Republik, Berlin. von Känel, A. and Scholz, D. (1969). Wirtschaftsräumliche Struktureinleiten mittlerer Ordnung in der Deutschen Demokratischen Republik. Petermanns Geographische Mitteilungen, 113(3):167-173. 


\title{
ON URBAN CHANGE IN FINLAND
}

\author{
Martti Hirvonen \\ Department of Economics, University of Tampere (Finland)
}

\section{DEFINITIONS OF FUNCTIONAL URBAN REGIONS}

Functional Urban Regions (FURs) are conventionally defined on the basis of the investigation of the commuting fields and economic hinterlands surrounding major urban centers. Alternative approaches relate to the concepts of central-place systems and spheres of city influence. These two notions traditionally adopted by geographers are based un the examination of the functions performed by cities with respect to their surrounding hinterlands. Using these concepts it is possible to delineate functional areas for different kinds of economic interaction such as manufacturing activity or service activities. These approaches are especially helpful for the analysis of the hierarchy of settlements and flow patterns of goods and services.

Many studies have been carried out in Finland to measure the "strength of attraction" of central places and the range of their influence. The most important applicationuriented work is probably one on "The System of Central Places and Spheres of Influence in Finland" (National Planning Office, 1967). This task was commissioned by the National Planning Office to determine the position of each central place in the Finnish urban system; attention was focused on the types of service which central places are capable of offering to their hinterlands. Another interesting study was one by Palomäki and Mikkonen (1972) who identified factors characterizing "functional urban centers". One should also mention a broad comparative work by the Nordic Commission on Regional Policy Research (NORDREFO, 1974) which dealt with the development of settlement systems: however, the regional delineation used in that study mainly follows the administratively defined city boundaries.

For the purposes of this paper, FURs are considered as units consisting of urban cores and economically linked hinterland zones. Such units are used as a framework for the discussion of recent urban trends and policies in Finland, particularly interregional and intraregional shifts in population distribution.

The geographical distribution of urban centers in Finland deviates from that of central Europe or other densely populated cuuntries. The average population density in Finland is only 15 persons $/ \mathrm{km}^{2}$ and the distances between large cities are often greater than $150 \mathrm{~km}$. Hence there are a number of regions without dominant urban centers. 
The delineation criteria for Finnish FURs were similar to those proposed within the framework of the Human Settlement Systems Task at the International Institute for Applied Systems Analysis. With regard to Scandinavian countries, Hall and Hay (1980) have defined FURs for Denmark, Norway, and Sweden. According to the procedures that they adopted, an urban core consists of a city containing at least 20,000 jobs to which all contiguous communities that contain at least 12.35 jobs per hectare are added. In the case of Finland this procedure was followed in the sense that employment of 20,000 was considered as equivalent to a population of 43,400 and the latter figure was treated as the minimum size for a core region. The regions were defined so that commuting across FUR boundaries is minimized. The rural regions are considered as those regions without integrated urban centers and with low population density. They cover large areas in the central and northern parts of Finland.

The analysis of the size and functions of urban centers resulted in the identification of 11 FURs and 13 rural regions which together completely cover the territory of the country (see Figure 1 and Table 1). The regionalization is based on the community administrative boundaries as of 1970 .

TABLE 1 The classification of the FURs in Finland (by population size of cores).

\begin{tabular}{lcc}
\hline Class size & $\begin{array}{l}\text { Population mean of } \\
\text { cores in class in 1974 }\end{array}$ & Cores \\
\hline$<74,999$ & 60,452 & 6 Kotka \\
& & 7 Lappeenranta \\
& 8 Jyväskylä \\
& 9 Kuopio \\
$75,000-99,999$ & 10 Vaasa \\
& 83,638 & 3 Pori \\
$100,000-199,999$ & & 4 Lahti \\
& & 11 Oulu \\
200,000 & 182,137 & 2 Turku \\
& & 5 Tampere \\
& 739,864 & 1 Helsinki \\
\hline
\end{tabular}

The resulting spatial patterns are summarized in Table 2, which also gives the corresponding data for other Scandinavian countries. Only one FUR in Finland, namely the Helsinki region, can be considered as a metropolitan region. With its population of more than 1 million in 1970 and its industrial value added of one-quarter $(25.11 \%)$ of the national total, the Helsinki region is by far the largest concentration of population and economic activity in Finland. Actually, the administrative city of Helsinki (the urban core of Helsinki includes the following administrative communities: Helsinki, Espoo, Kauniainen, and Vantaa) has experienced a decline in population in the 1970s. Also, manufacturing industry is moving out of the city of Helsinki, main, to the surrounding areas. 


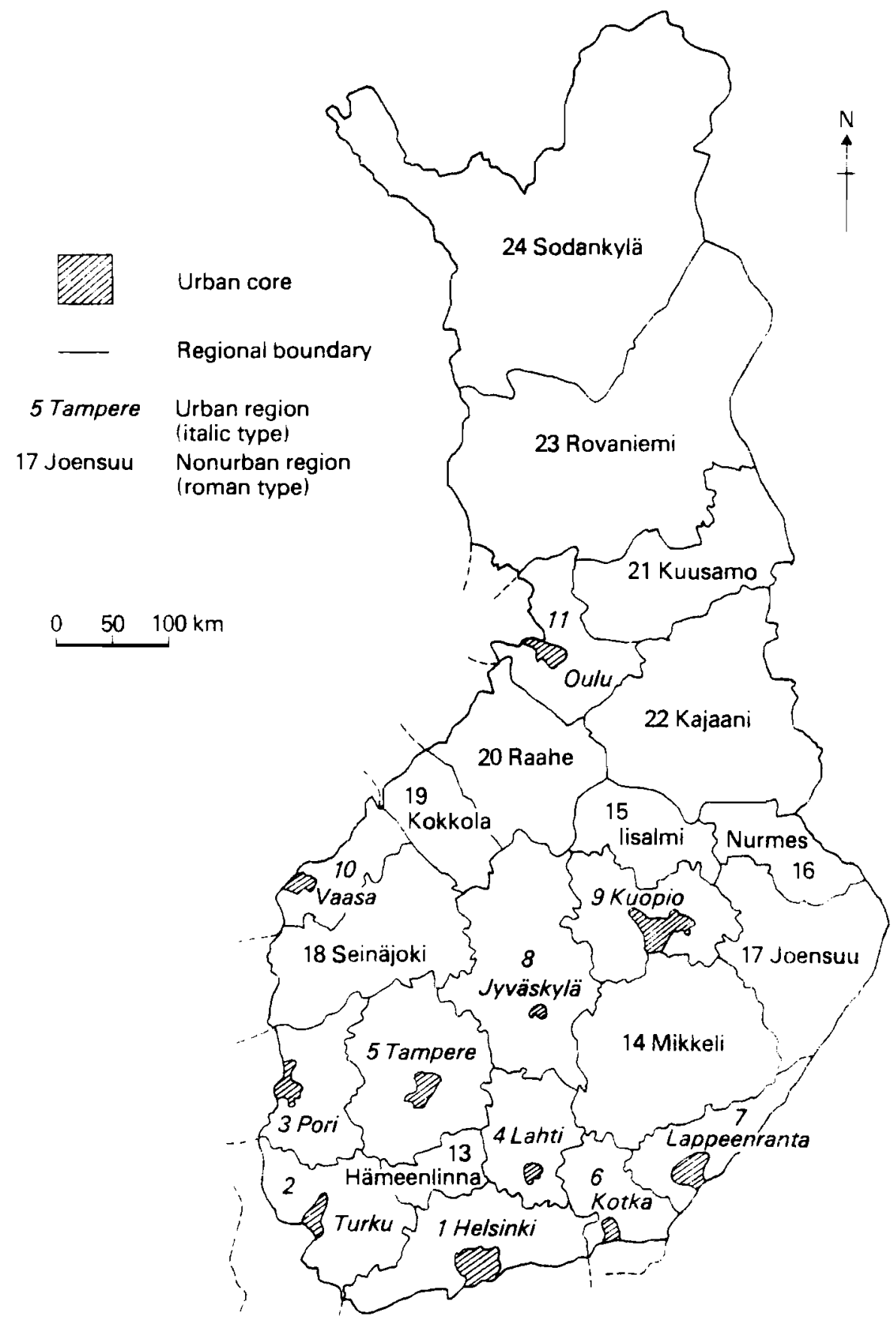

FIGURE 1 The urban and nonurban regions of Finland and the locations of the urban cores. 
TABLE 2 A summary of settlement patterns in the Scandinavian countries.

\begin{tabular}{lllll}
\hline Characteristic & \multicolumn{2}{l}{ Country } & & \\
\cline { 2 - 5 } & Denmark & Finland & Norway & Sweden \\
\hline Number of FURs & 12 & 11 & 10 & 22 \\
Number of rural regions & 21 & 13 & 24 & 25 \\
Total number of regions & 33 & 24 & 34 & 47 \\
Total population (1970) & $4,937,000$ & $4,598,000$ & $3,874,000$ & $8,076,000$ \\
Land area $\left(\mathrm{km}^{2}\right)$ & 43,000 & 305,000 & 324,000 & 411,000 \\
Population density (1970)(km $\left.{ }^{-2}\right)$ & 115 & 15 & 12 & 20 \\
Share of population living in & 79.9 & 64.1 & 66.0 & 81.4 \\
urban areas ${ }^{b}(1970)(\%)$ & & & & \\
Economically active population (1970) & & & & \\
$\quad$ female & 827,266 & 892,591 & 404,394 & $1,206,910$ \\
$\quad$ male & $36.1 \%$ & $42.1 \%$ & $27.7 \%$ & $35.4 \%$ \\
& $1,465,703$ & $1,225,666$ & $1,057,765$ & $2,205,758$ \\
\hline
\end{tabular}

The data for Denmark, Norway, and Sweden are from Hall and Hay (1980).

b An urban area is a community of at least 200 persons, where the distance between houses does not in general exceed $200 \mathrm{~m}$. This definition was accepted for Nordic countries in 1960.

\section{RECENT SPATLAL POPULATION TRENDS}

\subsection{Urbanization Patterns on the National Scale}

Finnish urbanization is a relatively recent phenomenon. The urban population accounts for a smaller proportion of the total population $(55.9 \%$ in $1960 ; 64.1 \%$ in 1970$)$ in Finland than in the rest of northern Europe. Major urban centers are concentrated southwest of the Vaasa-Tampere-Lahti-Kotka line, in the part of the country that, owing to its favorable climatic conditions and its having the best farmlands, has the most long-standing population. Industrial growth has spread along the Helsinki-Turku, Helsinki-Tampere, and Helsinki-Kotka transport routes. These three directions form the urbanized belts of southern Finland and emphasize the role of Helsinki in the settlement system. In the lake district and along the Gulf of Bothnia cities of medium size are few and are spread widely apart. Areas almost entirely lacking in cities of over 50,000 population are Suomenselkä, Kainuu, and Lapland.

During the past 20 years there have been no major changes in the patterns of population distribution among the major regions in Finland. Urbanization appears to continue via concentration processes within the core regions, as during earlier development stages. These trends can be seen from the data in Table 3, which gives the shares of the total population by major regions, disaggregated into urban and rural regions and an additional category of urban cores.

The percentages of the population living in functional urban cores show the vitality of urban centers located in northem and central Finland. This fact is often forgotten in studies on regions with a declining overall population size. However, a slightly declining tendency can be seen when the total of FURs in central and northern Finland is inspected. The population growth in southem Finland has been distributed more evenly among the core regions and their hinterlands. 
TABLE 3 Percentage population shares of major regions, 1955-1974.

\begin{tabular}{|c|c|c|c|c|c|c|c|c|c|c|}
\hline \multirow[t]{2}{*}{ Region } & \multicolumn{2}{|l|}{1955} & \multicolumn{2}{|l|}{1960} & \multicolumn{2}{|l|}{1965} & \multicolumn{2}{|l|}{1970} & \multicolumn{2}{|l|}{1974} \\
\hline & Cores & $\begin{array}{l}\text { Total } \\
\text { FURs }\end{array}$ & Cores & $\begin{array}{l}\text { Total } \\
\text { FURs }\end{array}$ & Cores & $\begin{array}{l}\text { Total } \\
\text { FURs }\end{array}$ & Cores & $\begin{array}{l}\text { Total } \\
\text { FURs }\end{array}$ & Cores & $\begin{array}{l}\text { Total } \\
\text { FURs }\end{array}$ \\
\hline $\begin{array}{l}\text { Southern Finland } \\
\text { (7 FURs) }\end{array}$ & 22.0 & 51.9 & 24.2 & 52.6 & 26.4 & 54.4 & 28.3 & 56.3 & 20.4 & 57.6 \\
\hline $\begin{array}{l}\text { Central and } \\
\text { northern Finland } \\
(4 \text { FURs })^{b}\end{array}$ & 4.3 & 14.9 & 4.5 & 14.7 & 5.1 & 14.5 & 5.4 & 14.5 & $6.1)$ & 14.3 \\
\hline Rural regions & & 33.2 & & 32.7 & & 31.1 & & 29.2 & & 28.1 \\
\hline Total & & 100.0 & & 100.0 & & 100.0 & & 100.0 & & 100.0 \\
\hline
\end{tabular}

a Helsinki, Turku, Pori, Lahti, Tampere, Kotka, and Lappeenranta.

b Jyväskylä, Kuopio. Vaasa, and Oulu.

Another in teresting phenomenon is the continuing increase of the population share of the Helsinki region (as well as of its core) and the growing percentages of the total population living in Turku and Tampere, the second-largest and the third-largest cities in Finland (see Table 4). The data show a clear tendency toward the strengthening of the position of the capital region in the country. The other two large centers have also been able to develop their core regions further but their FURs have only maintained their initial share in the total population of Finland.

TABLE 4 The percentage population shares of large urban centers, 1955-1974.

\begin{tabular}{|c|c|c|c|c|c|c|c|c|c|c|}
\hline \multirow[t]{2}{*}{ Center } & \multicolumn{2}{|l|}{$195 j$} & \multicolumn{2}{|l|}{1960} & \multicolumn{2}{|l|}{1965} & \multicolumn{2}{|l|}{1970} & \multicolumn{2}{|l|}{1974} \\
\hline & Cores & FURs & Cores & FURs & Cores & FURs & Cores & FURs & Cores & FURs \\
\hline Helsinki & 11.3 & 17.9 & 12.7 & 19.3 & 13.9 & 20.8 & 15.1 & 22.4 & 15.6 & 23.4 \\
\hline Turku + Tampere & 5.7 & 17.4 & 6.2 & 16.8 & 6.8 & 17.0 & 7.2 & 17.1 & 7.7 & 17.4 \\
\hline Total all cores & 26.4 & & 28.5 & & 31.5 & & 33.9 & & 35.4 & \\
\hline Total all FURs & & 66.8 & & 67.3 & & 68.9 & & 70.7 & & 71.9 \\
\hline
\end{tabular}

\subsection{Regional Centralization: Population Changes in the Functional Urban Regions}

During the 1950s and 1960s towns and cities located in various parts of the country were able to absorb people from nearby regions without any special regional policy measures. However, recent study (Engelstoff, 1977) indicates that the small centers (those with populations of less than 20,000 ) have been suffering net population losses. This polarization trend is rather clear in the 1960s and 1970s.

Figure 2 shows the general picture of population change by different classes of region in 1955-1960,1960-1965, 1965-1970, 1970-1975. The FURs have experienced sustained growth patterns. The rate of growth for the core areas has followed the popu. lation trends for the whole country. The latter were characterized by the low-growth period of 1965-1970, when as a result of heavy out-migration (to Sweden) the national 


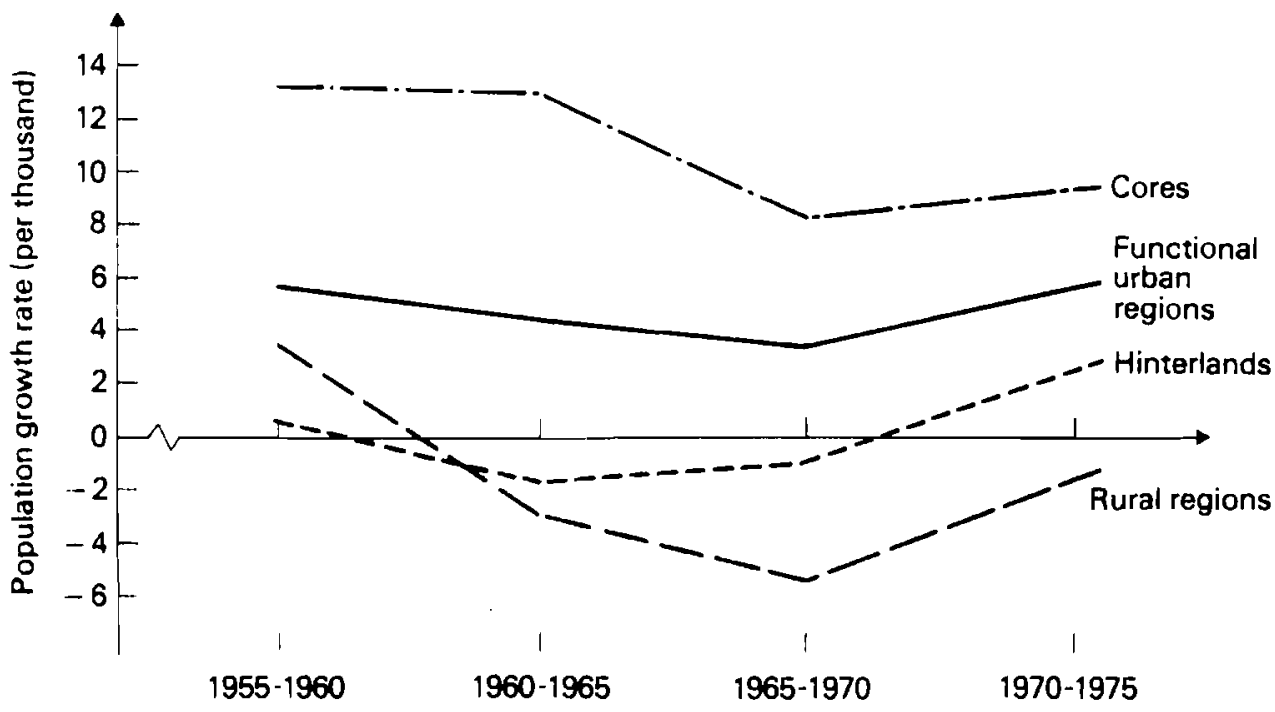

FIGURE 2 Population growth rates by different categories of regions in 1955-1960, 1960-1965, 1965-1970, and 1970-1975. (The growth rates have been normalized to five-year rates.)

population increased by only $0.6 \%$. It appears from the figure that the out-migration affected the rural regions most seriously; hence some of the migrants chose to move to Swedish cities rather than to Finnish core regions. It can also be seen that the natural growth rate in the rural regions and in the FUR hinterland areas could not match the net outflow from these regions after 1960 . The natural population growth remained at a high level in the northern and eastern parts of the country but leveled out during the 1960 s, a fact reflected in the data for rural regions. The concentration of population within the core areas continued during the whole period 1955-1975.

Figure 3 shows the population growth rates of the FURs classified by the size of their urban cores in 1970. Each line is identified by the mean value for the class. Only the largest core (i.e. Helsinki) was able to maintain its growth rate above the average level for all the FURs in Finland. The FURs with the smallest cores experienced the lowest growth rates - remarkably low when compared to the Helsinki rate. However, all the FURs gained population during the periods under investigation.

When the growth rates for individual time intervals are considered and the core population is treated as a variable, the dominance of the largest center is also quite pronounced (see Figure 4). In fact the Helsinki FUR experienced a slow decline of its growth rates, except for the last period, 1970-1975. This period was characterized by relatively rapid economic development which, however, has not continued since. Hence, one can expect an extension of the earlier trends after 1975. Figures 3 and 4 confirm the uniqueness of the Helsinki region within the Finnish urban system. It dominates the remaining regions to such an extent that the next-largest size class after Helsinki shows growth rates lower than those for medium-size centers; a wave-type growth pattern is observable during all the periods studied. 


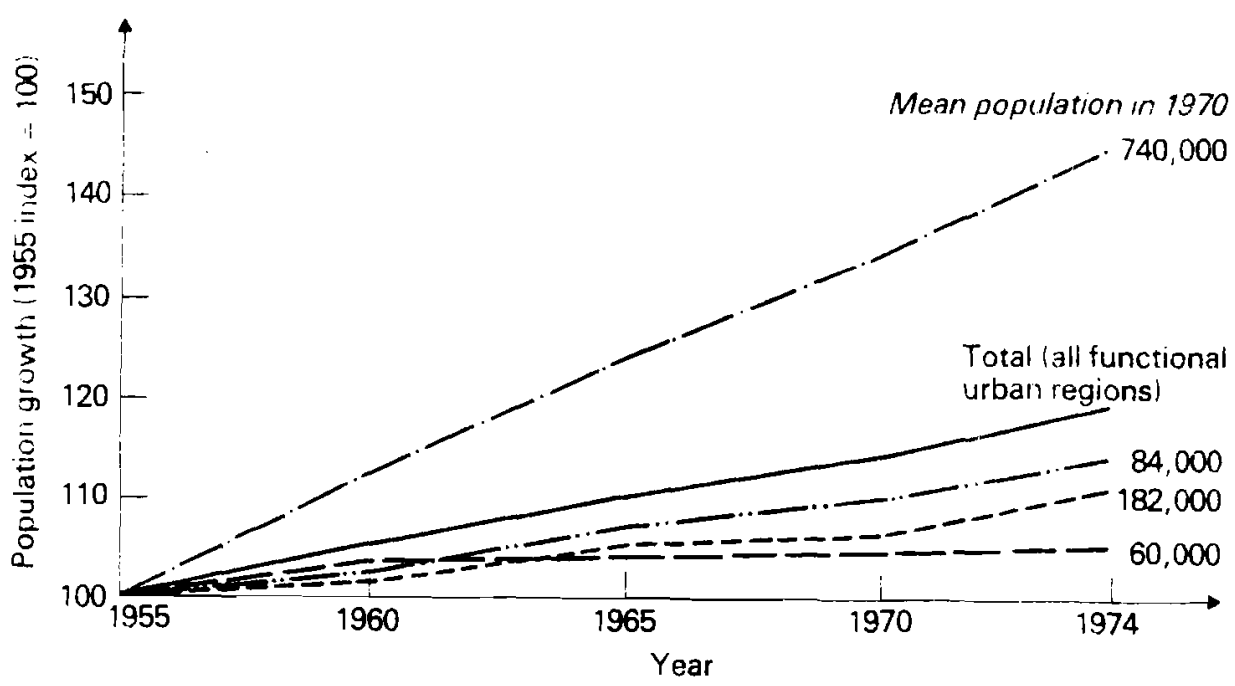

FIGIIRE 3 Population change of the FURs $(1955=100)$ classified by population size of urban core in 1970 .

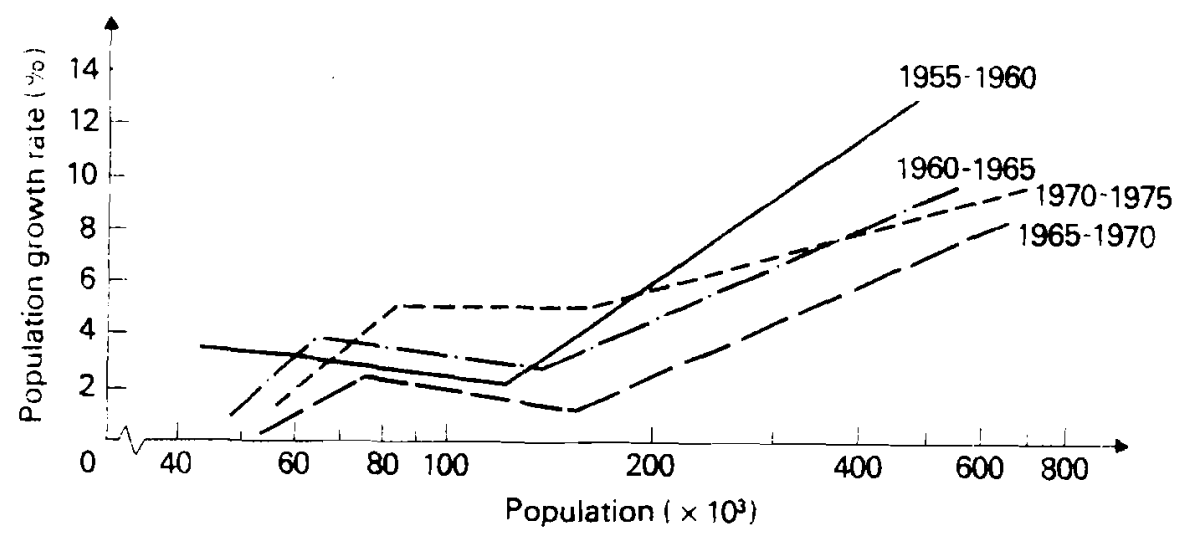

FIGURE 4 Population growth rates of the FURs classified by population size of urban core in 1970. (The 1970-1974 growth rates have been normalized to five-year rates.)

The Helsinki region, as well as the other urban centers of southern Finland, attracts migrants from the northern and eastern rural regions and also from the hinterlands of the FURs located in those parts of the country. Figure 5 presents the population growth of urban cores classified by their size in 1970 . The growth rates were highest in the period 1955-1965. Later, although the rates declined, all the core areas recorded positive growth. This trend is likely to continue in the near future.

The growth rates show a small dispersal among the size categories of areas, which proves that the hierarchical ranking of the main urban centers in Finland has remained approximately stable since 1955 . The only exception to this rule is the declining position of the smallest cores which are located in southeastern and central Finland. 


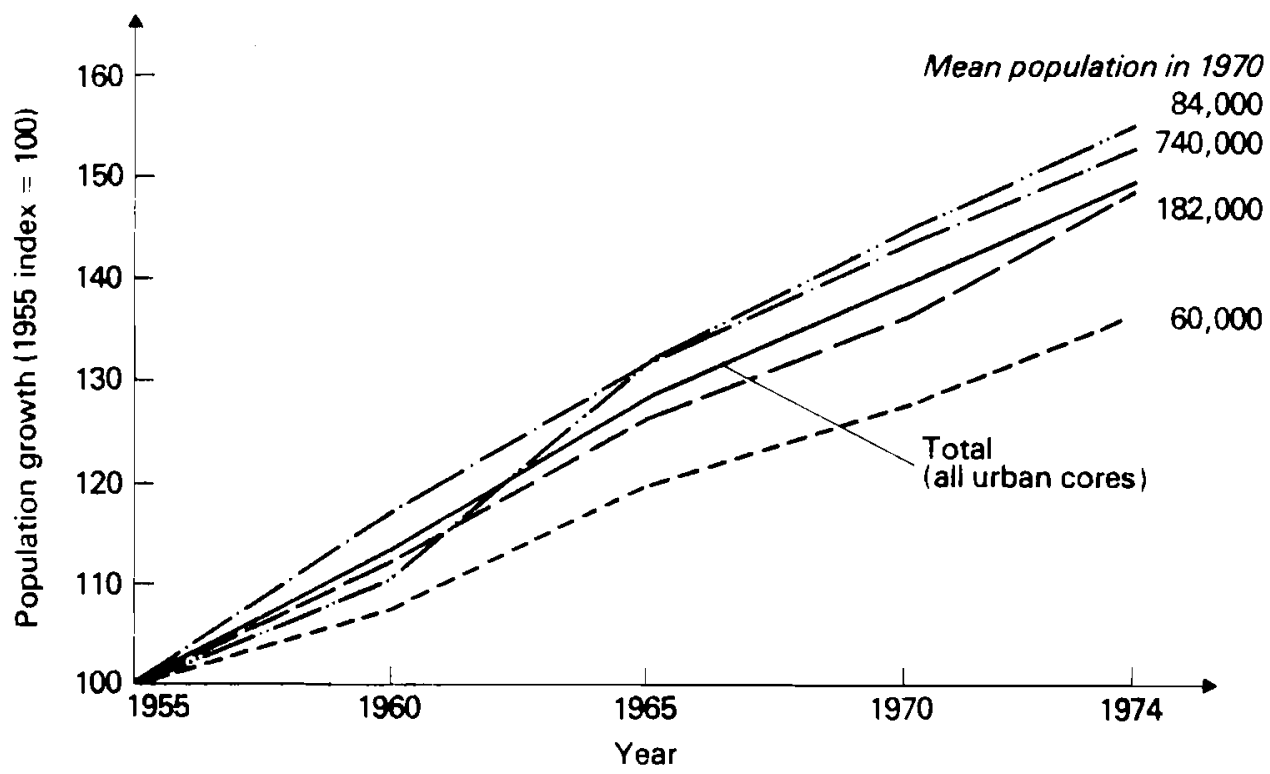

FIGURE 5 Population growth of urban cores $(1955=100)$ classified by population size of urban core in 1970 .

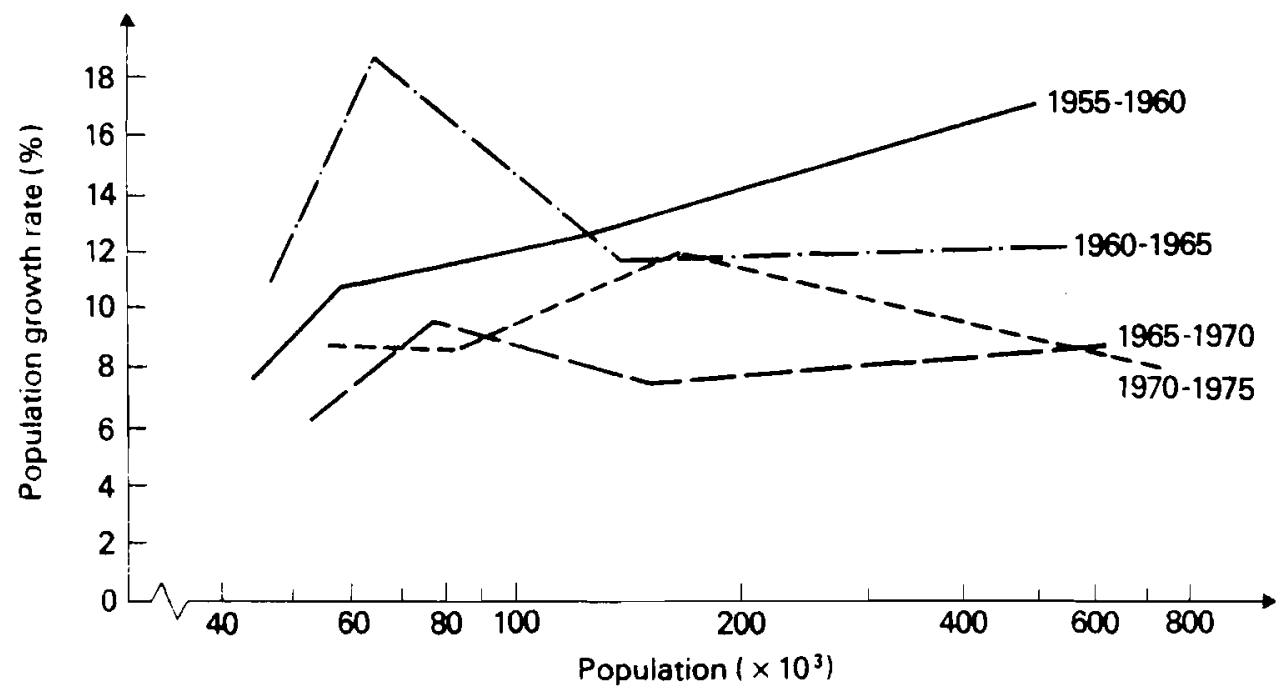

FIGURE 6 Population growth rates of urban cores classified by their population size in 1970. (The 1970-1974 growth rates have been normalized to five-year rates.) 
When the population trends for urban cores are inspected with the time interval kipt constant (Figure 6) it can be seen that the growth rate of the largest core (Helsinki) is steadily declining. The second-largest urban-core category also experienced relatively ripid growth during the last period studied. Therefore, in contrast to the case of the total FURs the dominance of the Helsinki core is diminishing relative to other large urban centers.

The rapid growth of urban cores is accompanied by a decline in hinterlands and rural regions (see Figures 7 and 8 ). Except for that of Helsinki, all the hinterland areas have been losing population since 1960 . The hinterland of the capital has been gaining population at increasing rates. Comparing Figures 3,7 and 8 , one can see firstly how strong the attraction of the capital region is and secondly how this growth has been transmitted from its core to the hinterland at an accelerating pace. In fact there are viable secondary centers in the hinterland of the Helsinki region which are expanding their own agglomeration economies and at the same time enjoying the agglomeration econonies of the nearby capital.

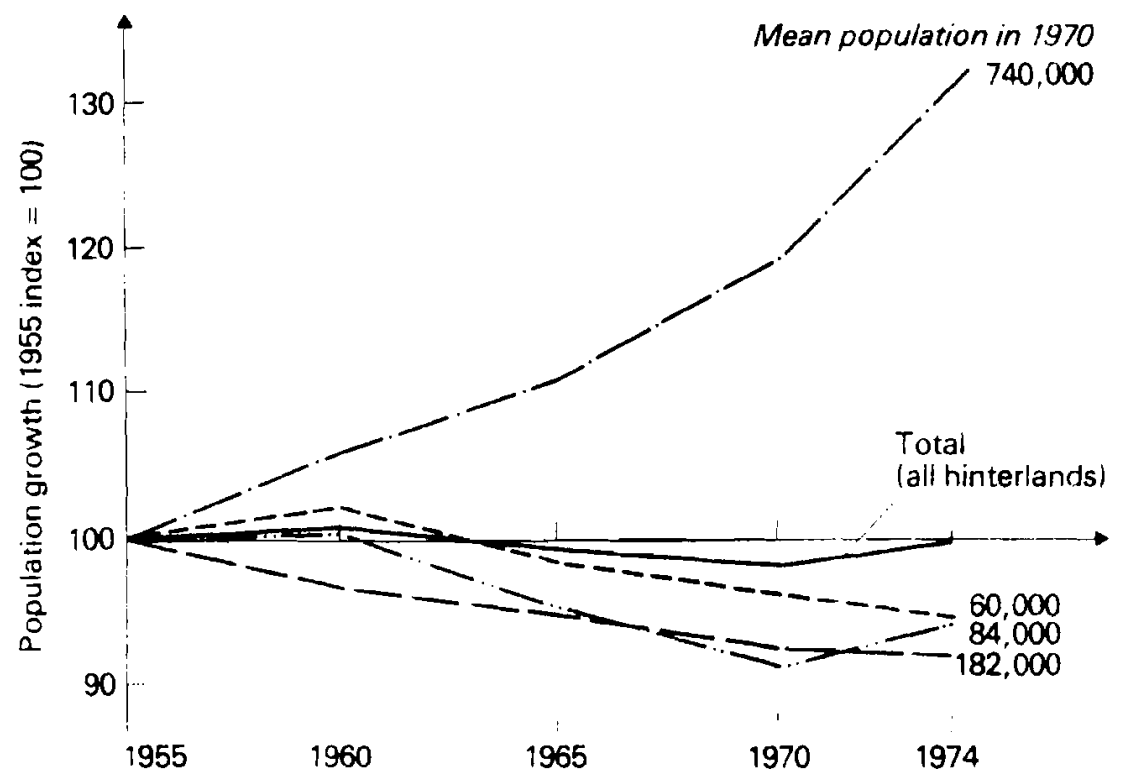

I IGURt 7 Population growth of hinterlands $(1955=100)$ classiried by size of urban core in 1970 .

Although the growth of core regions was rapid during 1955-1974, the rural regions were also able to increase their population during 1955-1960 because of their relatively high natural growth rates. However. in 1960-1974 there was a tendency of birth rates to level among regions which resulted in the continuous population decline of the rural regions. This declining tendency was most pronouns ad in 1965- 1970 but seems to have diminished in the 1970s. The general pictures for the rural regions and the hinterland reas of the FURs are very similar, although the latter units have been more effective in ietaining their population. 


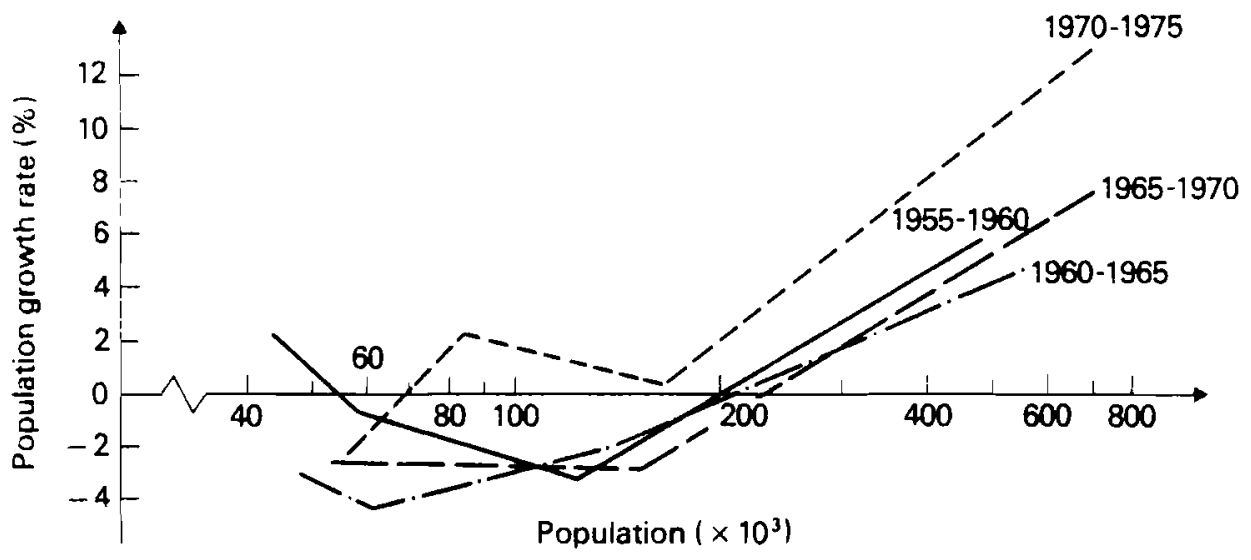

FIGURE 8 Population growth rates of hinterlands classified by size of urban core in 1970 . (The 1970-1974 growth rates have been normalized to five-year rates.)

Interregional and intraregional migration patterns varied over time; different trends were dominant during the various decades. In the 1950 s people were moving to the Helsinki region not only from origins in other parts of southern Finland but also from the western and eastern parts of the country. The core region situated furthest to the north (Oulu) was a destination for migrants even from central Finland. During the period 1960-1965 migration continued to Helsinki from the eastern parts of the country but the core regions of Lahti and Tampere also attracted relatively large numbers of migrants. The core area of the Oulu region in the north lost its attraction to migrants from central Finland. In 1965-1970 the regions of Lahti and Tampere were the second and third most important migration destinations after the Helsinki region. These centers competed for migrants originating from the urban hinterlands of southern Finland while Turku and Pori received population mostly from the eastern parts of the country. Net out-migration was greatest from the rural regions of Joensuu and Mikkeli and from the hinterland of the Kuopio region.

Lapland is an exceptional case with regard to migration patterns in spite of its distant location. In the 1950s and early 1960s it even received some net in-migration, and it did not become a region of net out-migration until the late 1960s. The migrants headed mainly for Sweden.

To sum up, the most important destination for interregional migration has been the FUR of Helsinki. The in-migration during the 1950s and 1960s amounted to onequarter of its total population as of 1970. During the 1970s both the FUR hinterlands and the rural regions have been able to improve significantly their relative competitive positions while continuing to feed the core areas. In the background of this is the increased attraction of specialized rural centers which are located far away from other centers. These specialized centers have been gaining job opportunities originating from the relocation of enterprises as a result of the regional development programs. 


\section{SPATIAL EMPLOYMENT STRUCTURE AND SHIFTS}

The total activity rates (economically active persons as percentages of the total population) are considerably higher for heavily populated urbanized regions. They decline with decreasing size of core, as shown in Table 5.

TABLE 5 Total professional-activity rates (1970) (percent).

\begin{tabular}{llllll}
\hline Region & \multicolumn{2}{l}{ Region size } & & & \\
\cline { 2 - 6 } & $200,000+$ & $100,000-199.999$ & $75,000-99,999$ & $5.74,999$ & Total \\
\hline I. LiRs & 50.6 & 47.6 & 45.8 & 44.9 & 47.5 \\
Cores & 52.4 & 49.7 & 47.2 & 47.2 & 50.0 \\
Hinterlands & 46.8 & 46.0 & 44.8 & 43.8 & 45.2 \\
Rural regions & & & & & 36.7 \\
Whole country & & & & & 44.3 \\
\hline
\end{tabular}

The high activity rates in large regions are explained by the high proportion of economically active women in large cores and by the accompanying lower proportion of children in the total population. To illustrate the typical economic structures, the shares of economically active people employed in three main sectors are shown in Figure 9 for different size classes of urban cores.

Manufacturing industry holds relatively the most important position in those FURs which are dominated by medium-size cores; the share of this sector is considerably smaller in the Helsinki region, but this is also true in the small regions in which the share of agricultural employment is rather high.

The Helsinki core region is dominated by service activities. The medium-sized cores are characterized by the preponderance of manufacturing and services; the small regions also have a relatively high service level reflecting their role as regional administrative and cultural centers. In the rural regions agriculture is still predominant, with service and manufacturing activities occupying the second and third ranks, respectively.

However, manufacturing increased its share in the total employment of the rural areas during 1955-1974. Table 6 shows that the rural areas even outpaced the urban hinterlands in gaining industrial employment which decentralized from larger cities outwards. This phenomenon can be only partly explained by the low initial level of indusirial employment in the rural regions. One possible explanation of this gain is a labor shortage in urban centers in the 1960 s and 1970 s caused by an increased labor demand by private and public service sectors. Thus the manufacturing establishments moved in increasing numbers to the hinterlands, where agglomeration economies had increased (see Kawashima, 1972), or to rural regions, where relatively cheap labor was still available. Small urban cores in central and northern Finland have also competed successfully for manufacturing jobs.

It may be of interest to compare the patterns of population change with shifts in industrial productivity. Productivity is expressed by two measures, namely the ratio between value added and employment and the ratio between income accrued to capital and employment. 

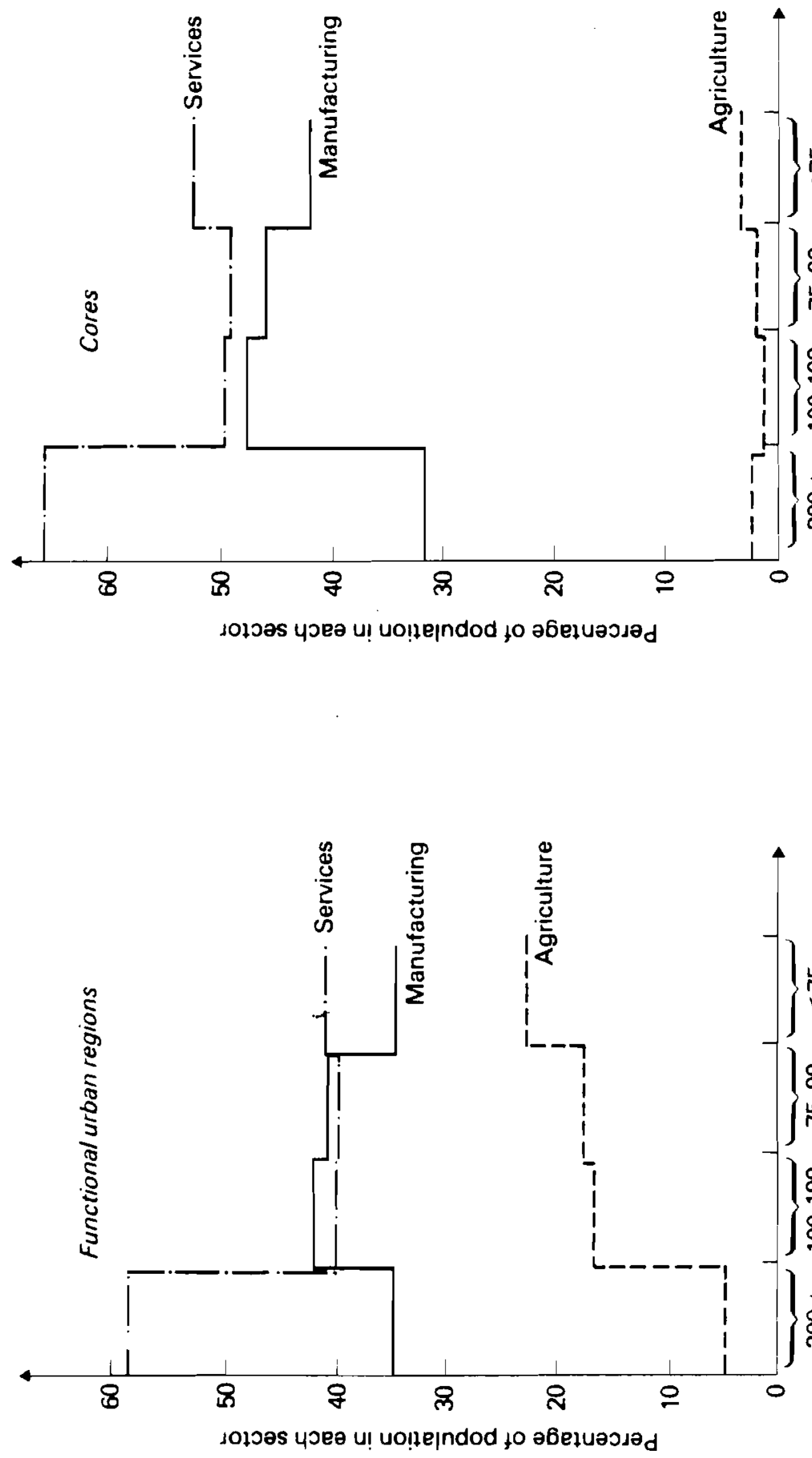
TABLE 6 Manulacturing employment shares (percent) by type of region, 1955-1974.

\begin{tabular}{|c|c|c|c|c|c|c|c|c|c|c|}
\hline \multirow[t]{2}{*}{ Region } & \multicolumn{2}{|l|}{1955} & \multicolumn{2}{|l|}{1960} & \multicolumn{2}{|l|}{1965} & \multicolumn{2}{|l|}{1970} & \multicolumn{2}{|l|}{1974} \\
\hline & Cores & FURs & Cores & FURs & Cores & FURs & Cores & FURs & Cores & FURs \\
\hline 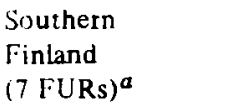 & 47.07 & 73.06 & 46.18 & 72.74 & 44.92 & 72.36 & 42.71 & 71.59 & 38.82 & 69.95 \\
\hline $\begin{array}{l}\text { Central and } \\
\text { northem Finland } \\
\left(4 \text { FURs }^{b}\right.\end{array}$ & 7.06 & 12.50 & 7.19 & 12.17 & 7.19 & 12.11 & 7.25 & 12.11 & 7.22 & 12.64 \\
\hline Total FURs & 54.13 & 85.56 & 53.37 & 84.91 & 52.11 & 84.47 & 49.96 & 83.70 & 46.04 & 82.29 \\
\hline Rural regions & & $\frac{14.44}{100.00}$ & & $\frac{15.09}{100.00}$ & & $\frac{15.53}{100.00}$ & & $\frac{16.30}{100.00}$ & & $\frac{17.71}{100.00}$ \\
\hline
\end{tabular}

a Helsinki, Turku, Pori, Lahti, Tampere, Kotka, and Lappeenranta.

${ }^{b}$ Jyvasklyä, Kuopio, Vaasa, and Oulu.

Figure 10 shows productivity-growth differences; these differences were especially pronounced in the 1970s. It is interesting to find that the Helsinki region, which increased its population the most rapidly, is characterized by productivity growth comparable to that for FURs dominated by medium-size cores. Small FURs have the highest productivity level and the highest productivity growth.

Figure 11 illustrates the pattern of productivity in the core areas. It differs somewhat from the pattern for the whole FURs in that the productivity increase in hinterland

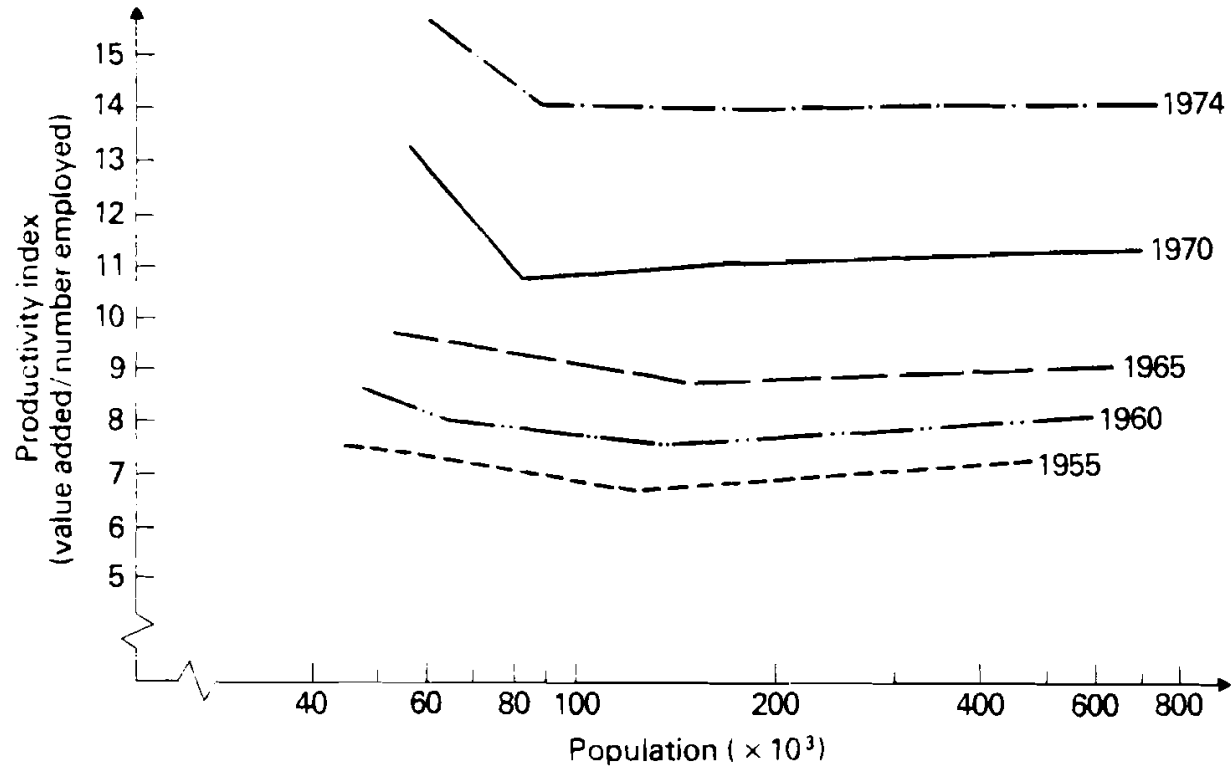

FIGURE 10 The productivity index (value added/number employed) in manufacturing industry in the FURs classified by population size of core in 1970 (1955 prices). 


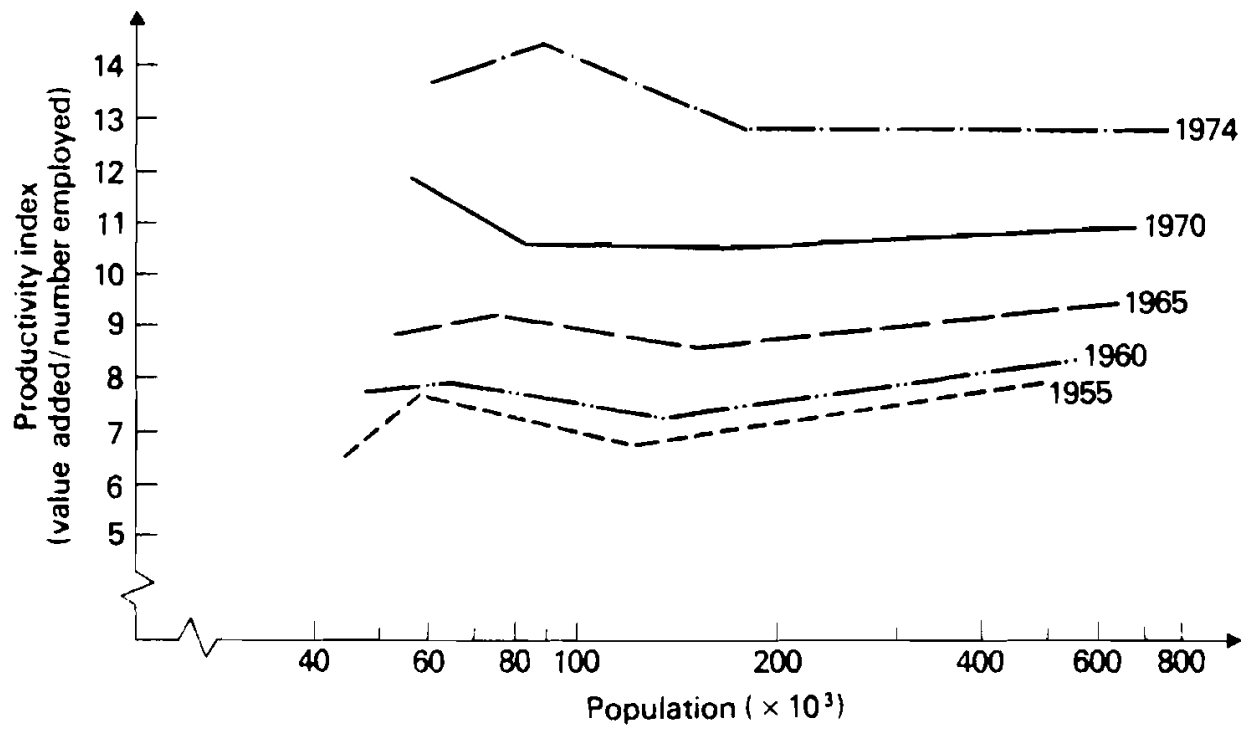

FIGURE 1] The productivity index (value added/number employed) in manufacturing industry in the urban cores classified by population size of core in 1970 (1955 prices).

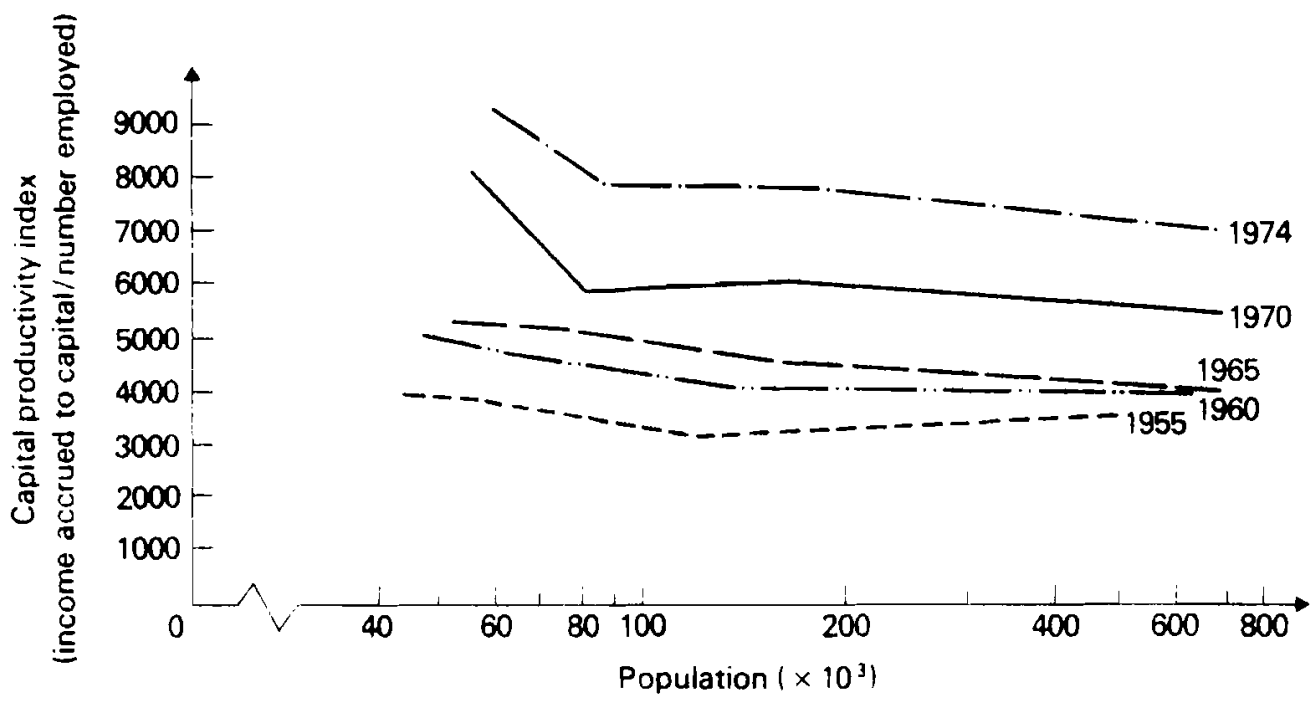

FIGURE 12 The capital productivity index (income accrued to capital/number employed) in manufacturing industry in the FURs classified by population size of core in 1970 (1955 prices).

areas seems to be higher than that in the cores. This wa. particularly the case during the 1970s. The Helsinki core had the lowest prusuctivity of all core areas in 1974 . Figures 10 and 11 aiso allow us to trace productivity changes by population size class of region. Of course, both the productivity and the population increased over time. 


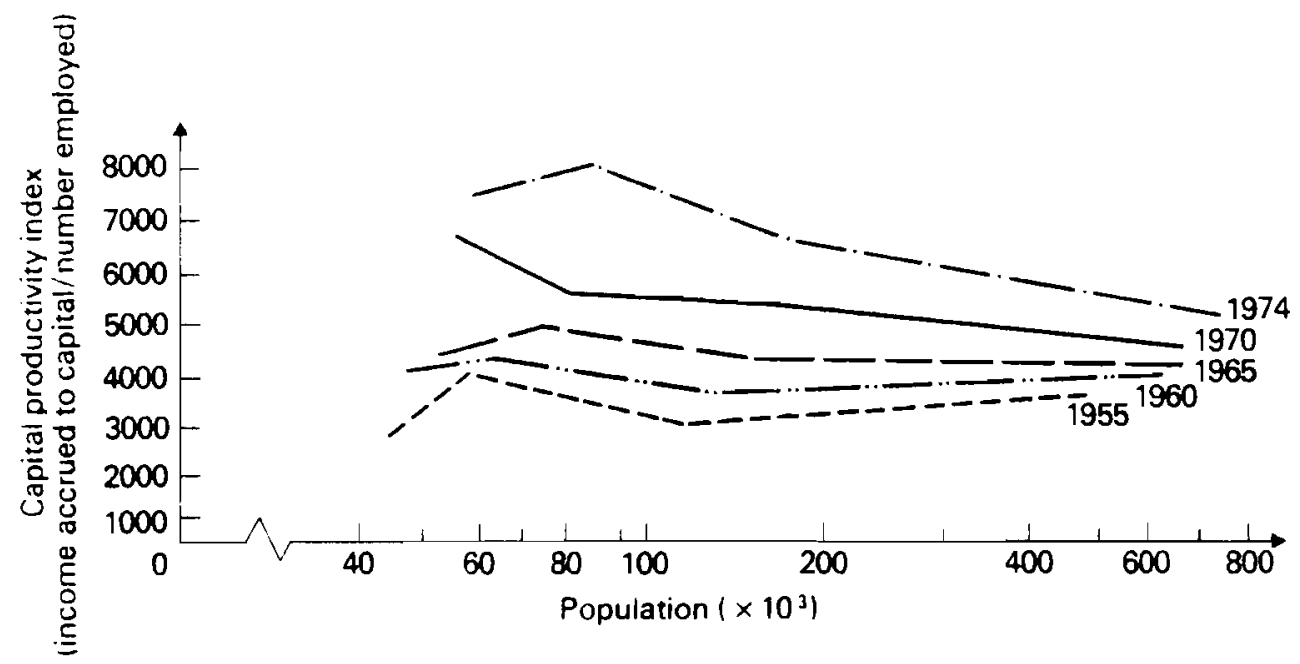

IIGURE 13 The capital productivity index (income accrued to capital/number employed) in manufacturing industry in the urban cores classified by population size of urban core in 1970 (1955 prices).

The interdependence between industrial capital productivity and population is illustrated in Figures 12 and 13 which show the values of income accrued to capital (income accrued to capital is measured by value added minus wages and salaries) divided by employment for individual categories of urban region. The patterns are similar to those in Figures 10 and 11 , respectively, implying that in FURs income accrued to capital develops mainly as labor income. When Figures 11 and 13 are inspected more closely some interesting observations can be made. Firstly, the income accrued to capital was growing very slowly in the Helsinki core and its relation to population growth was not as strong there as in the other cores. Secondly, capital productivity increased in small and medium-size centers at accelerating rates, which explains the negative slopes of the curves for 1970 and 1974. One can observe a similar but less pronounced tendency for the Helsinki region (Figure 12) where the population growth rates were very high, although declining over time.

Whether the low capital productivity in the Helsinki region explains the declining population growth rate is not clear. Further investigations are needed in order to gain a better understanding of the reasons for these phenomena and of the factors involved in spatial population movement in Finland.

\section{URBAN AND REGIONAL POLICIES IN FINLAND SINCE 1945 AND PROSPECTS FOR THE DEVELOPMENT OF HUMAN SETTLEMENTS}

Immediately after World War II Finland was a society undergoing industri..lization and less than one-third of the population lived in urban areas. While the main policy was to develop industrial activities, the labor supply from rural regions exceeded the industrial labor demand owing to the strong growth of productivity in agriculture. The movement 
of labor to rapidly growing industries characterized by high productivity was an important factor in the increase of well-being. In areas of net out-migration the investments made by society and individuals were left underutilized and the level of services declined. In contrast, in the places of destination, there was a continuous unsatisfied demand for new service facilities, dwellings, and infrastructure. Since regional centers during the 1950s were still able to attract labor from their own hinterlands, the field of regional policy was relatively undeveloped. Public interest in the development of human settlement systems did not start before the late 1960 s. By that time the migration had grown so rapidly that urgent policy measures were needed.

In 1966 the developing regions of Finland were defined and the first legislative measures (1966-1970) to develop industrial activity in those central and northern regions were taken. The beginning was very modest and the supporting measures could not stop the out-migration. In 1967 the urban centers were classified into six classes for policy purposes. A redefinition of regional policy was necessary and new legislation on regional policy (1970-1975) was based on the growth-center approach. In 1973 the coordination of regional planning was centralized in to the Office of the Prime Minister but at the same time the number of planning personnel in the provinces was increased. The provincial development plans were started in 1976.

The regional policy measures are largely directed at medium-sized and small centers in central and northern Finland. The favorable loan and taxation policy has attracted enterprises relocating from southern Finland to the developing regions. In addition to the industrial-development policy the government is developing plans to decentralize administration by relocating its new branches in different core regions.

In general, the regional policy measures have not been able to alter the mainstream of rapid social change. At best, the measures have moderated the effects of out-migration in regions with a net population loss by creating job opportunities in small centers. These measures, together with increased welfare programs in the field of health care and education which have contributed much to the general well-being at the regional and community levels, have probably to some extent diminished the necessity to migrate from the small centers at least.

The prospective direction of the development of human settlement depends greatly on the overall population trends in Finland. The Central Statistical Office (1975) has forecast that, assuming international emigration equal to immigration, the population of the country will increase by 10,000 per year in the 1970 s, growth will slow down in the 1980 s, and the total population will drop to $4,565,000-4,651,000$ in 2000 as compared to $4,720,000$ in 1975 .

The concentration of the young population in cities in the 1960s and 1970s will have the greatest impact on the urban system. In the late 1970s and 1980s the regions of Helsinki, Turku, Pori, Tampere, and Lahti will also be regions of net in-migration. The rural regions in central and northern Finland will probably continue to lose population unless stronger regional policy measures are applied. Regional differences in labor supply will be even larger than today. The age structure favors the southern parts of the country and in the rural areas agricultural labor is already aging. However, according to the forecasts the birth rate will remain at a slightly higher level in the northern parts of the country.

Considering the small total population of Finland and its growth expectations, special attention should be given to welfare programs concerned with family policy and 
labor participation. In spite of the absence of an explicit population policy in Finland the interest of the authorities and of nongovernmental organizations in population problems has increased. It is evident that numerous social policy measures have influenced unexpectedly the population development and labor supply by regions. For instance, the improved pension system has caused a remarkable decline in the participation of the male labor force in particular. The trend will continue in the future but the decline will not be so sharp. With regard to the supply of individual housing facilities, so far the effects of labor mobility have not been taken into account in housing policy. The difficult housing situation has diminished the mobility of labor and created difficulties for migrants. Also the shortage of dwelling units in the core regions and in the largest population centers in rural regions may have contributed to many of the decisions to move to Sweden.

The problems connected with rapid social change show that urban and regional policy should be more closely connected with general social and economic policy. In particular, the effects of migration on local labor markets should be studied over the long term. In the 1960 s and 1970 s the policy supported labor movement to the south and at the same time tried to develop stronger small and medium-sized communities in the developing regions. In order to diminish the imbalance in regional development this policy will probably continue and increasingly favor the developing regions. The interests of political parties have differed as to the question of whether the regional policy should favor small or large centers in the developing regions. So far the policy has favored small centers that are smaller than the urban-core areas.

\section{REFERENCES}

Central Statistical Office (1975). The Population of Finland, A World Population Year Monograph. Central Statistical Office, Hämeenlinna.

Engelstoff, S. (1977). Udviklingen i de Nordiske Bysystemer, 1960-1975. Bilaga till temanummer Ortssystempolitikens må och medel från NordRefos forskningsprojekt: Alternativa mönster för ortssystemets utforming. (Development in the Nordic system of cities, 1960-1975. Appendix to a special issue "Goals and Means of Urban System Policy" from the NordRefos Research Project: Alternative Patterns for the Shaping of Urban Systems.) Nordic Commission on Regional Policy Research, Stockholm.

Hall, P. and Hay, D. (1980). Growth Centers in the European Urban System. Heinemann Educational Books, London.

Kawashima, T. (1972). Urban production function and economies of urban agglomeration. Michigan University Microfilms, Ann Arbor, Michigan.

National Planning Office (1967). Suomen Keskus - ja Vaikutusaluejärjestelmä (LTT) (The system of functional centers and areas in Finland). Publications of the National Planning Office, Series A, 19

NORDREFO (1974). Information om regionalpolitik och regionalpolitisk forskning i Norden (1974:4). Temanummer: Ortssystempolitikens mal och medel. (Information on regional policy and regional policy research in the Nordic countries. Special issue on "Goals and Means of Urban System Policy", including hive appendixes.) Nordic Cominission on Regional Policy Research, Stockholm.

Palomäki, M. and Mikkonen, K. (1972). An attempt to simulate an optimal network of central places in Finland. Acta Wasaensia, No. 2. 



\title{
EXPLORATORY AND NORMATIVE ASSUMPTIONS IN THE IDENTIFICATION OF FUNCTIONAL URBAN REGIONS IN ROMANIA
}

\author{
Mircea Enache and Senino Holtier \\ Institute of Architecture "Ion Mincu", Bucarest (Romania)
}

\section{URBAN AND REGIONAL POLICIES IN ROMANIA SINCE WORLD WAR II}

Urbanization in Romania has been strongly influenced by the planned character of socioeconomic development as reflected in the demographic, spatial, and economic processes. In an attempt to achieve a balanced development of the country planning is focused on stimulating growth and directing growth to those areas and settlements which have traditionally experienced lower growth rates. The regional planning objectives are equity and efficiency, while the high rate of industrialization is considered to be the key to development.

The 1968 Regional Administration Act defined the present geographicadministrative units (ISLGC, 1976) which consist of 39 counties, 236 urban settlements (of which 47 are municipalities), 2.706 communities, and 13.149 villages (rural settlements). The regional policy objectives after the 1968 Act were to foster growth in less developed counties and to generate employment in areas and settlements which had a labor surplus. Industrialization is one of the basic factors of these processes. A major economic decision was that by 1980 each county should have reached a gross annual industrial output of 10 billion lei, which in some cases represents a twofold or threefold growth during the 1975-1980 period.

The normative character of economic and spatial planning in Romania is also illustrated by the regional reform itself. Prior to 1968 the national territory of Romania was divided into 16 regions. The 1968 administrative reform replaced the large-sized regions with units that were more easily manageable in order to stimulate the growth of second-order centers and to diffuse socioeconomic progress throughout the country. The reform simplified the administrative structure of the country by replacing the earlier three-tier structure (raion*, regional, central government) with a two-tier structure (county, central government) and by reducing the number of communities from 4,259 to 2,706 .

* The term raion corresponds approximately to the English county. 


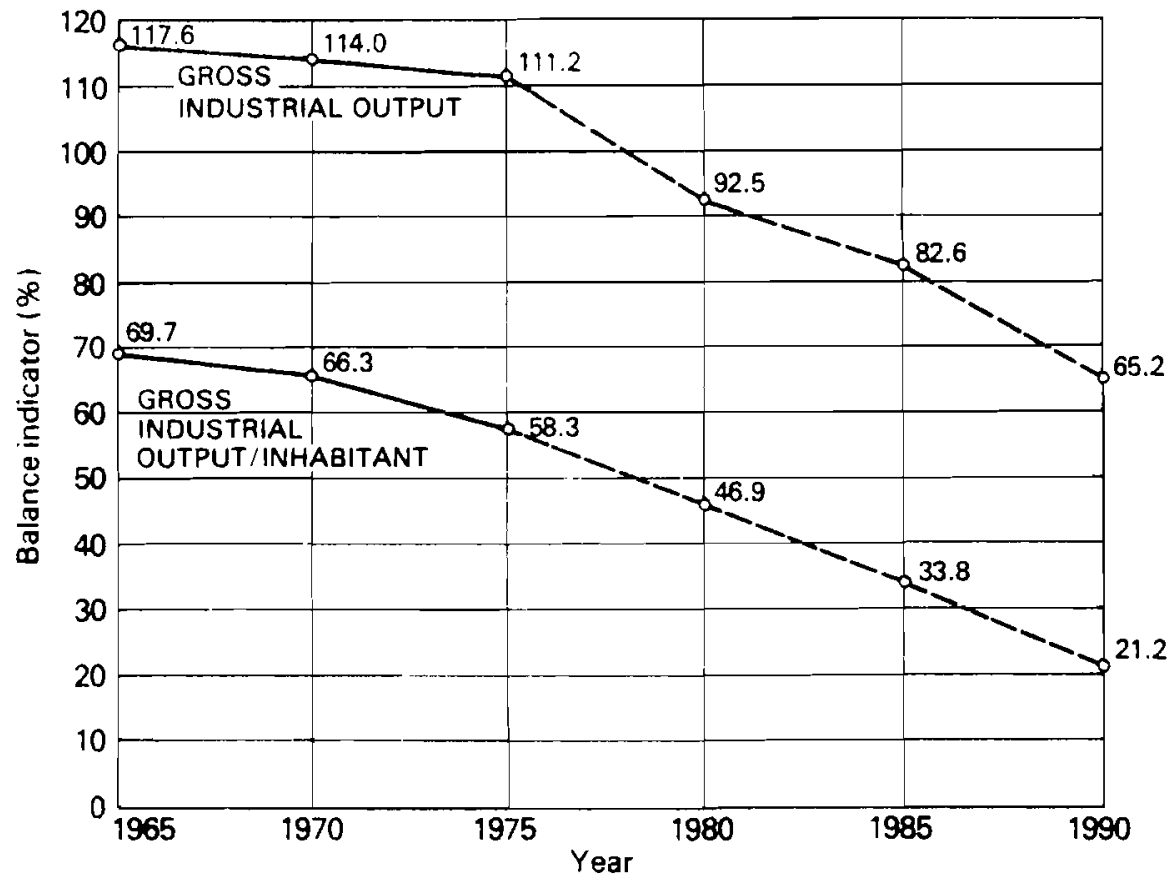

FIGURE 1 The balance indicator of the distribution of industrial output of the counties over the period 1965-1990 (the 1980-1990 figures are based on projections). (Source: Enache, 1978.)

Implicit in the reform was the designation of 23 new county capitals to act as growth centers. The result was that the new poles showed higher growth rates in the 1966-1977 decade (averaging 8.2\% a year) than the former regional capitals which grew in population during the same decade at an average rate of only $6.2 \%$ a year.

The process of more balanced regional development and the gradual equalization of the development of counties can be illustrated by a balance indicator of the distribution of industrial output over the period 1965-1990 (Figure 1). The indicator was computed by dividing the standard deviation by the arithmetic mean of the values for the counties and by expressing the result as a percentage. (The formula actually used was

$$
\text { Balance indicator }=\sigma / \vec{X}=\left\{\left(\Sigma X^{2}\right) / N-[(\Sigma X) / N]^{2}\right\}^{1 / 2} / \bar{X}
$$

where $X$ is the value of industrial output, $\sigma$ is the standard deviation, and $N$ is the total number of counties. This formula is similar to the indicator of inequality proposed by J.G. Williamson except that we do not weight it by the size of the region since the sizes of the regions are comparable.)

$T_{1}$ ? balance indicator shows a gradual equalization of the development of the counties over the period 1965-1990. This measure was computed for various characteristics including population, employment, and rates of urbanization (Enache, 1978) and it provided a basis for comparative analysis. 


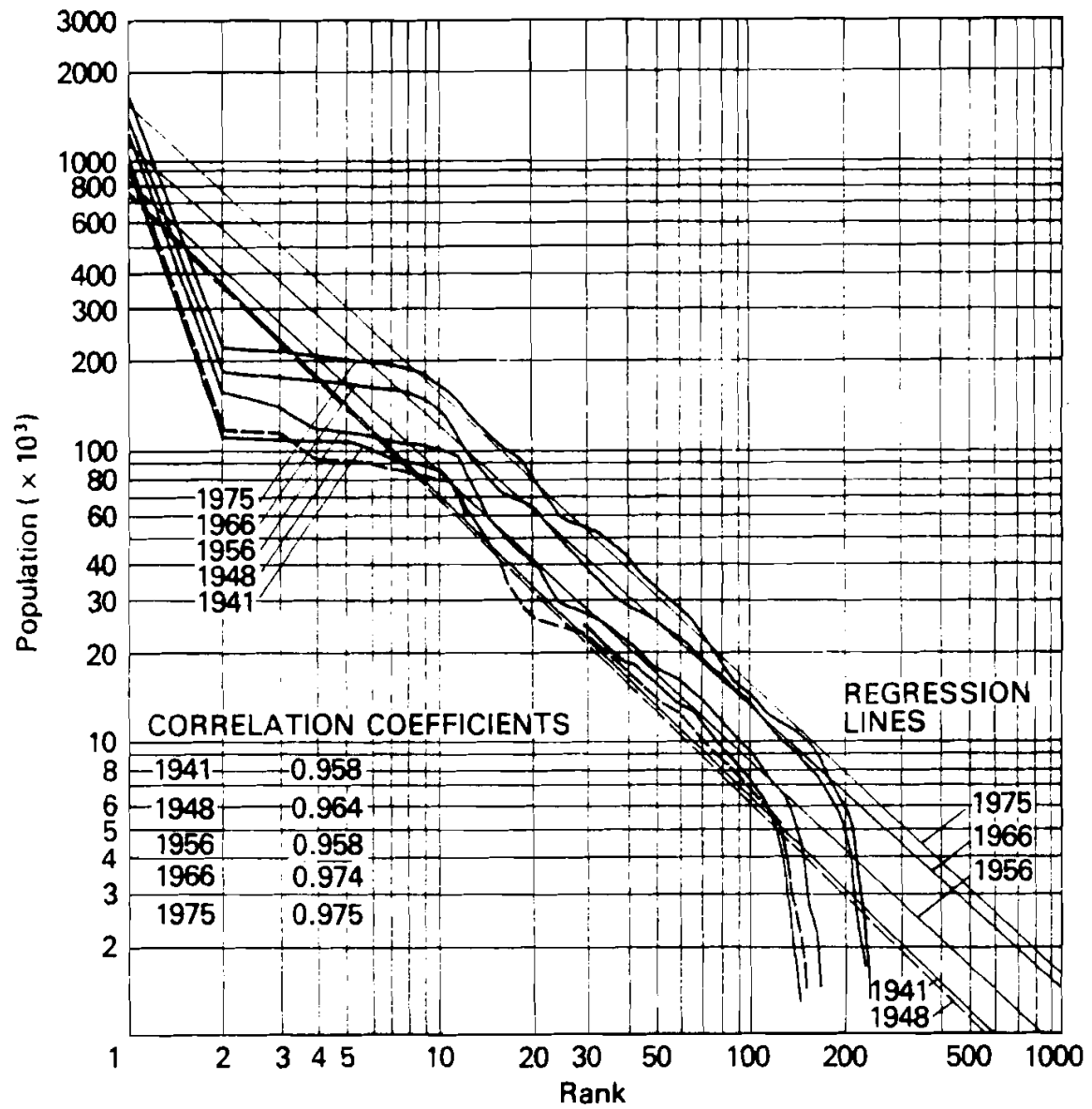

FIGURE 2 The rank-size distribution of Romanian urban settlements in the period 1941-1975. (Source: Enache, 1977a, p. 58.)

\section{DELINEATION OF FUNCTIONAL URBAN REGIONS AND THEIR HISTORICAL AND ECONOMIC CHARACTERISTICS}

One basic interpretation of the formation and development of national settlement systems refers to the urban rank-size pattern. It has been generally found that the regularity in city rank-size distributions for individual countries tends to increase over time and that it is positively correlated with the intensity and stability of human-occupancy and economic-activity patterns (Dziewonski, 1972).

In analyzing the rank-size distribution of urban settlements in Romania we chose an approach similar to the one proposed by Thomas (1967) using a log-normal distribution. We then compured the correlation coefficients of the time-series distributions over the period 1941-1975 (Enache, 1977a) as shown in Figure 2. The log-log size distribution of the Romanian cities indicates a lack of big cities, i.e. cities with populations 
of uver 250,000 . The correlation coefficients are generally increasing during the period 1941-1975.

The concept of rank-size distribution, unlike alternative interpretations of the formation and development of national settlement systems, has no explicit spatial dimension. One alternative intepretation refers to the hierarchical pattern of central places. This pattern evolves as a result of exogenous economic and technological factors involving the division of labor and functional specialization as well as trends towards concentration or deconcentration of population and economic activity. The growing specialization and functional interdependence on an interregional or even national scale are the base of a hierarchical central-place model.

However, Hansen (1975) and Parr (1973) have pointed out the generally ambiguous empirical role of central-place hierarchies. Reliance on a traditional market-oriented hierarchy of central places does not provide an adequate growth model (see also Pred, 1976 and Stöhr, 1974). The concept that is closest to a development theory of settlements is consequently the concept of growth poles. Despite the fact that the central-place theory is the dominant theory in studies of the settlement network in Romania it can be argued that the actual practice and decision making on a regional scale rely heavily on a built-in and sometimes hidden concept of growth poles.

The fourth concept used in defining Functional Urban Regions (FURs) in Romania was the notion of clusters of settlements (Enache, 1977c). The expansion of large cities to include surrounding smaller towns and communities in their sphere of influence, as well as linkages between neighboring cities in terms of labor and raw-materials supply and infrastructure building, are factors in explaining this notion.

At present 15 such clusters of settlements can be identified; they integrate some 100 urban settlements with a total population of 4.3 million people. Fourteen more clusters are taking shape now, and the future development policy will tend to stimulate the emergence of another seven (Figure 3).

The present and future clusters of settlements constitute a crucial lever of regional development since most of them emerge around county capitals, which means that a larger share of growth at county level is directed towards them. Each settlement cluster includes a major urban center and a number of smaller settlements (urban and rural) which develop linkages with the main center in terms of industrial and agricultural activities, labor and housing provision, sociocultural and commercial activities, services, recreation, etc. Socially, this implies the participation of the population residing in the sphere of influence of the main center in the activities occurring in that center.

The Romanian settlement clusters include, with six exceptions, a large city with a population of over 100,000. In most cases the main center is also a county capital. There are only eight county capitals which do not generate clusters (see Figure 3). However, there are a few urban centers which, without being county capitals, generate settlement clusters: the Jiu Valley, the Danube-Black Sea system, etc. (Enache, 1977c). Finally, if large cities with populations of over 200,000 are naturally centers of clusters, smaller cities with populations of over 100,000 or so share this quality and have important functions either at a county or at intracounty level. All the frregoing arguments justified our proceeding in delineating functional urban cuivs on the basis of the definition of settlement clusters. (However, as strict growth limits were delineated in 1973 for every settlement in the country (either urban or rural), it is reasonable in the special case of 


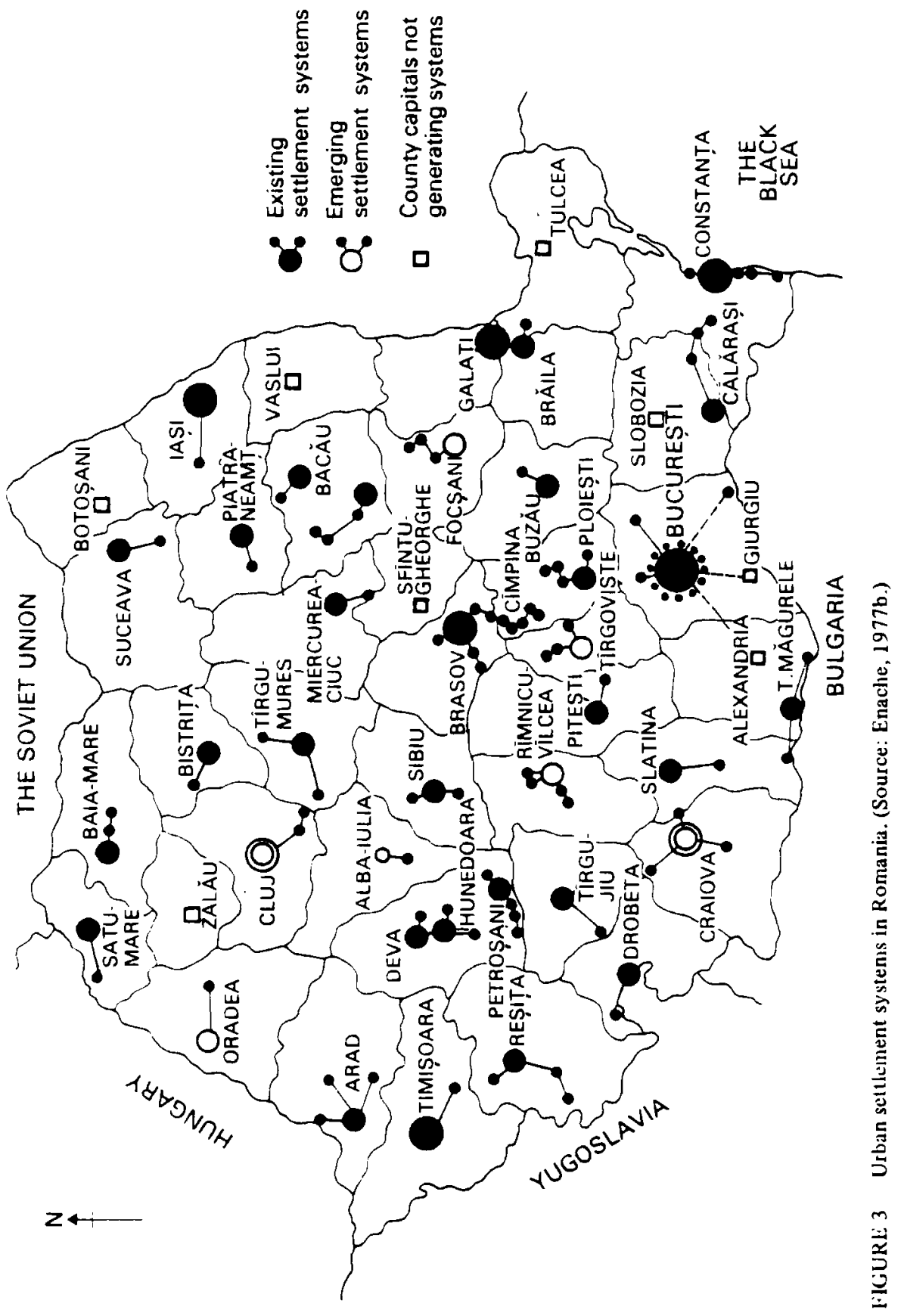


Romania to have nonadjacent urban cores. This means that, although the settiements in a cluster are functionally adjacent, they are physically not adjacent. The hectarage data for the FUR cores were computed accordingly.)

We added several more criteria (in addition to the ones for settlement clusters) for delineating FURs: the actual and potential commuting range, based on the pattern of spatial accessibility, as well as the established population size threshold of 50,000. (However, the rigorous application of the 50,000-population criterion would have resulted in the omission of several important regions of commuting oriented towards newly developed industrial centers: nameiy, Slatina (33), Vaslui (44), Călăraşi (24), Gh. Gh. Dej (6), and Petroşani (22) (Figure 4). In several cases two adjacent urban settlements with populations of over 50,000 each have been included in the same FUR: namely Brăila-Galaţi (11), Deva-Hunedoara (21), and Cluj-Turda (14).)

Secondary regionalization criteria used in the delineating procedure refer to other major types of regionally oriented spatial interaction (e.g. service linkages and interrelations) based on the structure of local administration whose spatial ranges, under planned-economy conditions, tend to be highly correlated (Korcelli, 1977). As in Poland, the introduction of supplementary criteria made it possible to delineate a set of FURs that exhaustively covers the whole national territory, even when a part of this territory is situated beyond the commuting sheds of large and medium-size urban centers. The study of present and emergent settlement clusters shows that it is possible to assume that the peripheral areas will eventually be pulled into the orbit of major urban centers. In many cases the commuting boundaries are coincident with the administrative boundaries (with some notable exceptions); this simplified the computation of size and population data for 1977 by allowing the direct use of census data.

Finally, two more criteria were taken into consideration in defining functional regions, namely, the role of individual cities as central places and potential growth centers and the potential population of urban places in the year 2000 as studied in several alternatives at the Institute of Planning, Housing, and Local Administration in Bucharest (ISLGC, 1977). According to these criteria, several more functional regions have been identified: Cîmpulung (4), Sighetu Marmaţiei (28). Bîrlad (45), Roman (32), Lugoj (42), Cîmpina (35), and Medias (49) (see Figure 4). The population estimates for the year 2000 for most of these settlements according to the national physical plan are $60,000-70,000$ people compared with their present populations of $35,000-45,000$.

To summarize, the steps taken in the identification of FURs in Romania fall into two broad categories: (1) exploratory assumptions and criteria and (2) normative inputs.

(1) The exploratory assumptions and criteria include the rank-size of urban places, the hierarchy of central places, the growth poles, the clusters of settlements with their defining criteria (size, relationships, central-place criteria, and commuting criteria) (the clusters of settlements delineate, in most cases, the FUR cores), and the FUR population threshold.

(2) The normative inputs are basically service linkages and their interrelation with the structure of local administration, regional equity considerations (i.e., the minimum gross annual industrial output per county to be reached by 1980 and by 1990), growth rates of relatively small but rapidly developing new industrial centers and the population potential of urban places in the year 2000 (indicative).

The resulting spatial units cover the whole national territory. As first-order units, 


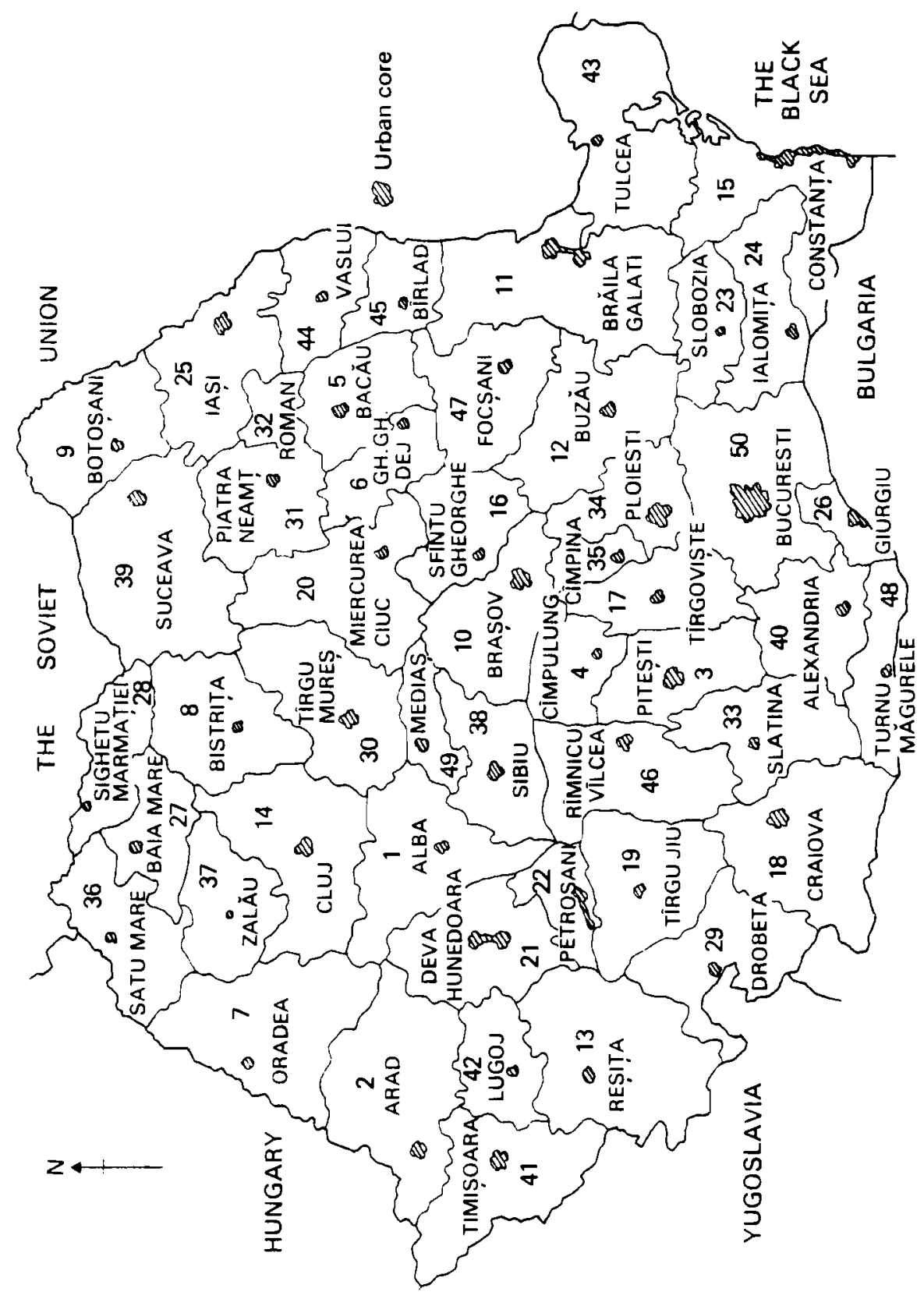


TABLE 1 Aggregated data for FURs in Romania, 1956-1977.

\begin{tabular}{llcrrr}
\hline Year & Division & $\begin{array}{l}\text { Minimum } \\
\text { population }\end{array}$ & $\begin{array}{l}\text { Maximum } \\
\text { population }\end{array}$ & $\begin{array}{r}\text { Average } \\
\text { population }\end{array}$ & $\begin{array}{r}\text { Average } \\
\text { area }\left(\mathrm{km}^{2}\right)\end{array}$ \\
\hline 1956 (February 21) & Core & 9,632 & $1,177,661$ & 73,274 & - \\
& Periphery & 54,357 & 656,703 & 276,515 & - \\
& Region & 100,829 & $1,834,364$ & 349,789 & 4,750 \\
1966 (March 15) & Core & 12,443 & $1,366,684$ & 96,027 & 29 \\
& Periphery & 47,500 & 697,263 & 286,036 & 4,721 \\
& Region & 133,496 & $2,063,947$ & 382,063 & 4,750 \\
1977 (January 5) & Core & 30,122 & $1,807,044$ & 140,997 & 24 \\
& Periphery & 43,301 & 790,806 & 290,191 & 4,726 \\
& Region & 152,500 & $2,957,850$ & $\mathbf{4 3 1 , 1 8 8}$ & $\mathbf{4 , 7 5 0}$ \\
\hline
\end{tabular}

their pattern is relatively close to the present administrative division into 39 counties ("judet"). The basic objective of the 1968 reform was, however, to create regions with a high degree of internal coherence with respect to the economy, settlement networks, and commuting fields. (See Enache et al., 1978a, 1978b for a more complete description of the regionalization procedure adopted.)

There is a strong correlation between the percentage of the population that is urban and the level of economic development of the FURs. The least urbanized region in the carly 1970s was Bistriţa (8) with $17.8 \%$ of its population urban while the most urbanized region was Deva-Hunedoara (21) with $68.0 \%$ of its population urban. Deva-Hunedoara has experienced a long tradition in urban living, with its early extractive and metallurgical industries. In general the highest percentages of urban population were recorded in highly industrialized regions (Braşov (10), Deva-Hunedoara (21), Sibiu (38), Constanţa (15)) while the lowest percentages were recorded in regions whose economy is still predominantly agrarian (Botoşani (9), Zalău (37), etc.).

\section{RECENT SPATIAL POPULATION AND EMPLOYMENT CHANGES IN FUNCTIONAL URBAN REGIONS $(1956,1966,1977)$}

The data gathered by the authors for the Human Settlement Systems Task of the International Institute for Applied Systems Analysis refer to the population of the 50 FURs defined at the 1956, 1966, and 1977 censuses, by core and region, employment (total, primary, secondary, and tertiary) at the 1956, 1966, and 1977 censuses, by core and region. and the sizes in square kilometers of cores and regions.

The published sources of the data were the 1956 and 1966 censuses and the 1977 Statistical Yearbook of Romania. The Yearbook offers preliminary population data from the 1977 census but the data only apply to the regional cores and to 20 regions which happen to be coincident with the respective counties of the present regional structure. Population data for the remaining 30 FURs were estimated by using a trend and correlation analysis.

Table 1 gives the aggregated data for the FURs in 1956, 1966, and 1977, i.e. the minimum population, the maximum population, the average population, and the average area of the cores, peripheries, and regions. It is worth noting that the average FUR in 
1977 had a population of 431,188 and was comparable in size to functional regions in other countries: 480,809 in France, 448,787 in Hungary, and 379,204 in the United Kingdom (Gordon and Kawashima, 1978).

Table 2 shows the population growth and distribution within the FURs by core, periphery, and region; it also shows aggregated data computed for size categories of the urban cores in 1977. The eight size categories follow roughly a logarithmic scale (populations of $50,75,100,150,200,500$ and 1000 thousand) in order to be compatible with international data.

The population increase for the region as a whole was in all cases (size categories) higher in the second decade of our analysis, i.e. 1966-1977. The population increase in the core was positive in all cases but one category of cores (population of 100,000 150,000 in 1977) experienced a slower increase in the second decade. The relatively high rates of natural population increase explains the general increase in the population living in the periphery al though the growth rates slow down somewhat in the second decade (1966-1977) and even became negative for the periphery of regions having a core population of $75,000-150,000$. The population share of the cores increased for all size categories, the most dramatic increase being from $26.59 \%$ in 1956 to $42.33 \%$ in 1977 for the $200,000-500,000$ category.

Table 3 shows the total employment shifts in the period 1956-1977 by core and region disaggregated by the same size categories of the core. The most notable shift of total employment $(141.21 \%)$ in the period 1956-1966 took place in cores having a population of 200,000-500,000, while the highest employment slift for the total FUR (121.78\%) occurred in Bucharest during the period 1966-1977.

Table 4 gives the disaggregated employment shifts (by primary, secondary, and tertiary activities) in the period 1956-1977 by core and region. (n all cases primary employment experienced a sharp decrease, which was accentuated in the second period 1966-1977. In the last ten years primary employment in the FURs declined to $65 \%$ of the initial (1966) level. The shift in secondary employment was higher in 1966-1977, in some cases reaching $170 \%$. It was matched by the increase in tertiary employment, although the figures are in most cases lower (around 130\%) with the exception of the smallest cores where the shift was $191.99 \%$. One explanation of this last case is of course the particular efforts to provide services for this category of urban cores.

The total population and total employment shifts by core size of FURs are illustrated in Figure 5, while the disaggregated employment shifts by core size of FURs during the same period (1956-1977) are shown diagrammatically in Figure 6.

An interesting conclusion can be drawn from an application of the balance indicator (presented in Section 1) to the FUR data. The smooth trend towards equalization is no longer clear (Figure 7). The indicator shows a certain imbalance of the regional distribution of primary employment over the period 1956-1977 which influences the change of total employment. However, activities which can be fully controlled through economic policy and economic investments show a more balanced distribution in 1977 than in 1966 and 1956; this applies to employment in the secondary and tertiary sectors. The distribution of secondary-sector employment over the 50 FURs shows a dispersion of $67.5 \%$ in 1956 , $47.8 \%$ in 1966 , and $43.1 \%$ in 1977 , while the distribution of tertiary-sector employment is smoothed (with a dispersion index of $42.1 \%$ in $1956,37.4 \%$ in 1966 , and $31.3 \%$ in 1977) through the effort to provide services in the less developed regions. 


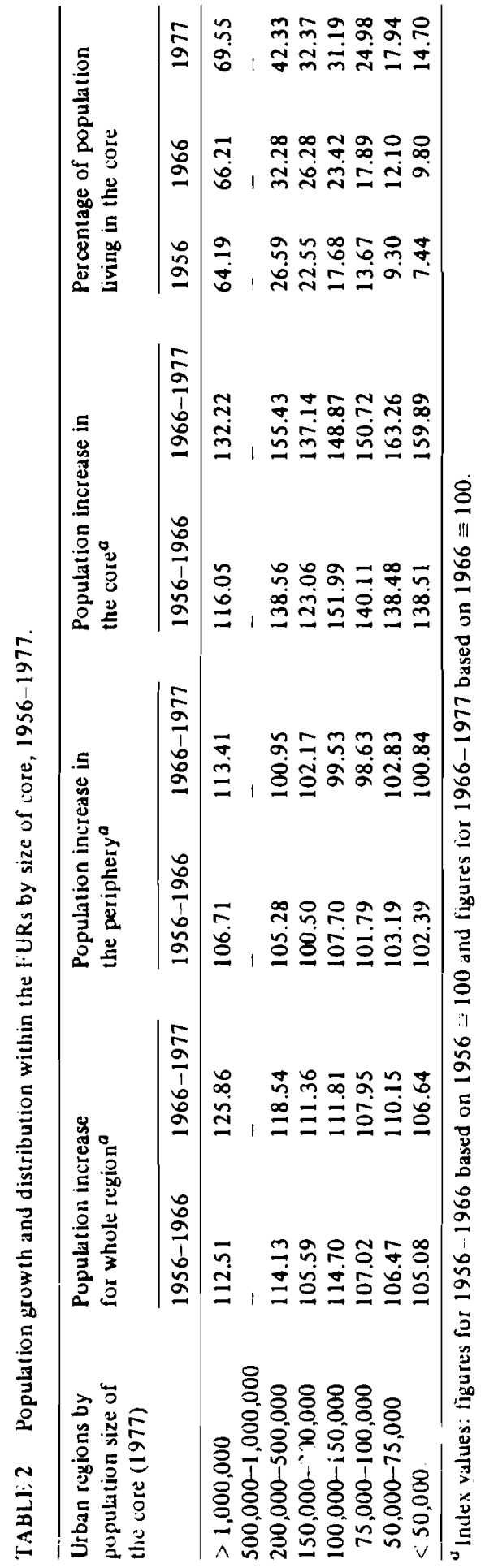


TABLE 3 Total employment shifts, by core and region, 1956-1977.

\begin{tabular}{|c|c|c|c|c|c|c|c|c|}
\hline \multirow[t]{2}{*}{$\begin{array}{l}\text { Urban regions by } \\
\text { population size } \\
\text { of the core }(1977)\end{array}$} & \multicolumn{2}{|c|}{$\begin{array}{l}\text { Total employment } \\
\text { in the core }\end{array}$} & \multirow{2}{*}{$\begin{array}{l}\text { Total } \\
\text { employ- } \\
\text { ment shift } \\
\text { in the core } \\
1956-1966\end{array}$} & \multicolumn{3}{|c|}{$\begin{array}{l}\text { Total employment } \\
\text { in the region } \\
\text { (thousands) }\end{array}$} & \multicolumn{2}{|c|}{$\begin{array}{l}\text { Total employment } \\
\text { shift in the region } b\end{array}$} \\
\hline & 1956 & 1966 & & 1956 & 1966 & 1977 & $1956-1966$ & $1966-1977$ \\
\hline$>1,000,000$ & 621,127 & 701,255 & 112.90 & 1,040 & 1,100 & 1,340 & 105.77 & 121.78 \\
\hline $500,000-1,000,000$ & - & - & - & - & - & - & - & - \\
\hline $200,000-500,000$ & 439,608 & 620,799 & 141.21 & 2,040 & 2,157 & 2,366 & 105.75 & 109.65 \\
\hline $150,000-200,000$ & 204,106 & 245,787 & 120.42 & 1,143 & 1,060 & 1,123 & 92.75 & 105.91 \\
\hline $100,000-150,000$ & 172,698 & 233,673 & 135.30 & 1,220 & 1,305 & 1,280 & 106.95 & 98.04 \\
\hline $75,000-100,000$ & 80,808 & 107,237 & 132.70 & 881 & 791 & 769 & 89.71 & 97.19 \\
\hline $50,000-75,000$ & 129,418 & 177,732 & 137.33 & 1,972 & 1,912 & 1,805 & 96.92 & 94.38 \\
\hline$<50,000$ & 121,944 & 162,614 & 133.35 & 2,149 & 2,023 & 1,981 & 94.14 & 97.87 \\
\hline
\end{tabular}

${ }^{a}$ The ratio of total employment in cores in 1966 to the total employment in cores in 1956, expressed as a percentage.

${ }^{b}$ The ratio of total employment in regions in 1966 (1977) to total employment in regions in 1956 (1966), expressed as a percentage.

TABLE 4 Disaggregated employment shifts, by core and region, 1956-1977.

\begin{tabular}{|c|c|c|c|c|c|c|c|c|c|}
\hline \multirow{4}{*}{$\begin{array}{l}\text { Urban } \\
\text { regions by } \\
\text { population } \\
\text { sizc of the } \\
\text { core }(1977)\end{array}$} & \multirow[t]{4}{*}{ Division } & \multicolumn{6}{|c|}{ Disaggregated employment shifts ${ }^{a}$} & \multirow{3}{*}{\multicolumn{2}{|c|}{$\begin{array}{l}\text { Percentage of } \\
\text { secondary } \\
\text { employment } \\
\text { in the core }\end{array}$}} \\
\hline & & \multicolumn{3}{|c|}{$1956-1966$} & \multicolumn{3}{|c|}{$1966-1977$} & & \\
\hline & & \multirow[b]{2}{*}{ Primary } & \multirow[b]{2}{*}{ Secondary } & \multirow[b]{2}{*}{ Tertiary } & \multirow[b]{2}{*}{ Primary } & \multirow[b]{2}{*}{ Secondary } & \multirow[b]{2}{*}{ Tertiary } & & \\
\hline & & & & & & & & 1956 & 1966 \\
\hline$\because 1.000,000$ & $\begin{array}{l}\text { Core } \\
\text { Region }\end{array}$ & $\begin{array}{l}22.65 \\
77.70\end{array}$ & $\begin{array}{l}120.42 \\
135.83\end{array}$ & $\begin{array}{l}112.76 \\
108.29\end{array}$ & 69.95 & 150.54 & 129.58 & 51.59 & 55.03 \\
\hline $500,000-$ & Core & - & - & - & - & - & - & & \\
\hline $1,000,000$ & Region & - & - & - & - & - & - & & \\
\hline $200,000-$ & Core & 80.05 & 146.42 & 140.59 & 66.73 & 171.94 & 136.43 & 58.87 & 61.04 \\
\hline 500,000 & Region & 84.70 & 155.07 & 138.42 & $00.1 \mathrm{~J}$ & 111.74 & $100.4 \mathrm{~J}$ & Jo.0 & 01.04 \\
\hline $150,000-$ & Core & 81.33 & 123.40 & 123.82 & 78.65 & 15211 & 130.23 & 61.93 & 40.68 \\
\hline 200.000 & Region & 71.95 & 138.07 & 126.28 & & & & & \\
\hline $100,000-$ & Core & 71.06 & 138.46 & 143.67 & 60.51 & 1 & 27.67 & 61.97 & 3.41 \\
\hline 150,000 & Region & 85.20 & 149.93 & 165.15 & 00.31 & 1 & 127.07 & 01.91 & 0.41 \\
\hline $75,000-$ & Core & 72.30 & 136.53 & 138.51 & 6173 & 152.56 & 13470 & 18 & 809 \\
\hline 100,000 & Region & 75.82 & 115.90 & 135.29 & 01.13 & 152.50 & 134 & 8 & 8.09 \\
\hline $50,000-$ & Core & 82.77 & 164.33 & 136.51 & 6268 & 171.52 & 140.40 & 52.17 & 62.43 \\
\hline 75,000 & Region & 84.67 & 161.27 & 135.52 & & & & 32.11 & 02.43 \\
\hline$<50,000$ & Core & 82.13 & 170.31 & 136.32 & $67 . ., 0$ & 170.85 & 191.99 & 39.13 & 50.27 \\
\hline & Region & 80.26 & 153.36 & 148.22 & $01 . .6$ & & & & \\
\hline
\end{tabular}

\footnotetext{
${ }^{a}$ Ratio of sectoral employment at end of period (1966 or 1977) to sectoral employment at the
} beginning of period (1956 to 1966), expressed as a percentage. 


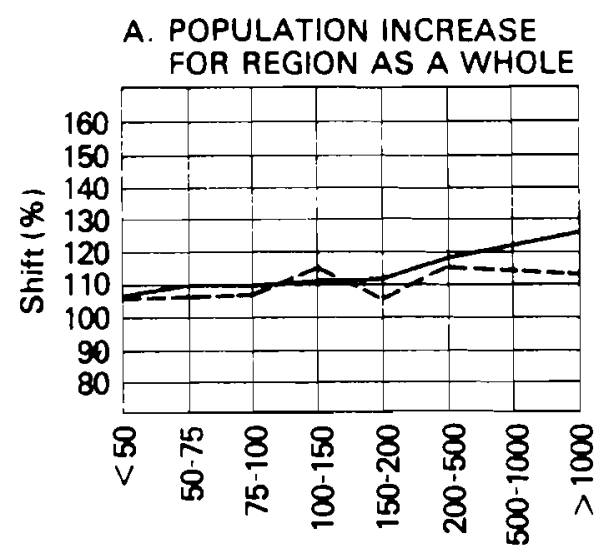

Core size of FUR $\left(\times 10^{3}\right)$

C. TOTAL EMPLOYMENT SHIFT IN THE REGION

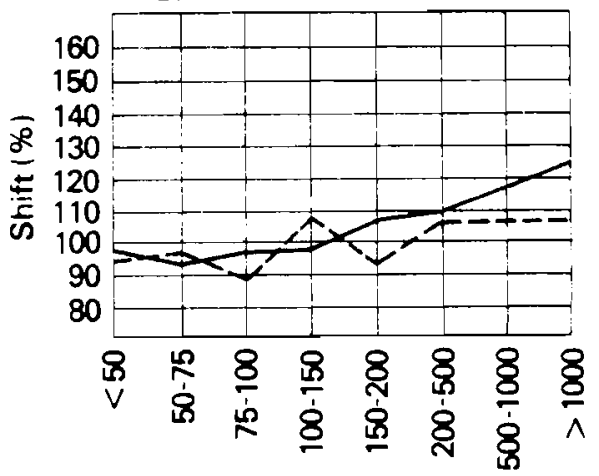

Core size of FUR $\left(\times 10^{3}\right)$
B. POPULATION INCREASE IN THE CORE

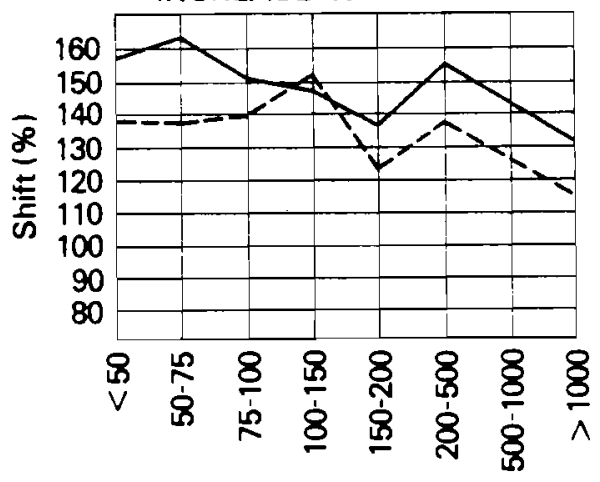

Core size of FUR $\left(\times 10^{3}\right)$

D. TOTAL EMPLOYMENT SHIFT IN THE CORE

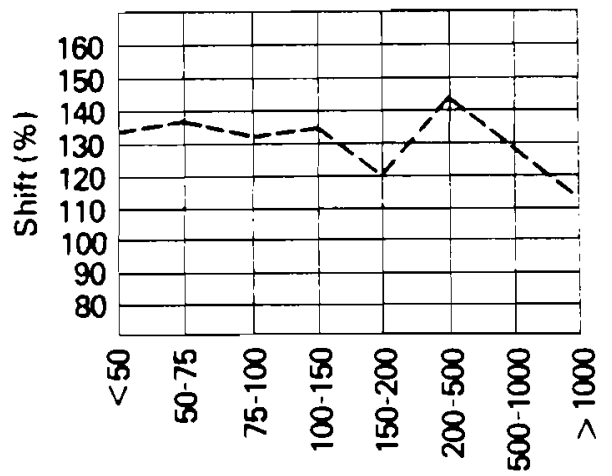

Core size of FUR $\left(\times 10^{3}\right)$

FIGURE 5 Population and total employment shifts in the period 1956-1977.

Another conclusion can be drawn from a comparison of the balance indicator for disaggregated employment by FURs and counties. With one exception (i.e. tertiary employment), the figures are higher for the FURs. When looking at this data, however, we have to bear in mind that there are 39 counties (plus Bucharest) while there are 50 FURs. This means that, in addition to the county-capital data (which roughly correspond to the FUR core data), the FUR data include second-order settlements located within some of the 39 counties.

Consequently the diagrams in Figure 7 show a tendency for grow th to be directed mostly to the county capitals and less to the second-order cities within the respective counties, the implied planning assumption being that development and progress will diffuse within a county. The result is that, while counties converge in their aevelopment and become more equally developed, imbalances can be expected at the intracounty level (as revealed by analysis of the 50 FURs) and should be dealt with accordingly (e.g. at 


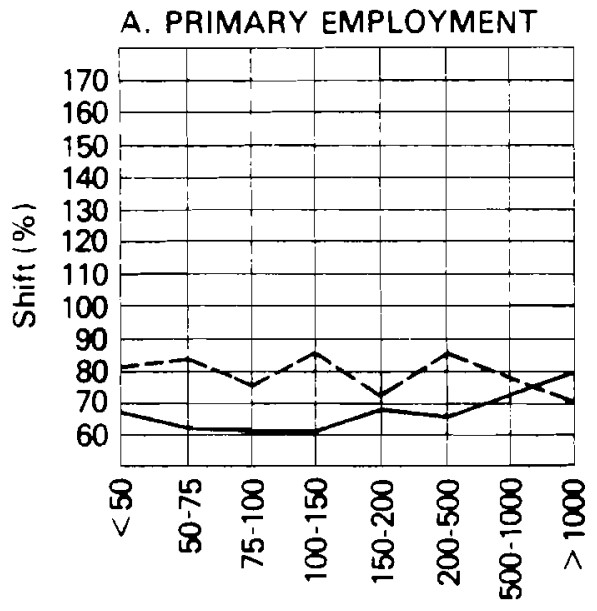

Core size of FUR $\left(\times 10^{3}\right)$

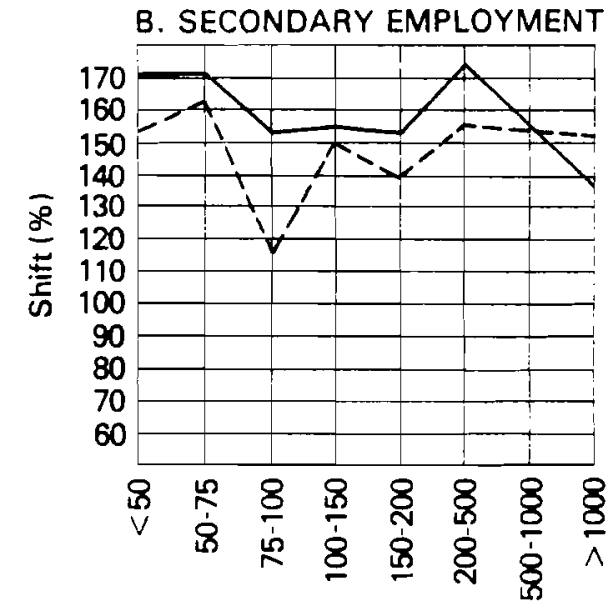

Core size of FUR $\left(\times 10^{3}\right)$
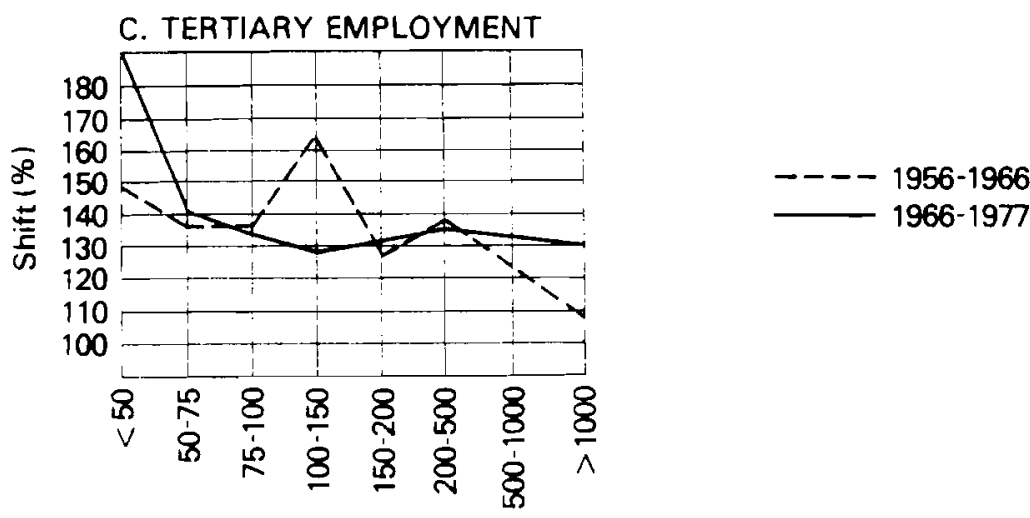

Core size of $\operatorname{FUR}\left(\times 10^{3}\right)$

FIGURE 6 Disaggregated employment shif ts in the period 1956-1977, by region.

local or county level). This is an interpretation of the greater dispersion from the arithmetic mean of population and employment in FURs than in counties. However, it should be noted that the analysis extends only to the data available so far for the FURs (e.g. population and disaggregated employment) and no comparison is possible yet between FURs and counties with regard to other indicators on which the data are abundant for counties.

A notable exception in the pattern of employment change among FURs and counties is tertiary employment (Figure 7) where the dispersion from the mean is higher (both in 1956 and in 1977) in counties than in FURs, which implies a highly balanced distribution of tertiary employment at the level of FURs. 


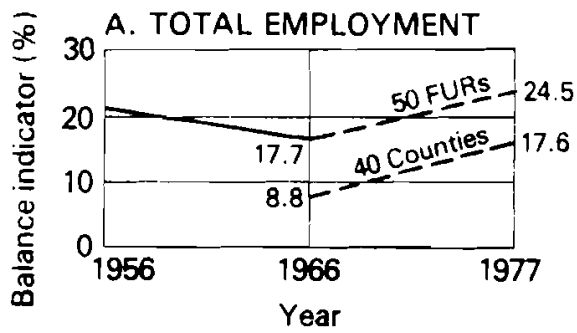

B. PRIMARY EMPLOYMENT
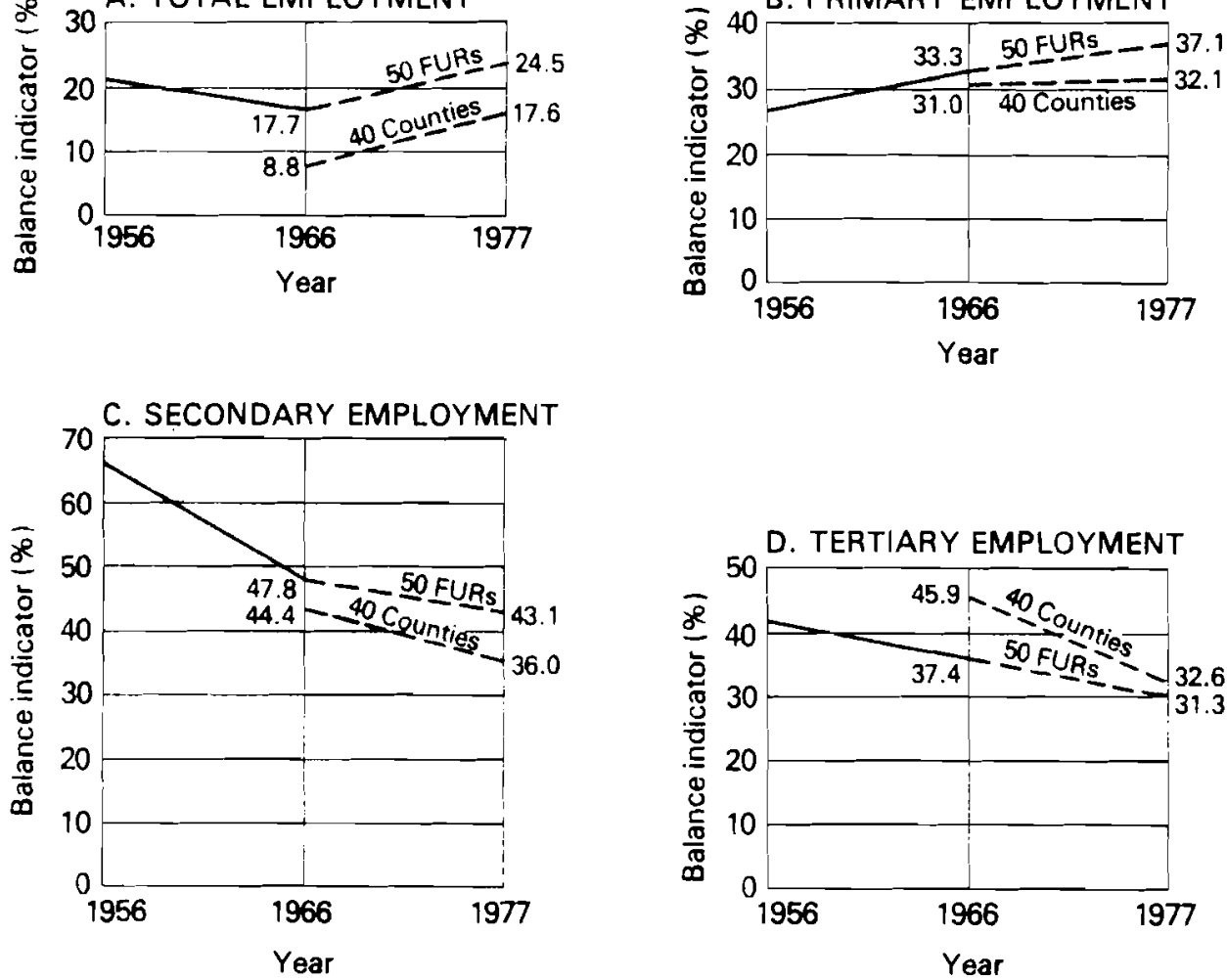

FIGURE 7 The balance indicator for total and disaggregated employment of counties and FURs in the years 1956, 1966, and 1977 (the 1977 figures are based on estimated data).

\section{PROSPECTIVE DIRECTIONS OF THE DEVELOPMENT OF HUMAN SETTLEMENTS IN ROMANIA}

The pattern of settlements in the year 2000 has been studied in alternatives which specify the size and functional category of each settlement, its economic and social structure, as well as its role in the region. Figure 8 shows several alternatives for future development of the settlement network. Altemative A represents an extrapolation of the present situation. The correlation coefficient for alternative A $(0.978)$ is higher than the coefficients for the period 1941-1975. Alternatives 1 and 2 are hypothetical and their respective correlation coefficients are 0.992 and 0.988 . The higher coefficient for alternative 1 is basically the result of the provision in that case for six cities with a population of $500,000-600,000$ which would fill the gap between the capital and the second-ranking cities of the country. In alternative 2 the six cities would only reach $350,000-400,000$ people each (Enache, 1977a).

We agree with Dziewoński (1972, p. 82) that, although it is impossible to define on the basis of rank-size distributions the relations and interdependences of individual set tlement units, it is possible to discuss the consequences of the growth (even the planned 


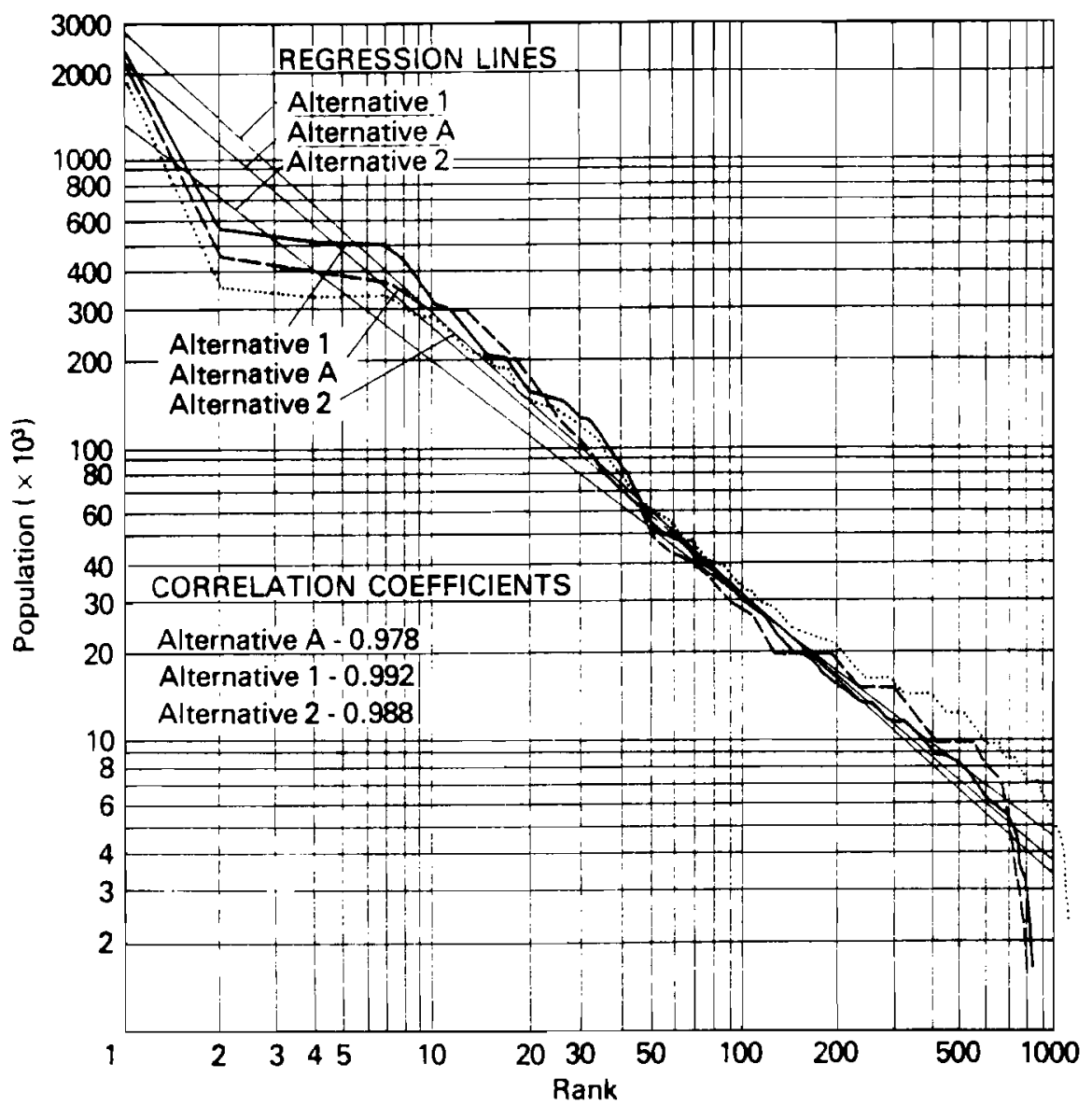

FIGURE 8 The rank-size distribution of Romanian urban settlements in the year 2000. (Source: Enache, 1977a, p. 58.)

growth) of an individual city or settlement unit for the whole system, taking into account the preservation or disruption of the whole system.

Finally, another important determinant of the future settlement network is the decision to transform (in the next 15-20 years) some 300-350 rural settlements into urban settlements. These "semiurban" places are chosen following criteria based on natural and human resources, geographical location, linkages within the region, accessibility, and housing provision (ISLGC, 1975). The location of new industrial and agricultural activities in these settlements will give them a mixed industrial-agrarian character. Their population is planned to be over 5,000 and they are expected to act as service centers for four or five nearby villages situated within a radius of $15-20 \mathrm{~km}$.

Romania's strategy for controlling and guiding urbanization is based on a consistent conceptio. 1 regarding the possibility of decisively influencing, under the conditions of a planned economy, the structure, size, and regional location of the settlement network by the allocation of activities and by guiding social processes, of which migration and commuting are of major importance. 


\section{REFERENCES}

Dziewonski, K. (1972). General theory of rank-size distributions in regional settlement systems: reappraisal and reformulation of the rank-size rule. RSA Papers, 29:73-86.

Enache, M. (1977a). Quantitative relationships in the settlement network. Arhitectura, No. 1.

Enache, M. (1977b). Urban agglomerations. Arhitectura, No. 4.

Enache, M. (1978). A balance indicator of the regional development. Revista Economică, No. 41 (October).

Enache, M., Holtier, S., Derer, P., and Stoenescu, L. (1978a). Delineating functional urban regions in Romania. The Institute of Architecture, Bucharest. March.

Enache, M., Stoenescu, L., and Derer, P. (1978b) Functional urban regions in Romania: basic data. The Institute of Architecture, Bucharest. June.

Gordon, P. and Kawashima, T. (1978). Human settlement systems: development processes and strategies. WP-78-23. International Institute for Applied Systems Analysis, Laxenburg, Austria.

Hansen, N. M. (1975) An evaluation of growth-center theory and practice. Environment and Planning, 7:821-832.

ISLGC (1975). Research for Establishing the Socioeconomic Conditions and the Measures to be Taken to Develop the New Urban Centers. ISLGC Project No. 266. Institute for Planning, Housing, and Local Administration, Bucharest.

ISLGC (1976). Papers for the National Physical Planning Program. Institute for Planning, Housing, and Local Administration, Bucharest.

ISLGC (1977). The National Settlement Network Study. Research project. Institute for Planning, Housing, and Local Administration, Bucharest.

Korcelli, P. (1977). An approach to the analysis of functional urban regions: a case study of Poland. RM-77-52. International Institute for Applied Systems Analysis, Laxenburg, Austria.

Parr, J.B. (1973). Growth poles, regional development, and central place theory. RSA Papers, $31: 175$.

Pred, A.R. (1976). The Interurban Transmission of Growth in Advanced Economies: Empirical Findings Versus Regional Planning Assumptions. RR-76-4. International Institute for Applied Systems Analysis, Laxenburg, Austria.

Stöhr, W. (1974). Interurban systems and regional economic development. Association of American Geographers Resource Paper, No. 26.

Thomas, E.N. (1967). Additional comments on population-size relationships for sets of cities. In W.L. Garrison and D.F. Marble (Editors), Quantitative Geography (Part I: Economic and Cultural Topics). Northwestern University Studies in Geography, No. 13. Northwestern University, Evanston, 1山inois. 


\title{
FUNCTIONAL REGIONS AND REGIONAL DEVELOPMENT IN HUNGARY
}

\author{
László Lackó \\ Division for Physical Planning and Regional Development, Ministry of \\ Building and Urban Development, Budapest (Hungary)
}

\section{INTRODUCTION}

This paper consists of four main parts. After this brief introduction, Section 2 describes procedures that have been adopted in the identification of Functional Urban Regions (FURs) in l Hungary and the delineation of their boundaries. Section 3 contains a brief characterization of the regions while Section 4 focuses on settlement trends as represented by changes in the population distribution and economic activity among, and within, the functional regions. (Sections 2,3 , and 4 are a revised and extended version of Chapters 2, 3, and 5 respectively of an earlier report by Lackó et al. (1978), which also included a detailed account of trends occurring within Hungarian urban regions during the 1960s.) Finally, in Section 5 the principles of urban and regional planning in Hungary are discussed together with their role in the evolution of settlement patterns.

\section{THE DELINEATION OF FUNCTIONAL URBAN REGIONS}

The regions were delineated partly by labor-force-attracting zones, partly by the general gravitational influences (services) of urban centers, and partly by the functional (hierarchical) situation of the central places. The urban labor-force-attracting regions are far from covering the whole territory of the country, but according to other calculations of attraction every settlement is linked to an urban center.

According to the population, employment, and commuting data of the 1970 census we delineated 23 regions (see Figure 1). This relatively high number is explained by the small number of cities and major centers and by the fact that for the greater part of Hungary the districts of gravitation of small and medium-size towns typically are only loosely interlinked. One can also see the strong polarization of the Hungarian economicspatial structure in the formation of the FURs. Lite main features are as follows.

The core areas of only four regions (Budapest (1), Miskolc (4), Györ (16), and Pécs (23)) are formed by urban agglomeration; the centers of other regions are single 


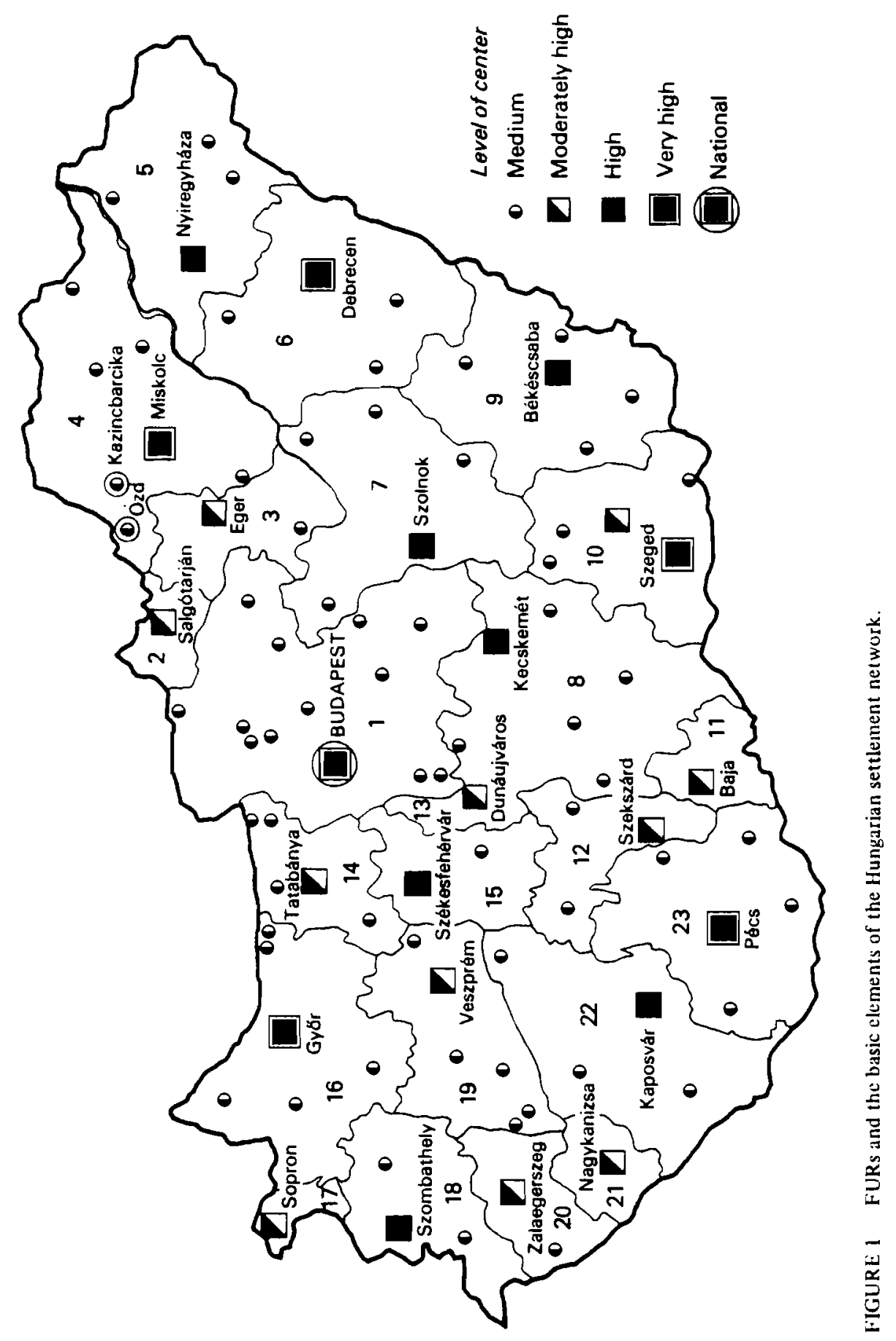


urban settlements. Two cities on the Hungarian Plain, Debrecen (population 190,000) and Szeged $(160,000)$, might yet agglomerate the neighboring settlements, but to a lesser degree.

The Budapest region emerges very conspicuously from the rest. The core area - the Budapest agglomeration - taken in the strictest sense has a population of 2.3 million, while the whole region has a population of 3 million. The core of the second-largest region (Miskolc) has a population that hardly exceeds 400,000 , while the whole region has a population of 0.75 million.

The industrial-economic centers of the country were formed in the northern districts. Of the 23 regions, five are located along the northern border (the Budapest, Miskolc, Györ, Salgótarján, and Ta tabánya regions) and comprise 4.7 million inhabitants, i.e. $45 \%$ of the population. The territorial concentration of industrially employed active earners is similarly strong; there is a very strong interrelation between the geographic distribution of industry and that of population. All the large cities are industrial; the Hungarian capital up to the mid-1960s was the largest industrial concentration in all eastem central Europe. More people worked in Budapest industrial enterprises than in those of the whole Upper Silesian industrial district of Poland.

In four regions the share of industrially employed earners exceeds $50 \%$ of the active population. The Budapest district is situated in their center. The other three - centers of mining, metallurgy, and energy production - maintain close cooperation with the industry of the capital. A highly specialized industrial ring surrounds the capital, carrying out high-level tertiary functions. In the relatively small territory of the four regions exactly half of the industrially employed population of the country is concentrated.

There are no significant industrial-urban agglomerations whose gravitation extends to considerable territory in the central and southern parts of the country. Of Pécs, Szeged. and Debrecen (cities with 160,000-190,000 inhabitants), only Pécs has a definite zone of agglomeration; in the other two cities the agglomeration process is still taking shape. In the Pécs district there are many functional zones with small populations and areas that are linked to relatively small centers. The economic-spatial structure of the Hungarian Plain and southwest Transdanubia is characterized mainly by regions which do not amalgamate into higher territorial units and which maintain very loose economic relations with each other. The center of such a region frequently links a large part of its functional zone to itself not by economic and labor-force attraction but by administrative, health, and educational gravitation.

The ratio of the population of the core to that in the attracted territories is very divergent. In the most highly developed regions (Budapest and Miskolc) the population of the core area is much larger than that of the attracted territory. In many respects these cores attract the whole territory of the country or several regions. In contrast, some smaller towns of the Hungarian Plain (e.g., Békéscsaba with 62,000 or Szolnok with 72,000 inhabitants) have large territories of gravitation but their intensity of gravitation is insignificant. In the Plain districts that are industrialized to a lesser degree, and also in the central and southwest districts lacking significant urban centers, a large part of the population is outside the influence of regular and strong urban gravitation.

In delineating the urban regions we took account of the results of a computation of functional spheres of influence obtained in another research project. The sphere of influence of the settlements at the top of the settlement network hierarchy was determined 
with the help of a type of interaction model. From the methodological point of view we treated the work of Hansen (1975) as a starting point. The interaction of centers of the highest level was computed so that factor values corresponded to their population size. The variables used in factor analysis express the size, importance, and "capacity" of the settlements (the number of inhabitants, the number industrially employed earners, the number of retail shops, the hotel capacity, the number of telephone receivers, and the seating capacity in cinemas). A more detailed evaluation of the results is to be found in the study by Lackó (1976).

The spheres of influence of the centers of highest level are shown in Figure 2. It is noticeable that they are of very different sizes. Among the smallest are Hódmezövásárhely, Sopron, Eger, and Salgótarján, while the largest (apart from Budapest) are Miskolc, Debrecen, Györ, and Nyiregyháza. It is obvious that the formation of the "borders" depends primarily on the situation of the settlements with respect to each other; however, the delineation conceals other significant phenomena. Thus, for instance, the northem boundary of the sphere of influence of Pécs can be delineated only very conditionally, which reflects the lack of a center in this area. The situation of the centers surrounding the capital deserves still more attention. Here circles of small radius (compared to the neighbouring settlements) were formed, and as a result the districts could not be closed in the direction of the capital. This is due to the differences in size and importance between Budapest and other centers. (The factor value for Budapest was 11.183 , for Tatabánya 0.158 , for Székesfehérvár 0.271 , for Dunaujváros -0.003 , for Kecskemét 0.196, for Szolnok 0.275, for Eger 0.074, and for Salgotarján 0.037.) The results of the computation cannot be evaluated horizontally. Figure 2 should be regarded as if Budapest were a high platform and other centers were situated on a lower level; the "relief" is indicated by the small arcs.

The sphere-of-influence considerations helped in the delineation of urban regions and served as additional data for the solution of disputed questions.

\section{MAIN CHARACTERISTICS OF THE URBAN REGIONS}

The regions can be divided into three groups. The first consists of Budapest itself. The second contains the large urban regions: 4 (Miskolc), 6 (Debrecen), 10 (Szeged), 16 (Gyor), and 23 (Pécs). The third includes the remaining centers which are mediumsize towns. This group can be divided into subgroups: the heavily industrialized urbanized centers (e.g., 14 (Tatabánya) and 19 (Veszprém)) and poorly developed regions whose centers have an administrative and service character rather than economic gravitation.

\subsection{The Budapest Region}

With its size and dynamism the capital plays an outstanding role in the economicspatial structure of the country. The considerable decline in the number of industrially employed earners in recent years does not mean that the significance of the capital has decreased since all the most important positions in political and economic life are still there. The overwhelming majority of industrial enterprises and the head offices of all the 


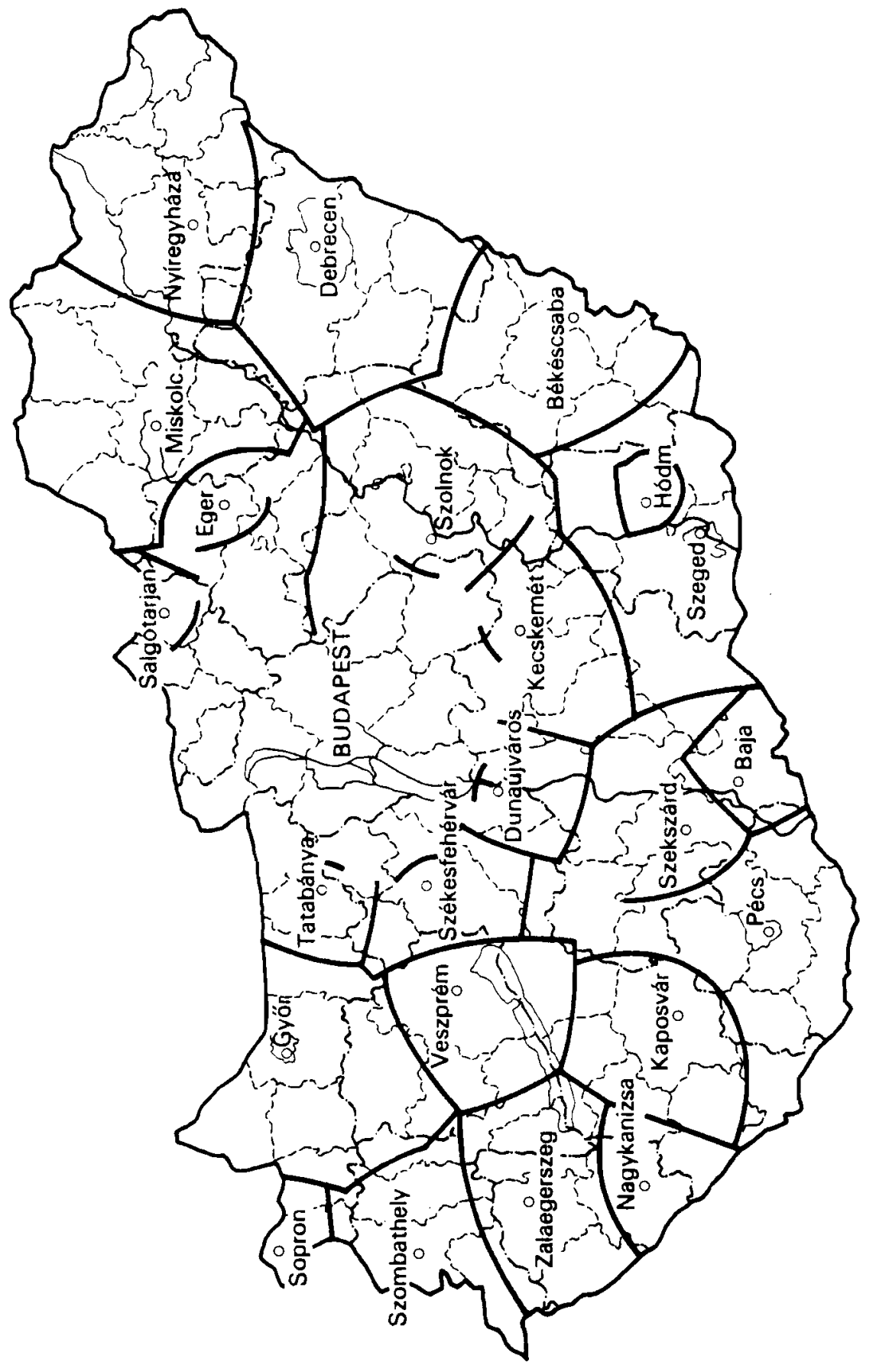


banks are in the capital. The electric machine-tool industry, precision engineering, and research and development in general are of outstanding importance in the industry of Budapest. About $30 \%$ of Budapest's industry exports its products abroad. Next to Moscow, the Hungarian capital is the largest of the European socialist capitals, its attractive force extending not only to the whole country but also in some respects beyond its borders.

The agglomerative ring that sticks closely to the capital belongs to the core area of the region. Originally it was the commuting zone of the capital but in the last two decades - owing mainly to the resettlement of Budapest's industry - its own industry has considerably developed and several dynamic satellite towns have been formed (Vác, Százhalombatta, and Gödöllo). The outer zone of gravitation of the region is also in the Budapest commuting region (approximately 220,000 persons commute daily to and from the capital). The population of the region shows rapid growth, partly because of the difficulties of moving into Budapest.

The agricultural and tourist functions of the region are important as well. The agriculture is highly intensive and the most advanced of the country. The capital-intensive development of agriculture was stimulated by the rapid decrease in the labor force. The high level of development was influenced by the great importance of the branches of intensive plant cultivation (flowers, vegetables, fruit, and viniculture), by favorable market possibilities, and by many branches of industrial activity flexibly accommodating to the needs of the market and maintaining cooperation with manufacturing industry. However, the natural conditions for agriculture are poor.

The most important center of tourism is Budapest itself; in 1975 it was the final destination of half of the 5 million foreign tourists who stayed in the country. The forestclad mountains north of the capital and the Danube Bend are also centers of tourism of national importance.

All the main railway lines and highways converge in Budapest, and the Free Port on the Danube is also located there. The very favorable transportation-geographic situation was of great importance in the rapid economic development that took place at the end of the 19th century and will probably strengthen the pre-eminence of Budapest in the future.

One can scarcely observe any suburban development in the Budapest agglomeration. The settlements of the commuters (the "dormitories") have the character of rural areas where agricultural activity among the population is widely spread.

\subsection{The Large-City Regions}

Three of the large urban settlements have traditional industrialized-urbanized core areas; the two Plain regions have preserved much of their rural past. Of the old industrial regions, two (Pecs and Miskolc) grew from their background of mining and energy production. In the past 20 years their production structure has been substantially enlarged; nevertheless, it is still rather lopsided, with manufacturing industry being insufficiently developed. In contrast, the core area of the Györ region is characterized by manufacturing industry. Although the central cities are not really large (Miskolc has 200,000, Pécs 165,000 , and Györ 120,000 inhabitants) they are quite dominant. 
The structure of the Miskolc region is peculiar. Its core area is formed by the second-largest industrial district in the country, situated in the valley of the Sajo river from the border to the Tisza river. The industrial zone is the main metallurgical and chemical district of the country. Almost without transition, the area of gravitation surrounding the core is one of the most underdeveloped zones of the country, with backward agriculture, small villages that are becoming depopulated, and poor transportation. Only the fertile southern agricultural zone is able to maintain some small towns.

Pécs and the surrounding mining district make up the core area of the Pécs region. The tertiary functions of Pécs are important. From medieval times onward it has been a cultural center; its university was founded in 1366 . Its manufacturing base is characterized by traditional light industry and there is a lack of dynamic modern branches of industry. The development of the city is mainly due to its being the organizational center of this important mining (anthracite and uranium ore) and tourist region. In the long run however, these functions will not be sufficient.

The core area of the Györ region (the Györ agglomeration) is one of the oldest industrial urban centers. Its development has been stimulated by its location halfway between Budapest and Vienna. Because of early industrialization, light industry is very important in its structure. Gyor's industry remained untouched by the great wave of industrialization immediately following World War II. However, expansion of the industrial base followed a little later. Mining and metallurgy were the first beneficiaries of these changes; since the 1960s Györ has received high priority in the program for road-vehicle production (lorries, dumpers, and various types of engine); this has strongly influenced the development of the whole city. Its tertiary functions, which for a long time were of little economic importance, have also started to develop. Following vigorous in-migration, the city has grown younger; the natural growth of the population is the highest of all Hungarian cities, exceeding twice the national average.

The small-town network of Gybr's sphere of influence is well developed. Agriculture is intensive; the region's stockbreeding has for decades been the most advanced in the country. Further advantages are assured by its proximity to Vienna and Bratislava

transit between Budapest and these cities (most of it passing through Gyor) is considerable.

The development and intemal territorial structure of the large urban regions of the Hungarian Plain - the Debrecen and Szeged regions - are somewhat peculiar. Both cities have for centuries been important trade and cultural centers of the Hungarian Plain. However, trade has been limited to agricultural products (grain, beef cattle) which did not accumulate large amounts of capital, and the cities remained almost completely untouched by capitalist development. In the period preceding World War II only an insignificant amount of industry settled there, with the foodstuff industry playing the dominant role. The administrative borders of the cities included a fair amount of agricultural territory, and the majority of their populations even as late as the period between the two World Wars was occupied with agriculture. The tertiary functions and cultural life of these "peasant cities" were, however, surprisingly developed: both cities have universities and research institutes of internatioral reputation, and literary, theatrical, and musical life is active.

Beginning in the 1960s, rapid development followed the stagnation of the one-anda-half decades after World War II. Considerable amounts of modern industry were located 
in the cities, their tertiary functions were strengthened, and the population rapidly increased. However, these still basically rural cities were unable to employ the surplus labor force of their sphere of influence since they themselves disposed of considerable surplus labor, which was absorbed first by the newly settled industry.

There are relatively many medium-size towns in the spheres of influence of Debrecen and Szeged, some of which have developed like "rural cities". For decades their population has stagnated, and in some cases has diminished. The region influenced is mainly agrarian. The Debrecen region is surrounded by an extensive agrarian belt with Debrecen as an island within it. The spatial structure of the Szeged region is better graduated and less dominated by the core city: the small towns are more important and the agriculture more intensive.

\subsection{The Regions of Medium-Sized Towns}

The districts belonging to the third group of urban regions can be divided into three parts according to their common internal features. The first part includes districts with heavy industry, relatively small area, and a homogeneous economic structure (the Salgótarján (2), Dunaujváros (13), Tatabánya (14), and Nagykanizsa (21) regions). Next there are mutually similar regions where the influence of the center, whilst not in dispute is administrative only. In this case each region is formed by a county and its administrative center; because of the weakness of any other observable attracting effect it would be unreasonable to split the counties (see the Nyiregyháza (5), Szolnok (7), Kecskemét (8), Bekescsaba (9), and Kaposvár (22) regions). The level of development of these mainly agrarian regions is rather low. Finally, there are the medium-sized urban districts that have been formed largely on the basis of their industrial production functions, with relatively strong urban gravitation (the Eger (3), Székesfehérvár (15), Szombathely (18), Veszprem (19), and Zalaegerszeg (20) regions).

The importance of commuting in various cities is illustrated in Table 1 . Note that this coefficient is only loosely related to the economic character of the cities since there are industrial centers with high and with low levels of commuting. A more definite interrelation can be seen in the fact that commuting is generally less important in the large cities than in settlements with small populations. There is, however, an exception:

Kecskemet, one of the medium-size towns, shows the lowest level of commuting of all the urban settlements.

Obviously this picture is due partly to the fact that the evaluation was carried out according to administrative boundaries. Thus intratown commuting does not figure in the commuting data; for towns with large territory (e.g., Kecskemét), relatively fewer, and for towns of small territory relatively more, commuters are taken into consideration.

The central cities of the urban regions are characterized by a fairly sizable positive commuting difference. The only exception is a subcenter of ${ }_{2}$ egion 4 , Kazincbarcika: there the share of out-commuters exceeds $10 \%$. Ins fact is connected with the multicenter nature of the region and the strongly industrialized character of the district. 
TABLE 1 Daily commuters to and from the centers of urban regions, 1970.

\begin{tabular}{|c|c|c|c|}
\hline \multicolumn{2}{|c|}{$\overline{\text { Region }}$} & \multirow[t]{2}{*}{ In-commuters ${ }^{a}$} & \multirow{2}{*}{$\begin{array}{l}\text { Net commuters } \\
\text { (in-commuters minus } \\
\text { out-commuters) }^{a}\end{array}$} \\
\hline No. & Name & & \\
\hline 1 & Budapest & 15.8 & 14.2 \\
\hline 2 & Salgótarján & 40.5 & 37.2 \\
\hline 3 & Eger & 26.5 & 24.8 \\
\hline \multirow[t]{3}{*}{4} & Miskolc & 26.9 & 23.8 \\
\hline & Kazincbarcika & 35.8 & 23.5 \\
\hline & Ozd & 33.0 & 30.4 \\
\hline 5 & Nyiregyháza & 25.6 & 24.4 \\
\hline 6 & Debrecen & 17.4 & 14.7 \\
\hline 7 & Szolnok & 28.5 & 26.7 \\
\hline 8 & Kecskemét & 13.5 & 12.6 \\
\hline 9 & Békéscsaba & 22.0 & 21.4 \\
\hline 10 & Szeged & 23.9 & 19.9 \\
\hline 11 & Baja & 24.8 & 23.3 \\
\hline 12 & Szekszárd & 37.6 & 34.2 \\
\hline 1.3 & Dunaujváros & 25.0 & 24.0 \\
\hline 14 & Tatabánya & 21.0 & 18.5 \\
\hline 1.5 & Székestehérvár & 32.0 & 27.0 \\
\hline 16 & Gyơr & 33.5 & 32.1 \\
\hline 17 & Sopron & 23.0 & 20.5 \\
\hline 18 & Szombathely & 31.0 & 28.9 \\
\hline 19 & Veszprém & 32.0 & 28.0 \\
\hline 20 & Zalaegerszeg & 32.5 & 26.9 \\
\hline 21 & Nagykanizsa & 23.5 & 20.9 \\
\hline 22 & Kaposvár & 23.8 & 22.5 \\
\hline 23 & Pécs & 15.6 & 4.9 \\
\hline
\end{tabular}

${ }^{a}$ As a percentage of resident earnets.

\section{RECENT CHANGES IN THE URBAN REGIONS}

The 1970s proved to be a special era in the development of the Hungarian economy. During the period 1971-1975 the natural growth rate of the population about doubled (reaching $2.1 \%$ in five years) with the country having passed its demographic nadir. The territorial stability of the population further strengthened, and migration markedly diminished. The territorial concentration of the population almost ceased. For instance, during the period 1960-1970 the population diminished in seven counties whereas during 1971-1975 it diminished in only one; in 1970 the net "profit" of Budapest from migration amounted to $0.97 \%$ of the population whereas in 1975 it was $0.24 \%$. The great territorial shifts of population came to an end; only negligible alterations in the present geographic map of population can be expected in the future.

The main characteristics of the development of the urban network are the following. First, the growth of population in the large urban settlements has become independent of the development of industry; these settlements have entered a kinc a postindustrial phase. Second, the medium-sized towns continue to experience the highest rate of growth; however, the situation of the small urban settlements has also been released from 
its previous deadlock. The economic upturn in the small towns has been brought about mainly by the decentralized development of industry but service functions have been considerably amplified as well. The number and the influence of secondary local centers inside the FURs have also increased.

The number of permanent migrants has considerably decreased while the number of commuters has greatly risen - by $20 \%$ in five years. Some research workers consider the increase in commuting as an unfavorable phenomenon but in our view the unfavorable effects can be largely neutralized by developing transportation.

Important changes have occurred in the geographic distribution of the industrially employed population. The number of this sector of the population increased by only $1 \%$ during the 1970s. The changes in the industry of the Budapest region are very conspicuous. Although in the outer district of gravitation the industrially employed population somewhat increased it declined markedly in the core - by $12 \%$ in five years. Particularly significant was its decline in the capital where in ten years (1965-1975) it diminished by 120,000 . At the same time it continued to grow relatively rapidly in the industrially back. ward regions of the Hungarian Plain and South Transdanubia - by $16 \%$ in five years (and in region 5 (Nyiregyháza) by $37.4 \%$ ). As a result of this development in contrasting directions the share of the industrially backward regions in the industry of the country had increased by 1975 to $21 \%$ from $18.5 \%$ in 1970 , the share of the Budapest region having fallen back to $31.5 \%$ from the 1970 level of $40.1 \%$.

The decentralized territorial development of industry is due to two factors. First, in the contemporary system of economic management, industrial enterprises make independent decisions in many matters of development. As a result of the chronic lack of labor in Budapest the enterprises of the capital have established many factories in the urban and large rural settlements of the Hungarian Plain that dispose of a free labor force. Second, in order to spur more rapid development of the backward regions a central fund for territorial development was established in the State budget; the bulk of this fund has been used in the development of industry. Two-thirds of it has been used in four regions (Nyiregyháza (5), Debrecen (6), Szolnok (7), and Békéscsaba (9)) of the Hungarian Plain. Region 5 alone received half of the fund.

The main features of the territorial location of industry have also been formed. Further territorial dispersion is expected to slow down, with technical reconstruction coming into the spotlight. Coal mining can once again look forward to guaranteed development, thus improving the situation of the old industrial regions. (In region 2 (Salgotarján) during the period 1970-1974 the number of people employed in coal mining dropped by $30 \%$. Through accelerated development of other branches of industry and lowering of the pensionable age to 55 for miners, problems of unemployment were avoided in the region.) In the Tatabánya region (14), influenced by increases in the price of oil, decisions have been adopted to open new mines; in the long run this may happen in the Miskolc region (4) as well.

It will be possible to develop a new industrial center in the Szekszárd region (12) where the first atomic power station in the country is being erected on the Danube.

The districts of influence of several urban regions (e.g., Nyiregyháza (5), Békéscsaba (9), and Zalaegerszeg (22)) may preserve their agricultural character. Because of the rapid modernization of agriculture and the equalization of industrial and agricultural income levels this should cause no particular social problems, although it will be accompanied by 
TABLE 2 Percentage changes of the population in the urban regions, 1970-1975.

\begin{tabular}{|c|c|c|c|c|}
\hline \multicolumn{2}{|c|}{ Region } & \multicolumn{3}{|c|}{ Division } \\
\hline No. & Name & Core & Hinterland & FUR \\
\hline 1 & Budapest & +1.4 & +2.6 & +1.7 \\
\hline 2 & Salgótarján & +8.4 & -0.1 & +2.6 \\
\hline 3 & Eger & +12.4 & -2.0 & +1.4 \\
\hline 4 & Miskolc & +5.9 & +1.2 & +3.5 \\
\hline 5 & Nyiregyháza & +16.5 & +4.2 & +5.7 \\
\hline 6 & Debrecen & +9.8 & +2.6 & +4.8 \\
\hline 7 & Szolnok & +9.4 & +1.8 & +2.9 \\
\hline 8 & Kecskemét & +8.8 & 0.0 & +1.5 \\
\hline 9 & Békéscsaba & +7.3 & -0.01 & +0.9 \\
\hline 10 & Szeged & +4.6 & -0.9 & +0.9 \\
\hline 11 & Baja & +4.1 & -2.6 & -0.2 \\
\hline 12 & Szekszârd & +14.1 & -1.5 & +0.6 \\
\hline 13 & Dunaujváros & +17.2 & -1.9 & +6.7 \\
\hline 14 & Tatahánya & +7.5 & +2.1 & +3.2 \\
\hline 15 & Székestehérvár & +17.1 & -1.6 & +4.7 \\
\hline 16 & Gybr & +7.3 & +1.1 & +3.4 \\
\hline 17 & Sopron & +7.6 & -2.6 & +2.6 \\
\hline 18 & Szombathely & +13.6 & -1.9 & +1.7 \\
\hline 19 & Veszprém & +19.3 & +0.8 & +2.9 \\
\hline 20 & Zalaegerszeg & +17.2 & -3.8 & +1.3 \\
\hline 21 & Nagykanizsa & +11.7 & -2.9 & +2.7 \\
\hline 22 & Kaposvár & +10.1 & -1.7 & +0.3 \\
\hline 23 & Pécs & +3.4 & +0.7 & +1.9 \\
\hline
\end{tabular}

slow out-migration of the population. Large-scale agriculture has developed several related industrial and service activities that slow down rural out-migration.

On considering the changes in the population, interesting modifications can be seen (Table 2). Between 1970 and 1975 there was a slow increase in the population in the majority of the regions; in one region, however, a small decrease occurred. A deeper analysis shows a more differentiated pattern of change (see Table 2).

The general trend for the core areas is population growth ranging from $1.4 \%$ to 19.3\%. The fastest growth (15-19\%) can be found in the middle and eastern Transdanubian regions and in the northeastern corner of the country (Szabolcs-Szatmár county) where the natural population increase is very high and the planned industrialization process is characteristic of the period under discussion. The cores of these regions are single medium-sized cities, whose importance is generally increasing nowadays in Hungary. The slowest rate of growth (1.4\%) characterizes the Budapest agglomeration. Low rates of growth also occur in some of the southern regions (Szeged (10), Baja (11), and Pécs (23)) and in the Miskolc agglomeration. It is worth underlining that the two most strongly agglomerated regions excel in slow population growth; this trend is analogous to the population decrease in the highly urbanized regions of other countries.

With regard to the hinterland areas, 13 of the 23 regions and losing their population. The decrease is the biggest $(-2.6 \%$ to $-3.8 \%)$ in West Transdanubia. The growing $(2.1-4.2 \%)$ hinterland areas are those in the Great Plain and in the highly industrialized 
Budapest and Tatabánya regions. In a few regions (Székesfehérvár (15), Veszprém (19), Zalaegerszeg (20), and Nagykanizsa (21)) growth in the core is accompanied by a decrease in the hinterland; these regions are characterized by the predominance of centripetal migrations.

All except one (Baja (11)) of the FURs are characterized by a moderate overall increase in population. The highest growth rates have occurred in the Dunaujvaros heavy-industrial region (6.7\%), Szabolcs-Szatmár and Hajdu-Bihar counties, and the Székesfehervár region. In all these units industrial development has been very fast in the 1970s, although their initial levels of industrial development were different; SzabolcsSzatmár and Hajdu-Bihar belonged to the industrially underdeveloped regions while the other two were industrialized somewhat earlier. The lowest growth rates can be seen in two regions of the South Great Plain (Békéscsaba (9) and Szeged (10)) and in Somogy county.

5

\section{URBAN AND REGIONAL PLANNING AND POLICIES}

The objectives and tasks of spatial development, and the conditions of their realization, are determined by the general political and socioeconomic goals and requirements of the country. In accordance with the relevant government resolutions, provision should be made for (1) the efficient utilization of national economic resources and the resources of individual regions; (2) moderation of the material and cultural differences in living standards between individual regions by bringing the levels of employment, productivity, and supply nearer to each other; and (3) rational modernization of living conditions.

Tasks related to the regional distribution of forces of production include the following: (1) the reduction of disproportions in regional economic structure; (2) the development of regions of high industrial potential in order to achieve a rational level of concentration and an improvement in economic efficiency; (3) the efficient utilization of labor by spatially differentiated labor management; (4) the promotion of a regional and economic redistribution of labor and population; (5) (for the sake of the regional development of industry) modemization of the settlement structure, the intensification of cooperation, the complex utilization of raw-material and energy sources, the effective utilization of labor, and a joint use of infrastructure; (6) an increase in agricultural production primarily by intensive development of regions of high potential; (7) in regions of low agricultural potential, the development of types of farming which are not very capital-or labor-intensive; (8) provision for and modernization of direct communication links between regional centers; $(9)$ in commuting regions, the improvement of travel conditions; (10) the development of regional water-supply systems in order to meet evergrowing demands; (11) gradual provision for conditions facilitating a more equal regional distribution of human capital, and the development of major scientific, cultural, and educational centers in the peripheral regions; and (12) utilization of the economic and cultural potential of economic regions and settlements when locating industries that are particularly sensitive to the research and development base.

Tasks related to the realization of the social policy objectives of spatial development include (1) the reduction of supply-level differentials between settlements of the same function, size, and character; (2) the gradual elimination of housing shortages in 
every region of the country by the coordination of different housing-construction methods and forms; and (3) the further reduction of regional income differentials.

Tasks related to the coordination of the regional distribution of productive forces and of the development of settlements include (1) the selective development of industry in the Budapest region, emphasizing interindustry linkages and research and development activity; (2) the gradual solution of spatial conflicts in the Budapest region;(3) the selection of development centers and their expansion following the rules of dynamic economic development and concentration of industrial and infrastructural investments; (4) provision for the development of rural centers; and (5) the promotion of environmental protection.

The development scheme for the national settlement system has been centrally approved: the government adopted and published it as a resolution in 1971. The scheme outlines the desirable long-term aim (the structure of the settlement system for the year 2000) and indicates the ways in which it should be implemented.

The objectives of the scheme, based on the general spatial policy, are the following: (1) the development of a settlement system corresponding to the rational spatial pattern of production forces in the long term and the development of service systems at com. munity levels; (2) the reduction of the existing differentials in the service-provision levels of settlements within the same functional categories; (3) the reduction of disparities in living conditions between settlements of various functions; (4) the allocation and development of public facilities according to the hierarchical settlement levels; (5) the provision of recreational facilities to mitigate the harmful aspects of urbanization; (6) the development of national networks for communication, power, water supply, etc, in accordance with the spatial pattern of the settlement system; and (7) the provision of rapid low-cost methods of access to work places from residences.

For the implementation of these objectives the scheme establishes a hierarchical settlement system. In the planned transformation of the system the basic issue is to determine the development tendency of towns in accordance with the socioeconomic potential of the country. The development potential of individual towns is determined by the size of their sphere of attractions.

The role of Budapest in the planned national settlement system is that the political, administrative, and management center of the country as well as the center of a large region. The Budapest metropolitan area accommodates one-quarter of the national population and offers jobs for tens of thousands of commuters. Differentiated demands have induced the formation of a large-scale supply and service system and are stimulating further development of the capital region.

The second level in the settlement system consists of a group of cities of over 100,000 inhabitants, centers of regions extending over several counties and country districts. These centers perform high-level management functions and multiple urban service functions and they possess a considerable industrial base; agglomeration processes are already visible in their surroundings.

In addition to the existing large cities, 18 smaller centers have been selected for intensive develofment to form future high-level centers. At present these are medium-size lowns at various levels of development but of a generally high growth potential. A considerable share of regional development resources has been directed to these urban centers, and consequently their functional and physical expansion has already occurred. 
The next layer in the settlement system consists of medium-level centers that also play an important role in the future spatial redistribution of population at the national level. The following criteria determine their functions: the center and its region of attraction should have a population of at least $30,000-40,000$; it must be suited for industrial development and must possess suitable transport networks and medium-level communal and public facilities. In keeping with its long-term requirements, the national scheme considered 107 settlements as capable of performing the role of medium-level centers in the future; of these 56 are towns and 51 are villages (rural settlements) undergoing vigorous urbanization.

At present there are 3,162 villages in Hungary, of which $120-130$ are within the spheres of urban agglomerations. The growth of another $220-240$ villages is determined by their recreational and tourist attractions and capacity. The development of agriculture entails the formation of large farms. Relatively large villages that are located favourably with respect to transport lines are suitable management and processing centers for such farm complexes. In these villages the growth of both population and housing stocks is expected to progress rapidly.

The development plans therefore provide for the differentiation of rural settlements. This leads to the formation of 120-130 special low-level management centers and $500-520$ general low-level centers. The special centers are villages of 5,000-10,000 inhabitants performing service functions for the surrounding villages. The remaining lowlevel centers are envisaged as rural settlements with 3,000-6,000 inhabitants each.

A uniform spatial-planning system emerged in Hungary when extensive economic development (dealing with entire regions or sectors) was gradually giving way to intensive development (concentrating on particular subregions or industries). Such a system became necessary, and its elaboration was facilitated by accumulated planning experience and theoretical knowledge. Spatial planning is defined as a comprehensive system for preparing plans of different characters, time scales, and depths within which spatial development and physical plans are accommodated. Spatial-development plans are parts of national economic plans. The physical plans are elaborated under the responsibility and direction of the Ministry of Building and Urban Development while the development plans are made under the overall management of the National Planning Office. The Ministry takes part in the elaboration of development plans as a leading institution among the participating authorities.

The integration of the Hungarian spatial-planning system is achieved by linking the spatial-development and physical plans, i.e., by the interdependence of the aims and objectives of plans forming a hierarchy based on temporal and spatial scales. The spatialdevelopment and physical pians, though relatively independent of each other, are based on complex coordinated and overlapping planning operations.

During the three decades of development following World War II, Hungary has made considerable progress toward the realization of basic targets: the advancement of the economy, the improvement of the living conditions of the whole society, and the raising of the cultural, service, and income levels of the population. These advances have been facilitated to a considerable extent by spatial-development activity; at the beginning this was primarily urban pranning activity affecting the development of individual settlements but later the system of regional planning was introduced. In the past decade the development of regions and settlements has become an integral part of national 
sucioeconomic development objectives and at the same time a means of realizing comprehensive objectives.

In close relationship with industrial development, a number of new settlements have been created. A new center for iron and steel production has been sited along the River Danube with a new town of Dunaujváros. In the construction of new towns and settlements the the principles of socialist urban development were applied for the first time. Even in the first few years industrial plants were set up in several provincial towns which had previously had no or hardly any industry.

The realization of the program for bauxite and aluminum production has been reflected in the development of settlements in the northern and middle Transdanubian region. As a result of planned development several provincial settiements have become important industrial centers. To the fomer industrial cities (Budapest, Miskoic, and Györ) over 60 new industrial centers have been added, with over 5,000 workers each. In recent years the transformation of rural settlement has been progressing. The modernization of agriculture is particularly significant in this respect.

The development of urban and rural infrastructure has been accelerated since the 1960 s. One of the main characteristic features of this development has been the construction of new large residential estates in the capital, the county administrative centers, and the regions that have been most affected by the economic development. The housing stock of the villages has been rising at a rapid rate as well.

The rapid development of industry and the reorganization of agricuiture have generated rural-urban migrations. These have created pressures on the infrastructural capacity of the destination areas. One of the most complicated urban and physical development problems of the last three decades has been that of the Budapest region. The development of its services and infrastructure could not keep abreast with the large-scale in-migration of the past decades. Since the mid-1960s, however, the development of housing and public transport (including the construction of the underground railway) have brought about numerous favorable changes in the region.

Considerable results have also been attained in the development of the cultural and educational functions of the provincial centers. In addition to the expansion of the traditional centers of intellectual life, a number of universities, high schools, scientific research institutes, planning and design of fices, etc., have been allocated to several provincial towns.

It can be concluded that spatial development has gradually come into harmony with national social and economic objectives and has promoted the development of the country as a whole. It has coordinated with improving efficiency the realization of the development targets of the productive and service sectors of the national economy.

\section{REFERENCES}

Hansen, N.M. (1975). A critique of economic regionalizations of the United States. RR-75-32. International Institute for Applied Systems Analysis, Laxenburg, Austri..

Lacko, L. (1976). Application possibilities of canonical corieiaion, cluster analysis, and a type of interaction models in regional analysis. Tervgazdasági Közlemények, No. 2.

l ackó, L., Enyedi, G. and Köszegfalvi, G. (1978). Functional urban regions in Hungary. CP-78-4. International Institute for Applied Systems Analysis, Laxenburg, Austria. 


\section{.}




\title{
RECENT TRENDS IN URBAN GROWTH AND POPULATION REDISTRIBUTION IN CANADA*
}

\author{
Larry S. Bourne \\ Centre for Urban and Community Studies, University of Toronto, Ontario \\ (Canada)
}

In the relatively short period of a decade, long-established trends in urban growth and population redistribution within developed industrial societies appear to have been reversed. Among these established trends perhaps the most prominent have been rapid urban expansion, the concentration of economic wealth and social life in a few large metropolitan complexes, and the depopulation of the national periphery and of small towns and cities. To the extent that these trends became part of the conventional wisdom of planners and policy makers, they in turn shaped the kinds of urban and regional policies which were introduced.

Most if not all of these images, and the policies based on them, are now outdated. Canada is no exception, although, as we shall see, there is a considerable difference in the extent and degree of reversal of past trends. What then are these trends? First, there has been a dramatic decline in the rate of national population growth, and thus in the rate of urban growth, and an even more dramatic shift in the demographic structure of the population. Second, the historical trend of increasing metropolitan concentration has slowed, if not ceased, and the growth rate of several of the largest centers has now dropped below the national population growth rate. Third, migration flows appear to have shifted since the late 1960s away from the largest metropolitan areas towards smaller centers and resource-based regions. Although our data on migration are still limited there is also reasonable evidence of a return migration flow to peripheral regions which have for long been net exporters of population. Finally, our preliminary analyses of these trends has shown that many of the traditional relationships in urban growth (e.g., between employ. ment and income growth and population movements) no longer hold true. Clearly a reassessment of our images of the processes and evolving patterns of urbanization in Canada is in order.

\footnotetext{
* An earlier and more extensive version of this paper appeared as a discussion paper of the Centre for Urban and Community Studies at the University of Toronto (see Bourne, 1978). More detailed empirical analyses are provided in Boume and Simmons (1979).
} 


\subsection{Objectives}

The basic question posed in this paper is why have these shifts taken place - in what most observers of Canadian urbanization have considered to be both natural and inevitable trends - and what are their spatial, social, and policy implications? How similar are the Canadian trends to those recorded in other developed countries? What differences, in a comparative context, are attributable to the unique spatial and structural properties of the Canadian urban system, and which are due to the stage of urbanization in Canada and the specialized economic bases of many Canadian regions? Although declining rates of fertility and lower levels of foreign immigration may account for much of the overall decline in national population growth rates, what accounts for the changing spatial distribution of population growth and urban concentration and the relative decline of large cities? Have production and agglomeration economies changed, or preferences for places to live and work, or both? Or are these changes due in large part to government policy in the form of an explicit or implicit strategy of population deconcentration?

With these questions in mind, the paper initially undertakes to document recent trends in urban growth and population distribution in Canada and to set these in an appropriate historical context. The emphasis is on population growth - on the underlying components of aggregate population and demographic change - since this is where data on a spatially disaggregated basis are most readily available. The principal data source is the 1976 Census of Canada (Statistics Canada, 1977a). It is of course an overly simplistic and narrow interpretation to equate urban growth with population growth, but as yet data on other indexes of growth such as income, employment, and economic linkages are not available in any detail for the most recent census period.

The next part of the paper examines the spatial patterns of recent population change, on different spatial scales, and attempts to explore, to the extent that available data allow, some of the relationships that are evident in these patterns. The third main part includes a preliminary debate on selected social, political, and planning questions raised by these recent trends. For example, how do we plan for a steady-state urban system when that system is premised on the assumption of continued growth? Do spatial and regional inequalities increase or decrease under conditions of declining growth? To what extent are existing planning instruments suited to a situation of slow growth and what are the implications for specific policies such as regional development?

\subsection{Defining Appropriate Urban Regions}

One of the principal themes of the research program of the International Institute for Applied Systems Analysis on human settlements is the identification of appropriate regions for the study of changes in the settlement system. The emphasis has been on encouraging researchers from various countries to develop standardized techniques for delineation in order to facilitate cross-national comparisons, which reflect the functional organization of each national territory around a set of urban nodes. These Functional Urban Regions (FURs) in turn become the basis for data collection and subsequent analysis. The units employed in the following discussion of Canadian urban trends 
conform to this concept of FURs. However, it is stressed here that comprehensive analyses of urban population growth must be based on more than one spatial scale since not all components exhibit the same spatial variability.

The principal empirical focus of this discussion is the Canadian urban system, which is viewed on three very different spatial scales. First are the 23 Census Metropolitan Areas (CMAs) with populations of over 100,000 . These areas account for about $55 \%$ of the population of the nation but less than $1 \%$ of its geographic area. Second, reference is made to 125 urban-centered regions with populations of 10,000 or more which were defined initially by Simmons $(1974,1977,1978)$ and which encompass all but a fraction of the population and essentially cover the entire settled ecumene of the country (Figure 1). These regions approximate the FURs used in other IIASA studies, except that they tend to be considerably larger than the daily commuting radius of the largest urban core. In other instances data for the ten provinces are introduced to demonstrate trends which tend to be obscured, or for which data are unavailable, at the urban system level.

The use of the 125 urban regions also facilitates a comparison of population growth rates by level in the urban hierarchy, where level is defined on the basis of functional criteria (i.e. linkages) as well as city size. In this example the functional criteria include not only the labor-market area of each urban area as defined by commuting flows but also the degree of dependence of a region or small center on a larger center.

\section{THE CHANGING COMPONENTS OF POPULATION GROWTH}

The initial assertion made in describing recent trends in Canadian urbanization is that these trends represent new and different paths of urbanization and thus provide the outline of an emerging urban reality. Admittedly there is at present little solid empirical evidence of the widespread deconcentration of population and urban decline (the counterurbanization phenomenon) that has been observed in the United States and parts of western Europe (see Berry, 1978; Hansen, 1978). Nevertheless, the available Canadian data do indicate that significant structural and spatial changes are taking place which warrant careful analysis and continued monitoring.

The essential component in our concern here with urban growth is the declining rate of national population growth. This decline in itself is not a particularly recent phenomenon, however. Average growth rates in Canada have declined steadily from over $3.0 \%$ per annum in the early 1950 s to less than $1.3 \%$ in the $1971-1976$ period. The latter figure is the lowest recorded in this century except for the decade of the great depression in the 1930s (Table 1). Growth rates were similarly low 40-50 years earlier during the depression of the 1890s.

The factors responsible for this recent decline are now well documented (Ministry of State for Urban Affairs, 1975a, b, 1977; Science Council of Canada, 1975; Ray et al., 1976). First, as in most western countries fertility rates have dropped to their lowest level in over 50 years (Stone and Marceau, 1977). In fact the aggregate fertility rate in Canada is now less than 16 per thousand compared to 28 per thousand in the 1951-1956 period. The sum of age-specific birth rates (the number of children per female in the reproductive age cohorts) has dropped to 1.8 , well below the reproduction rate. Despite the entrance of the postwar baby-boom population into the age groups of highest fertility during the 


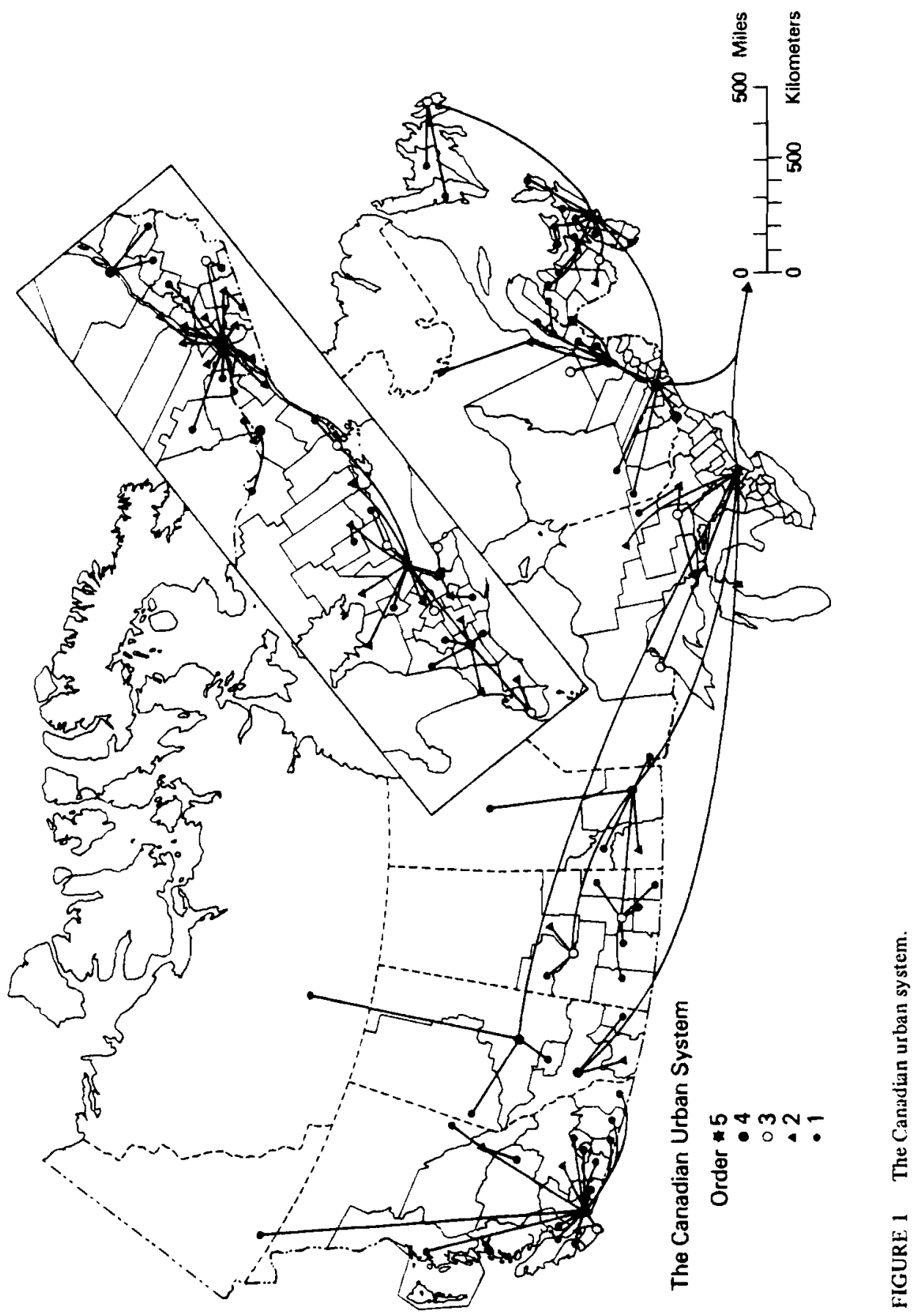




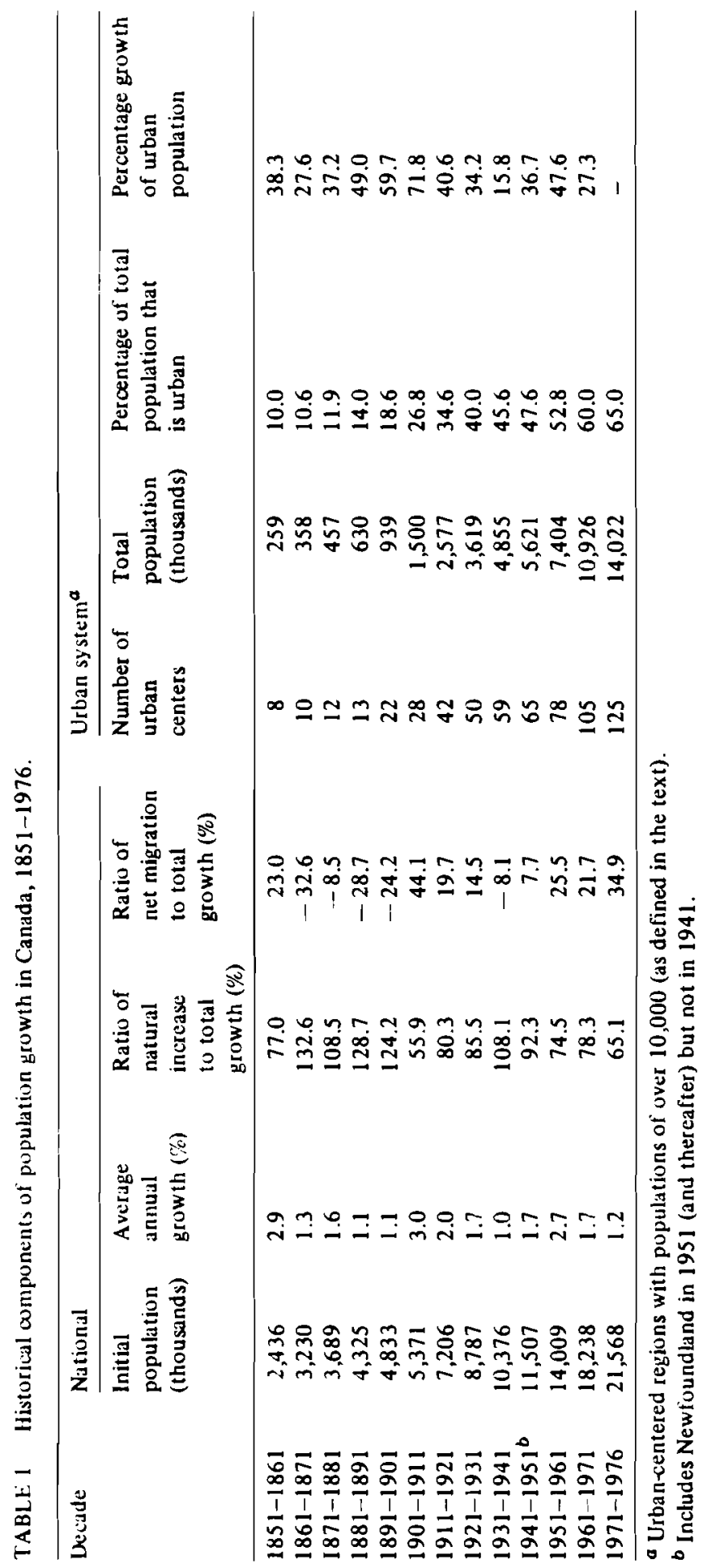


1970s there is little sign of the fertility rate turning significantly upward, although its decline has been arrested since 1975. It should also be noted that the base point for these changes has been higher in Canada than in most other countries. The aggregate fertility rate in Canada during the 1950s was among the highest in the industrial world, and thus the recent decline has been even more dramatic.

The second component, the rate of net foreign immigration, has always been a major contributor to the population growth of Canada and typically a distinctively cyclical phenomenon (with postwar peaks in 1957, 1967, and 1974). The rate of foreign immigration has declined slowly since the 1960 s and precipitously since 1975 . The effect of continually tightening immigration regulations, reflecting the higher unemployment rates in Canada, has been to reduce the average inflow to 150,000 persons annually. For 1978 the total was only about 115,000 and it is certain to be less in 1979. Again predicting the future course of this component of population growth and its regional impact is a highly tenuous exercise (Department of Manpower and Immigration, 1975).

The third component undergoing a dramatic change is the demographic structure of the population. This structure has been altered by three principal factors: (1) the movement of the small wartime and large postwar baby-boom populations through the various age cohorts; (2) the declining number of young children due to the drop in fertility; and (3) the increasing number of elderly following from a steadily declining death rate. The population is now aging and the age-structure pyramid is becoming markedly skewed toward the middle and older cohorts. Here perhaps future trends are somewhat more predictable. Apart from the uncertain contribution of net immigration to future growth, the progression of age cohorts is at least more easily charted over time.

In Table 2, which provides population forecasts by age cohort and life-style group through to 1986, we see the demographic origins of the current rapid growth of the labor force and the anticipated senior-citizen boom in the 1980 s. Of course all demographic structures are dynamic and some change is inevitable; however, both the absolute and relative scales of these demographic transitions are substantial. The implications of these transitions for Canadian public policy, in terms of the provision of social services, economic planning, labor-force needs, housing demand, etc., remain to be defined. These impacts are the subject of the last section of this paper.

\section{PATTERNS OF URBAN AND REGIONAL GROWTH}

The degree of economic and regional differentiation in Canada implies that changes in the aggregate components of population growth will not be uniformly distributed among cities and regions. In fact a critical first step in assessing the implications of recent changes is a recognition that spatial variability in growth rates is an important policy concern. Uncertainty and variability are nothing new, as Table 1 indicates.

It is also evident in the Canadian context that different aggregate growth rates and different combinations of the components of population growth produce markedly different spatial patterns. During periods of rapid aggreg a grow th (particularly high rates of natural increase) almost all areas witness grow 'h. During periods of high foreign immigration growth tends to become more focused spatially. Similarly, as the contribution of natural increase to aggregate growtin declines, spatial variability increases. 
TABLE 2 Actual and projected demographic change in Canada, 1941-86 (population in thousands) ${ }^{a, b}$.

\begin{tabular}{|c|c|c|c|c|c|c|c|c|c|}
\hline $\begin{array}{l}\text { Household } \\
\text { type }\end{array}$ & $\begin{array}{l}\text { Age } \\
\text { cohort }\end{array}$ & $\begin{array}{l}1941- \\
1951\end{array}$ & $\begin{array}{l}1951- \\
1956\end{array}$ & $\begin{array}{l}1956- \\
1961\end{array}$ & $\begin{array}{l}1961- \\
1966\end{array}$ & $\begin{array}{l}1966- \\
1971\end{array}$ & $\begin{array}{l}1971- \\
1976\end{array}$ & $\begin{array}{l}1976- \\
1981\end{array}$ & $\begin{array}{l}1981- \\
1986\end{array}$ \\
\hline Family & $0-4$ & +670 & +261 & +273 & -59 & -381 & +128 & +251 & +143 \\
\hline Family & $5-9$ & +352 & +409 & +272 & +221 & -47 & -430 & +127 & +251 \\
\hline Family & $10-14$ & +30 & +304 & +421 & +238 & +217 & -50 & -420 & +127 \\
\hline Family/single person & $15-19$ & -62 & +104 & +270 & +405 & +277 & +210 & -50 & -428 \\
\hline Student/single person & $20-24$ & +56 & +40 & +54 & +277 & +428 & +285 & +209 & -50 \\
\hline Family & $25-34$ & +363 & +240 & +67 & +2 & +406 & +694 & +661 & +489 \\
\hline Family & $35-44$ & +432 & +272 & +250 & +153 & -16 & +42 & +361 & +684 \\
\hline Adult & $45-54$ & +180 & +204 & +267 & +200 & +213 & +158 & -3 & +43 \\
\hline Adult & $55-64$ & +163 & +77 & +135 & +190 & +252 & +173 & +201 & +142 \\
\hline Adult/senior citizen & $65+$ & +318 & +158 & +147 & +148 & +205 & +199 & +259 & +247 \\
\hline
\end{tabular}

a Source: Census of Canada, 1941-1971; calculations from Statistics Canada (1977b).

"Note that the more significant changes are shown in italics.

\subsection{Metropolitan Growth and Concentration}

The period of rapid postwar urban growth in Canada now appears to be nearing an end. Urbanization as a structural and spatial process will continue but at a much reduced rate. The proportion of the Canadian population now living in urban centers, according to the traditional criteria (i.e., in urban places of over 1,000 population), has now reached $78 \%$ and is likely to converge on a stable figure of roughly $80 \%$. Perhaps a more useful criterion is that relating to the process of metropolitan, i.e., the concentration of the population of a nation in its largest metropolitan centers. This process also has slowed in Canada, particularly in response to declining foreign immigration and shifts in interregional migration as well as the differing economic fortunes of metropolitan-based manufacturing sectors of the economy.

In 1976 there were 24 urban centers in Canada which had populations of over 100,000 , of which 23 were defined as CMAs at that date (see Table 3). Obviously the average growth rates of these cities have declined in the recent census period (1971-76). Moreover, there is little or no correlation between the size of centers and their population growth rates. Almost onc-half of these centers are growing more slowly than the national iverage, and two (Windsor and Sudbury) registered absolute al though slight population declines.

The very different growth performances of sectors of the Canadian economy is particularly evident in these figures. Of the 11 centers which grew most rapidly in this period, eight are political capitals, including the national capital region (Ottawa-Hull). The remaining three grew for very different reasons: Calgary (oil investment), KitchenerWaterloo (industrial overspill from Toronto and Hamilton), and to a lesser extent Vancouver (regional service functions, metals, forest industries, and climate). Of course these administrative capitals also serve other expanding roles for their provinces and fur the entire nation (Victoria (retirement), Toronto (tertiary services), and Edmonton (northern development)) but the political function is nonetheless crucial in ensuring cuntinued growth. 


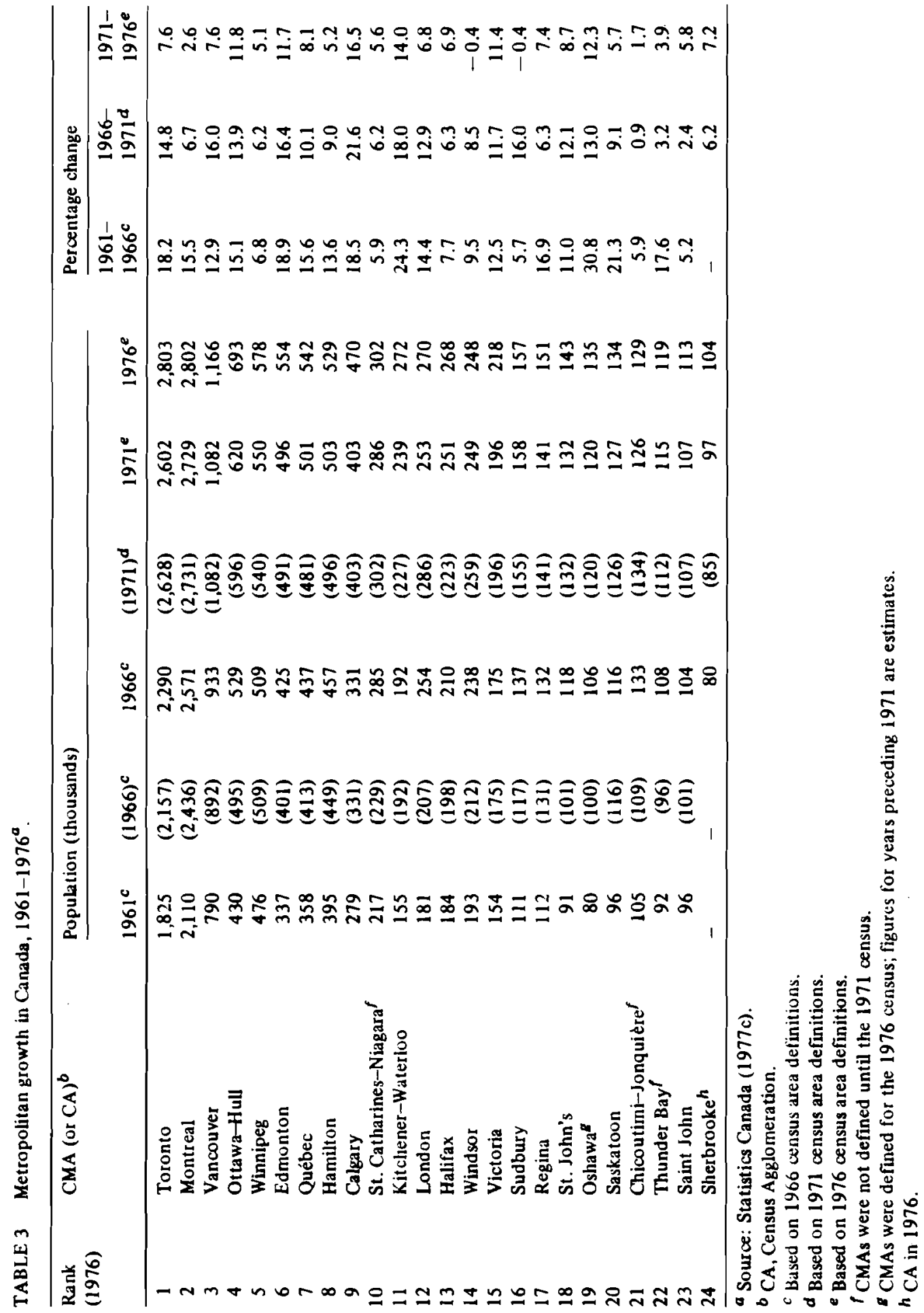


TABLE 4 The degree of metropolitan population concentration in Canada, 1941-1976.

\begin{tabular}{lllll}
\hline Year & $\begin{array}{l}\text { Population of three } \\
\text { national metropolises } \\
\text { (thousands) }\end{array}$ & $\begin{array}{l}\text { Total } \\
\text { national } \\
\text { population } \\
\text { (thousands) }\end{array}$ & $\begin{array}{l}\text { Percentage of } \\
\text { population in } \\
\text { three national } \\
\text { metropolises }\end{array}$ & $\begin{array}{l}\text { Percentage of } \\
\text { population in } \\
23 \text { metropolitan } \\
\text { areas }\end{array}$ \\
\hline 1941 & 2,449 & 11,507 & 21.3 & 40.2 \\
1951 & 3,244 & 14,009 & 23.2 & 44.9 \\
1961 & 4,725 & 18,238 & 25.9 & 48.3 \\
1971 & 6,415 & 21,568 & 29.7 & 55.4 \\
1976 & 6,771 & 22,993 & 29.5 & 55.5 \\
\hline
\end{tabular}

Measured in terms of aggregate populations, metropolitan concentration has also not increased during the last quinquennial census period (Table 4). The proportion of Canada's population resident in the three largest metropolitan areas remained roughly the same over the 1971-1976 period (29.7\% in 1971 and $29.5 \%$ in 1976). Admittedly this is a rather crude index on which to discuss the issue of population decentralization. Moreover, most of the relative decline is attributable to the recent stagnation of growth in Montreal and to the fact that some of the growth of Toronto and Vancouver and other smaller metropolitan areas has simply spread outside the CMA boundaries. The latter development represents a continuation of the long-established process of interregional decentralization of population into increasingly distant portions of the urban field (Friedmann, 1973; Berry and Gillard, 1977; Blumenfeld, 1977). How much of the decline in metropolitan concentration is attributable to this process and how much of it represents decentralization on a larger regional scale is unclear.

An alternative view of urban growth is provided by aggregating population figures for the 125 FURs defined earlier (see Figure 1 and Table 5). When population growth rates are calculated for the five levels in this hierarchy it is evident that size is no longer a principal determinant of growth (correlation coefficient $r=-0.043$ ). Growth rates were higher in 1971-1976 for those regional centers with populations of 300,000-500,000 and for smaller regional centers $(50,000-100,000)$ than for the largest centers. In Canada at least, regional and economic diversity produces highly variable growth rates over time and between cities of different size. No simple generalizations, or economic-growth models, will suffice in this context.

TABLE 5 Population growth of urban-centered regions, by level in the urban hierarchy, 1971-1976.

\begin{tabular}{lccc}
\hline Level in hierarchy & $\begin{array}{l}\text { Number } \\
\text { of centers }\end{array}$ & $\begin{array}{l}\text { Population } \\
1976 \text { (thousands) }\end{array}$ & $\begin{array}{l}\text { Growth rate } \\
\text { 1971-1976 (\%) }\end{array}$ \\
\hline National metropolises & 3 & 6,771 & 4.9 \\
Major regional centers & 8 & 4,829 & 8.4 \\
Regional centers & 14 & 3,453 & 3.7 \\
Small regional centers & 36 & 4,308 & 8.1 \\
Local centers & 64 & 3,633 & 5.1 \\
Tutals & 125 & 22,994 & 6.4 \\
\hline
\end{tabular}




\subsection{Migration Patterns}

This variability in growth in part reflects differences in migration flows between regions and within the urban size hierarchy. For the latter, where the latest available data are for 1966-1971, a number of important shifts took place (Simmons, 1977). For some time the two largest metropolitan centers were exporting native-born population and gaining through foreign immigration. This trend has continued through into the 1970s, suggesting that the very recent declines in foreign immigration noted earlier are likely to have their most severe impact on the largest centers, and particularly the inner cities of those centers. Nevertheless, population growth did show a significantly high correlation with net migration $(r=0.799)$ and with foreign immigration $(r=0.514)$ during the earlier 1966-1971 period.

TABLE 6 Provincial growth rates and interprovincial migration, 1961-1976.

\begin{tabular}{|c|c|c|c|c|c|}
\hline \multirow[t]{2}{*}{ Province } & \multicolumn{2}{|c|}{$\begin{array}{l}\text { A verage annual geometric } \\
\text { grow th rate }{ }^{a}(\%)\end{array}$} & \multicolumn{3}{|c|}{ Net interprovincial migration ${ }^{b}$} \\
\hline & $1966-1971$ & $1971-1976$ & $1961-1966$ & $1966-1971$ & $1971-1976$ \\
\hline Newfoundland & 1.14 & 1.33 & $-15,213$ & $-19,344$ & $-1,856$ \\
\hline Prince Edward Island & 0.57 & 1.15 & $-2,970$ & $-2,763$ & $+3,754$ \\
\hline Nova Scotia & 0.86 & 0.98 & $-27,125$ & $-16,396$ & $+11,307$ \\
\hline New Brunswick & 0.57 & 1.31 & $-25,679$ & $-19,596$ & $+16,801$ \\
\hline Québec & 0.84 & 0.68 & $-19,860$ & $-122,735$ & $-77,610$ \\
\hline Ontario & 2.05 & 1.42 & $+85,369$ & $+150,712$ & $-38,559$ \\
\hline Manitoba & 0.52 & 0.66 & $-23,470$ & $-40,690$ & $-26,828$ \\
\hline Saskatchewan & -0.62 & -0.11 & $-42,094$ & $-81,398$ & $-40,753$ \\
\hline Alberta & 2.16 & 2.46 & $-1,984$ & $+32,008$ & $+58,571$ \\
\hline British Columbia & 3.12 & 2.46 & $+77,747$ & $+114,966$ & $+92,285$ \\
\hline Canada & 1.51 & 1.29 & & & \\
\hline
\end{tabular}

a Sources: Statistics Canada (1971); Ministry of State for Urban Affairs (1977).

${ }^{b}$ Source: Statistics Canada (1977d).

More recent data, on a provincial basis, reveal that a substantial shift in interregional growth and migration flows took place in the 1971-1976 period (Table 6). Growth rates fell in the industrial heartland (southern Ontario and Québec) and British Columbia and increased in the traditional periphery (the Atlantic and Prairie regions). Net provincial migration to British Columbia dropped while that to oil-rich Alberta increased substantially. In contrast, Ontario shifted from a positive balance of over 150,000 interprovincial migrants in 1966-1971 to a loss of about 38,000 in 1971-1976. (It is interesting to note that the loss of population through migration in Québec, although still high, actually declined between 1966-1971 and 1971-1976. However, preliminary data for 1977, following the election of the separatist Parti Quebecois government in November 1976, indicate that the net outflow has again increased. How much of this outflow can be attributed to sectoral employment problems (the textile industries) which are particularly severe in Québec, to regional attractiveness (rapid growth in the west) which has affected 
all of eastern Canada, or to uncertainty on the future political status of Quebec is impossble to estimate.) Moreover, the three Maritime provinces registered a positive net migration balance for the first time since the depression of the 1930s. Out-migration from Manitoba and Saskatchewan remained substantial but declined somewhat to levels more typical of the early 1960s. If these trends were to persist over the long term the future fabric of urban (and regional) Canada could be very different from that in the past.

\section{ALTERNATIVE HYPOTHESES}

Hypotheses which purport to explain these recent trends in urban growth and migration, particularly the relative decline of large cities and the renewal of growth in some peripheral regions, remain largely untested. There are also far too many hypotheses to discuss in any detail here. Moreover, given the extent of regional differentiation in economic structure and, to a lesser extent, in life-styles in Canada, hypotheses advanced for one spatial scale or for one region may have little validity on another scale or for different regions. What can be done here, however, is to raise issues over and above those of demographic structure which more formal models may wish to address in subsequent research.

\subsection{The Economic-Base Hypothesis}

Perhaps the most obvious explanation is that of job shifts and the changing structure of the national economy to achieve greater efficiency in production. The argument, developed largely in reference to the USA, is that shifts in the national economy, notably the relative decline in manufacturing and the obsolescence resulting from a lack of investment in the urban physical plant, have been particularly detrimental to the older metropolitan areas and industrial districts. New industrial jobs have been created, if at all, in lower-cost areas, new tertiary employment has become more footloose locationally, and primary jobs have increased in those areas that are fortunate enough to have resources which are currently in high demand. This is the approach taken by numerous authors in attempting to account for metropolitan decline and regional decentralization in the USA (Kain, 1975: Sternlieb and Hughes, 1975; Leven, 1978). It is essentially an economic-base argument. (For a provocative review of this hypothesis, as reflected in the papers in Sternlieb and Hughes (1975), see Vining (1977).)

In the Canadian context, however, we must take into account regional differentials in economic and political structure as well as the differences in industrial structure between Canada and the USA. Because Canada is much more dependent on resource industries, aggregate growth will fluctuate widely with international commodity markets. These fluctuations also have a highly variable regional impact, given the intense regional specialization 1 . Jted earlier. However, manufacturing, apart from that which is tied directly to the resource industries, has not migrated away from the industrial heartland to the same extent as in the USA; it simply has not expanded as it did in the 1950s and 1960s (Table 7). 
TABLE 7 Regional distribution of population and manufacturing activity, 1961-1975 .

\begin{tabular}{|c|c|c|c|c|c|c|}
\hline \multirow[t]{3}{*}{ Region } & \multicolumn{2}{|c|}{ Population (\%) } & \multicolumn{4}{|c|}{ Manufacturing industry } \\
\hline & \multirow[b]{2}{*}{1961} & \multirow[b]{2}{*}{1975} & \multicolumn{2}{|c|}{ Employment (\%) } & \multicolumn{2}{|c|}{ Value added $(\%)$} \\
\hline & & & 1961 & 1975 & 1961 & 1975 \\
\hline Atlantic & 10.4 & 9.5 & 4.6 & 4.7 & 3.8 & 4.1 \\
\hline Québec & $(28.8)$ & $(27.1)$ & $(33.5)$ & $(30.6)$ & $(30.5)$ & $(27.6)$ \\
\hline Ontario & (34.2) & (36.1) & $(47.2)$ & $(48.9)$ & $(50.3)$ & $(50.8)$ \\
\hline Central & 63.0 & 63.2 & 80.7 & 79.5 & 80.8 & 78.4 \\
\hline Prairies & 17.4 & 16.2 & 7.0 & 7.4 & 7.1 & 8.4 \\
\hline British Columbia & 9.2 & 10.8 & 7.7 & 7.9 & 8.3 & 9.1 \\
\hline Canada & 100.0 & 100.0 & 100.0 & 100.0 & 100.0 & 100.0 \\
\hline
\end{tabular}

Source: Department of Industry, Trade, and Commerce, Ottawa, 1978.

In order to identify the spatial implications of industrial growth and decline in Canada one must also consider the differential response attributable to extensive foreign ownership and the predominantly branch-plant structure of the manufacturing sector in Canada. Britton (1978), for example, has argued that the locational behavior and investment strategies of foreign-owned branch plants are inherently different from those of locally owned firms. In particular, the former underinvest relative to head-office plants in times of declining growth and import new technologies and investment during periods of rapid growth. They also tend to be more conservative in their choice of location as well as in technological innovation. The result is that downturns in the economy tend to be felt earlier and more severely and to last longer in Canada than in the USA.

If job creation were a dominant factor in the variability of population growth, one might expect to find significant correlations between employment, wages, and growth. Drawing again on previous work by Simmons (Table 8), one finds that there appears to

TABLE 8 Relationship between population growth and indexes of production (simple correlations) ${ }^{a}$.

\begin{tabular}{|c|c|c|c|c|c|c|c|c|}
\hline \multicolumn{2}{|c|}{ Variable } & \multicolumn{7}{|c|}{ Variable No. } \\
\hline No. & Description & 1 & 2 & 3 & 4 & 5 & 6 & 7 \\
\hline 1 & $\begin{array}{l}\text { Population growth } \\
\text { rate }(1971-1976)\end{array}$ & 1.000 & & & & & & \\
\hline 2 & $\begin{array}{l}\text { Employment growth } \\
\text { rate }(1971-1976)\end{array}$ & 0.241 & 1.000 & & & & & \\
\hline 3 & $\begin{array}{l}\text { Wage growth rate } \\
(1971-1976)\end{array}$ & 0.087 & 0.244 & 1.000 & & & & \\
\hline 4 & $\begin{array}{l}\text { Population (1971) } \\
\text { (in logarithms) }\end{array}$ & -0.043 & 0.005 & -0.099 & 1.000 & & & \\
\hline 5 & Wage rate $(1971)$ & 0.247 & -0.168 & -0.308 & 0.002 & 1.000 & & \\
\hline 6 & $\begin{array}{l}\text { Per capita income } \\
\text { (1971) }\end{array}$ & 0.420 & 0.717 & -0.322 & 0.379 & 0.609 & 1.000 & \\
\hline 7 & $\begin{array}{l}\text { Population growth } \\
\text { rate }(1966-1971)\end{array}$ & 0.792 & 0.056 & -0.087 & 0.030 & 0.450 & 0.601 & 1.000 \\
\hline
\end{tabular}

a Source: Simmons (1979). 
be only a modest relationship $(r=+0.241)$ between employment and population growth during the 1971-1976 period among the 125 urban-centered regions and almost no relationship between population growth and increases in average wages $(r=+0.087)$. Population growth was indeed higher in areas of higher per capita income $(r=+0.420)$ and wage levels $(r=+0.247)$ but employment growth was not.

In Canada at least one clearly has to look beyond aggregate national models to explain regional economic growth. For example, the recent net migration balances registered in the Maritime provinces obviously reflect in part the declining job opportunities in Ontario, the traditional destination of most out-migrants from the region. (These trends also reflect the increasing importance of a variety of government transfer payments and social security programs which have the effect of reducing the disadvantages of remaining in traditional low-income regions.) The growth of some smaller centers throughout the country, but particularly in southern Ontario, Alberta, and British Columbia, represents in part movements of the retired population and in part the extension of commuting patterns and the growth of local public employment.

\subsection{The Cultural Predisposition and Amenities Hypothesis}

A second hypothesis on the changing metropolitan fabric looks more to the demand side, i.e. to cultural predispositions and social preferences. People move to locations providing environmental amenities and access to friends and services and away from places which have disamenities such as pollution, congestion, or high cost. Berry $(1970,1975$, 1976), for example, sees the regional decentralization of the population of the USA as an integral part of that society's preference for low-density living and newness (which is facilitated of course by higher incomes) and its rejection of collective action on the increasing disarnenities of older urban centers. There is also some evidence of a higher rate of retum migration to nonmetropolitan areas, perhaps to reestablish old family ties, to retire, or to make unemployment more palatable (Morrison, 1975).

\subsection{The Unintended-Policy Hypothesis}

A third hypothesis, or more appropriately a cluster of related hypotheses, concerns the role of governments and the public sector generally in designing a national urban fabric which includes a declining metropolitan core. The argument is that the summary effects of a myriad of policies (or nonpolicies) in housing, transportation, construction, and taxation has been, largely unintentionally, to devalue what is old and to subsidize what is new. In the USA, at least, research by the Rand Corporation and others has suggested that tax policies encourage new construction rather than rehabilitation, thus penalizing older and particularly larger metropolitan centers (Vaughan, 1977). Government employment and procurement policies have tended to favor nonmetropolitan areas, or urban areas in the south and west, and tariff policies have forced certain ndustries, and thus specific locations, to bear the brunt of competition on international markets. The list of potential examples for this argument is long; however, to date it has not been possible to sort out the complex multifaceted impacts of a public sector as large as that in the USA. 
In Canada the dominant form of this argument is the reverse: that government policies have drained the periphery to maintain the strength of the heartland. Only recently, it is argued, have the pressures of economic and regional decentralization been sufficiently strong to begin to override the centralizing practices of the federal government. There is, however, lit tle evidence to support this contention either. (For a cross section of differing perspectives on these issues, see Lithwick, 1972; Bettison, 1975; Bourne, 1975; Gertler and Crowley, 1977; Matthews, 1977; and Economic Council of Canada, 1977.) Instead, centralizing practices have perhaps been strongest at the regional level, because of provincial government policies, rather than at the federal level. Of course there are also differences in government and institutional structures which preclude simple comparative generalizations.

\subsection{Other Hypotheses}

There are obviously numerous other relevant hypotheses, and variations of the three theses that have been outlined briefly above, on declining growth rates and spatial variability. One alternative would be a view of the space economy as essentially a random process (Curry, 1976). Rapid cconomic growth (or decline) in these terms takes place almost in the lashion of a random walk. In the Canadian context economic growth is highly vulnerabie to external events (e.g., changes in the prices of staple products) which are largely unpredictable in both timing and locational impact.

Whatever type of urban-growth model is hypothesized, the importance of regional variability and economic uncertainty should not be underestimated. As a result of economic uncertainty governments are increasingly forced into a reactive mold of policy formulation. Policies in effect assume away one obvious characteristic of the future uncertainty. Long-term planning becomes less rather than more common. At the same time, economic uncertainty increases the attractiveness of the larger urban agglomerations, where some of the risks of uncertainty can be more easily averted. This in turn could lead to greater regional (and social) inequalities.

\subsection{Synthesis}

In the Canadian context it is not at all obvious which, if any, of these hypotheses on urban growth is most applicable. Nor are the trends which these hypotheses purport to explain, notably decentralization and metropolitan decline, as yet clearly established in Canada. For example, there is no single dominant sun-belt phenomenon as there is in the USA; nor is there a significant degree of metropolitan decay. Canadian cities remain relatively healthy, subject of course to real economic differences and inequalities between regions. Also, there has been no widespread decentralization of industrial jobs through migration or technological change. Regional economic diversity and independence tend to produce highly varied growth rates and employment opportunities across the country both at any one time and over time.

Nor is the unintended-policy hypothesis particularly applicable. A highly decentralized federal system of government effectively precludes the evolution of any policy aimed 
at centralizing economic and urban development at the national level. If anything, the reverse has been the case. Policies in such sensitive areas as transportation and tariffs have tended to preserve the status quo, often inadvertently preventing further centralization of population and economic activity. Recent political uncertainty in the country as a whole, and specifically with regard to Québec, also adds a rather different dimension to any attempt to account for national growth patterns in terms of public policy, intentional or unintentional. At the provincial level, as noted, the story is very different. This does not mean that researchers can ignore the effects of national policies but rather that simple generalizations are of ten misleading and that any assessment of the spatial imprint of public policy must differentiate between the various scales at which that policy is applied.

\section{SELECTED IMPLICATIONS FOR RESEARCH AND POLICY}

The well-established trend toward much slower population and urban growth rates in Canada is important for at least two reasons. First, since future population growth is likely to be considerably less than anticipated only a few years ago, our expectations and the complex institutional machinery and planning instruments that we have built up to meet those expectations must be revised. There is already considerable evidence that this adjustment process is taking place in certain sectors of economic planning and capital investment (Science Council of Canada, 1977).

Second, declining growth is important in the normative sense that the degrees of freedom (the options) that are available for the design of the future form of urban settlement in Canada have changed. In some instances the options are likely to be fewer in number, as in the establishment of new growth centers in declining regions or in the creation of suburban new towns. Fewer of these massive investments will be needed. In other instances the options may actually increase, e.g., through the opportunity to improve the quality of services in areas which were formerly growing at a rapid rate or in those areas which suffered because limited resources had to go elsewhere. It is incorrect to assume that the rate of change will decline in proportion to the rate of aggregate growth. As Alonso (1973) points out, even with zero population growth overall one could expect structural change within cities and in the urban system to continue if not to increase.

At the level of the urban system perhaps the first and most obvious implication of declining aggregate population growth is that the average growth rate for all cities in Canada has declined and is likely to con tinue to do so. As the entire frequency distribution of urban growth rates shifts downward more metropolitan centers will decline absolutely in population, as Windsor and Sudbury did between 1971 and 1976. Other cities will discover that their anticipated levels of population growth over the next few years, if not decades, will be close to zero. Historically, of course, numerous small cities in Canada have had experience of stagnant or declining populations. Whether the next generation of declining towns will be the same ones remains to be determined.

The problem in terms of expectations may in fact be the opposite of Toffler's widely quoted "future shock". If the rate of new building and of physical urban expansion declines roughly in correspondence with population growth we may find that the future looks very much like the present. As Eversley (1976) argues, the shock may be in an 
awareness that very little, rather than too much, will change in the future, at least in terms of the built environment to which most urban planning policies are directed.

A related question with regard to the urban system is whether the variability of growth rates will increase or decrease as the overall mean growth rate declines. Statistically one might expect the variance to decline as the mean declines but in the Canadian urban system empirical analyses do not show this relationship to be consistent (Simmons, 1974). Directly and indirectly, greater variability could lead to increased inequalities between cities and regions in terms of the size of the local tax base, the number of job opportunities, and the quality of public services. Such inequalities have been a persistent and divisive ingredient in the Canadian federation (Economic Council of Canada, 1977).

The question of inequalities also raises the need to rethink many of our planning practices and policies which assume a now overly optimistic rate of growth in discounting future returns. For example, mortgaging of social investments will need to be more restrictive and investment horizons in general may need to be considerably longer than they are at present. Somehow we must undertake to build the element of uncertainty, which seems to be inherent in Canadian urbanization, in to the process of policy formation.

One specific need in this area is to revise our forecasts of future urban population growth in line with the emerging urban realities. Almost all projections based on data from the 1950s and 1960s are now too high. Forecasts of the population of Canada at the turn of the century (2001) have declined steadily from upper limits of 42.0 million for projections made a decade ago to about 30.0 million for recent projections (Bourne et al., 1974). Recent forecasts by the Department of Finance indicate that the rate of population growth is expected to decline still further in the 1980s and 1990s. In addition, labor-force growth is expected to decline even faster from its very high level of $3.5 \%$ annually in the early 1970s. Productivity and the rate of growth in gross national product are also expected to be lower in the 1980s and 1990s than during the 1960s and 1970s. These last estimates, although directly reflecting the slow growth of the population and labor force as well as a stagnant economy, do suggest that the resources available for technological innovation and for responding to the problems created by a smaller-than-anticipated population base may also be significantly reduced.

To the extent that the previous estimates became part of the conventional wisdom in planning for the urban future of Canada, the revised expectations are important. Although Canada has not had a national urban strategy or even a set of explicitly urban policies which requires immediate rewriting, there are a complex array of sector policies at federal and provincial levels and planning policies at the local level which now require reexamination. Governmental expenditures on a wide range of services (capital-investment decisions on infrastructure are one important example) must be revised, al though not necessarily downwards. Similarly, municipal budgetary planning based on an expected future flow of revenue from residential and business taxes as well as from per capita grants given by senior levels of government must be adjusted accordingly. Further, the expected growth of the economic base including public institutions should be discounted. If the decline is greatest in those urban areas which already have serious problems in providing new jobs and income-earning opportunities, the impact may be even more severe.

However, there are counterbalancing factors. Slower growth may, as argued below, allow municipalities to catch up on services such as the provision of storm and sanitary sewers, transportation, and social overhead capital. Slower population growth will reduce 
the number of new labor entrants and thus may ease some serious but localized unemploy. ment problems. It may also reduce the aggregate demand for housing and land, thereby reducing inflationary price increases.

The aging of the population will also alter mobility and consumption patterns since each age group behaves somewhat differently. An extensive list of consumer goods and services will be affected. Obviously housing and recreational demand will shift toward the needs of the middle-aged and elderly populations. Locations that are favored for retirement will continue to grow but at the expense of other locations. Educational demands will change in a corresponding fashion. Aggregate household investment patterns will also shift, as older populations tend to spend less and save more. Whether these shifts will be more or less significant than others which have taken place in the postwar years remains to be seen.

Slower population and economic growth will not lead, by definition, to improvements in the urban environment. For example, reduced rates of economic growth do not seem to have produced less pollution. Nor will slower population growth necessarily lower the costs of public services since many of these costs represent fixed overhead costs. Moreover, given that these services are normally provided to populations spread over a defined geographic area, which seldom shrinks, spatial servicing costs may remain much the same or even increase.

\subsection{Some Planning and Policy Consequences}

As implied in the foregoing, the institutional consequences of the new urban reality are indeed substantial. At a most basic level declining population growth rates alter the underlying premises of many urban policies and planning procedures. In most instances in the past we were able to avoid dealing with the determinants of current urban problems by emphasizing that attempts were being made to influence increments to the urban system. Thus most of our urban policies were directed to planning new subdivisions, large-scale redevelopment, the design of new transportation systems, new-town schemes, and regional development incentives, rather than at the difficult problem of reallocating resources.

Policy priorities now need to be revised. Increasingly we shall be faced with difficult choices, based on an awareness that with an urban system which is not growing rapidly what we do in one location may preclude doing something in another location. For example, decisions to build new towns or to stimulate the growth of existing centers will have to be assessed against the consequences of preempting growth from somewhere else. Industrial incentive schemes for lagging regions will become more of a zero-sum game between competing alternatives. The issues are obviously much more complex than these examples imply but the examples do suggest the importance of viewing urbanization in terms of an integrated space economy and system of cities which is set within a context of continued uncertainty.

At a local level these difficult trade-offs become even more apparent. For example, large-scale suburban developments, encouraged by improvements in transportation and servicing facilities, will have to be weighed against the possible inducement to inner-city decline. There is a danger of course that faced with these increasingly difficult trade-offs 
few policy decisions will be taken at all. In Canada, which has not had a national urban policy in any form, formal revisions to urban policies are not as important as revisions to sector policies. What is necessary is that the criteria for decisions on substantial programs and public investment (e.g., decisions relating to capital funding for new housing, urban in frastructure, and airports) should also be reassessed.

\section{CONCLUSIONS}

The argument in this paper is that a new urban reality is emerging in Canada. Significant changes have been documented in population growth rates, interregional and international migration, demographic structure, and metropolitan concentration. These trends in turn raise a number of basic questions with regard to the implications of the emerging urban fabric for public policy, planning, and research.

Perhaps the foregoing interpretations represent an overreaction to recent and essentially short-term trends. Relative to most western countries, urban growth in Canada will continue in the foreseeable future at a significantly high rate. There is not sufficient evidence to warrant a firm conclusion that metropolitan decline will become widespread. Recent shifts in migration flows may also turn out to be short-term cyclical responses to particular changes in the national economy, as has often been the case in the past. Moreover, if our past record is anything to go by, projections based on these recent trends will also probably be wrong.

Nevertheless, it does not seem unreasonable to conclude that many of our perceptions and expectations of urbanization, as well as the policies and research strategies based on those perceptions, are now outdated. The parameters of urbanization, of population growth, and of migration have indeed changed. If we add to these changes continued inflation and economic uncertainty and fluctuations in the prices of staple products, then the overall climate for urban growth no longer closely resembles that of the 1950 s and 1960s. Policies must be designed to deal with, or at least to allow for, both slower urban growth and economic uncertainty.

The aggregate spatial structure of the Canadian urban system is still much the same as it was a decade or two ago and only minor changes in that structure are anticipated in the immediate future. There has been a continual historical process of economic deconcentration in Canada, particularly from industrial to resource regions and from the east to the west generally. However, this economic shift and the power it represents are also increasingly likely to lead to a major adjustment in the Canadian political fabric.

Thus with declining urban growth rates, demographic change, and economic and political uncertainty, a new set of problems emerges. In part this conclusion reflects the long-standing tendency in our society to redefine - or "reframe" in Schon's words (Schon, 1977) - old problems rather than to undertake to solve these problems, but in part at least the urban problems are now different and inherently more political. Rapid growth, where it does occur, becomes more location specific and thus more of a regional or localized problem than a probleı $i$ on the national scale. However, its impact may also be more severe, necessitaling more spatially sensitive national policies. Redistribution and the reallocation of existing resources become more central policy issues than the anticipation and redirection of rampant growth. 
Urban planning must turn increasingly to the improvement of the existing built environment rather than the design of new urban monuments (Eversley, 1976). Similarly, as Gans (1975) illustrates, we must begin planning explicitly for cities which are declining in population and resources. The tasks involved are perhaps less exciting than those in the cra of unlimited growth but they are no less important.

\section{REFERENCES}

Alonso, W. (1973). Urban zero population growth. Daedalus, The No-Growth Society, Special Issue 102:191-206.

Berry, B.J.L. (1970). The geography of the US in the year 2000. Transactions of the Institute of British Geographers, 13:21-53.

Berry, B.J.L. (1975). The decline of the aging metropolis: cultural bases and social processes. In G. Sternlieb and J.W. Hughes (Editors), Post-Industrial America. Rutgers University Press, Rutgers, New Jersey, pp. 175-186.

Berry, B.J.L. (1976). Urbanization and Counterurbanization. Urban Affairs Annual Review, No. 11. Sage Publications, Beverly Hills, California.

Berry, B.J.L. (1978). The counterurbanization process: how general? In N. Hansen (Editor), Human Settlement Systems. Ballinger, Cambridge, Massachusetts, pp. 25-50.

Berry, B.J.L. and Gillard, Q. (1977). The Changing Shape of Metropolitan America. Ballinger, Cambridge, Massachusetts.

Bettison, D.G. (1975). The Politics of Canadian Urban Development. University of Alberta Press. Edmonton.

Blumenfeld, H. (1977). Beyond the Metropolis. Papers in Planning and Design. Department of Urban and Regional Planning, University of Toronto, Toronto.

Bourne, L.S. (1975). Urban Systems: Strategies for Regulation. A Comparative Analysis of Urban Policy in Australia, Britain, Canada and Sweden. Oxford University Press, Oxford.

Bourne, L.S. (1978). Emergent realities of urbanization in Canada: some parameters and implications of declining growth. Research Paper No. 96. Centre for Urban and Community Studies, University of Toronto, Toronto.

Bourne, L.S. and Simmons, J.W. (1979), Canadian Settlement Trends: The Spatial Pattern of Growth, 1971-76. Major Report No. 15. Centre for Urban and Community Studies, University of Toronto, Toronto.

Bourne, L.S., et al. (Editors) (1974). Urban Futures for Central Canada. Perspectives on Forecasting Urban Growth and Form. University of Toronto Press, Toronto.

Britton, J.N.H. (1978). Locational perspectives on free trade for Canada. Canadian Public Policy, IV(1):4-19.

Curry, L. (1976). Locational theoretic style and urban policy. Economic Geography, 52(1):11-23.

Department of Manpower and Immigration (1975). Internal migration and Immigrant Settlement. Information Canada, Ottawa.

Economic Council of Canada (1977). Living Together: A Study of Regional Disparities. Ministry of Supplies and Services, Ottawa.

Eversley, D. (1976). Planning Without Growth. Fabian Society Papers, London.

Friedmann, J. (1973). The future of the urban habitat. In L.S. Bourne and J.W. Simmons (Editors), Systems of Cities: Readings on Structure, Growth and Policy. Oxford University Press, New York, pp. 80-82.

Gans, H. (1975). Planning for declining cities. Journal of the America I Institute of Planners, 41 : 305-307.

Gertler, L. and Crowley, R. (1977). Changing Canada's Cities. McClelland and Stewart, Toronto.

Hansen, N. (Editor) (1978). Human Settlement Systems: International Perspectives on Structure, Change and Public Policy. Ballinger, Cambridge, Massachusetts. 
Kain, J.F. (1975). Implications of declining metropolitan population on housing markets. In G. Sternlieb and J.W. Hughes (Editors), Post-Industrial America, Rutgers University Press, New Brunswick, New Jersey, pp. 221-230.

Leven, C.L. (1978). The Mature Metropolis. D.C. Heath, Lexington, Massachusetts.

Lithwick, H. (1972). Urban policy making: shortcomings in political technology. Canadian Public Administration, 15:571-584.

Matthews, R. (1977). Canadian regional development strategy: a dependency theory perspective. Plan Canada, 17(2):131-143.

Ministry of State for Urban Affairs (1975a). Interim population projections of 22 census metropolitan areas, 1971-2001. Discussion Paper B-75-10. Ministry of State for Urban Affairs, Ottawa.

Ministry of State for Urban Affairs (1975b). Canadian Settlements. Perspectives. Information Canada, Ottawa.

Ministry of State for Urban Affairs (1977). Recent trends in the growth of Canadian urban centres. Background Paper. Settlement Patterns Directorate, Ottawa. (Mimeograph.)

Morrison, P. (1975). The current demographic context of national growth and development. Rand Paper Series, P-5514. Rand Corporation, Santa Monica, Califomia.

Ray, D.M. et al. (1976). Canadian Urban Trends, Copp Clark, Toronto.

Schon. D.A. (1977). Framing and reframing the problems of cities. (Mimeograph.)

Science Council of Canada (1975). Perceptions 1 : Population. Science Council of Canada, Ottawa.

Science Council of Canada (1977). Canada as a conserver society. Resource uncertainties and the need for new technologies. Report No. 27. Science Council of Canada, Ottawa.

Simmons, J.W. (1974). The growth of the Canadian urban system. Research Paper 69. Centre for Urban and Community Studies, University of Toronto, Toronto.

Simmons, J.W. (1977). Migration and the Canadian urban system: Part 1, spatial patterns. Research Paper 85. Centre for Urban and Community Studies, University of Toronto, Toronto.

Simmons, J.W. (1978). The great Canadian factor analysis: dimensions of variation in the Canadian urban system. Research Paper 93. Centre for Urban and Community Studies, University of Toronto, Toronto.

Simmons, J.W. (1979). Mysteries of urban growth: a cross-sectional analysis of the Canadian urban system. Research Paper 114. Centre for Urban and Community Studies, University of Toronto, Toronto.

Statistics Canada (1971). Census Bulletin 92-702. Statistics Canada, Ottawa.

Statistics Canada (1977a). Census of Canada, 1976: Preliminary Population Counts, Census Metropolitan Areas and Census Agglomerations. Statistics Canada, Ottawa. (Mimeograph.)

Statistics Canada (1977b). Household and family projections to 2001. Catalogue 91-517 (Series C Forecasts). Statistics Canada, Ottawa.

Statistics Canada (1977c). Final population counts. Catalogue 92-806 (October). Statistics Canada, Ottawa.

Statistics Canada (1977d). International and interprovincial migration in Canada: 1961-1962 to 1975-1976. Catalogue 91-208. Statistics Canada, Ottawa, pp. 107-111.

Sternlieb, G. and Hughes, J.W. (Editors) (1975). Post-Industrial America: Metropolitan Decline and Inter-Regional Job Shifts. Rutgers University Press, New Jersey.

Stone, L.O. and Marceau, C. (1977). Canadian Population Trends and Public Policy Through the 1980s. Institute for Research on Public Policy, Montreal.

Vaughan, R.J. (1977). The urban impacts of federal policies: Vol. 2, Economic development. R-2028KF/PC. Rand Corporation, Santa Monica, Califomia.

Vining, D.R., Jr. (1977). Review of post-industrial America. Joumal of Regional Science, 17(1): $141-146$. 


\title{
SETTLEMENT SYSTEMS: DEVELOPMENT AND MANAGEMENT STRATEGIES
}

\author{
A.V. Kochetkov and O.S. Pchelintsev \\ All-Union Institute for Systems Studies, Academy of Sciences of the USSR, \\ Moscow (USSR)
}

\section{INTRODUCTION}

Changes in the settlement system are a global process occurring in countries with different social structures and development levels. All over the world networks of rural commu nities are being transformed into hierarchical systems of small, medium-sized, and large towns. Within this system a transition occurs from point-like urban centers to a system of urban agglomerations and urbanized zones. As research and planning experience shows, the problems that are posed by this process can only be soived efficiently through a systems-oriented organization of a network of settlements within the framework of nationwide long-term socioeconomic planning.

The analysis of settlement organization at an international level can be seen as an important tasks since separate studies of individual national set tlement strategies have been reported on extensively in the available literature (see Swain and McKinnon, 1974).

\section{POPULATION (OCCUPANCY PATTERNS) AND SETTLEMENT}

Population is defined here as the totality of people inhabiting a territory and sharing certain demographic, socioprofessional, cultural-educational, ethnic, and other characteristics. The term settlement is used to denote the process (and also the result) of the spatial location of residential units that interact with one another as well as with other gravitation centers. The latter are represented by cultural institutions, service establishments, and recreation facilities as well as industrial plants viewed as sites where labor is employed. Specific gravitation centers include attractive natural landscapes.

The settlement system takes shape as the result of the functional and spatial organization (including self-organization) of settlement units and gravitation centers. An efficient organization is one that leads to the improvement of socioeconomic living conditions while providing for intensive links between the residential units and the gravitation centers. 
According to the type of gravitation center (centers of regional importance and me tropolitan complexes) and the intensity of relations with it (daily, periodic, and sporadic services) one can distinguish various territorial levels in the settlement system. It is convenient to use as a starting point the notion of a settlement unit (where the majority of the system-forming relationships are concentrated) and then go upward to a system of such units or downward to their planning elements.

The chief characteristic of the population is its activity level, which depends on the pattern of material production and evolves through development phases corresponding to the specific combinations of social, natural, economic, and cultural factors in the area concerned.

Different types of production and services present different requirements with regard to the structure of the economic and social space and therefore with regard to the shaping of the network of settlements. For example, a village (rural place) is a specific settlement form which meets the technological and social needs of traditional agriculture. As handicraft separates from farming, communications and trade develop, towns emerge, and urbanization sets in. This process is accelerated by industrialization once the extracting and manufacturing indust ries have become cornerstones of production. This evolutionary phase culminates in a hierarchical system of large, medium-sized, and small towns linked by railroads and waterways.

Electricity, private and high-speed municipal transport, the telephone, and advanced public services make up the basis for suburbanization and the transition from "point" towns to city agglomerations and urbanized areas, and even megalopolises.

The latest stage in settlement evolution has been related to the scientific and technological revolution. For the first time ever it has become possible to rebuild the entire settlement system according to a plan and in keeping with socioeconomic targets (the degree to which this is possible varies for countries with different social systems and different levels of economic and social planning development). Technological progress and the shift from extensive to intensive economic growth produce profound changes in way of life, with a sharply increased share of information activity in a person's time budget and more leisure time. The human aspect of settlement - individual needs and preferences concerning dwellings, amenities, and transport - move to the foreground. Migration begins to play a major part in shaping the residential structure (involving commuting and intraregional and interregional migration). As a result new requirements are imposed on the settlement pattern which now has to ensure a wide range of social and spatial conditions for improved living standards, human development, manpower reproduction, and the efficient functioning and progress of the modern economy.

\section{A CONCEPT OF SETTLEMENT SYSTEM}

The systems-oriented organization of settlement derives its importance from the increasing role of spatial factors in socioeconomic development. Until recently these factors were largely associated only with the economic effects of production concentration and were studied in the framework of the location of enterprises and industries. It is characteristic of the present period that residential factors are such that social, cultural, and ecological considerations are actively influencing the functional and spatial 
organization of the settlement network. This has strong impacts on the course of economic development and the basic parameters of the way of life such as individuals' time budgets.

The reasons for this are the following: (1) a high level of urbanization in the developed countries and the extraordinary growth of urbanization in the developing countries. leading to the increasing importance of interdependences between the hierarchical structure of towns and cities and the spatial pattern of production; the role of agglomeration cionomies; (2) the changing pattem of social preferences towards a broader compound conception of the quality of life and the sociocultural and ecological milieux, i.e., characteristics closely linked with the settlement patterns; (3) the development of the transport infrastructure integrating residential units into systems and enhancing the effect exerted by a given settlement pattem on production and social processes; and (4) the increased availability of resources, which allows a choice of strategies, forms, and patterns of settlement, the emergence of major social institutions aiming at the implementation of this potential, including socially owned means of production, centralized long-range planning combined with strong local administration and democratic procedures for identifying public needs and interests.

The settlement strategy under these conditions becomes a major tool for the transtormation of all sociospatial structures and living conditions and a key to controlling the location of production, migration, and regional development. The implementation of these wider socioeconomic functions of settlement is of course not a smooth process. For a long time social and ecological targets have existed solely as needs of which people have been aware but which they have not internalized into a structure of decision-making criteria. However, the inevitably growing conflicts between economic development and the quality of life and between the effective organization of the sociospatial environment and the handicaps in the functioning of traditional urban and rural settlement patterns inakes systematic transformation of the existing network of settlements a necessity.

The technological revolution gives top priority in industrial location to such factors as distance to scientific, educational, and cultural facilities, infrastructure, landscape and climate, skilled manpower, availability of vacant land, water resources, and adequate housing. Conversely, traditional technological and economic factors (raw materials, transport, and energy), until recently thought of as basic in the dynamics of industrial location. are now losing some of their importance (Urbanization, Scientific and Technical Revolution, and the Working Class, 1972). Social qualities of settlements such as the elimination of socioeconomic differences between the urban and rural environments and the cultural and educational activity of ethnic minorities are also growing in importance.

All this means that a failure to pay due regard to the active role of settlement will in the long run hamper economic growth, which increasingly depends on labor quality which is now largely a product of the social and spatial environment, i.e., of the functional and spatial organization of the residential network.

A transition to a system-oriented organization of the settlement network therefore requires a revision of the theoretical location models of production and of the mechanisms of allocating resources between industries and regions so as to take into account the intervening factors and long-term socioeconomic goals. In practical terms this will mean raising the values of social and ecological goals relative to the values of economic goals and providing more resources for infrastructure and services. 


\subsection{Settlement Development Goals}

If a settlement network is to develop efficiently it must be a process directed by clearly defined goals (Use of Applied Systems Analysis in Urban Design and Development Management, 1974; Urbanization and Settlement Problems, 1976). In terms of control management, settlement location can be viewed as the technology of achieving by means of functional and spatial organization three major types of goal: namely, social, ecological, and economic.

The social goal of settlement is to ensure the basis for an adequate standard of living for both the urban and rural populations whatever their choice of residence is. This goal is subdivided into a number of specific targets: (1) comfortable living environment and amenities; (2) a controlled population density; (3) easy access (in space and time) to, and a wide choice of places of employment, recreation, services, etc.

The ecological goal is to ensure standards of environmental preservation and improvement. This implies that by means of functional and spatial organization we preserve favorable sanitary conditions, green zones, and natural landscapes (with due consideration of the growing pressure on recreation areas), enforce noise control in residential areas, and maintain water and other ecological balances.

The economic goal of settlement is to ensure the efficient location of production and the growth of productivity. This involves creating favorable conditions for advanced training and education of the labor force, the development of industrial zones and research centers, provisions for the economic development of cities, only limited use of high-quality land for construction sites, etc.

Experience shows that these goals can be defined as operationally ranked and can be expressed in terms of specific time standards or at least described in terms of quantitative and qualitative targets. Thus it is possible to assess priorities and to choose effective settlement strategies.

\subsection{Settlement Development Problems}

General problems of a system-oriented organization of settlement are related to the following: (1) excessive growth of the few big agglomerations resulting in the underdevelopment of regional and local centers, social and economic depression in peripheral areas, and deteriorating economic, social, and ecological conditions in the agglomerations themselves; (2) the continuing existence of a great number of isolated small and mediumsized settlements offering a limited choice of employment, recreation, and educational opportunities: (3) inefficient land use (urban encroachment on good farm land, devastation of natural landscapes and green areas, deterioration of recreational areas, and longer commuting times when traveling to work and other destinations); (4) underutilization of the scientific, tech.rical, cultural, and educational potential of cities due to insufficient development of their zones of influence; (5) environmental pollution and industrial and transport noise; and (6) poor elaboration and/or partial implementation of plans and projects. 


\subsection{Resources and Constraints}

If we look at the organization of the settlement network as a goal-oriented process we must first identify the resources and constraints as represented by a set of natural, demographic, social, economic, and administrative factors of settlement. The functional and spatial organization is a process whereby all these resources are integrated since it is the only way in which human-settlement development goals can be achieved (Problems of Modern Urbanization, 1972; Resources, Environment, Settlement, 1974).

The underlying decision-making process consists of an analysis of the available resources at four principal hierarchical levels (nation, region, settlement group, settlement unit), a forecast of resource demands, an estimation of the possible growth of resources in time, and, finally, the planning (allocation) of resources. The analysis and estimation of resources is carried out in terms of their amount, composition, and technical, economic, and socioecological characteristics. The short supply of internal resources at each level (e.g., the lack of free land plots, recreation zones, investment capital, and employment opportunities) is estimated and the potential for supplying it from the resources of the upper level are considered. The general conditions of resource mobility in the system under study determine the mobility between the hierarchical levels themselves. There is a tendency towards a gradual decrease of the spatial isolation of individual communities, changing boundaries of the lower-level units, and increasing integration of the upper-level units. This process is based on the growing horizontal mobility of population which in turn depends on increasing professional specialization, cultural and educational levels, recreational needs, transport infrastructure, and other factors.

The effective use of resources depends on the combination of labor-intensive and labor-saving as well as capital-intensive and capital-saving characteristics of settlement patterns, in accordance with particular resource constraints. An estimation of the resourceutilization intensity in the domain of settlement can differ greatly from that in the production sphere. For example, intensive land use and very high population and building densities may be economically efficient but they normally lead, ceteris paribus, to a deterioration of living conditions. This means that one should rather opt for smaller-scale buildings and larger green areas.

For present-day conditions it is essential to keep in mind that many of the resources that play a part in the organization of settlement systems (the recreational quality of the environment, economic externalities, leisure time, etc.) have no market price and appear in the decision-making considerations as nonmonetary costs and benefits. This necessitates substituting for them more easily measurable and marketed resources which are meticulously accounted for and economized on in private as well as state-owned enterprises. However, economic evaluations of such nonmonetary factors have been made possible owing to cost-benefit analysis and have been successfully practised in planning and development. In the domain of settlement planning, economic estimates of land, ecological consequences (especially of environmental pollution), recreation resources, and leisure time are particularly important. Based on the costs of substitution of the resource in question, such estimates should allow $₫$ general the implementation of corresponding payment relationships. The evaluation of the cost of leisure time may be a specific tool in planning the residential network. Indeed one can regard settlement as a cybernetic device for implementing the spatial and temporal standards of the socially preferable model of 
way of life. Deviations of the real time budget from that standard constitute an important parameter of the quality of life and can be assessed in cost-benefit terms. In the USSR this cost, taken as corresponding to the productivity increment of a working hour in material production, was estimated for the mid-1970s at 65-90 kopecks an hour (subjective consumer estimations giving the "willingness to pay" for an extra leisure hour also present values in the range $0.5-1$ ruble) (Gurevich et al., 1978).

Together with the economic criteria, the direct social criteria of the utilization of natural-ecological, scientific-technical, and organizational-managerial resources have been gaining in importance (in the last case the government policy of creating model dwelling complexes, new cities, and settlement networks is in itself an important resource).

The set of settlement-development constraints largely coincides with the set of resource constraints. Apart from that, technological change, industrial trends, and social change play a major role. For example, structural economic shifts lead to substantial differences in the development of human settlements: generally cities with an economic base consisting of new and fast-growing industries have shown faster rates of growth.

Another group of conditions that determine the organization of the residential system are social conditions. These factors include increasing social mobility, improving educational and cultural standards, an increased amount of leisure time, motoring, etc. By their joint effect the factors generate a certain "social orientation" of the location of production, stimulating migration into areas with favorable social, cultural, and naturalclimatic conditions, diverse employment opportunities, and rich recreational and service facilities.

There is an objective succession in the development of the settlement patterns themselves, and this also leaves an imprint on the choice of strategies for their transformation. A planner of a settlement network must take into account the following.

(1) The evolution of the settlement is a concentrated sociospatial expression of the development of human activity itself and in that sense represents an objective and inevitable process. The planner must base his decision making for this life pattern on the entire model of the human way of life, which can be expressed operationally, for example, in terms of time budgets; i.e., he can only choose freely from a set of settlement patterns (types of functional and spatial organization) which conform to the given activity pat. terns (of course, with due regard for the reciprocal effect that his choice will have on these patterns).

(2) From this point of view many settlement development concepts that have traditionally been suggested by architects and urban planners and which involve priority being given to the growth of isolated small and medium-sized towns or lack of recognition of the role of the hinterland zones of major urban centers, etc. in fact violate the system-oriented planning principle. They address the planning problems apart from or even contrary to the needs of economic and social development, production intensification, the merging of research and development and industrial organizations, the growth of cultural and educational needs, improved recreation facilities, and other factors.

(3) Changes in existing settlement patterns, if the patterns are viewed as unfavorable, are generally connected with changing social institutions. The nature of these changes, their scale, and the capacity to implement them under the given structure of interests and social forces should be clearly understood by a planner who wants to avoid utopian projects. 
A number of these factors, especially the social ones, can be expressed rather clearly by goal functions defined within the framework of multicriteria models of settlement. The remaining factors must be taken into account in forming goal alternatives.

\subsection{Main Alternatives in the Organization of Settlement Systems}

For an objective evaluation of the main development altematives one must define the goals, resources, and constraints in the organization of settlement systems.

The basic alternatives are (1) centralized self-contained development, (2) balanced self-contained development, (3) interlinked group development, and (4) linear development.

The altematives are characterized in Table 1 and their three-factor dynamic evaluation is given in Figure 1.

Since the settlement criteria are of diverse nature (social, economic, ecological, etc.) it is convenient to estimate them quantitatively on the basis of some standards, i.e., as deviations from these standards. The general estimate of an alternative can be defined as the average weighted (with respect to goal priorities) sum of the estimates over all criteria.

Estimates can be made in monetary terms. The criterion will be the discounted difference of the complete (retaining the implementability estimate) socioeconomic effect and the costs of achieving it. As can be seen from a comparison of the diagrams

TABLE 1 Outline of the main alternatives of settlement system organization.

\begin{tabular}{|c|c|c|c|}
\hline $\begin{array}{l}\text { Centralized } \\
\text { self-contained } \\
\text { development } \\
\text { (see Figure 1a) }\end{array}$ & $\begin{array}{l}\text { Balanced } \\
\text { self-contained } \\
\text { development } \\
\text { (see Figure } 1 \text { b) }\end{array}$ & $\begin{array}{l}\text { Interlinked group } \\
\text { development } \\
\text { (see Figure Ic) }\end{array}$ & $\begin{array}{l}\text { Linear } \\
\text { development } \\
\text { (see Figure 1d) }\end{array}$ \\
\hline $\begin{array}{l}\text { (1) Number and popu- } \\
\text { lation of towns with } \\
\text { more than } 250,000 \\
\text { inhabitants increase } \\
\text { (2) Growth of smail } \\
\text { and medium-size } \\
\text { towns is limited } \\
\text { (3) Urban agglom- } \\
\text { erations develop } \\
\text { (4) Settlement inter- } \\
\text { relations are not } \\
\text { regulated; they can be } \\
\text { traced only in agglom- } \\
\text { erations }\end{array}$ & $\begin{array}{l}\text { (1) Predominant } \\
\text { growth is in small } \\
\text { and medium-size } \\
\text { towns } \\
\text { (2) Growth of } \\
\text { larger centers is } \\
\text { limited } \\
\text { (3) Growth of } \\
\text { urban agglomer- } \\
\text { ations is limited }\end{array}$ & $\begin{array}{l}\text { (1) Towns develop as } \\
\text { centers, subcenters, } \\
\text { or other elements of } \\
\text { group systems of } \\
\text { settlement of various } \\
\text { sizes joined together } \\
\text { into regional and } \\
\text { national systems } \\
\text { (2) Urban agglomer- } \\
\text { ations are recon- } \\
\text { structed on the basis } \\
\text { of group-system } \\
\text { projects } \\
\text { (3) Outlying areas } \\
\text { develop on the basis } \\
\text { of group systems of } \\
\text { settlement with a } \\
\text { common infrastructure } \\
\text { rather than around } \\
\text { individual "growth } \\
\text { centers" }\end{array}$ & $\begin{array}{l}\text { (1) Main and second- } \\
\text { ary axes of develop- } \\
\text { ment are formed as } \\
\text { integrated utility and } \\
\text { transportation infra- } \\
\text { structure channels } \\
\text { (2) New jobs are } \\
\text { concentrated within } \\
\text { 1-2 travel hours from } \\
\text { development axes } \\
\text { (3) Creation of new } \\
\text { and development of } \\
\text { existing small and } \\
\text { medium-size towns } \\
\text { as well as reconstruc- } \\
\text { tion of villages is } \\
\text { confined to zones } \\
\text { accessed tn the } \\
\text { development axes }\end{array}$ \\
\hline
\end{tabular}


(a) "Big Cities" (centralized growth)

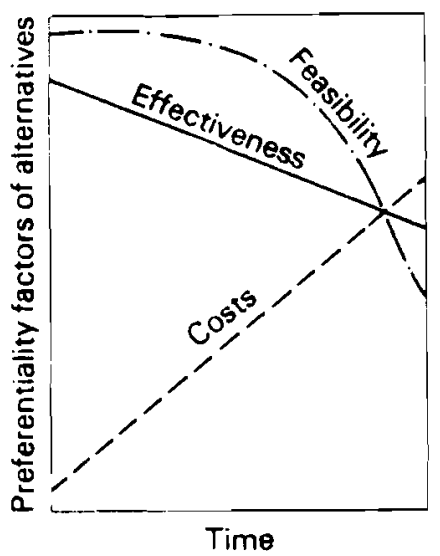

(c) "Group Systems" (interlinked growth)

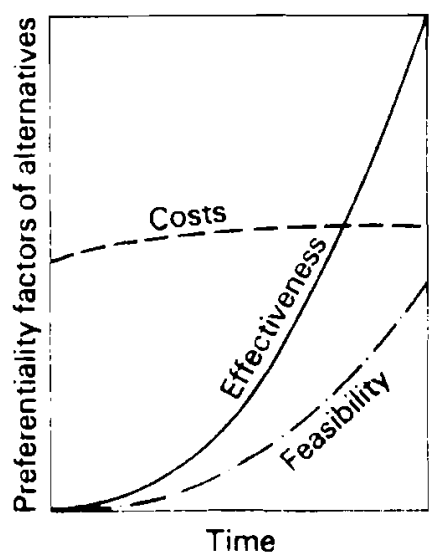

(b) "Uniformity" (balanced growth)

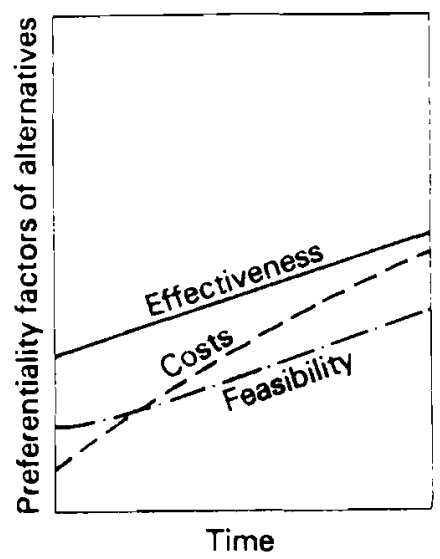

(d) "Axes" (directional growth)

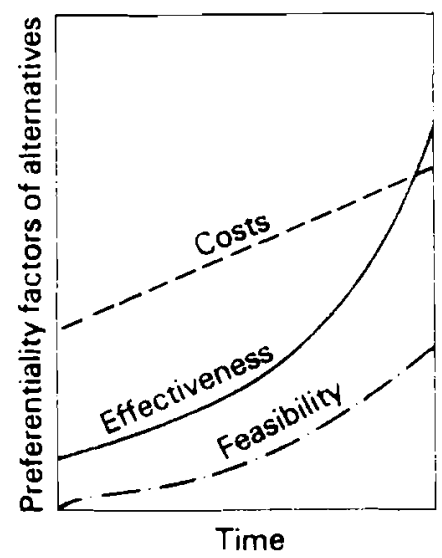

FIGURE 1 The dy namics of the relationships of preferentiality of the main settlement alternatives. A short description of each settlement alternative is given in Table 1.

in Figure 1, the system-oriented development of a residential network (alternative (c)) on the basis of long-term projects (plans) has the highest effectiveness, which increases with time; costs are high but increase more slowly as the transport infrastructure expands. The feasibility of this alternative, not high initially, increases gradually at later stages as resources grow while the problems of alternative developments become aggravated. Hence we can conclude that under the conditions of the scientific and technological revolution the specific form for implementing the systems approach in urbanization and settlement organization is the plan-governed creation of a new type of settlement unit - group systems of human settlements. These groups are defined as interlinked sets of urban and rural 
communities whuch are connected by territorial and production linkages, have a common urban core (central city) within 1-2 hours' travel time, an integrated transport and engineering infrastructure as well as service and recreation networks, and are linked in terms of joint use of zones situated between individual settlements (Khodzhaev et al., 1977).

The efficiency of settlement organization on the basis of group systems of settlement manifests itself in the following ways: (1) integration of economic and social interests on the basis of the simultaneous growth of production concentration and population decentralization, achieved through transition from local (point-like) spatial patterns to zonal organization; (2) improved control of urbanization, i.e., effective limitation of metropolitan growth through redistribution of existing and new working places in favor of the external zones: (3) favorable conditions for the development of small and mediumsize settlements which, having been included in the system, can grow as a result of the decentralization of specialized branches of the central city's enterprises; (4) reduced time spent on travel to cultural, service, and recreational centers, expanded choice of activities for the rural as well as the urban population, and increased possibilities for intensified professional and cultural contacts which are particularly important for people living in small urban communities; and (5) favorable conditions for faster growth and better use (1) the transport and engineering infrastructure and the construction-industry capacities and services by avoidance of the negative effects of overcrowding or, conversely, the excessive spread of urban activities (these negative developments are unavoidable when industries are concentrated in very limited already-crowded areas of the old urban nuclei or when attempts are made to establish industrial plants in each of the independently developing small and medium-sized towns, respectively.)

At the regional level the task is to select the centers and to coordinate the development of the group systems of various sizes, thereby taking into account the urbanization dynamics and the growth of the transport infrastructure (the latter influences both the size and the number of systems). At the national level the task is to choose the centers, to coordinate the development of the regional systems, and to solve special problems of settlement in the boundary zones.

\subsection{The Adequacy of Urban and Settlement Models}

The analysis of problems and the choice of characteristics for a systems-oriented settlement organization under the particular sucioeconomic conditions of each nation calls for the widespread use of models of urbanization, migration, and the growth of hierarchical city systems. A number of relevant models have been built and empirically tested. These include the Lowry-type models of urban spatial structure (Lowry, 1964; Garin, 1966: Wilson, 1974; Systems Approach Used in Urban Planning and Development, 1977; Crecine, 1968), the Forrester-type models of urban growth (Forrester, 1974), and the Harvard Planning School model (Steinitz and P. Rogers, 1970). Also the literature on migration modeling and on hierarchical patterns of settlement (starting from the classical studies of Christaller and Lösch) is quite abundant (see for example: Goldstein and Moses, 1973; Stouffer, 1940; Wadycki, 1974; Miller, 1972; A. Rogers, 1967, 1975; Isard, 1974; Matlin, 1972; Doxiadis, 1967). Several review papers are available which discuss the merits and limitations of the individual types of model referred to here. Hence in the 
present paper only a brief treatment of some general features of urban and settlement models will be given.

The growing scale, complexity, and dynamism of socioeconomic change call for the development and application of mathematical models in settlement planning. However, in practice the introduction of this approach has been rather slow. This has generally been due to (a) the limitations of existing settlement models, and (b) the lack of a suitable organizational framework in existing administrative procedures.

The critical condition for introducing models into settlement planning and urban management is the improvement of the quality of the models with respect to the treatment of (a) the object of modeling (i.e., the settlement system itself), (b) the control process in the operational time dimension, and (c) the psychological stereotype of the decision maker.

In order to meet the first condition one has to take into account numerous socioeconomic relationships by formulating explicitly the following types of models: (i) qualitative models of settlement systems which consider characteristics, tendencies, and mechanisms of settlement development; (ii) qualitative models of settlement control; (iii) models of individual blocks suitable for formalization blocks in the control system; (iv) models of the control blocks that are unsuited for a formal representation (including the operational models of the decision maker's behavior); ( $v$ ) models of the interaction of the formalized and the nonformalized blocks in the operational control-time dimension.

Fully formalized models are typically characterized by significant lacunae in their descriptions of the settlement system. However, an explicit formulation of alternative models is impossible without major breakthroughs in the methodology of the systems analysis of settlement and without progress in the general theory of the control of socioeconomic processes. A substantive and down-to-earth approach in this context deals with the choice of strategies and alternatives of settlement development in relation to the development of the organization and methods of control. The organizational aspect of urban and settlement management is now moving to the foreground since it largely determines the capacity for system-based control of the entire settlement process on the basis of national programs. This assumes the interdependence of the methods and technology, of optimum locational choice on the one hand and the methods and technology of management on the other.

\section{METHODOLOGICAL ASPECTS OF SYSTEMS ANALYSIS OF SETTLEMENT}

Systems analysis does not as yet constitute any closed system of strict formal rules for research and decision making. It grows out of the need for interdisciplinary synthesis in the tield of management and control of complicated and fast-growing systems (settlement is one of these) and so appears as an open, flexible, and expanding methodology,

For its part, the systems analysis of settlement is making a certain impact on the general methodology of systems research. This impact stems from the specific place that settlemen. occupies in the structure of contemporary socioeconomic development.

Decision making in socioeconomic fields represents a specific and basically nonformal optimization since formalized models usually cover selected relationships only. Therefore the synthesis of spatial models into an integrated system of models of 
socioeconomic development will be a major task for systems analysis. Some interesting results in this field have already been achieved (see for example Danilov-Danilyan and Zavelsky, 1975). In modeling socioeconomic processes it is essential for the description of the system to be subordinated to the tasks of the comprehensive management of the system's development; i.e., the systems-orientation criterion in socioeconomic research is not a comprehensive description of the elements and relationships in the object under study as such but rather their description in decision-making terms.

All these characteristics (problem orientation, the subordination of the description of a system to the requirements of control, an emphasis on the solution (and not just registration) of social problems) reflect new aspects in the work of systems analysts and designers which are linked with their orientation towards social values and interests. This becomes a necessity since the aggravation of the settlement problem goes parallel to the expansion of mankind's resources and potentials and the formation of institutions and social forces that are capable of ensuring efficient solutions of these problems.

This problem orientation in the systems analysis of settlement has certain methodological consequences; in particular it brings a bias towards the consideration of the structure of social needs rather than the economic interests of previously formed components of the regional economy. The systems model of settlement is an expression of the need for a more comprehensive socioeconomic approach and a shift to a balanced structure of criteria, with the ecological and social targets being given greater weight than is the case in the conventional production-oriented model. One can even say that the systems analysis of settlement, because of its links with a wide range of regional planning and management problems, most strongly represents the tendency for bringing the structure of the objective function into harmony with the system of social values and resources.

Indeed ecological and social values are gaining inportance when they are closely interwoven with the spatial aspect of planning and management, which involves among other things the solution of industrial problems such as the location of industries, the coordinated development of industries in a region, and the formation of technical infrastructure. However, the central place in regional management is occupied by functions concerned with settlement organization, the development of the living environment of people and their professional activity, the efficient use and protection of natural resources, and the development of social infrastructure and services.

\section{REFERENCES}

Crecine. J.P. (1968). A dy namic model of urban structure. P-3803. Rand Corporation, Santa Monica, California.

Danilov-Danilyan, V.I. and Zavelsky, M.G. (1975). Systems of Optimum Long-Range Planning of the National Economy. Problems of Theory and Methodology, Nauka, Moscow. (In Russian.)

Doxiadis, C. (Director) (1967). Emergence and Growth of an Urban Region: The Developing Urban Detroit Area. Detroit Edison Company, Detroit, Michigan.

Forrester, J. (1974). Development Dy namics of a City. Progress Publications, Moscow. (In Russian.)

Garin, R.A. (1966). A matrix formulation of the Lowry model for intrametropolitan activity location. Journal of the Am' '-an Institute of Planners, 32(4):361-364.

Goldstein, G.S. and Moses, L.N. (1973). A survey of urban economics. Journal of Economic Literature, 11(2):471-495.

Gurevich, G.L., Melnikov, D.I. and Pchelintsev, O.S. (1978). On economic evaluation of leisure time. 12vestiya Akademii Nauk SSSR, Seriya Ekonomicheskaya, (1). (In Russian.) 
Isard, W. (1956). Location and Space Economy. Wiley, New York.

Khodzhaev, D.G., Kochetkov, A.V. and Listengurt, F.M. (1977). Settlement Systems in the USSR. Ekonomika, Moscow. (In Russian.)

Lowry, I.S. (1964). A Model of Metropolis. RM-4035-RC. Rand Corporation, Santa Monica, California.

Matlin, I.S. (1975). Modeling of Population Distribution. Nauka, Moscow. (In Russian.)

Miller, E.A. (1972). Note on the role of distance in migration: costs of mobility versus intervening opportunities. Journal of Regional Science, 12(3):475-478.

Problems of Modern Urbanization (1972). Statistika, Moscow. (In Russian.)

Resources, Environment, Settlement (1974). Nauka, Moscow. (In Russian.)

Rogers, A. (1967). Markovian policy model for interregional migration. Papers of the Regional Science Association, 17:205-224.

Rogers, A. (1975). Introduction to Multiregional Mathematical Demography, Wiley, New York.

Steinitz, C. and Rogers, P. (1970). A system analysis model of urbanization and change: an experiment in interdisciplinary education. MIT Report No. 20. Massachusetts Institute of Technology, Cambridge, Massachusetts.

Stouffer. S.A. (1940). Intervening opportunities: a theory relating mobility and distance. American Sociological Review, 5(6):845-867.

Swain, H. and McKinnon, R.D. (Editors) (1975). Issues in the Management of Urban Systems and Strategies, CP-75-4. International Institute for Applied Systems Analysis, Laxenburg, Austria.

Systems Approach Used in Urban Planning and Development (1977). Stroyizdat, Moscow. (In Russian.)

Urbanization and Settlement Problems (1976). Mysl, Moscow. (In Russian.)

Urbanization, Scientific and Technological Revolution, and the Working Class (1972). Nauka, Moscow. (In Russian.)

Use of Applied Systems Analysis in Urban Design and Development Management (1974). Stroyizdat, Moscow. (In Russian.)

Wadycki, W.J. (1974). Alternative opportunities and inter-state migration. Some additional results. Review of Economics and Statistics, 56(2):254-257.

Wilson, A.G. (1974). Urban and Regional Models in Geography and Planning. Wiley, London. 


\title{
POPULATION DISPERSAL FROM CORE REGIONS: A DESCRIPTION AND TENTATIVE EXPLANATION OF THE PATTERNS IN 20 COUNTRIES
}

\author{
Daniel R. Vining, Jr., Robert Pallone, and Chung Hsin Yang \\ Department of Regional Science, University of Pennsylvania, \\ Philadelphia (USA)
}

"Urban growth is essentially a great city growth." (Weber, 1899, p. 488)

"Once a city is larger than any other in its country, this mere fact gives it an impetus to grow that cannot affect any other city, and it draws away from all of them in character as well as size." (Jefferson, 1939, p. 227)

"The evident tendency of people to congregate in larger and larger cities represents an attraction of people for people that turns out to have a mathematical as well as a merely verbal resemblance to Newton's law of gravitation." (Stewart, 1947, p. 471)

"The macro-locational tendency throughout the world is for industrial regions already large and powerful to attract still more population, and thus the industrial population of the world has become concentrated in a few regions." (Clark, 1964-1965, p. 195)

"The historical evidence in both the developing and the developed economies indicates that the concentration of population in the big cities is a strong and pervasive trend." (Beier et al., 1975, p. 24)

"Steady urbanization in situ, equal in rate from region to region, and without largescale accelerating internal migrations, would create few serious problems, if any. But the reality in nearly all countries seems to be the polarized growth pattern of the urban system with the background of an increasing regional imbalance. Rapid urbanization has distorted the traditional network and hierarchy of settlement. Uncoordinated, often excessive, expansion of the largest cities and leading urban agglomeraitions is accompanied by stagnation of most of the old regional centres and medium-size and smaller towns. By rapid out-migration, peripheral and less developed rural areas are losing their main potential, a young and active labour force." (Schöller, 1975, p. 69) 
"The demographic history of most countries in this century suggests a strong tendency for population to cluster. This has been especially true in the period since the advent of industrialization and the decline of the agricultural sector. . Generally, not only have urban populations grown substantially more rapidly than populations as a whole, but the most rapid urban growth has been in the largest cities." (Crowley, 1977, p. 258)

"Different parts of the world are shrinking at different rates, ... mainly to the advan. tage of large settlements, which are benefiting from the cumulative advantages of early growth. . The main consequence of these trends is centralization - the growth of big cities. . " (Coates et al., 1977, p. 238)

\section{INTRODUCTION}

The foregoing passages express the dominant paradigm in spatial demography; we shall call it, after Alexandersson and Falk (1974), the "concentration paradigm". There is growing evidence, however, that the "macro-locational tendency" towards ever-increasing concentration in the core regions of the developed countries, at least, is near exhaustion. The objective of this paper is to document this fact. We defer to a later paper and to other scholars the task of explanation, though we do advance a tentative hypothesis to explain the variations observed. Our principal aim here, however, is simply to establish that the concentration paradigm no longer provides an accurate model of the population geography of the developed countries.

The data that we shall use to demonstrate our thesis are internal-migration statistics showing the number of persons moving between the major administrative subdivisions of 20 countries: Belgium, Canada, Czechoslovakia, Denmark, the Federal Republic of Germany (FRG), Finland, France, the German Democratic Republic (GDR), Hungary, Iceland, Italy, Japan, the Netherlands, Norway, Poland, South Korea, Spain, Sweden, Taiwan, and the United Kingdom (UK). The United States of America has been omitted because the recent reversals in migration flows between sparsely and densely populated regions in that country have been extensively reported elsewhere (see Beale, 1977; Berry and Dahman, 1977; McCarthy and Morrison, 1977; Sternlieb and Hughes, 1977; Tucker, 1976; and Vining and Strauss, 1977). Our data sources are given in the Appendix.

The core regions of a country are those regions which are economically and politically dominant; they contain the principal cities of the country and have traditionally experienced high rates of in-migration from the other, less urbanized, peripheral regions. The identification of these regions poses little difficulty. Their areal extent, however, is subject to considerable controversy and disagreement. The regionalization problem remains unsolved in our field, and we do not intend to solve it here. However, to establish our thesis it suffices to specify regional boundaries that defune larger rather than smaller areas around the core, thus increasing the probability that all of the core region will be within the region so defined. If such an "overbounded" region shows declining net migration then the "true" core region contained within it must do so as well unless there is net migration from the remainder of this region to the core portion, a doubtful proposition in the light of the strong decentralization tendencies within highly urbanized 
regions. We have therefore drawn very wide boundaries around the core regions in anticipation of the objection that the net flows away from them that are recorded here are simply an overspill of population beyond their conventionally defined boundaries. More. over, to allay fears that our results are sensitive to the way in which these regions are defined we also show, wherever it is feasible to do so, migration into the core regions for altemative definitions of these regions. These definitions, i.e., the constituent administrative subdivisions of the regions, and their principal cities, are given in Table 1.

It is a fact that the trends in immigration and natural increase sometimes run counter to those in internal migration. This is taken up at several points in our paper. Here we wish to stress the fact that within the developed countries migration is on balance no longer towards the core regions.

\section{A DESCRIPTION OF THE TRENDS}

Among the countries studied, it is useful to distinguish four categories: (1) countries whose core regions have, by and large, experienced a long-term decline in net in-migration since the 1950s and are now experiencing net out-migration, (2) countries whose core regions experienced a sharp drop in net in-migration beginning around 1970 after stable or rising net migration over the 1950s and 1960s but have not yet reached the point where sustained out-migration is observed, (3) countries whose core regions exhibit a constant but low positive migration balance, and (4) countries whose core regions not only continue to receive large numbers of migrants from the remaining regions but also show increasing trends with respect to net in-migration.

In the first category are the countries of the most densely populated and heavily industrialized region of Europe, the northwest: Belgium, Denmark, France, the Netherlands, and the FRG. Figure 1 shows a gradual decline in net migration towards the core regions of these countries since the 1950s and migration, on balance, away from these regions over much of the 1970s. In the case of the Netherlands this out-migration, contrary to a claim by Blumenfeld (Blumenfeld, 1974, p. 194), is more than just an extension of the Randstad region to the southeastern part of the Netherlands, which lies on the periphery of Europe's strongest urban field, the Rhine-Ruhr area. Figure 1 shows the south as a whole to be losing population to the relatively isolated and rural north. The Rline-Ruhr itself, after decades of gaining population from the more rural states of the FRG in the north and southeast, is now losing population to these states. As Blumenfeld writes, "in Germany, a historical west-to-east slope in prosperity has given rise to eastwest migration that has gone on for over a century and is still continuing within the Federal Republic of Germany" (Blumenfeld, 1973, p. 123); however, as Figure 1 shows, this east-west tilt in migration was in fact reversed sometime in the early 1960s. How. ever, despite the Rhine-Ruhr's being the most populous urban field in Europe it is, of all the core regions of Europe, paradoxically the least dominant within its own country. The peripheral regions of the FRG to the north and southeast contain two of its largest cities (Hamburg and Munich). This rather even distribution of cities across the FRG may explain the early flow of population away from its largest agglomeration in the Ruhr, though of course the distribution of cities itself must eventually be explained. The core regions of the remaining three countries shown in Figure 1, those surrounding the capitals 


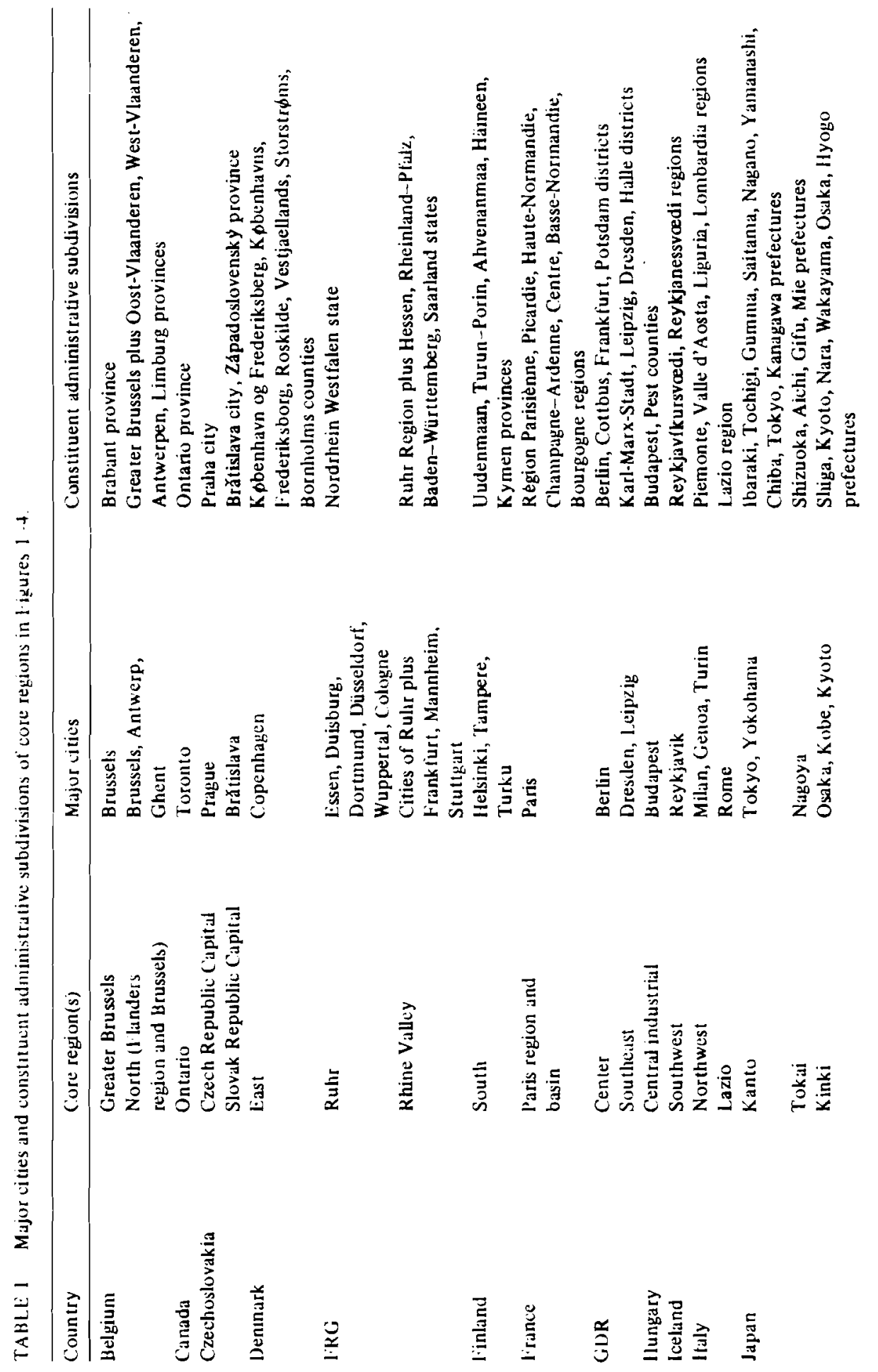



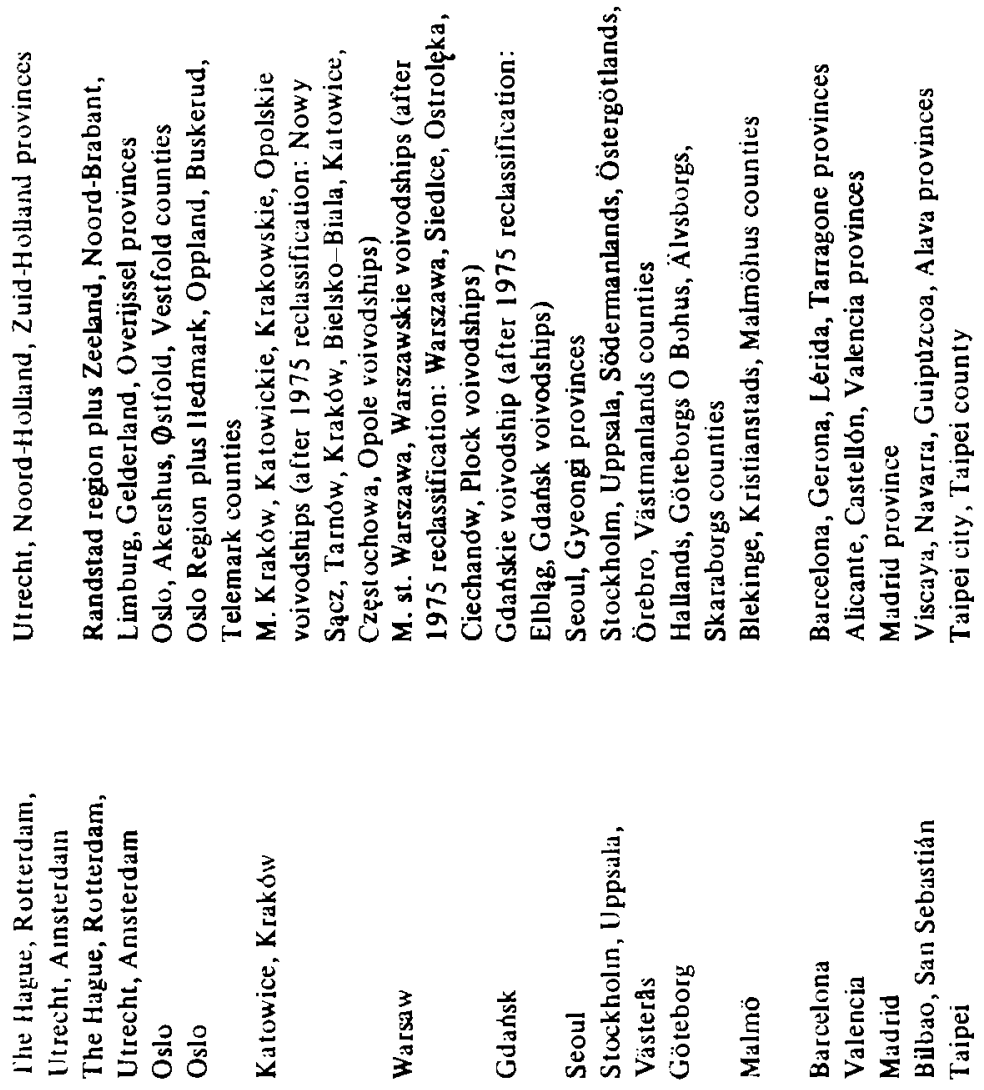

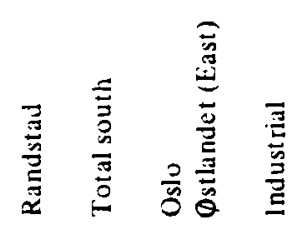
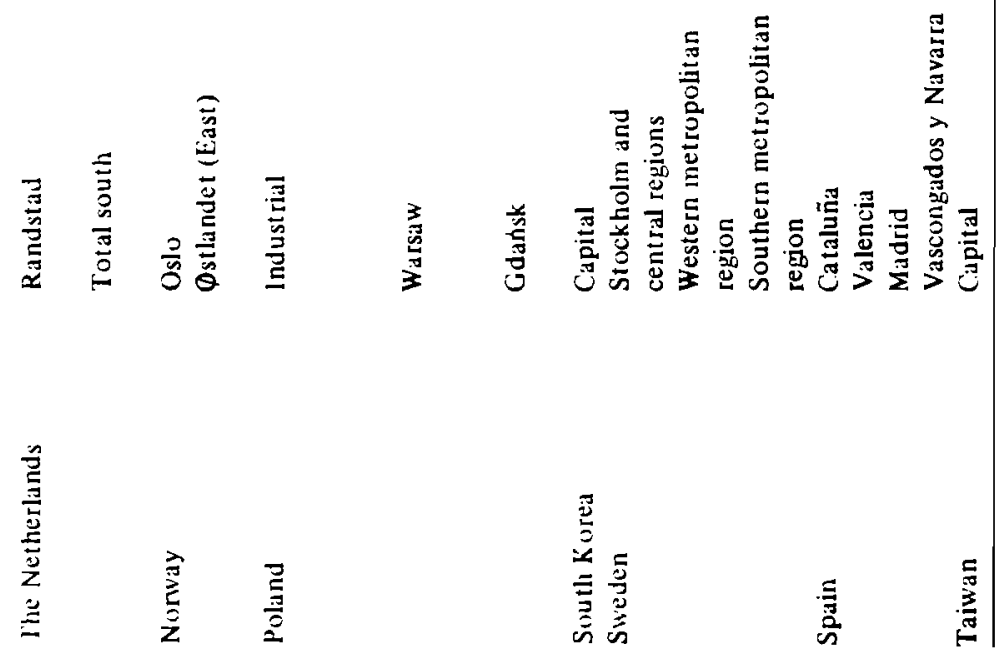

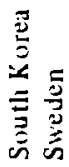

$\frac{3}{3}$

㿣 

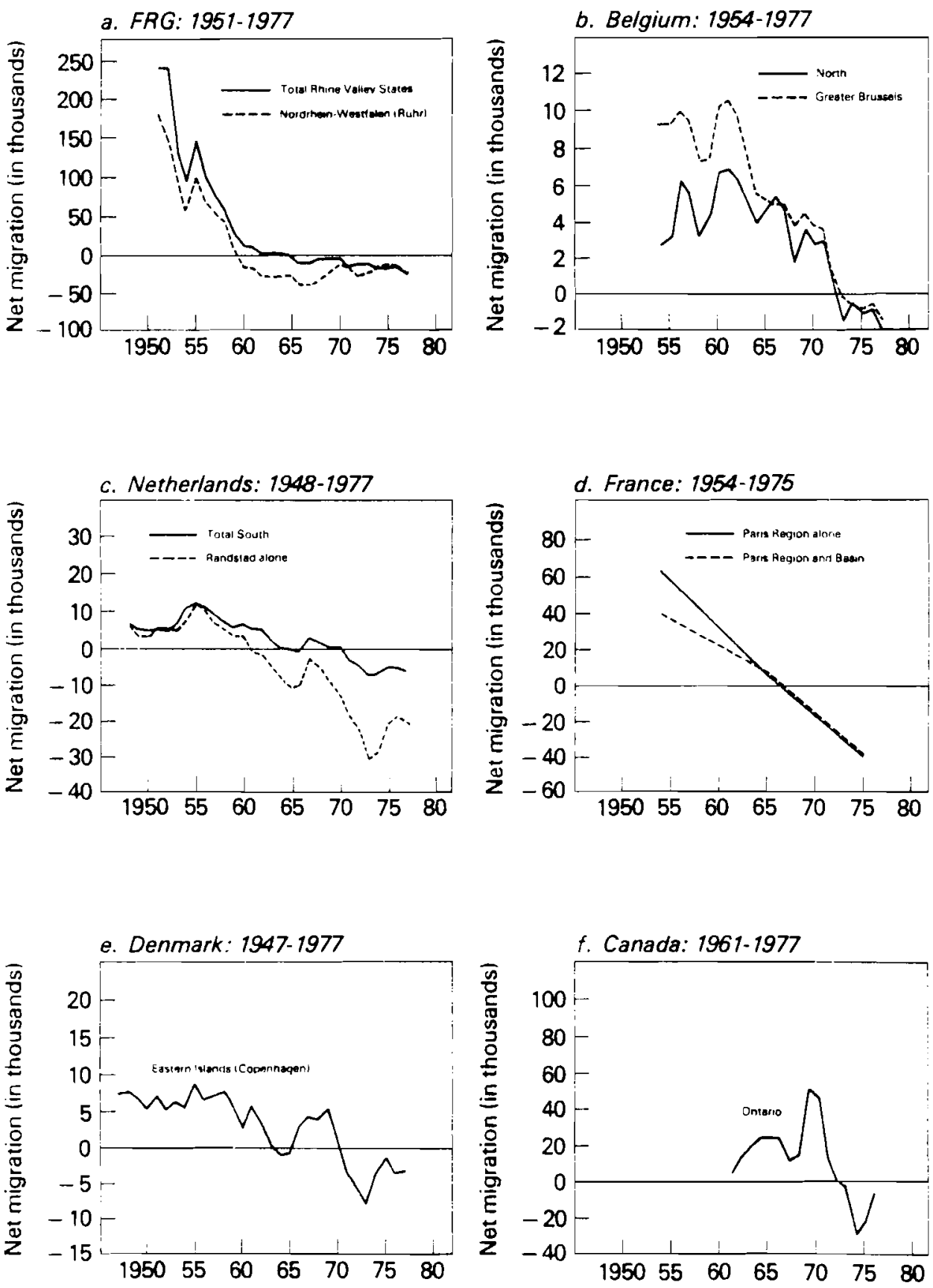

FIGURE 1 Annual net internal migration to core regions of countries in category (1): (a) the FRG, $1951-977$ (excludes net migration from West Berlin); (b) Belgium, 1954-1977 (1963 data not available); (c) the Netherlands, 1948-1977 (net migration from the Zuid IJsselmeer Polders and moves of unknown destination and origin omitted); (d) France, 1954-1975 (annual average net internal 
of Denmark, Belgium, and France (i.e., Copenhagen, Brussels, and Paris, respectively), are uncontroversial; they are clearly dominant and primate in character and are just as clearly overbounded. To the Brussels region we have added the entirety of the Flanders region, which contains the other large city in Belgium, Antwerp. Migration is clearly away from this region and towards the less densely populated south; this is a reversal of the long-standing drift of the Belgian population towards the highly urbanized and industrialized northern half of the country (van Prag, 1978). In Denmark and France the migration away from the capital regions towards Jutland and southern and western France, respectively, seems to have become an enduring trend in both countries. Finally, we have added Canada to this category, because of the very large net outflow from its historic core region in Ontario and Quebec.

The second category includes countries on the periphery of western Europe and one country outside Europe: Finland, Iceland, Italy, Japan, Norway, Spain, Sweden, and the UK. Here we find a significant drop in net migration towards the core regions only after 1970 and maximum flows into the core regions during the 1960s (Figure 2), in contrast to the countries of category (1) where the decline in net flows towards the core regions is, with the exception of Canada, continuous over the entire postwar period. In two of the countries in this category (Finland and Norway) the highest rate of migration towards the core regions (here defined to be southern Finland and eastern Norway, respectively) was actually recorded at the end of the 1960s. In Sweden we observe two more or less similar peaks in the rate of migration from the north into the metropolitan regions of the south, one at the beginning of the 1960s and the second at the end. The Tokaido region of Japan and the northwestern and central regions of Italy likewise experienced maximum net inflows at the beginning and end of the 1960 s but the second peak is considerably lower than the first in both cases. The data for Iceland, showing net movements into the capital, Reykjavik, and the surrounding southwest region, exhibit no trend until the 1970s when a sharp decline to zero is recorded.

Annual statistics showing net internal migration towards the principal attractor region of Great Britain (the southern half of England) are unfortunately unavailable. What are available, however, are data showing net movements between Scotland and the rest of the UK which should provide an approximate mirror image to net movements into the south, since net movements into marginal regions of other countries (e.g. northern Norway and Sweden, or the Mezzogiorno of Italy) provide a mirror image for net movements into these countries' core regions (e.g. eastern Norway, southern Sweden, and northwestern Italy, respectively). Our figure for the UK therefore shows net migration into Scotland from the rest of the UK going from positive to negative along the vertical axis. The picture is of a sharp decline in net out-migration from Scotland after 1970, the mirror image of which should be a sharp decline in net in-migration to the core region of Great Britain, southern England.

Spain is a difficult country to classify. Beginning around 1974, its principa] attractor region (roughly the nor theastern quadrant of the country) experienced a rapid

migration for 1954-1962,1962-1968, and 1968-1975 shuwn at the midpoints of these periods); (e) Denmark, 1947-1977 (excludes net migration from Greenland and the Faroe Islands); (f) Canada, 1961-1979 (data for fiscal years). The regions are defined in Table 1; for the data sources, see the Appendix. 

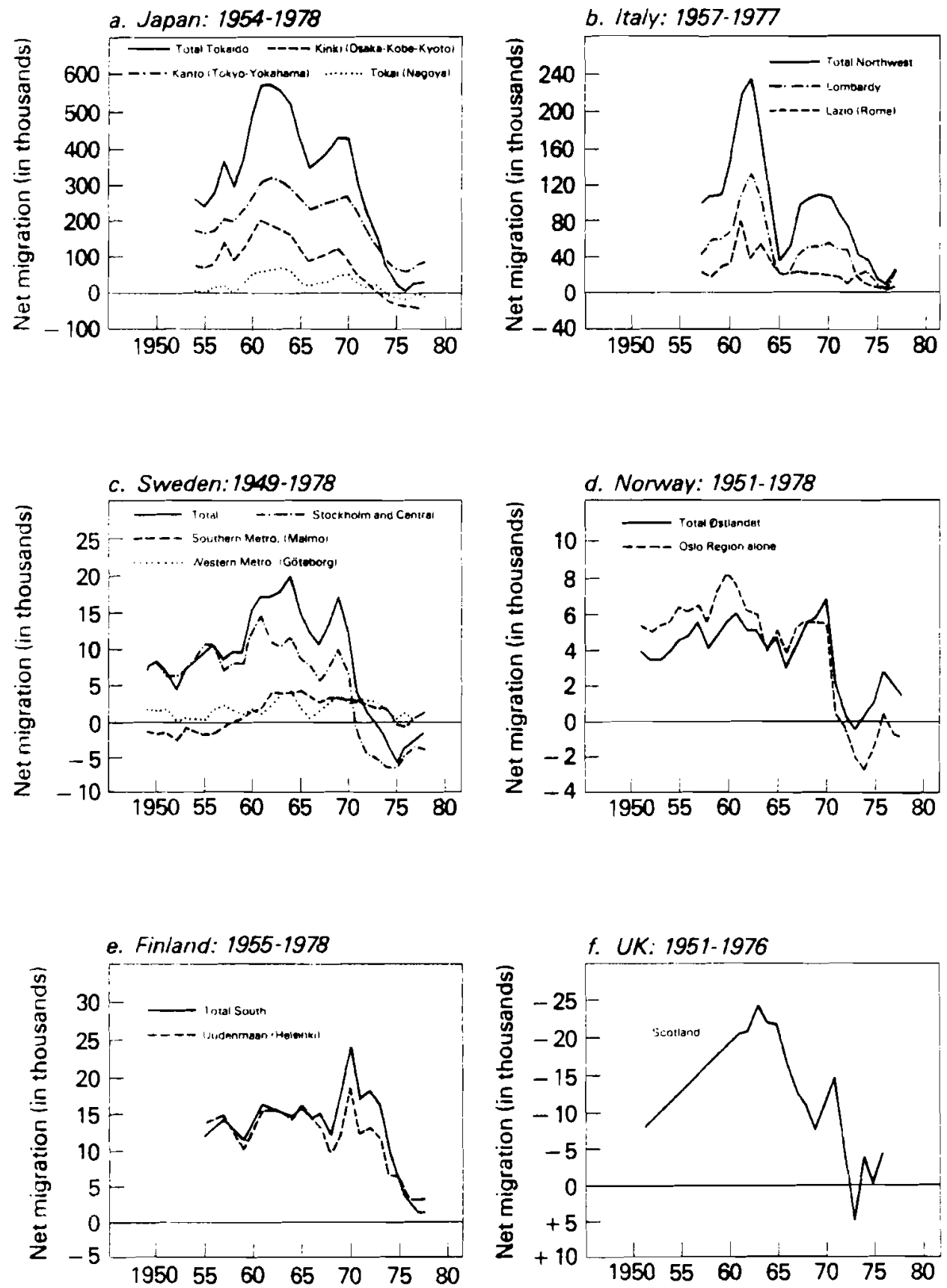

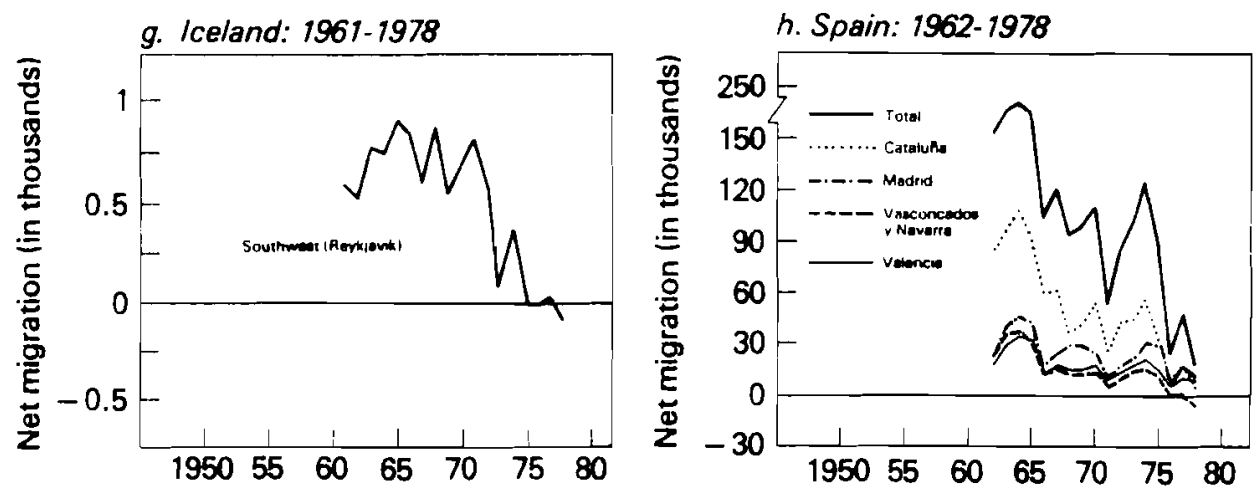

FIGURE 2 Annual net internal migration to core regions of countries in category (2); (a) Japan, 1954-1978; (b) Italy, 1957-1977 ("1961-1962 migration figures are inflated as a result of the abolishment in February 1961 of the 1939 law regulating internal migration. . . Overreporting for these years . . may be on the order of 20\%" (Salvatore (1977), p. 398); 1977 data are provisional); (c) Sweden, 1949-1978; (d) Norway, 1951-1978 (data for 1970 include migration occurring in previous years but not reported until the population census of 1970); (e) Finland, 1955-1978; (f) the UK, 1951-1976 (annual average net intemal migration for 1951-1961 shown at midpoint); (g) Iceland, 1961-1978; (h) Spain, 1962-1978. The regions are defined in Table I; for the data sources, see the Appendix.

drop in net migration; however, it is difficult to call this a long-term trend, given the recession that struck the country around this time. The level of interregional migration as a whole has dropped very substantially in Spain, and this explains a large part of the decline in net migration towards its core regions. By contrast, the declines in net migration towards the core regions of the countries of categories (1) and (2) preceded the great economic contraction of $1974-1975$ and cannot be attributed to large declines in overall levels of inter regional migration, which have remained steady or declined slightly. Moreover, net migration into northeastern Spain has fallen nowhere near zero. In all countries of category (2) except Spain, however, we observe by the middle of the 1970s a rough balance in population flows between core and periphery, though there are reasons, taken up in the next section, for believing that sustained flows away from the core regions will never be observed, in cont rast to those in countries of category (1).

The third category in our sample includes Czechoslovakia, the GDR, Hungary, and Poland. None of these countries show systematic and sustained declines in net migration toward their major cities and surrounding regions. The Saxony region, which contains all the major cities of the GDR except Berlin and is its principal industrial district, has lost population to the rest of the GDR since the early 1960s and thus resembles the great industrial district of the FRG, the Ruhr, where a similar depopulation has taken place over the last 20 years. However, in contrast to the countries of western Europe, internal migration in the GDR continues to be strongly focused on the capital city, Berlin, and the surrounding central region; a significant shift towards the sparsely populated north has yet to be observed. In fact, net migration towards Berlin has actually drifted upwards during the 1970s, as it has towards the larger cities of Poland. Net flows into the capital 

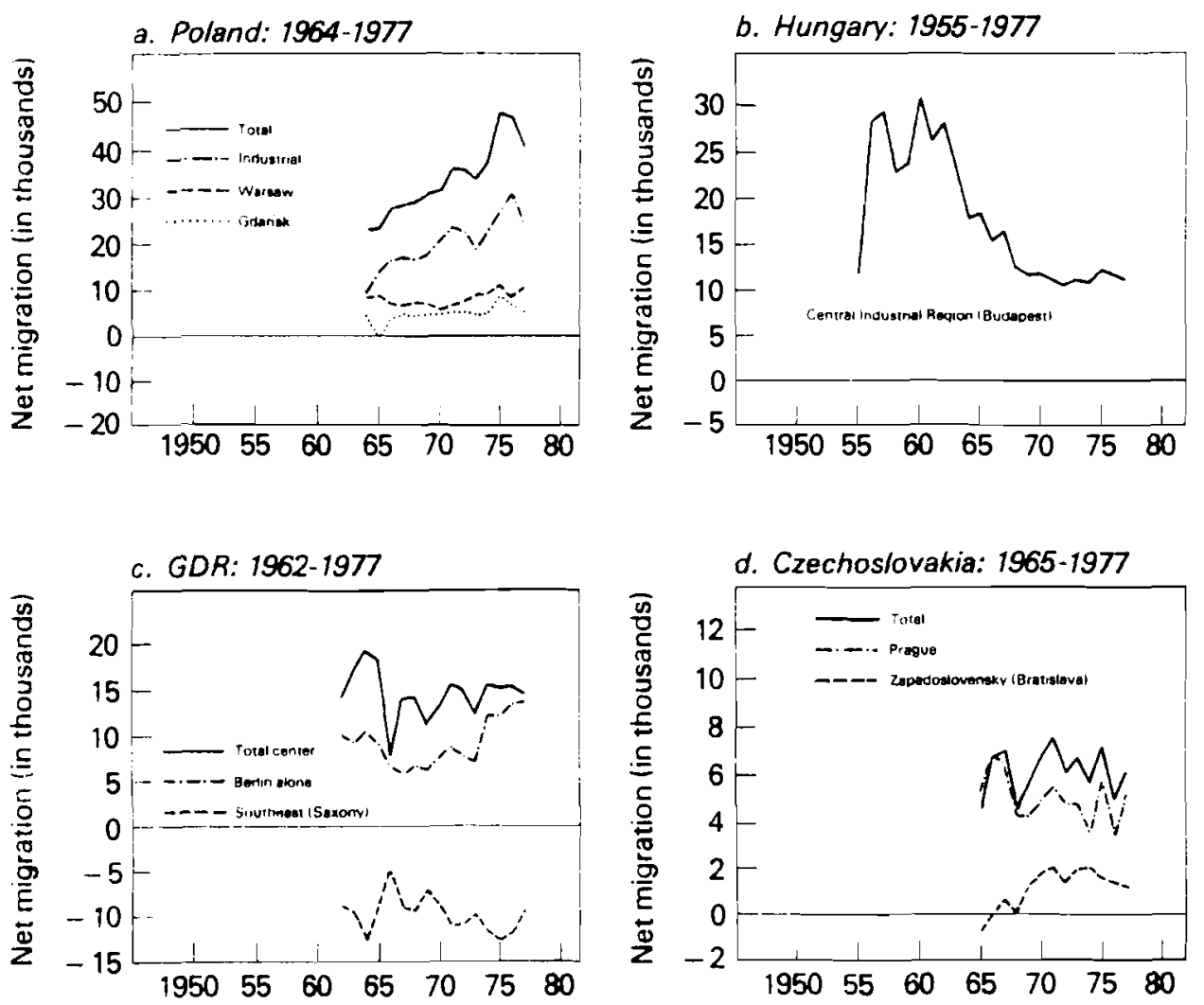

FIGURE 3 Annual net intemal migration to core regions of countries in category (3): (a) Poland, 1964-1977 (definitions of core regions changed from 1975 onwards owing to changes in administrative subdivisions); (b) Hungary, 1955-1977 (temporary migrants excluded: data for 1955 and 1956 include moves of unknown origin); (c) the GDR, 1962-1977; (d) Czechosiovakia, 1965-1977 (net foreign immigration included). The regions are defined in Table 1; for the data sources, see the Appendix.

cities of the two republics of Czechoslovakia, Prague and Bratislava, have been approximately constant over the last decade and a half. Though net flows tow ards the capital of Hungary, Budapest, fell during the 1960s, there has been no continuation of this trend during the 1970s (see Figure 3). However, while the level of net migration into the principal cities of the eastern European countries has not declined over the 1970s and even shows signs of growing, the level itself, when expressed as a rate, is significantly lower than corresponding rates in western Europe and in Japan during their period of rising population concentration. Furthermore, the rates of natural increase in the principal core regions of the eastern European countries are extremely low relative to the rates in the regions outside the core regions, a fact which has reduced the growth differential between core and periphery significantly (Vining and Kontuly, 1978, p. 55).

Finally, in our fourth category are two countries, Taiwan and South Korea, in which net migration towards the core is both very large and possibly still growing (see Figure 4). 
a. Taiwan: 1957-1978

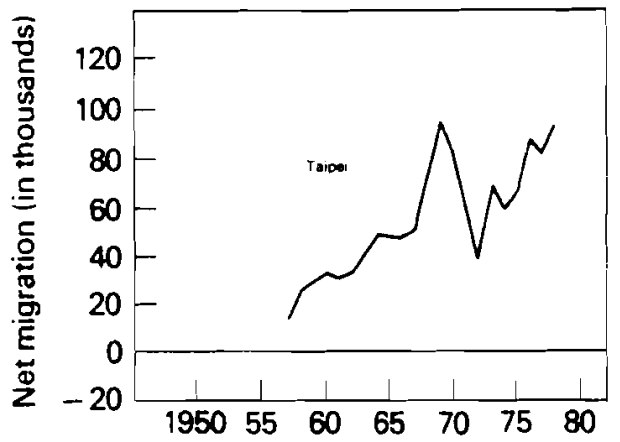

b. South Korea: 1955-1977

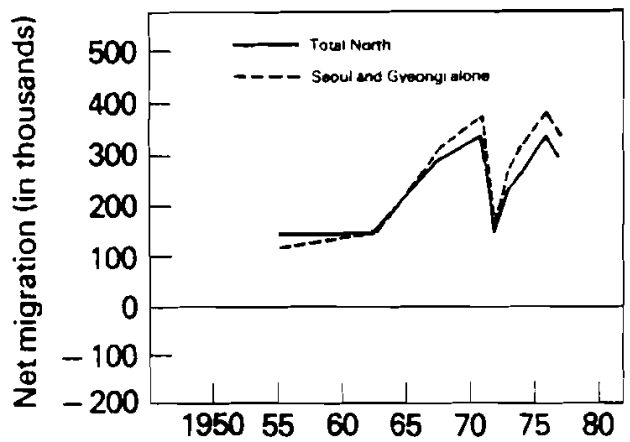

FIGURE 4 Annual net internal migration to core regions of countries in category (4): (a) Taiwan, 1957-1978 (net foreign immigration included; the very large net migration into the Taipei region in 1969 is due to a change in the registration system to include moves of armed-forces personnel); (b) South Korea, 1955-1977 (net migration for 1975 unavailable; annual average net migration of 1955-1960, 1961-1965, and 1966-1970 shown in midpoints of these periods).

Higgins writes, ". . the enormous problems of regional disparities and urban agglomeration generated by the rapid industrialization of Korea . . . have led to a concentrated effort to plan the entire urban structure in relation to the pattern of regional development, and a strategy of decentralization, that holds much interest for other count ries facing similar problems." (Higgins, 1978, p. 611.) Whatever the interest this effort to plan the urban structure of South Korea may hold there is no evidence of its having any effect on the flow of persons towards South Korea's largest city and its surrounding territory. The most recent net flows towards this region have been among the highest in recorded history, as were the most recent net flows towards Taipei.

\section{A TENTATIVE EXPLANATION OF THE PATTERNS OBSERVED IN FIGURES $1-4$}

How can we explain the patterns observed in Figures 1-4? We submit the following tentative "model" of these patterns. During the phase of rapid industrialization there is a universal tendency for the population of a country to agglomerate in those regions containing the largest cities, i.e., for a movement to take place from the sparsely populated peripheral regions to the densely populated core regions. This movement is, in the words or Weber $(1899$, p. 417), "mainly in obedience to economic causes. . Production increases with increasing density, and more particularly with increasing concent ration." All the countries in our sample were in this phase in the 1950s and six (perhaps seven if we include Spain) continued to be in it in the 1970s.

As economic growth proceeds, however, the costs of agglomerating still more population and capital in the high-density core regions rise and eventually choke off the economic advantages of further agglomeration in the core (see the essays in Leven, 1978). However, the point at which the returns to location in core and periphery are equalized will come sooner in countries whose peripheries offer competitive sites for urban and industrial development (i.e., competitive in the absence of agglomeration economies) 
than in countries where these sites are inherently inferior. In fact in the peripheries of sume countries the deficiencies of physical geography may be so great as to virtually preclude urban and industrial development in any region but the core. We submit that what distinguishes the countries of category (1) from those of category (2) is precisely the absence of physical barriers to urban and industrial development in the peripheries of the former and the existence of these barriers in the peripheries of the latter.

The countries of category (1) have peripheries that are well endowed with sites for urban and industrial development. The climates, soils, and topographies of southwest France, Jutland in Denmark, the northern Netherlands, or Bavaria in the FRG (all predominantly rural areas which have in the past experienced heavy outflows of population towards large cities in other regions) are all perfectly suitable for large-scale urban and industrial development. As long as there were productivity advantages in agglomerating population and production in the core regions, these regions stagnated and in some cases actually suffered depopulation. However, once the agglomeration economies began to disappear and even to become diseconomies there was a strong tendency to locate new productive facilities in the peripheral regions since the sites for production in these regions were the equal of those in the core regions except perhaps for their location, a disadvantage largely neutralized through modern transportation and communication systems. (An exception here would be Austria where the "peripheral" areas of the west, though possessed of a much less ideal terrain for modern settlements than the Vienna region, are situated in a much superior location, particularly with respect to traffic and trade with western Europe. There has accordingly been a long-term drift of population westward in Austria which has gone on since the breakup of the Austro-Hungarian empire (see Osterreichischen Statistischen Zentralamtes, 1978, p. 9).) Thus, by this theory, the gradual decline in migration towards the core regions of the countries of northwest Europe that is shown in Figure 1 merely reflects the concurrent gradual decline in the productivity advantages of agglomerating still more population and industry in the core regions, given the competitive sites which exist in the peripheries of these countries. Likewise, the provinces to the west of Ontario, and also Quebec, do not suffer from any deficiencies of site but rather from deficiencies of location vis-a-vis the population centers of the USA and Canada. Indeed, the physical resources of these provinces(e.g. oil and wheat) give them absolute site advantages over the eastern provinces, and the rapidly increasing value of these site-specific resources obviously now exceeds the agglomeration advantages of the more densely populated eastern provinces.

In contrast to the countries of northwest Europe, the peripheries of the countries of category (2) are at a clear natural disadvantage relative to the core regions. In the Scandinavian countries the regions outside the major urban regions all possess difficult topographies and climates: little flat land and what there is broken up into small patches by mountains and fjords, and in the northern areas long dark winters and cool damp summers. The difficult terrain makes industrial development difficult and unprofitable. Flat plains are necessary for the building of cities, the laying down of roads, the construction of factories, etc. The poor climate makes it difficult to attract and keep labor. Northern Norwa.' is particularly cursed in both respects. In Italy, the physical limitations of tite Mezzogiorno are well known and include a difficult topography and an uncertain water supply. Its Mediterranean climate, however, seems to be optimal for humans and may work ultimately to its advantage if the other deficiencies in physical geography can 
be overcome. In Japan the singular lack outside the Tokaido area is flat land for building. The plains of central Pacific Honshu, where the largest population concentrations in the country are located, are by far the most extensive in Japan. Hokkaido, the northernmost island of the Japanese archipelago and still relatively underpopulated, has ample flat land but a difficult subarctic climate. Kyushu, the southernmost island, has a warm and relatively benign climate but a serious deficiency of plain land. The rest of Honshu outside the Tokaido area is likewise deficient in plain land. Finally, the southwest corner of Iceland and the southern half of England are also clearly much the favored regions environmentally in those countries.

In the light of the greatly inferior natural endowments of the peripheries of these countries, the near balance in migration flows between core and periphery in them is remarkable. However, it is only a balance, and a precarious one at that. In Figure 2, note that there is still a positive net migration into the core regions of Norway, Japan, and Italy from their peripheral regions and that Scotland continues to lose population to the remainder of the UK, although in all cases net migration to the core has fallen significantly from its levels of the 1960s; in Sweden the decline seems to have bottomed out and to be retuming to net balance. In none of the countries of category 2 is there strong migration away from the core of the kind we find in northwest Europe (and, even more prominently, in the USA). Furthermore, in Sweden and Norway there continues to be strong migration from abroad into the core regions; this has more than compensated for the losses due to intemal migration (see Tables 2 and 3 ). (There is virtually no recorded migration into Japan and immigration into Italy now consists mainly of guest workers returning to their homes in the south.) In contrast, in France and the FRG foreign migration has been checked, and the core regions of these countries are losing population through both internal and extemal migration (see Chi, 1977; and Vining and Kontuly, 1978 , p. 62). Finally, in a number of the countries of category 2 there have been recent upturns in the net migration of persons towards the core regions. All these facts make us doubt that a strong movement away from the core regions of these countries will ever be observed. The prospects are, at best, for a net balance between core and periphery rather than an actual migration away from the core towards the periphery, in contrast to the countries in northwest Europe and, of course, most dramatically the USA, where the net movement away from the traditional core region of the northeast has become quite sig. nificant.

It is not clear why a net balance should occur at all in countries where the physical geography so overwhelmingly favors the core regions and where the returns to further investment are still higher in the core than in the periphery, even in the absence of agglomeration economies. It is possible that at a certain level of economic development there is an economic surplus that is sufficient to maintain population levels in the peripheral areas, despite the inefficiencies involved in doing so. Such policies appear to be in response to a widespread, perhaps even universal, drive on the part of the population to live in low-density settlements and particularly in the highly valued one-family house. (Brox writes as follows of a village in Iceland: "In recent years the community has recruited people from Reykjavik and othe large towns, as young men from these towns have been fishing with local boats and eventually become engaged to local girls. It is obviously easier to establish a household in a fishing village than in the capital, especially when highly valued goods, such as one-family houses, are taken into consideration." 
TABLE 2 Net intemal migration and net foreign immigration into the metropolitan regions ${ }^{a}$ of Sweden, 1973-1978b.

\begin{tabular}{lllll}
\hline Year & $\begin{array}{l}\text { Net internal } \\
\text { migration }\end{array}$ & $\begin{array}{l}\text { Net foreign } \\
\text { immigration }\end{array}$ & $\begin{array}{l}\text { Metropolitan } \\
\text { regions' share } \\
\text { of total net foreign } \\
\text { immigration }\end{array}$ & $\begin{array}{l}\text { Metropolitan } \\
\text { regions' share } \\
\text { of Swedish } \\
\text { population }\end{array}$ \\
\hline 1973 & -208 & $-9,732$ & - & \\
1974 & $-2,607$ & 5,944 & 0.714 & 0.692 \\
1975 & $-5,980$ & 12,504 & 0.768 & \\
1976 & $-4,600$ & 15,914 & 0.797 & \\
1977 & $-2,477$ & 19,369 & 0.845 & \\
1978 & $-1,571$ & 12,073 & 0.861 & \\
\hline
\end{tabular}

a Sue Table 1 .

b Sources: Belfolkningsförändringar 1975 Del Församlingar, Kommuner och A-regioner, Statistiska Centralbyrân, Stockholm, Table 7, p. 128; Statistiska meddelanden-Be 1977:2, Statistiska Centralbyrån, Stockholm, Table 1, pp. 8-9; Statistiska meddelanden-Be 1978:3, Statistiska Centralbyrån, Stockholm, Table 1, pp. 8-9; ibid., 1979, Table 1, pp. 8-9.

TABLE 3 Net internal migration and net foreign immigration into the $\emptyset$ stlandet $^{a}$ region of Norway, $1971-1978^{b}$

\begin{tabular}{lllll}
\hline Year & $\begin{array}{l}\text { Net intemal } \\
\text { migration }\end{array}$ & $\begin{array}{l}\text { Net foreign } \\
\text { immigration }\end{array}$ & $\begin{array}{l}\text { Ostlandet's } \\
\text { share of total } \\
\text { net foreign } \\
\text { immigration }\end{array}$ & $\begin{array}{l}\text { Qstlandet's } \\
\text { share of } \\
\text { population }\end{array}$ \\
\hline 1971 & 2,221 & 3,883 & 0.587 & \\
1972 & 416 & 2,114 & 0.478 & 0.490 \\
1973 & -397 & 1,516 & 0.440 & \\
1974 & 266 & 2.839 & 0.577 & \\
1975 & 1,153 & 2,877 & 0.603 & \\
1976 & 2,899 & 2,614 & 0.535 & \\
1977 & 2,219 & 2,741 & 0.544 & 0.549 \\
1978 & 1,489 & 2,183 & &
\end{tabular}

a See Table 1.

${ }^{b}$ Source: Flyttest atistikk 1978, Statistiska Centralbyra, Oslo, Table 3, p. 18.

(Brox 1974, pp. 252-253).) This drive, however, has been traditionally frustrated by the lack of modern services and facilities (the demand for which may be said to take precedence over the demand for space) in precisely the areas where space is cheapest and most abundant, i.e. in the sparsely populated peripheral areas. Only a wealthy nation is able to accommodate this drive by extending modern urban infrastructure and services into virtually all parts of its territory (see the description of the situation in northern Norway given by Brox, 1978). In countries where the economic returns of maintaining such settlement systems are low because, for example, the topography requires that the settlements be dispersed as in the Scandinavian countries, the costs or doing so are at least partially borne by the importation of foreign workers into the core regions to take the place of native workers who are no longer forced by economic necessity to move to the core, 
which is the only region where modern industrial activity is profitable or even possible. However, these costs are also reflected in continued erosion of population from the peripheries of many of the countries of category 2 , though this erosion is dramatically Jower now than in the past because of subsidies and transfer payments to the periphery.

\section{ACKNOWLEDGMENTS}

The research reported in this paper was supported by a grant from the National Science Foundation and by the Office of Population Research, Princeton University. The senior author is indebted to Ottar Brox for stimulating the line of thought adumbrated in Section 3. This acknowledgment of debt should not be taken to mean that Professor Brox is in agreement with these ideas; in fact, there is little doubt that he would take exception to them.

\section{REFERENCES}

Alexandersson, G. and Falk, T. (1974). Changes in the urban pattern of Sweden 1960-1970: the beginning of a return to small urban places? Ge oforum, 18:87-92.

Beale, C. (1977). The recent shift of the United States population to nonmetropolitan areas, 1970-75. International Regional Science Review, 2:113-122.

Beier, G., Churchill, A., Cohen, M. and Renaud, R. (1975). The task ahead for the cities of the developing countries. Staff Working Paper No. 209. International Bank for Reconstruction and Development.

Berry, B. and Dahman, D. (1977). Population redistribution in the United States in the 1970s. Population and Development Review, 3:443-471.

Blumenfeld, H. (1973). Growth rate comparisons: The Soviet Union and German Democratic Republic. Land Economics, 49:122-132.

Blumenfeld, H. (1974). The effects of public policy on the future urban system. In L. Bourne et al. (Editors), Urban Futures for Central Canada. University of Toronto Press, Toronto, pp. 194198.

Brox, O. (1974). Local and political conditions for the maintenance of marginal communities. In E. Bylund, H. Linderhom, and O. Rune (Editors), Ecological Problems of the Circumpolar Area: Papers from the International Symposium at Lulea, Sweden, June 28-30, 1971. Norrbottens Museum, Lulea, pp. 245-255.

Brox, O. (1978). Phases in the development of north Norwegian settlement structure. Lecture. University of Edinburgh, February 27, 1978.

Chi, D. (1977). Bilan démographique 1976 estimations provisoires. Economie et Statistique, 86 (February): 69-73.

Clark, C. (1964-1965). The location of ind ustries and population. Town Planning Review, 35:195218.

Coates, B., Johnson, R. and Knox, P. (1977). Geography and Inequality. Oxford University Press, Oxford.

Crowley, R. (1977). Population redistribution: perspectives and policies. In A. Brown and E. Neuberger (Editors), Internal Migration - A Comparative Perspective. Academic Press, New York, pp. $255-274$.

Higgins, R. (1978). Review of "Economic Growth and Structure in the Republic of Korea" bv P. Kuznets, Joumal of Economic Literature, 16:609-611.

Jefterson, M. (1939). The law of the primate city. Geographical Review, 29:226-232.

Leven, C. (Editor) (1978). The Mature Metropolis. Lexington Books, D. C. Heath, Lexington, Massachusetts. 
McCarthy, K. and Morrison, P. (1977). The changing demographic and economic structure of nonmetropolitan areas in the United States. International Regional Science Review, 3:123-142.

Osterreichischen Statistischen Zentralamtes (1978). Vienna, p. 9.

Salvatore, D. (1977). An econometric analysis of internal migration in Italy. Journal of Regional Science, 17:395-408.

Schöller, P. (1975). The problems and consequences of urbanization. In R. Jones (Editor), Essays on World Urbanization. George Philip and Sons, London (for Commission on the Processes and Patterns of Urbanization, the International Geographical Union), pp. 67-92.

Sternlieb, G. and Hughes, J. (1977). New regional and metropolitan realities of America. Journal of American Institute of Planners, 43:227-240.

Stewart, J. (1947). Empirical mathematical rules concerning the distribution and equilibrium of population. Geographical Review, 37:461-485.

Tucker, $C$ (1976). Changing patterns of migration between metropolitan and nonmetropolitan areas in the United States: recent evidence. Demography, 13:435-443.

van Praag, P. (1978). Belgium: population policies and demographic evolution in retrospect. Zeitschrift für Bevölkerungswissenschaft, 4:365-382.

Vining, D. and Kontuly, T. (1978). Population dispersal from major metropolitan regions: an international comparison. International Regional Science Review, 3:49-73.

Vining, D. and Strauss, A. (1977). A demonstration that the current deconcentration of population in the United States is a clean break with the past. Environment and Planning A, 9:751-758.

Weber, A. (1899). The Growth of Cities in the Nineteenth Century - A Study in Statistics. Volume 11 of Studies in History, Economics, and Public Law, Columbia University. MacMillan, New York. (Reprinted in Cornell Reprints in L'rban Studies, Cornell University Press, Ithaca, New York, 1963.)

\section{APPENDIX: DATA SOURCES FOR FIGURES 1-4}

\section{Belgium}

Annuaire Statistique de la Belgique 1955, Institut National de Statistique, Brussels, pp. 90-91; ibid., 1956, pp. 88-89; ibid., 1957, pp. 86-87; ibid., 1958, pp. 80-81; ibid., 1959, pp. 78-79; ibid., 1960, pp. 78-79; ibid., 1961, pp. 78-79; ibid., 1962, pp. 82-83; ibid., 1963, pp. 82-83; ibid., 1964, pp. 48-49; ibid., 1965. pp. 54-55; ibid., 1966, pp. 58-59; ibid., 1967, pp. 58-59; ibid., 1968, pp. 52-53; ibid., 1970, Table 14, pp. 48-49, Table 17, pp. 54-55; ibid., 1971, Table 17, pp. 38-39; ibid., 1972, Table 16, pp. 34-35; ibid.. 1973, Table 16, pp. 34-35; ibid., 1974, Table 16, pp. 36-37; ibid., 1975, Table 16, pp. 36-37; ibid., 1976, Table 16, pp. 36-37; ibid., 1977. Table 16, pp. 36-37; ibid., 1978. Table 14, pp. 32-33.

\section{Canada}

International and Interprovincial Migration in Canada 1961-1962 to 1975-1976, Authority of Minister of Industry, Trade and Commerce, Ottawa, p. 45; ibid., 1976 and 1977, p. 31.

\section{Czechoslovakia}

Statistická Rocenka Ceskoslovenské Socialistické Republiky 1966, Federálni Statistický Úrad, Ceský Statisticky Úrad, Slovenský Statisticky Úrad. Praha, Table 3-15a, 
p. 84 : ibid., 1967, Table 3-12a, p. 83 ; ibid., 1968, Table 3-12a, p. 83 ; ibid., 1969, Table 3-12a, p. 92; ibid., 1970, Table 3-12a, p. 92; ibid., 1971, Table 4-7a, p. 106; ibid., 1972, Table 4-7a, p. 106; ibid., 1973, Table 3-8a, p. 89; ibid., 1974, Table 4-9a, p. 105; ibid., 1975, Table 4-9a, p. 111 ; ibid., 1976, Table 3-7, p. 87; ibid., 1977, Table 4-9a, p. 98; ibid., 1978, Table 4-9a, p. 98.

\section{Denmark}

Befolkningens Bevaegelser 1947, Danmarks Statistik, Copenhagen, pp. 38-40; ibid.. 1948, pp. 44-46; ibid., 1949, pp. 46-48; ibid., 1950, pp. 46-48; ibid., 1951, pp. 48-50; ibid., 1952, pp. 48-50; ibid., 1953, pp. 56-58; ibid., 1954, pp. 58-60; ibid., 1955, pp. 68-70; ibid., 1956, pp. 62-64; ibid., 1957, pp. 56-58; ibid., 1958, pp. 54-57; ibid., 1959, pp. 54-57; ibid., 1960, pp. 78-81; ibid., 1961, pp. 78-81; ibid., 1962, pp. 80-83; ibid., 1963, pp. 80-83; ibid., 1964. pp. 72-77; ibid, 1965, pp. 72-77; ibid., 1966, pp. 74-87; ibid., 1967, pp. 74-87; ibid., 1968, pp. 74-87; ibid., 1969, pp. 60-73; ibid., 1970, pp. 50-55; ibid., 1971, pp. 74-75; ibid., 1972, pp. 76-77; ibid., 1973, pp. 94-95; ibid., 1974, pp. 94-95; ibid., 1975, pp. 92-93; ibid., 1976, pp. 98-99; ibid., 1977, pp. 108-109.

\section{Federal Republic of Germany}

Statistisches Jahrbuch 1953 für die Bundesrepublik Deutschland, Statistisches Bundesamt, Wiesbaden, Table 26, p. 70; ibid., 1954, Table 29, p. 68; ibid., 1955 , Table 28, p. 66; ibid., 1956, Table 27, p. 64; ibid., 1957, Table 28, p. 65; ibid., 1958, Table 28, p. 59; ibid., 1959, Table 29, p. 59; ibid., 1960, Table 3. p. 73; ibid., 1961, Table 3, p. 72; ibid., 1962, Table 3, p. 70; ibid., 1963. Table 3, p. 64; ibid., 1964, Table 3, p. 68; ibid., 1965, Table 3, p. 73; ibid., 1966, Table 3, p. 68; ibid., 1967, Table 3,p.61; ibid., 1968, Table 3, p. 55; ibid., 1969, Table 3, p. 55; ibid., 1970, Table 3, p. 55; ibid., 1971, Table 3, p. 55; ibid., 1972, Table 3, p. 53; ibid., 1973, Table 3, p. 65; ibid., 1974, Table 3, p. 64; ibid., 1975, Table 4.16, p. 79; ibid., 1976, Table 4.17, p. 77; ibid., 1977, Table 3.36, p. 78: ibid., 1978, Table 3.33, p. 77; ibid., 1979, Table 3.33, p. 77.

\section{German Democratic Republic}

Statistisches Jahrbuch 1964 der DDR, Staatlichen Zentralverwaltung fur Statistik, Berlin, Table 7, p. 503; ibid., 1965, Table 7, p. 513; ibid., 1966, Table 7, p. 523; ibid., 1967. Table 7. p. 525 ; ibid., 1968, Table 7. p. 521 ; ibid., 1969, Table 9, p. 441 ; ibid., 1970, Table 9, p. 439; ibid., 1971, Table 9, p. 438; ibid., 1972, Table 9. p. 445; ibid., 1973, Table 36, p. 473; ibid., 1974, Table 8, p. 424; ibid.. 1975, Table 8, p. 396; ibid.. 1976, Table 8, p. 396; ibid., 1977, Table 8, p. 392; ibid., 1978, Table 8, p. 348; ibid., 1979, Table 8, p. 350. 


\section{Finland}

Suomen Tilastollinen Vuosikirja 1956, Tilastokeskus Statistikcentralen Helsinki, Table 58, p. 66; ibid., 1958, Table 59, p. 66; ibid., 1960, Table 57, p. 66; ibid., 1962, Table 57, p. 64; ibid., 1964, Table 58, p. 68; ibid., 1965. Table 58, p. 68; ibid., 1966 , Table 58, p. 68; ibid., 1967, Table 58, p. 68; ibid., 1968, Table 58, p. 68; ibid., 1969 , Table 59, p. 68; ibid., 1970, Table 59, p. 68; ibid., 1971, Table 57, p. 68; ibid., 1972. Table 54, p. 76; ibid., 1973, Table 55, p. 77; ibid., 1974, Table 54, p. 76; ibid., 1975, Table 57, p. 76; ibid., 1976, Table 57, p. 76; Väestönmuutokset 1975, Tilastokeskus Statistikcentralen, Helsinki, Table 9, pp. 20-21; ibid., 1976, Table 10, pp. 20-21; ibid., 1977, Table 1, pp. 8-9; Tilastotiedotus Statistisk Rapport 1979:5, Tilastokeskus Statistikcentralen, Helsinki, Table 1, pp. 3-4.

\section{France}

Annuaire Statistique de la France 1965, Institut National de la Statistique et des Etudes Economiques. Paris, Table 1, p. 61 ; Annuaire Statistique de la France 1973, Institut National de la Statistique et des Etudes Economiques, Paris, Table 1, p. 48: Regional Statistics 1975, Statistical Office of the European Communities, LuxembourgKirchberg, 1977, Table 9, pp. 216-217.

\section{Hungary}

Magyarország Népesedése 1959, Központi Statisztikai Hivatal, Budapest, Table 9.3, p. 82; ibid., 1960, Table 9.12, pp. 134-135; ibid., 1961, Table 9.22, pp. 222-223; ibid., 1962, Table 8.22, pp. 216-217; Demográfiai Evkönyv 1963, Központi Statisztikai Hivatal, Budapest, Table 8.22, pp. 214-215; ibid., 1964, Table 8.22, pp. 204-205; ibid., 1965, Tables $8.22,8.24$, pp. 236-237, 240-247; ibid., 1966, Tables $8.22,8.24$, pp. 236$237,240-247$; ibid., 1967, Tables $8.20,8.22$, pp. 228-229, 232-238; ibid., 1968, Tables $8.22,8.24$, pp. $240-241,244-251$; ibid., 1969 , Tables $8.20,8.22$, pp. $240-241,244-251$; ibid., 1970, Tables $9.20,9.22$, pp. 250-251, 254-261; ibid., 1971, Tables $9.25,9.27$, pp. 286-287, 290-297; ibid., 1972. Tables 10.36, 10.38, pp. 358-359.361-368; ibid., 1973, Tables $10.32,10.34$, pp. 318-319, 321-328; ibid., 1974, Tables 10.33, 10.35, pp. 342-344, 346-353; ibid., 1975, Tables 10.27, 10.29, pp. 310-311, 314-321; ibid., 1976, Tables 10.27, 10.29, pp. 316-317, 320-327: ibid., 1977. Tables 10.29, 10.31 . pp. $336-337.340-347$.

sueiand

Private communication from the Statistical Bureau of Iceland. 
Italy

Annuario Statistico Italiano 1959, Istituto Centrale di Statistica, Roma, Table 30, p. 27 ; ibid., 1960, Table 29, p. 27 ; ibid., 1961, Table 20, p. 24 ; ibid., 1962, Table 47 , p. 52; ibid., 1963, Table 52, p. 61 ; ibid., 1964, Table 49, pp. 50-51; ibid., 1965, Table 23 , p. 39 ; ibid., 1966 , Table 27 , p. 34 ; ibid., 1967 , Table 28 , p. 37 ; ibid., 1968 , Table 25 , p. 22 ; ibid., 1969, Table 24 , p. 21 ; ibid., 1970 , Table 25 , p. 23 ; ibid., 1971, Table 22 , p. 20 ; ibid., 1972, Table 15, p. 23 ; ibid., 1973, Table 16, p. 16; ibid., 1974, Table 26, p. 52 ; ibid., 1975, Table 26, p. 53; ibid., 1976, Table 24, p. 43 ; ibid., 1977, Table 18 , p. 28 ; ibid., 1978, Tables 9,14 , pp. $10,14$.

Japan

Internal Migration in Japan, 1954-1971, Bureau of Statistics, Office of the Prime Minister, Tokyo, Table 2, pp. 16-17; Annual Report on the lnternal Migration in Japan Derived from the Basic Resident Registers, 1972, Bureau of Statistics, Office of the Prime Minister, Tokyo, Table 3, pp. 34-35; ibid., 1973, Table 3, pp. 10-11; ibid., 1974, Table 3, pp. 10-11; ibid., 1975, Table 3, pp. 10-11; ibid., 1976, Table 3, pp. 10-11; ibid., 1977, Table 2, pp. 8-9; ibid., 1978, Table 2, pp. 8-9.

\section{The Netherlands}

Statistiek van Binnenlandse Migratie, 1948-1952, Centraal Bureau voor de Statistiek, Utrecht, p. 34; ibid., 1953-1955, p. 16; ibid., 1956-1957, p. 16; ibid., 1958-1959, p. 18; ibid.. 1960-1961, p. 20; ibid., 1962-1963, p. 18; ibid., 1964-1965, p. 16; ibid., 19661968 , p. 36; ibid., 1969, p. 35; ibid., 1970-1971, p. 59; Maandstatistiek van Bevolking en Volksgezondheid 1972, Centraal Bureau voor de Statistiek. The Hague, pp. 154-155; ibid., 1973, pp. 18-19; Statistiek van de Binnenlandse Migratie 1974-1975, Centraal Bureau voor de Statistiek, Utrecht, p. 34 ; Maandstatistiek van Bevolking en Volksgezondheid 1978, Centraal Bureau voor de Statistiek, The Hague, pp. 24-25, 500-501.

\section{Norway}

Flyttingene i Norge 1971 og 1949-1973, Statistisk Sentralbyra, Oslo, Table 13, pp. 42-43; Flyttestatistikk 1974, Statistisk Sentralbyra, Oslo, Table 3, p. 19; ibid., 1975, Table 3, p. 19; ibid.,1976, Table 3, p. 19; ibid., 1977, Table 3, p. 17; ibid., 1978, Table 3, p. 18.

Poland

Zawadzki, S.M., Ten Years of Polish Inte rregional Migration Data, Urban and Regional Systems Working Paper WP-75-122, October 1975, International Institute for 
Applied Systems Analysis, Laxenburg, Austria, pp. 9-18; private communication from the Central Statistical Office of Poland; Rocznik Demograficzny 1976, Glowny Urzad Statystczny, Warszawa, Table II, pp. xx-xxi; ibid., 1977, Table II, pp. xx-xxi; ibid., 1978, Table II, pp. xxï-xxiii

\section{South Korea}

Tai Hwon Kwon, Estimates of net inte mal migration for Korea 1955-1970, Bulletin of the Population and Development Studies Center (Seoul National University), Vol. 4 (November 1975), pp. 54-101, Table 1, pp. 70-81; Korea Statistical Yearbook 1972, Economic Planning Board, Seoul, Table 18, p. 51 ; ibid., 1973, Table 18, p. 51; ibid., 1974, Tables 18, 20, pp. 51-53; ibid., 1976, Tables 20, 23, pp. 53-55, 57; ibid., 1977. Tables 20, 22, pp. 55-58; ibid., 1978, Tables 20, 22, pp. 59-62.

Spain

Las Migraciones Interiores en Espana Decenio 1961- 1970, Instituto Nacional de Estadistica, Madrid, 1974, pp. 99-121; Anuario Estadistico de España 1972, Instituto Nacional de Estadistica, Madrid, Table 3.3.1, pp. 460-464; ibid., 1973, Table 3.3.1, pp. 468-472; ibid., 1974, Table 3.3.1, pp. 475-478; ibid., 1975, Table 3.3.1, pp. 475478; ibid., 1976, Table 3.3.1, pp. 475-478; ibid., 1977, Table 3.3, pp. 475-479; ibid.. 1978, Table 3.3, pp. 476-480; Anuario Estadistico de España, edition manual, 1979, Instituto Nacional de Estadistica, Madrid, Table 3, pp. 543-544.

\section{Sweden}

Statistisk Årsbok För Sverige 1952, Statistiska Centralbyrån, Stockholm, p. 68; ibid., 1954, p. 61 ; ibid., 1957, p. 65 ; ibid.. 1960, p. 36; Folkmängdens förändringar, 1961. Statistiska Centralbyrån, Stockholm, Table 7.4, pp. 88-89; ibid., 1962, Table 6.4, pp. 90-91; ibid., 1963, Table 6.4, pp. 86-87; ibid., 1964, Table 6.2, pp. 90-91; ibid., 1965. Table 6.2. pp. 110-111; ibid., 1966, Table 6.3, pp. 104-105; Befolkningsförändringar 1967 Del. 3 Hela riket och länen m m, Statistiska Centralbyrân, Stockholm. Table 6.2, pp, 102-103; ibid., 1968, Table 6.1, pp. 134-135; ibid., 1969, Table 6.1, pp. 138-139; ibid., 1970, Table 6.1, pp. 148-149; ibid., 1971, Table 6.1, pp. 144-145; ibid., 1972, pp. 144-145; ibid., 1973, Table 6.1, pp. 144-145; Befolkningsförändringar 1975 Del Forsamlingar, kommuner och A-Regioner, Statistiska Centralbyrån, Stockholm, Table 7, p. 128; Statistiska meddelanden, Be 1977:2, Statistiska Centralbyrån, Stockholm, Table 1, pp. 8-9; Statistiska meddelanden, Be 1978:3, Statistiska Centralbyrån, Stockholm, Table 1, pp. 8-9; ibid., 1979. Table 1, pp. 8-9.

\section{Taiwan}

Private communication, Ministry of Interior, Taipei. 


\section{United Kingdom}

Annual Report 1977. Part 2 - Population and Vital Statistics, Registrar General Scotland, Edinburgh, Table 01.1, p. 51. 



\title{
DECONCENTRATION WITHOUT A "CLEAN BREAK"
}

\author{
Peter Gordon \\ Department of Economics, University of Southern California, Los Angeles, \\ Califormia (USA)
}

\section{INTRODUCTION}

In a number of recent papers it has been argued that settlement patterns in the United States may be characterized by a clear "reversal" of past trends, by "significant changes", by a "rural renaissance", or by a "clean break with the past". Much less has been written about human settlement changes in the other developed countries. This paper reviews some of the recent literature on counterurbanization in the USA and also looks at data that have been collected within the framework of the Human Settlement Systems Task of the International Institute for Applied Systems Analysis (IIASA) to describe recent settlement trends in Europe and Japan. Both the literature review and the analysis of the new data file cause us to register some scepticism with regard to the "cleanbreak" thesis. Rather, a continued "wave" of urban decentralization as well as renewed rural growth seem to be in progress.

\section{BACKGROUND}

While scholars interpret the US evidence with varying certitude, most conclude that we are witnessing fundamentally new phenomena and that the "shift" occurred either in the late 1960 s $^{*}$ or the early 1970s. Berry and Dahmann (1977, p. 444) note that

". . . for the first time the growth rate of metropolitan areas has dropped below that of nonmetropolitan areas. More significantly, the long-term inflow of persons from nonmetropolitan areas has been reversed; as recently as the 1960 s there was a net flow of migrants from nonmetropolitan areas. Since then, however, these areas have added

\footnotetext{
* It is important to note that Berry and Dahman (1977) do not restrict their analysis to 1970 and beyond. They assert that "signs of a shift away from the long-term trend of metropolitan growth exceeding that of nonmetropolitan areas in the United States first appeared during the 1960s" (Berry and Dahman, 1977, p. 448).
} 
residents largely as the result of increased out-migration from metropolitan areas ... While the total population increased 13.3 percent during the 1960 s, the number of individuals residing in metropolitan areas increased 16.6 percent, a rate of metropolitan increase that was 25 times the rate for nonmetropolitan areas. Since 1970, however, a reversal has occurred; nationwide statistics for the first half of the 1970s indicate that population has increased 6.3 percent in nonmetropolitan areas and only 3.6 percent in metropolitan areas."

Vining and Kontuly (1977) have suggested that the "new" patterns of settlement can also be detected in other economically advanced countries. In documenting declining in-migration into core areas, spatial units as large as $20-30 \%$ of each nation's territory were chosen. This was done in order to contain most of the effects of spread of the populations from central cities within the regions thus defined. However, even this approach cannot detect whether intrametropolitan relocations are of increasing length and increasingly exurban, as a "wave theory" of development might predict.

The fact that there are bound to be major measurement problems is significant. It suggests that the issue is not really resolved. Zelinsky admits that "what is abundantly clear is that our attempts to understand the turnaround phenomenon have been straining our factual and theoretical resources to their limits" (Zelinsky, 1978, p. 15).

The data which we present in this paper contain evidence which supports the wave theory as an al temative hypothesis to the clean break. The wave theory has been around for some time and it suggests that we might be observing more of some very traditional trends: growth take place at the centers of smaller cities and is increasingly removed from the center as the city becomes larger. The diseconomies of agglomeration are not simply to be associated with bigness but can be located in older central cities.

We are not the first to suggest that the US data, which most of ten underline cleanbreak reports, are unable to really test the hypothesis of a reversal against the idea of continued spillover growth (Wardwell, 1977). Yet, it is the very ambiguity of the US results which underlines our interest in the new data file. We shall argue that, since the US data cannot defeat the wave hypothesis and since the new data file does support it, the notion will have to stand for a while longer.

Rural-to-urban population shifts are a trend of long standing through most of the world. Thus it would certainly be intriguing to find that this process has suddenly been reversed. Yet, it should be obvious that metropolitan-to-nonmetropolitan movements, using the US Census Bureau definitions, (1) do not necessarily imply urban-to-rural movements and (2) can just as readily reflect a continuation of outward growth. We need only imagine that the large metropolitan areas are continuing their long-established outward growth and that this growth has now extended beyond the formally defined current boundaries of the Standard Metropolitan Statistical Areas (SMSAs). The growth will then show up as nonmetropolitan growth. We must further imagine that urban development continues in the smaller cities and within their metropolitan boundaries. Of course the attractiveness of rural areas may be increasing at the same time.

It must be mentioned that ciean-break advocates have entertained the possibility of a continued wave effect but have rejected it by noting that the most dramatic net migration changes have taken place in those counties in the USA that are nonadjacent to the metropolitan areas (Morrison, 1977). However, an arrangement of the US data in 
TABLE I Locational breakdown of population growth in the USA ${ }^{a}$.

\begin{tabular}{|c|c|c|c|c|c|c|c|}
\hline \multirow[t]{2}{*}{ Population category } & \multirow{2}{*}{$\begin{array}{l}\text { Provisional } \\
1975 \\
\text { population } \\
\text { (thousands) }\end{array}$} & \multicolumn{2}{|c|}{$\begin{array}{l}\text { Annual population } \\
\text { change rate }(\%)\end{array}$} & \multicolumn{2}{|c|}{$\begin{array}{l}\text { Annual natural } \\
\text { increase rate }(\%)\end{array}$} & \multicolumn{2}{|c|}{$\begin{array}{l}\text { Annual net } \\
\text { migration } \\
\text { rate }^{b}(\%)\end{array}$} \\
\hline & & $\begin{array}{l}1960- \\
1970\end{array}$ & $\begin{array}{l}1970- \\
1975\end{array}$ & $\begin{array}{l}1960- \\
1970\end{array}$ & $\begin{array}{l}1970- \\
1975\end{array}$ & $\begin{array}{l}1960- \\
1970\end{array}$ & $\begin{array}{l}1970- \\
1975\end{array}$ \\
\hline USA Total & 213,051 & 1.3 & 0.9 & 1.1 & 0.7 & 0.2 & 0.2 \\
\hline \multicolumn{8}{|l|}{ Metropolitan } \\
\hline Total, all SMSAs ${ }^{c}$ & 156.098 & 1.6 & 0.8 & 1.1 & 0.7 & 0.5 & 0.1 \\
\hline$>1.0$ million & 94,537 & 1.6 & 0.5 & 1.1 & 0.6 & 0.6 & -0.2 \\
\hline $0.5-1.0$ million & 23,782 & 1.5 & 1.0 & 1.2 & 0.8 & 0.4 & 0.3 \\
\hline $0.25-0.5$ million & 19,554 & 1.4 & 1.3 & 1.2 & 0.8 & 0.2 & 0.5 \\
\hline$<0.25$ million & 18,225 & 1.4 & 1.5 & 1.2 & 0.8 & 0.2 & 0.7 \\
\hline \multicolumn{8}{|l|}{ Nonmetropolitan } \\
\hline $\begin{array}{l}\text { Total, all nonmetropolitan } \\
\text { counties }\end{array}$ & 56,954 & 0.4 & 1.2 & 0.9 & 0.6 & -0.5 & 0.6 \\
\hline $\begin{array}{l}\text { In counties from which: } \\
\quad 20 \% \text { commute to SMSAs }\end{array}$ & 4,407 & 0.9 & 1.8 & 0.8 & 0.5 & 0.1 & 1.3 \\
\hline $10-19 \%$ commute to SMSAs & 10,011 & 0.7 & 1.3 & 0.8 & 0.5 & -0.1 & 0.8 \\
\hline $3-9 \%$ commute to SMSAs & 14,338 & 0.5 & 1.2 & 0.9 & 0.6 & -0.4 & 0.6 \\
\hline$<3 \%$ commute to SMSAs & 28,197 & 0.2 & 1.1 & 1.0 & 0.6 & -0.8 & 0.5 \\
\hline $\begin{array}{l}\text { Entirely rural counties } \\
\text { not adjacent to an SMSA }\end{array}$ & 4,661 & -0.4 & 1.3 & 0.8 & 0.4 & -1.2 & 0.9 \\
\hline
\end{tabular}

a Source: unpublished preliminary statistics furnished by Richard L. Forstall, Population Division, US Bureau of the Census, and Calvin L. Beale, Economic Research Service, US Department of Agriculture. ${ }^{b}$ Includes net immigration from abroad, which contributes newcomers to the USA as a whole and to the metropolitan sector, thereby producing positive net migration rates for both.

c Population inside SMSAs or, where defined, standard consolidated statistical areas. In New England, New England county metropolitan areas are used.

d "Entirely rural" means that the counties contain no town of 2,500 or more inhabitants. Source: Morrison (1977).

icrms of a locational breakdown of nonmetropolitan growth (Table 1) reveals that in the most recent years annual growth is greatest in those nonmetropolitan counties which are most linked to the metropolitan centers. The annual net in-migration rates diminish regularly as we move away from SMSAs (see also Tucker, 1976). Thus the US data do not rule out the wave theory and statements such as "clearly the migration reversal cannot be explained away as just more metropolitan sprawl or spillover because it is affecting distinctly remote and totally rural nonmetropolitan areas, as well as those adjacent to metropolitan centers" (Morrison, 1977, p. 6) are not really conclusive. In fact the most compelling position is probably that of Wardwell who underlines the complexity of recent trends as well as our inability to interpret them unequivocally. Wardwell cites the fact that $63 \%$ of in-migration to nonmetropolitan counties takes place in those nonmetropolitan counties that are adjacent to metropolitan counties and says that "this suggests that the spillover effect of continued deconcentration of metropolitan centers is a substantial force in producing the observed patterns of nonmetropolitan county growth". 
He also reports that the growth rate of counties which were classified as nonmetropolitan in 1970 but were reclassified as metropolitan in 1974 "is substantially greater (10\%) during this period than that of counties which retained their nonmetropolitan classification" (Wardwell, 1977, p. 159). Beale (1977, p. 116) counters that "the more impressive fact would seem to be the convergence of growth rates of these two classes of counties".

Berry and Dahmann $(1977$, p. 450$)$ report that

"In the South ... the central cities of metropolitan areas with less than one million residents have gained population ... In the West the largest gains have been occurring in central cities of metropolitan areas with less than one million residents."

All these observations are consistent with the version of the wave theory outlined in the foregoing.

Obviously there is something going on in the nonadjacent counties which demands attention. Wardwell suggests that this growth can be explained by new propensities toward retirement and recreation and that these new phenomena can be analyzed on top of the wave effect rather than in its place.

The most stirring of the reversal reports is the one by Vining and Strauss (1977, p. 755) who say that

"Nonmetropolitan counties well removed from the commuting range of 250 or so SMSAs are growing at a significantly higher rate than the SMSAs themselves, though at a somewhat lower rate than the nonmetropolitan counties adjacent to these SMSAs.

This fact represents a clear and unmistakable break with past trends of long duration."

We have added the italics to emphasize a possible non sequitur. Vining and Strauss go on tu look for evidence from a source other than the migration data; they process populationstock data through the well known Hoover index of population dispersion. (The Hoover index is given by $H_{\mathrm{t}}=\frac{\hbar}{2} \Sigma_{i}^{k}\left|p_{i t}-a_{t}\right| 100$ where $p_{i t}$ refers to the proportion of a country's population residing in area $i$ at time $t$ and $a_{i}$ refers to the proportion of that nation's area taken up by subarea $i$. The index varies from 0 to 100 , i.e., from a reading of perfectly uniformly distributed population to perfect concentration.) Interpreting trends in the index in a novel way the authors conclude that a wave effect can be rejected and that a clean break is in fact observed.

In describing the pre-1970 US settlement changes the authors note that the Hoover index, calculated for various levels of spatial aggregation, moves in opposing directions. They view this quirk in the index as a "resource". Previously, for example, the index would turn up when the spatial units were US counties, indicating urbanization. At the same time, the index would turn down when the units were states, indicating a movement of the population to the less populated Midwest and West. Thus a clean break is signalled when the index, computed for all levels of aggregation turns down, as it does for the most recent years. However, computations of the Hoover index for small spatial units can show a downturn and still be consistent with the wave effect. Table 1 underlines this view: the small or lightly populated nonmetropolitan counties and the smaller SMSAs are the major gainers; looking a where the major nonmetropolitan growth is taking place we are back to spmover effects. In other words if we were to compute the Hoover index for US spatial units which combine metropolitan areas with only the adjacent counties Table 1 suggests that we might not obtain a downturn after all. 
That test would consider a subset of spatial units and would be distinct from the Hoover-index computations of Vining and Strauss for the State Economic Areas (SEAs) defined by the United States Bureau of the Census. Their SEA test deals with a collectively exhaustive set of spatial units and could be marred by the effect which Vining and Strauss describe in their paper: the Hoover index computed over states may show decentralization even while substantial urbanization is taking place because of the movement (from rural areas) to urban centers which happen to be in the less populous regions of the country. In any event, a different application of the Hoover index which avoids some of these difficulties was developed for the Functional Urban Regions (FURs) data file (see later).

Most of the evidence that has been cited up to this point has been from the works of the clean-break advocates. Clearly, neither side has proven its case. The problem lies with the way in which the data are reported. The US Census Bureau divides the country into two population concentrations: metropolitan and nonmetropolitan areas. The former are made up of a central city and a suburban area. Any additional large cities within the metropolitan areas are included as part of the central city. Nonmetropolitan areas include all the area outside metropolitan areas. Unfortunately this way of reporting data is not "functional". Since SMSA boundaries tend to be county boundaries the exact or nearly exact limit of the commuting field is usually not adequately approximated. The same applies to temporal change in the labor-market area. Thus as the wave of development spreads outward and spills over SMSA lines a "reversal" is perceived though none may have occurred.

Cliff and Robson (1978, p. 163) report that since most reporting units

“. . are defined as distinct physical nucleations rather than in functional terms, then in studying changes over time, the researcher is caught on the horns of two dilemmas: whether to use an unchanging areal definition of each town or to alter the definition so as to match most closely the changing form of the town at successive dates, and whether to use a fixed or fluctuating number of towns throughout the period."

The ambiguity of the US data arises precisely because of these two dilemmas.

Yet, we do not want to continue to plumb the US data, having maintained that it cannot hold the answer. Rather, we propose to examine a new data file for some indication of what has transpired in the recent experience of Europe and Japan.

\section{THE DATA FILE AND DEFINITIONS}

An effort was made, within the framework of the Human Settlements Systems Task at IIASA, to define comparable sets of urban areas for 18 nations in western and eastern Europe and for Japan*. Data on population, employment, and area have been stored for these countries for the years 1950,1960, and 1970, with post-1970 data available for five of the countries. The actual deline-ions have emphasized urban-core areas, their hinterlands, and the residual rural areas. The core areas and their associated hinterlands make

\footnotetext{
- The present analysis covers all these countries except Romania.
} 
up FURs. These are defined so that commuting across FUR boundaries is minimal. In that sense they are similar to the US Bureau of Economic Analysis regions and represent functional labor markets.

The most useful aspects of this data file are consistency and comparability between the various nations. Enough data are available to compute a variety of Hoover indexes for many regional sets and subsets. For this we adopt the following notation: $H_{i}(t)$ is the Hoover index computed for some nation over the set of regions $i$ for year $t ; H_{i}(t)$ is the Hoover index computed for a nation over the union of the set of regions $i$ and $j$ for year $t$.

It should be noted that the index will be computed for sets of regions which are exhaustive as well as for subsets of regions. Vining and Strauss looked at Hoover indexes for a variety of regional delineations for the USA, yet all of these were exhaustive delineations. If the set of regions for which we compute the index is exhaustive then the proportions of population and area are defined with the national totals as denominators. However, if the set is some subset, e.g., the set of all urban areas, then the denominators used in computing percentages refer to the total urban area and population. The reason for this convention is that we wish to observe trends in $H_{i}$ which are not affected by trends in other subsets of regions. We hope to show that this modified version of the Hoover index renders it a more powerful tool.

We denote $u$ as the set of all urban-core areas, $h$ as the set of all hinterland areas, $i$ us the set of all rural areas, and $s$ as the set of all functional urban areas (each of which is an urban core plus a hinterland); uhr and sr are exhaustive unions of regional subsets.

A compact way of representing Hoover-index trends for 18 developed countries over the 20-year span 1950-1970 is the array of index changes, i.e., concentration changes, as shown in Table 2. The post-1970 performance is shown in Table 3 for some countries. Overall population concentration is measured by considering the behavior of the first two indexes which are defined over exhaustive sets of areas. We note that three groupings are possible. Since far more data are available for the years up to and including 1970 these results are examined first. An obvious grouping of nations can be seen. The countries of group A show increasing concentrations of their populations for all spatial levels of aggregation;most growth took place in the most populous spatial units. (Actually the index only allows change towards more or less dense settlements to be detected. However, the strong correlation between size and density allows us to use the more useful size characterizations.)

The countries of group B are of interest because they show increasing concentration of population except with respect to urban cores. The straight column of minuses for $H_{u}$ (group $B$ ) shows that the smaller urban cores are experiencing more of the growth than the larger urban cores. This should be linked with the pluses in the next column. In fact, across groupings and for as many as 16 of the 18 countries, the larger hinterlands grew fuster than the smaller ones. If we recall that large urban cores are associated with the larger hinterlands then spillover growth is suggested. In fact for the 12 countries which have minus signs for the change in $H_{\mathrm{u}}$ together with plus signs for the change in $H_{\mathrm{h}}$ it seems that the diminishing importance of the largest urban-core areas and the concurrent increasing importance of the large hinterland areas is strong c vidence of a wave effect and reinforces scepticism as to the clean break. The cuintries of group $\mathrm{C}$ show deconcentration in the light of the signs on Hoover-index changes computed for exhaustive sets of areas; i.e., the overall figures are heavily weighted by the effect noted for the urban cores. 
TABLE 2 Population concentration trends indicated by direction of Hoover-index changes, $1950-1970^{a}$.

\begin{tabular}{|c|c|c|c|c|c|}
\hline Country & $H_{\text {uhr }}$ & $H_{\mathrm{sr}}$ & $H_{\mathbf{u}}$ & $H_{\mathrm{h}}$ & $H_{\mathrm{s}}$ \\
\hline \multicolumn{6}{|l|}{ Giroup A } \\
\hline Spain & + & + & + & + & + \\
\hline $\operatorname{Japan}^{b}$ & + & + & + & + & + \\
\hline Finland & + & + & + & + & + \\
\hline Italy & + & + & + & + & + \\
\hline \multicolumn{6}{|l|}{ Group B } \\
\hline Norway & + & + & - & + & + \\
\hline Sweden & + & + & - & + & + \\
\hline Denmark & + & + & - & + & + \\
\hline Portugal & + & + & - & + & + \\
\hline France & + & + & - & + & + \\
\hline Ireland & + & + & - & + & + \\
\hline Hungary $^{b}$ & + & + & - & + & + \\
\hline Federal Republic of Germany ${ }^{b}$ & + & + & - & + & + \\
\hline \multicolumn{6}{|l|}{ Group C } \\
\hline Great Britain & - & - & - & + & - \\
\hline Netheriands & - & - & - & + & - \\
\hline Switzerland & - & - & - & + & - \\
\hline Belgium & + & - & - & + & n.c. ${ }^{c}$ \\
\hline Austria $^{b}$ & n.c. ${ }^{c}$ & - & - & - & - \\
\hline Poland $b$ & - & - & - & - & - \\
\hline
\end{tabular}

Except Japan and Hungary (1960-1970) and Finland (1955-1970).

$b$ Delineated in terms of urban cores and hinterlands only; there are no nonhinterland rural areas.

c n.c., not calculated.

TABLE 3 Post-1970 population concentration trends for those countries for which FUR data are available ${ }^{a}$.

\begin{tabular}{lllllll}
\hline Country & Period & $H_{\mathrm{uhr}}$ & $H_{\mathrm{sr}}$ & $H_{\mathrm{u}}$ & $H_{\mathrm{h}}$ & $H_{\mathrm{s}}$ \\
\hline Poland & $1970-1973$ & $+(\mathrm{R})$ & n.c. & $+(\mathrm{R})$ & $+(\mathrm{R})$ & n.c. \\
Japan & $1970-1975$ & + & + & + & + & + \\
Hungary & $1970-1975$ & + & n.c. & - & + & n.c. \\
Finland & $1970-1974$ & + & + & n.c. & + & + \\
Denmark & $1970-1975$ & $-(\mathrm{R})$ & $-(\mathrm{R})$ & - & + & $-(\mathrm{R})$ \\
\hline
\end{tabular}

$a(R)$ indicates a reversal from the pre-1970 trends shown in Table 2. n.c., not calculated.

(A similar table was computed for the interval 1960-1970. Surprisingly, very little changed. Poland and Switzerland changed places between groups $B$ and $C$. The number of countries for which we have a negative change for $H_{\mathrm{u}}$ together with a positive change for $H_{\mathrm{b}}$ remained at 12 .)

Of course post-1970 data are more interesting because the alleged reversals are a recent phenomenon. Unfortunately, these data are limited to on'y five countries. Table 3 shows that Japan continued to concentrate at all leveis of aggregation. However, the actual numbers show that the rate of increase in Hoover-index values falls for each year between 1970 and 1975. Perhaps Japan will soon be in group B. Denmark is the clearest 
example of transition from group B to group $C$, suggesting that there may be a natural evolutionary sequence. In the case of Poland the raw data suggest that there is a decline in the relative importance of the large cities, yet, within that set, growth is skewed towards the larger urban cores.

\section{PROBLEMS OF INFERENCE}

As mentioned already, the delineations on which our data file is based for functional urban areas are defined by commuting patterns for 1970 . The hinterland is usually defined as areas from which at least $15 \%$ of commuting is to the central city. Obviously areas which were functional spatial units in 1970 might not have been so for 1950 or for 1960 . Thus a bias similar to that which we have discussed with respect to the US data is built into our sample. The crucial difference is that the definitional units differ. Hinterlands are much more spatially extensive than the US metropolitan suburban areas. Thus our Hoover index computed over the set of hinterland areas would be akin to looking at some suburban and some adjacent as well as some nonadjacent but linked counties for the US sample. Also, our use of the Hoover index is somewhat novel in that we have been able to look at hinterland and core areas separately. It is these crucial differences which cause us to believe that our approach permits an analysis that is surely possible with the US data but which is not of ten practiced because of the convenient availability of standard reporting units (disaggregated only into metropolitan or nonmetropolitan).

We should also consider the extent to which the fixed boundaries of our sample have biased our own computations. Looking at the definition of the Hoover index we find that all the $p_{i t}$ certainly changed over time while constant values for $a_{i}$ were used. Nevertheless, $a_{i}$ should also have a $t$ subscript because the boundaries of the functional areas certainly advance with population growth. In fact if the FUR boundaries advanced such that areal proportions kept exact pace with population changes then the Hoover index would remain constant. This could not occur in a situation such as the investigation of Vining and Strauss because of their use of fixed administrative boundaries but it is very much a problem when the regional definitions are supposedly functional and encompass a subset of regions. We recognize this problem of possible bias in our fixedarea regions and counter by asserting that, over the relatively short time span considered, it is likely that population changes were much greater than areal changes. Thus the calculated indexes should certainly change, although the rate of change may be overstated in our results.

Cliff and Robson suggest the obvious: any sort of functional regions which are studied over time must be made up of constituent units for which data are available so that recalculations can be made for alternative areal units. Zelinsky does precisely this in his study of Pennsylvania settlement systems. Of course this procedure introduces new problems of how to reclassify the smaller spatial units. In spite of this Zelinsky gets closer to events than many of the other cited studies and comes out on the side of a wave effect. Writing about the period 1950-1970, he concludes that what is observed in the US is "a reconcentration of people within distances of some 25 to 35 miles of the metropolitan center" (Zelinsky 1978, p. 37). 


\section{5}

\section{CONCLUSION}

Our survey of some of the evidence presented for US settlement patterns suggests that there is cause for scepticism with respect to the clean-break hypothesis. For the 18 countries of our sample we have been able to look at developments beyond the metropolitan areas and these suggest that a continuing wave effect is taking place rather than a clean break. Since there is no reason to expect that settlement patterns in Europe, Japan, and the USA evolve in opposite fashions the findings from the FUR file lend some support for the wave-effect conclusion in the US. In that respect, we side with Wardwell's judgment that the US record alone is too complex to denote a clean break with the past.

Yet, the Hoover-index values that have been computed are perhaps also suitable for the testing of some demoeconomic hypotheses. Human settlement patterns, it has been suggested, change in response to new technologies, a new age structure of the population, and new social arrangements especially with regard to pensioning and retirement practices. McCarthy and Morrison (1977) sustain similar hypotheses for the US case. An attempt to develop similar tests for the FUR data file was less successful. Collinearity hampered proper test specifications and generated ambiguous results.

The standard urban economic models of Alonso and Mills suggest that rising incomes and declining travel costs explain flatter bid-rent curves and eventual expansion of the metropolis. Other urban and regional economic theories of various degrees of formality are available in support of the wave effect. A preference for small-town life has long been used to explain suburbanization. The data seem to suggest that this trend is as strong as ever and that it is taking place at ever-greater distances from central cities, especially if these central cities are large. Wardwell concludes that people are showing "a clear desire for living in smaller-sized places within commuting radius of the metropolitan center, and for smaller-sized places beyond that radius in preference to living within the center itself" (Wardwell, 1977, p. 176; our italics).

None of this is really new. Commuting radii are growing as usual. Central-city decline, as W. Thompson suggests, is a cause as well as an effect. For example, if we de tect central-city growth in the smaller cities and peripheral growth in the larger cities we may hypothesize that agglomeration diseconomies emerge in central locations when the metropolis is mature. Wardwell quotes Thompson's detailing of this hypothesis: Thompson suggests that large urban areas are the natural incubators of new industrial formation and innovation only as long as their industries are centrally located. As soon as plants begin to decentralize, as they inevitably do on reaching maturity, the centers of the larger cities lose this important function and begin to decline.

This is related to Vernon's hypothesis (Vernon, 1960). Vernon suggests that central cities are hospitable to innovation and new industrial processes because they are the scene of external economies. Yet, as plants grow, they seek scale economies rather than external economies and therefore seek cheap lands in the peripheral areas. Thus they leave the center and add to its decline in two ways: by not being there and by no longer providing external economies to newcomers.

The theory that is available on behalf of a reversal thesis (see for example Friedmann 1973 ) is much slimmer.

Obviously, more theory building and more testing are required. Working across an international cross section with the aid of a small sample does not guarantee definitive 
results. Yet, policy issues such as whether or not planning ought to be done at metropolitan levels depend in part on whether metropolitan areas are expanding or whether they are becoming ever less important.

\section{REFERENCES}

Beale, C.L. (1977). The recent shift of United States population to nonmetropolitan areas, 1970-1975. International Regional Science Review, 2:113-122.

Berry, B.J.L. and Dahmann, D.C. (1977). Population redistribution in the United States in the 1970s. Population Development Review, 3:443-471.

C.liff, A.D. and Robson, B.T. (1978). Changes in the size distribution of settlements in England and Wales, 1801-1968. Environment and Planning A, 10:163-171.

Friedmann, J. (1973). Urbanization, Planning, and National Development. Sage Publications, Beverly Hills, California.

McCarthy, K.F. and Morrison, P.A. (1977). The changing demographic and economic structure of nonmetropolitan areas in the United States. International Regional Science Review, 2:123-142.

Morrison, P.A. (1977). Current demographic change in regions of the United States. P-6000. Rand Corporation, Santa Monica, California.

Tucker, C.J. (1976). Changing patterns of migration between metropolitan and non-metropolitan areas in the United States: recent evidence. Demography, 13:435-443.

Vernon, R. (1960). Metropolis 1985. Harvard University Press, Cambridge, Massachusetts.

Vining, D.R. and Kontuly, T. (1977). Population Dispersal from Major Metropolitan Regions: An International Comparison. International Regional Science Review, 3:49.

Vining, D.R. and Strauss, A. (1977). A demonstration that the current deconcentration of population in the United States is a clean break with the past. Environment and Planning A, 9:751-758.

Wardwell, J.M. (1977). Equilibrium and change in non-metropolitan growth. Rural Sociology, 42: $156-179$.

Zelinsky, W. (1978). Is nonmetropolitan America being repopulated? The evidence from Pennsylvania's minor civil divisions. Demography, 15(1):13-39. 


\section{APPENDIX A: LIST OF IIASA PUBLICATIONS ON HUMAN SETTLEMENT SYSTEMS*}

BOOK

N. Hansen, Human Settlement Systems: International Perspectives on Structure, Change and Public Policy. (Published in 1978 by Ballinger, Cambridge, Massachusetts.)

\section{RESEARCH REPORTS}

N. Hansen, A Critique of Economic Regionalizations of the United States. RR-75-32.

A. Pred, The Interurban Transmission of Growth in Advanced Economies: Empirical Findings Versus Regional-Planning Assumptions. RR-76-04.

\section{RESEARCH MEMORANDA}

P. Hall, N. Hansen, and H. Swain, Urban Systems: A Comparative Analysis of Structure, Change and Public Policy. RM-75-35.

N. Hansen, International Cooperation and Regional Policies Within Nations. RM-75-48.

P. Hall, N. Hansen, and H. Swain, Status and Future Directions of the Comparative Urban Region Study: A Summary of Workshop Conclusions. RM-76-59.

N. Hansen, Growth Strategies and Human Settlement Systems in Developing Countries. RM-76-02.

N. Hansen, Systems Approaches to Human Settlements. RM-76-03.

N. Hansen, The Economic Development of Border Regions. RM-76-37.

P. Korcelli, The Human Settlement Systems Study: Suggested Research Directions. RM-76-38.

P. Nijkamp, Spatial Mobility and Settlement Patterns: An Application of a Behavioural Entropy. RM-76-45.

*For further information on r: 4 SA publications contact R. McInnes, Publications Department. IIASA, A-2361 Laxenburg, Austria. 
N. Hansen, Alsace Baden-Basel: Economic Integration in a Border Region. RM-76-51.

G.O. Kiseleva, Commuting: An Analysis of Works by Soviet Scholars. RM-76-64.

K. Sherrill, Functional Urban Regions in Austria. RM-76-71.

N. Hansen, Economic Aspects of Regional Separatism. RM-77-10.

K. Sherrill, Functional Urban Regions and Central Place Regions in the Federal Republic of Germany and Switzerland. RM-77-17.

T. Kawashima, Changes in the Spatial Population Structure of Japan. RM-77-25.

N.J. Glickman, Growth and Change in the Japanese Urban System: the Experience of the 1970's. RM-77-39.

N.J. Glickman, The Japanese Urban System During a Period of Rapid Economic Development. RM-77-46.

N.J. Glickman, The Management of the Japanese Urban System: Regional Development and Regional Planning in Postwar Japan. RM-77-47.

N.J. Glickman, Financing the Japanese Urban System: Local Public Finance and Intergovernmental Relations. RM-77-48.

P. Korcelli, An Approach to the Analysis of Functional Urban Regions: A Case Study of Poland. RM-77-52.

P. Nijkamp, A Spatial Complex Analysis of Agglomeration and Settlement Pattems. RM78-09.

P. Gordon, Deconcentration without a "Clean Break". RM-78-39.

\section{COLLA BORATIVE PAPER}

L. Lacko, G. Enyedi, and G. Koszegfalvi, Functional Urban Regions in Hungwry. CP-78-04. 


\section{APPENDIX B: LIST OF PARTICIPANTS}

\section{EXTERNAL PARTICIPANTS}

William Alonso

Director

Center for Population Studies

Harvard University

9 Bow Street

Cambridge, Mass. 02138

USA

José Antunes Ferreira

Technical University of Lisbon

IST \& CESUR

Avenida Rovisco Pais

Lisbon 1

Portugal

David Batten

Department of Economics

University of Goteborg

Fack

40010 Göteborg 3

Sweden

Dieter Bockemann

Technical University Vienna

Institute for City and Region Research

Karlsplatz 13

1040 Vienna

Austria

Larry S. Bourne

Centre for Environmental Studies

62/65 Chandos Place

London WC2N 4HH

United Kingdom
Ulf Christiansen

Danish Building Research Institute

Post Box 119

2970 Hфrsholm

Denmark

Leonid Davidov

Center for the Study of Population

Problems

Moscow State University

Leninskye Gory

Moscow

USSR

Roy Drewett

The London School of Economics \& Political Science

University of London

Houghton Street

London WC2A $2 \mathrm{AE}$

United Kingdom

Mircea Enache

Institute of Architecture "Ion Mincu"

Academy Street 18-20

Bucarest

Romania

Maria do Ceu Esteves

Center for Planning Studies

Av. D. Carlos I, 126

Lisbon 2

Portugal 
Manfred Fischer

Institute of Geography

University of Vienna

Universitätsstrasse 7

1010 Vienna

Austria

Rolf Funck

Institute for Political Economy \& Economic Research

University of Karlsruhe

Kollegium am Schloss, Bay IV

Postfach 6380

7500 Karlsruhe 1

Federal Republic of Germany

John B. Goddard

Regional Development Studies

Department of Geography

University of Newcastle upon Tyne

Daysh Building, Claremont Road

Newcastle upon Tyne NE1 7 RU

United Kingdom

Peter Gordon

Department of Economics

University of Southern California

University Park

Los Angeles, Cal. 90007

USA

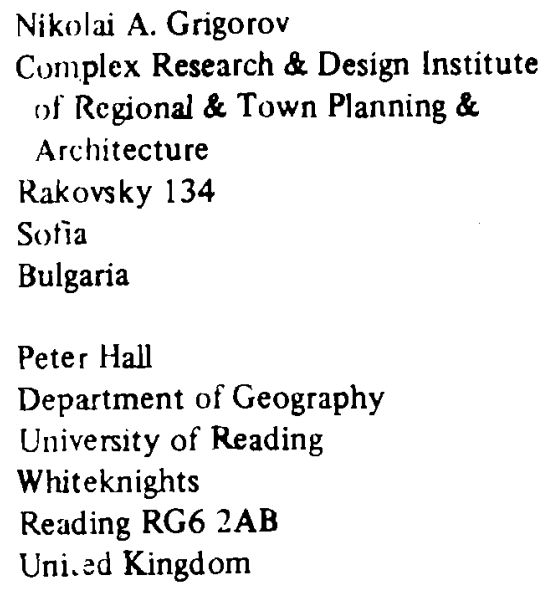

Niles Hansen

Department of Economics

University of Texas

Austin, Tex. 78712

USA

Dennis G. Hay

Department of Geography

University of Reading

Whiteknights

Reading RG6 2AB

United Kingdom

Joachim Heinzmann

Head of Scientific Secretariat

Institute of Geography \& Geology

of the Academy of Sciences

Dimitroff-Platz 1

701 Leipzig

German Democratic Republic

Martti Hirvonen

Department of Economics

University of Tampere

Kalevantie 4

33100 Tampere

Finland

Allen C. Kelley

The Esmee Fairbairn Research Centre

Heriot-Watt University

Department of Economics

Chambers Street

Edinburgh EH1 $1 \mathrm{HX}$

Scotland

Piotr Korcelli

Institute of Geography \& Spatial

Organization

Polish Academy of Sciences

Krakowskie Przedmiescie 30

Warsaw

Poland 
László Lackó

Division for Physical Planning \&

Regional Development

Ministry of Building \& Urban

Development

Pf. 613

1370 Budapest

Hungary

Luurent \& Chantal Leveille

Technical University of Vienna

Institute for City \& Region Research

Karlsplatz 13

1040 Vienna

Austria

Elisabeth Lichtenberger

Institute of Geography

University of Vienna

Universitätsstrasse 7

1010 Vienna

Austria

Heinz Liidemann

Institute of Geography \& Geology

of the Academy of Sciences

Dimitroff-Platz 1

701 Leipzig

German Democratic Republic

C. Maneri

Gondwana Spa

Comagina Generale e Impianti

Via Dell'Orso 2

20121 Milano

Italy

Koichi Mera

Institute of Socio-Economic Planning

University of Tsukuba

Sakura-mura, Niihari-gun

Ibaraki-ken, 300-31

Japan
Peter Nijkamp

Department of Economics

Free University

P.O. Box 7161

Amsterdam

Netherlands

Oleg Pchelintsev

All-Union Institute for Systems Studies Academy of Sciences

29 Rylev Street

Moscow 119034

USSR

William C. Pendleton

Program Officer

Resources \& Environment

The Ford Foundation

320 East 43rd Street

New York, N.Y. 10017

USA

\section{Aribert Peters}

Institute for City \& Regional Planning

Fechnical University of Berlin

Erkelenzdamm 61

1 Berlin 36

Federal Republic of Germany

Pierluigi Raule

Gondwana Spa

Comagina Generale e Impianti

Via Dell'Orso 2

20121 Milano

Italy

Uwe Schubert

Interdisciplinary Institute for Urban \&

Regional Studies

University of Economics

Hasenauerstrasse 42

1190 Vienna

Austria 
Wolfgang Steinle

Directorate General for Regional Policy

Cummission of the European

Communities

23- 27 Av. de la Joyeuse Entrée

1040 Brussels

Belgium

K. Stigelbauer

Institute of Geography

University of Vienna

Universitätsstrasse 7

1010 Vienna

Austria

Walter B. Stöhr

Interdisciplinary Institute for Urban

and Regional Studies

University of Economics

Hasenauerstrasse 42

1190 Vienna

Austria

Gunnar Türnquist

Department of Social \& Economic

Geography

Royal University of Lund

Sölvegatan 13

22362 Lund

Sweden

George Usin

Central Research and Design Institute of Town Planning

Academy of Sciences

Moscow

USSR

Danicl R. Vining, $J_{r}$.

Department of Regional Science

University of Pennsylvania

3718 Locust Walk/CR

Philadelphia, Pa. 19104

USA
Frans Willekens

Mens en Ruimte v.z.w.

Froissartstraat 118-120

1040 Brussels

Belgium

Helmut Wintersperger

European Coordination Centers for

Research \& Documentation in Social

Science

Gruinangergasse 2

P.O. Box 974

1011 Vienna

Austria

\section{IIASA PARTICIPANTS}

Murat Albegov

Integrated Regional Development

Åke Andersson

Integrated Regional Development

Gennady Dobrov

Management and Technology

Bruce F. Johnston

Human Settlements and Services Area

A. Karlqvist

Guest Scholar

Tatsuhiko Kawashima

Human Settlements and Services Area, and Integrated Regional Development

Roman Kulikowski

Integrated Regional Development

Agostino Labella

Integrated Regional Development

Didier Launay

Energy Systems.Program 
Jacques Ledent

Human Settlements and Services Area

Roger Levien

Director

Shoichi Nogushi

System and Decision Sciences Area

Lennart Ohlsson

Human Settlements and Services Area

Dimiter Philipov

Human Set tlements and Services Area

Andras Pór

Computer Services

Andrei Rogers

Human Settlements and Services Area

Evgenii N. Shigan

Human Settlements and Services Area 


\section{AUTHOR INDEX}

Bourne, L.S., 139

Enache, M., 107

Gordon, P., 193

Hansen, N., 7

Heinzmann, J., 61

Hirvonen, M., 89

Holtier, S., 107

Kawashima, T., 21

Kochetkov, A.V., 159

Korcelli, P., 1, 41

Krönert, R., 73

Lackó, L., 123

Pallone, R., 171

Pchelintsev, O.S., 159

Vining, D.R., Jr., 171

Yang, C.H., 171 